\title{
The Effectiveness of lowa's Automated Red Light Running Enforcement Programs
}

Final Report December 2007

\section{Sponsored by}

the Iowa Department of Transportation

(CTRE Project 05-226)

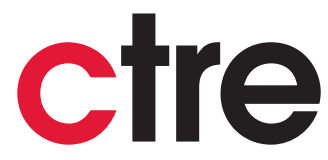

Center for Transportation Research and Education

IOWA STATE UNIVERSITY 


\begin{abstract}
About CTRE/ISU
The mission of the Center for Transportation Research and Education (CTRE) at Iowa State University is to develop and implement innovative methods, materials, and technologies for improving transportation efficiency, safety, and reliability while improving the learning environment of students, faculty, and staff in transportation-related fields.
\end{abstract}

\title{
Disclaimer Notice
}

The contents of this report reflect the views of the authors, who are responsible for the facts and the accuracy of the information presented herein. The opinions, findings and conclusions expressed in this publication are those of the authors and not necessarily those of the sponsors.

The sponsors assume no liability for the contents or use of the information contained in this document. This report does not constitute a standard, specification, or regulation.

The sponsors do not endorse products or manufacturers. Trademarks or manufacturers' names appear in this report only because they are considered essential to the objective of the document.

\section{Non-discrimination Statement}

Iowa State University does not discriminate on the basis of race, color, age, religion, national origin, sexual orientation, gender identity, sex, marital status, disability, or status as a U.S. veteran. Inquiries can be directed to the Director of Equal Opportunity and Diversity, (515) 294-7612. 
Technical Report Documentation Page

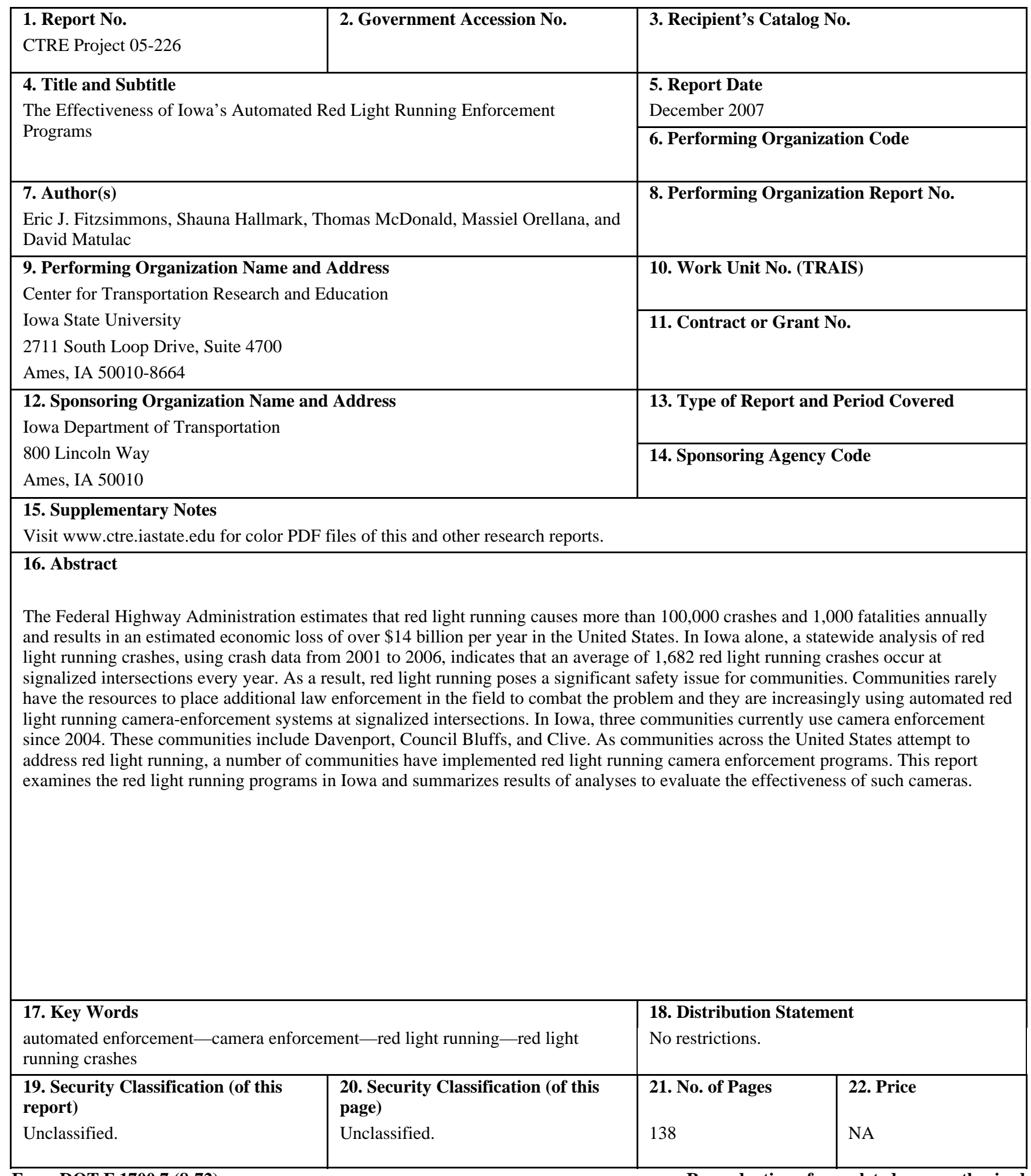

Form DOT F 1700.7 (8-72)

Reproduction of completed page authorized 


\title{
The EfFectiveness of IoWA's Automated RED LIGHT RUNNING ENFORCEMENT Programs
}

\author{
Final Report \\ December 2007 \\ Principal Investigator \\ Shauna Hallmark \\ Associate Professor \\ Department of Civil, Construction, and Environmental Engineering, Iowa State University \\ Co-Principal Investigator \\ Thomas McDonald \\ Safety Circuit Rider \\ Center for Transportation Research and Education, Iowa State University \\ Research Assistants \\ Eric J. Fitzsimmons and Massiel Orellana \\ Project Monitor \\ David Matulac \\ Traffic Operations Engineer \\ Iowa Department of Transportation
}

\author{
Authors \\ Eric J. Fitzsimmons, Shauna Hallmark, Thomas McDonald, Massiel Orellana, and David Matulac \\ Preparation of this report was financed in part \\ through funds provided by the Iowa Department of Transportation \\ through its research management agreement with the \\ Center for Transportation Research and Education, \\ CTRE Project 05-226. \\ A report from \\ Center for Transportation Research and Education \\ Iowa State University \\ 2711 South Loop Drive, Suite 4700 \\ Ames, IA 50010-8664 \\ Phone: 515-294-8103 \\ Fax: 515-294-0467 \\ www.ctre.iastate.edu
}




\section{TABLE OF CONTENTS}

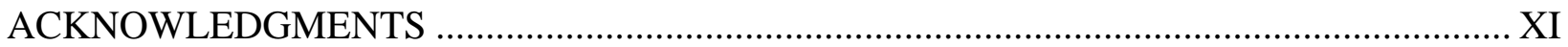

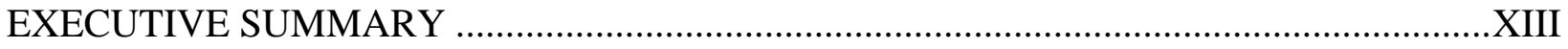

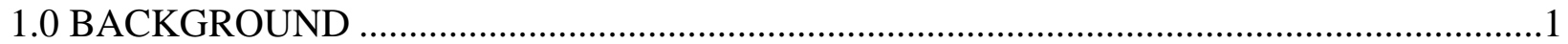

1.1 Characteristics of Red Light Runners .......................................................................1

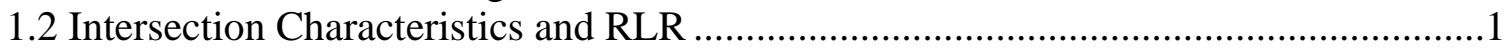

1.3 Engineering Countermeasures to Reduce Red Light Running .......................................2

1.4 Use of Automated Enforcement to Reduce Red Light Running.....................................7

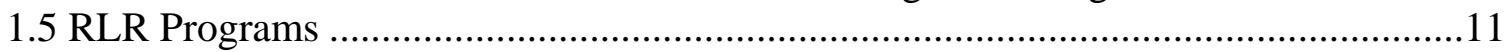

1.6 Metrics to Evaluate the Effectiveness of RLR Cameras................................................13

1.7 RLR Violation Frequency and Crash Relationship .......................................................14

1.8 Effectiveness of Camera Enforcement in Reducing Red Light Running .....................15

1.9 Legal and Social Concerns .....................................................................................18

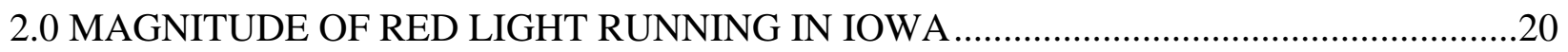

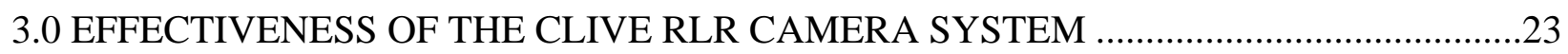

3.1 Background on the Clive RLR Program....................................................................23

3.2 Legal Challenges.....................................................................................................30

3.3 Evaluation of the Effectiveness of the Clive RLR Camera System...............................32

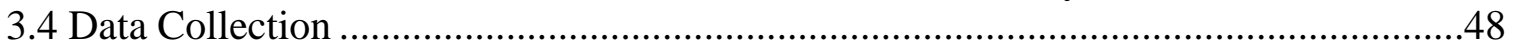

3.5 Analysis of Clive Violation Data ..............................................................................49

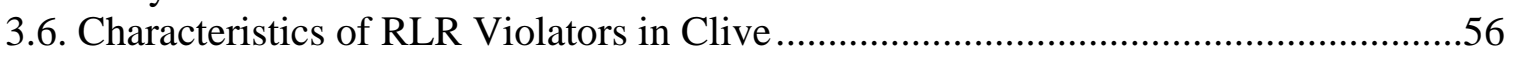

4.0 SUMMARY OF THE RLR CAMERA PROGRAM IN COUNCIL BLUFFS, IA..................60

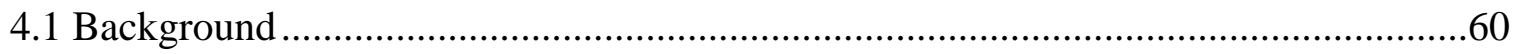

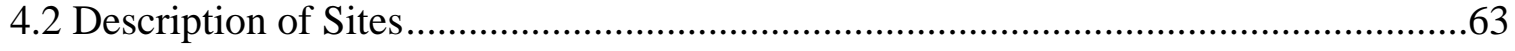

5.0 SUMMARY OF THE RLR PROGRAM IN DAVENPORT, IA ..........................................70

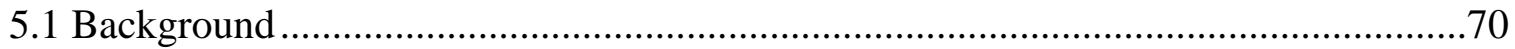

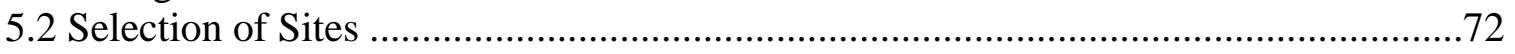

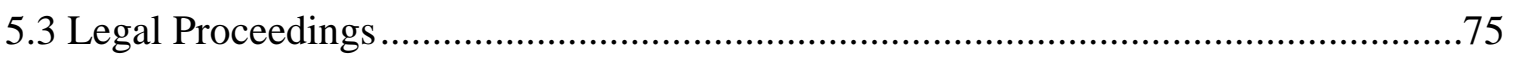

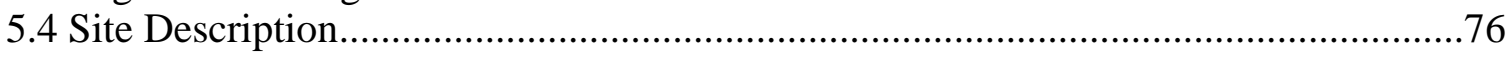

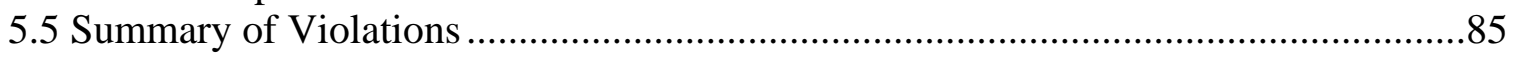

6.0 EVALUATION OF REDUCTION IN CRASHES FOR COUNCIL BLUFFS AND

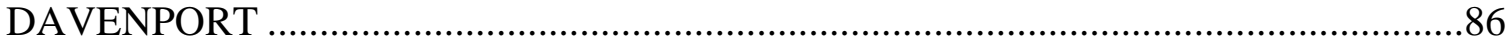

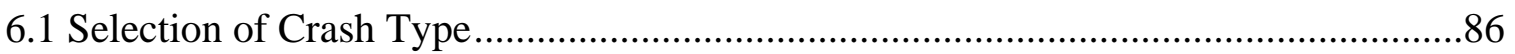

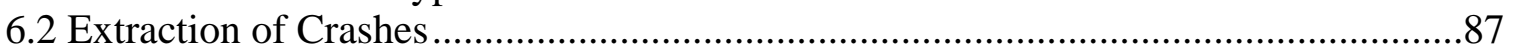

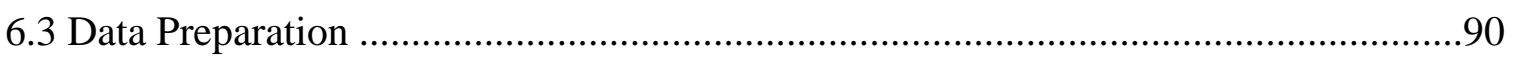

6.4 Descriptive Statistics Methodology ………………….............................................91

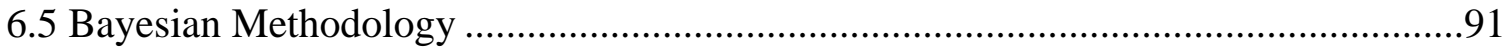

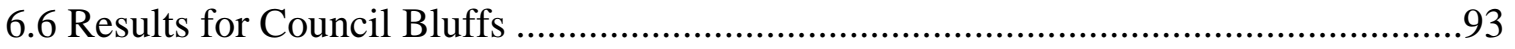

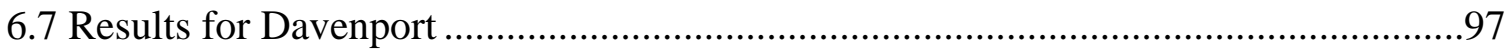


7.0 SUMMARY.

8.0 REFERENCES

APPENDIX A : METHODOLOGY TO IDENTIFY SIGNALIZED INTERSECTIONS

A-1 


\section{LIST OF FIGURES}

Figure 1.1. Signal with high intensity yellow retroreflective tape on backplate (Miska et al., 1998).

Figure 1.2. CDOT specified high-speed intersection traffic signal (Salek, 2006) ......................5

Figure 1.3. Advance intersection warning signs (MUTCD, 2002) ..........................................6

Figure 1.4. Gatso RLR camera system (Atlanta, GA) ...........................................................8

Figure 1.5. Transol RLR camera (Davenport, IA, image source: Quad City Times)....................9

Figure 1.6. First picture taken by an automated RLR enforcement camera (Mesa, AZ) (Image source: City of Mesa Police Department:

http://www.cityofmesa.org/police/traffic/redlight_photos.aspx)

Figure 1.7. Second picture taken by an automated RLR enforcement camera (Mesa, AZ) (Image source: City of Mesa Police Department:

http://www.cityofmesa.org/police/traffic/redlight_photos.aspx)...................................11

Figure 1.8. Predicted effect of RLR on intersection crash frequency (Bonneson et al., 2003).....15

Figure 2.1. RLR crashes as a percentage of all signalized intersection crashes .........................22

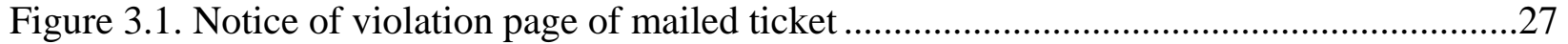

Figure 3.2. Notice of violation for Clive page of mailed ticket.................................................28

Figure 3.3. Page of mailed ticket with instructions .........................................................29

Figure 3.4. Location of study intersections.........................................................................34

Figure 3.5. Roadway, traffic, and signal timing characteristics for 156th St. \& Hickman Rd......35

Figure 3.6. RLR camera system monitoring eastbound traffic at 156th St. \& Hickman Rd. ........36

Figure 3.7. RLR camera system monitoring northbound traffic.............................................36

Figure 3.8. Roadway, traffic, and signal timing characteristics for 142nd St. \& Hickman Rd.....37

Figure 3.9. RLR camera system monitoring eastbound traffic at 142nd St. \& Hickman Rd........37

Figure 3.10. Roadway, traffic, and signal timing characteristics for 128th St. \& Hickman Rd....38

Figure 3.11. Northbound traffic for 128th St. \& Hickman Rd. ..................................................38

Figure 3.12. Roadway, traffic, and signal timing characteristics for 100th St. \& Hickman Rd....39

Figure 3.13. Northbound traffic for 100th St. \& Hickman Rd. .............................................39

Figure 3.14. Roadway, traffic, and signal timing characteristics for 86th St. \& Hickman Rd......40

Figure 3.15. Southbound traffic for 86th St. \& Hickman Rd. ..................................................40

Figure 3.16. Roadway, traffic, and signal timing characteristics for 86th St. \& Douglas Ave.....41

Figure 3.17. Southbound traffic for 86th St. \& Douglas Ave...................................................41

Figure 3.18. Roadway, traffic, and signal timing characteristics for 100th St. \& Douglas Ave...42

Figure 3.19. Northbound traffic for 100th St. \& Douglas Ave..............................................42

Figure 3.20. Aerial view of traffic for 100th St. \& Douglas Ave............................................43

Figure 3.21. Roadway, traffic, and signal timing characteristics for 35th St. \& University Ave..43

Figure 3.22. Southbound traffic for 35th St. \& University Ave...............................................44

Figure 3.23. Roadway, traffic, and signal timing characteristics for 60th St. \& University Ave..44

Figure 3.24. Westbound traffic for 60th St. \& University Ave. ..............................................45

Figure 3.25. Aerial view of traffic for 60th St. \& University Ave. .............................................45

Figure 3.26. Roadway, traffic, and signal timing characteristics for Oralabor Rd. \& State St. ....46

Figure 3.27. Northbound traffic for Oralabor Rd. \& State St. .................................................46

Figure 3.28. Roadway, traffic, and signal timing characteristics for N. Warrior Ln. \& Hickman

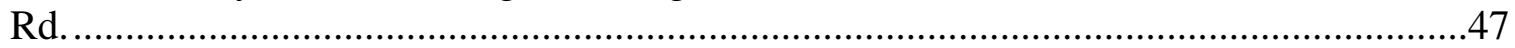

Figure 3.29. Eastbound traffic for N. Warrior Ln. \& Hickman Rd. ..........................................47

Figure 3.30. Schematic of data collection..........................................................................48 


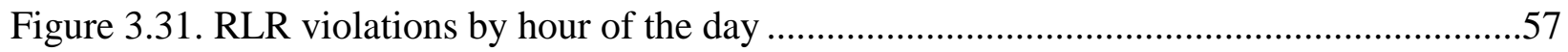

Figure 3.32. Distribution of time into red for left-turning vehicles ........................................58

Figure 3.33. Distribution of time into red for through vehicles............................................59

Figure 3.34. Distribution of time into red for right-turning vehicles.....................................59

Figure 4.1. Advance warning signs ..............................................................................61

Figure 4.2. Location of camera-enforced and control intersections in Council Bluffs ................62

Figure 4.3. Roadway, traffic, and signal timing characteristics for Broadway and 35th St. .........64

Figure 4.4. Eastbound traffic for Broadway and 35th St..................................................64

Figure 4.5. Roadway, traffic, and signal timing characteristics for Broadway and 21st St..........65

Figure 4.6. Westbound traffic for Broadway and $21^{\text {st }}$ St. ..................................................65

Figure 4.7. Roadway, traffic, and signal timing characteristics for Broadway and 16th St.........66

Figure 4.8. Eastbound traffic for Broadway and 16th St.....................................................66

Figure 4.9. Westbound traffic for Broadway and 16th St...................................................67

Figure 4.10. Roadway, traffic, and signal timing characteristics for Kanesville Blvd. and 8th St.67

Figure 4.11. Eastbound traffic for Kanesville Blvd. and 8th St...........................................68

Figure 4.12. Westbound traffic for Kanesville Blvd. and 8th St. ..........................................68

Figure 4.13. Roadway, traffic, and signal timing characteristics for 7th St. and Willow Ave.....69

Figure 4.14. Southbound traffic for 7th St. \& Willow Ave....................................................69

Figure 5.1. Davenport RLR and automated speed camera system. .........................................72

Figure 5.2. Camera-enforced and control intersections in Davenport.......................................74

Figure 5.3. Roadway, traffic, and signal timing characteristics for Kimberly Rd. and Brady St..77

Figure 5.4. Eastbound traffic for Kimberly Rd. and Brady St...............................................77

Figure 5.5. Westbound traffic for Kimberly Rd. and Brady St...............................................78

Figure 5.6. Northbound traffic for Kimberly Rd. and Brady St. .............................................78

Figure 5.7. An aerial image of traffic for Kimberly Rd. and Brady St....................................78

Figure 5.8. Roadway, traffic, and signal timing characteristics for 35th St. and N. Harrison St. .79

Figure 5.9. Southbound traffic for 35th St. and N. Harrison St.................................................80

Figure 5.10. Northbound traffic for 35th St. and N. Harrison St............................................80

Figure 5.11. Roadway, traffic, and signal timing characteristics for Welcome Way and Kimberly $\mathrm{Rd}$.

Figure 5.12. Southbound, east lane traffic for Welcome Way and Kimberly Rd........................81

Figure 5.13. Southbound, west lane traffic for Welcome Way and Kimberly Rd.......................82

Figure 5.14. Roadway, traffic, and signal characteristics for Lincoln Ave. and Locust St...........82

Figure 5.15. Eastbound traffic for Lincoln Ave. and Locust St...........................................83

Figure 5.16. Westbound traffic for Lincoln Ave. and Locust St. ............................................83

Figure 5.17. Roadway, traffic, and signal timing characteristics for Kimberly Rd. and Elmore Ave.

Figure 5.18. Eastbound traffic for Kimberly Rd. and Elmore Ave.............................................84

Figure 5.19. Westbound traffic for Kimberly Rd. and Elmore Ave. .........................................85

Figure 6.1. Posterior distributions of the average in total crashes over expected crash frequencies for Davenport.....

Figure 6.2. Posterior distributions of the average in RLR-related (non-rear-end) crashes over expected crash frequencies for Davenport ...................................................................105

Figure 6.3. Posterior distributions of the average in RLR-related rear-end crashes over expected



Figure 6.4. Difference in average of expected total crashes (Davenport) .................................109 Figure 6.5. Difference in average of expected RLR-related (non-rear-end) crashes (Davenport)109 Figure 6.6. Difference in average of expected RLR-related rear-end crashes (Davenport) ........110 


\section{LIST OF TABLES}

Table 1.1. Effectiveness of countermeasures used to improve signal visibility ..........................5

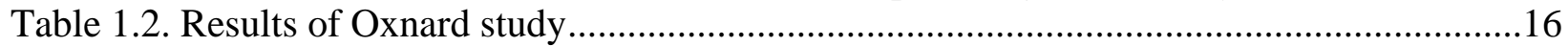

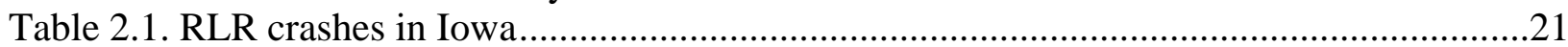

Table 3.1. Vendor's initial study and the number of violations for each approach......................24

Table 3.2. RLR violations for camera-enforced intersections_-Clive .....................................51

Table 3.3. RLR violations for control intersections - Clive ....................................................52

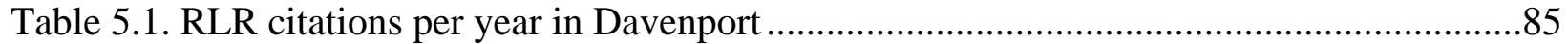

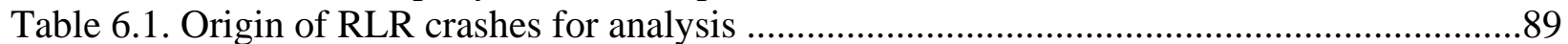

Table 6.2. Broadside crashes by type .................................................................................90

Table 6.3. Changes in total crashes for RLR camera-enforced intersections before and after treatment for simple statistics —Council Bluffs.........................................................94

Table 6.4. Changes in total crashes for control intersections before and after treatment for simple statistics-Council Bluffs

Table 6.5. Changes in RLR-related (non-rear-end) crashes for RLR camera-enforced intersections before and after treatment for simple statistics-Council Bluffs................95

Table 6.6. Changes in RLR-related (non-rear-end) crashes for control intersections before and after treatment for simple statistics—Council Bluffs ...................................................95

Table 6.7. Changes in RLR-related rear-end crashes for RLR camera-enforced intersections before and after treatment for simple statistics-Council Bluffs .................................96

Table 6.8. Changes in RLR-related rear-end crashes for control intersections before and after treatment for simple statistics-Council Bluffs.

Table 6.9. Changes in total crashes for RLR camera-enforced intersections before and after treatment for descriptive statistics-Davenport

Table 6.10. Changes in total crashes for control intersections before and after treatment for descriptive statistics-Davenport

Table 6.11. Changes in RLR-related (non-rear-end) crashes for RLR camera-enforced intersections before and after treatment for descriptive statistics—Davenport

Table 6.12. Changes in RLR-related (non-rear-end) crashes for control intersections before and after treatment for descriptive statistics-Davenport .

Table 6.13. Changes in RLR-related rear-end crashes for RLR camera-enforced intersections before and after treatment for descriptive statistics-Davenport

Table 6.14. Changes in RLR-related rear-end crashes for control intersections before and after treatment for descriptive statistics-Davenport

Table 6.15. Expected crash frequency per site for total crashes for RLR camera-enforced intersections-Davenport

Table 6.16. Expected crash frequency per site for total crashes for camera-enforced intersections-Davenport

Table 6.17. Posterior mean and 95\% credible set of the expected crash frequency-Davenport101

Table 6.18. Expected crash frequency per site for RLR-related crashes for camera-enforced intersections-Davenport

Table 6.19. Expected crash frequency per site for RLR-related crashes for control intersectionsDavenport.

Table 6.20. Posterior mean and 95\% credible set of the expected crash frequency-Davenport102 
Table 6.21. Expected crash frequency per site for RLR-related rear-end crashes for cameraenforced intersections-Davenport

Table 6.22. Expected crash frequency per site for RLR-Related rear-end crashes for control intersections-Davenport

Table 6.23. Posterior mean and 95\% credible set of the expected crash frequency-Davenport104

Table 6.24. Expected difference in crash frequency for total crashes for camera-enforced intersections-Davenport ..............................................................................................106

Table 6.25. Expected difference in crash frequency for total crashes for control intersections-

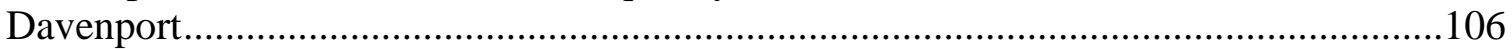

Table 6.26. Posterior mean and 95\% credible set of the expected difference in crash frequency averaged over sites ....................................................................................................... 106

Table 6.27. Expected difference in crash frequency for RLR-related crashes for camera-enforced intersections-Davenport .............................................................................................107

Table 6.28. Expected difference in crash frequency for RLR-related crashes for control

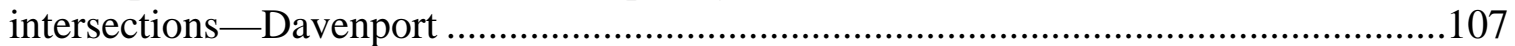

Table 6.29. Posterior mean and 95\% credible set of the expected difference in crash frequency averaged over sites — Davenport ..................................................................................107

Table 6.30. Expected difference in crash frequency for RLR rear-end crashes for cameraenforced intersections-Davenport ................................................................................108

Table 6.31. Expected difference in crash frequency for RLR rear-end for control intersections-



Table 6.32. Posterior mean and 95\% credible set of the expected difference in crash frequency averaged over sites—Davenport ........................................................................................108 


\section{ACKNOWLEDGMENTS}

The research team would like to thank the Iowa Department of Transportation for funding this project. Special thanks to Mr. Dave Matulac for serving as the project monitor and to Dr. Michael Pawlovich for providing a dataset of signalized intersections in the state as well as providing access to the crash narratives. We would also like to thank a large number of individuals who provided data and information for the project. They include the following:

- City of Clive

- City of Davenport

- City of Council Bluffs

- Ronald Bunting - Iowa DOT

- Dennis Henderson - City of Clive City Manager

- Pamela L. Shannon - City of Clive City Clerk

- Chief Robert P. Cox - Chief of Police, City of Clive

- Jim Dewitt - City of Clive Public Works Operation Supervisor

- Sgt. John Brodersen - City of Clive Police Department

- John B. Larson - City of Urbandale Assistant Director of Engineering

- Tom Dozler - City of Ankeny Public Works

- Ray Weiser - Scott County GIS Office

- Lt. Michael G. Venema - City of Davenport Police Department

- Al Berg - City of Davenport Finance Department

- Gary Statz - City of Davenport Traffic Engineer

- Gregory Reeder - City of Council Bluffs Public Works Director

- Mark Franz - City of Council Bluffs Traffic Superintendent

- Ron Johnson - Iowa Signal, for the City of Waukee

- Richard Retting - Insurance Institute for Highway Safety

\section{DISCLAIMER}

This study was sponsored by the Iowa Department of Transportation. Several communities provided information and gave permission for data collection to occur. However, the study is not endorsed by any of the communities represented. 


\section{EXECUTIVE SUMMARY}

Statewide, an analysis of red light running (RLR) crashes, using crash data from 2001 to 2006, indicates that an average of 1,682 RLR crashes occur at signalized intersections in Iowa every year. This accounts for $20.6 \%$ of all crashes and $35.0 \%$ of fatal and major injury crashes at signalized intersections. RLR crashes tend to be broadside and other types of more severe crash types, which may explain the disproportionate percentage of fatal and major injury crashes.

As communities across the United States attempt to address red light running, a number of communities have implemented RLR camera enforcement programs. Iowa currently has three communities that have started using camera enforcement since 2004. These communities include Davenport, Council Bluffs, and Clive. As of October, 2007, the state of Iowa currently has no state-mandated laws regarding the use of automated enforcement or recommended scheduled traffic fine for violations captured by photography. Each community that installed an automated enforcement system in Iowa enacted local, municipal ordinances, which are allowed by the Code of Iowa, but cannot supersede established traffic laws. Automated enforcement (red light running and speed monitoring cameras) programs have been implemented through city ordinances in Iowa as civil infractions, similar to parking tickets. Civil violations require only identification of the vehicle owner for citation. The Code of Iowa applies criminal, not civil, penalties for violation of traffic signals, which necessitates identification of the driver by a police officer.

The objective of this research project was to evaluate the effectiveness of RLR cameras in Iowa. Cameras were installed on six approaches at four intersections in Clive in June 2006. The ideal way to evaluate the effectiveness of RLR cameras is to evaluate the reduction in crashes from before cameras were installed to after. However, since the cameras in Clive weren't installed until the end of 2006, less than one year of after data was available, which was not sufficient to conduct a crash analysis. As a result, the only way to evaluate the effectiveness of Clive's automated RLR enforcement system was to perform a cross-sectional analysis that compared RLR violations at camera instrumented intersections to a group of control intersections. Approaches at seven control intersections were chosen that had similar characteristics as the camera-enforced intersections. RLR violations were collected by movement at the control intersections approaches for one day at peak hours. Violation data for the RLR camera-enforced approaches were also collected from the city. A generalized linear model was used to determine statistical significance of the differences between violations between the study locations with RLR cameras and the control intersection. The model indicated that approaches with cameras had a significant and statistically significant lower number of RLR violations than the approaches at control intersections. The reduction depended on volume and movement. To illustrate, the average expected number of violations for a right turn movement with a volume of 200 vehicles per hour without a camera is 9.3 violations per peak period ( 2 hours). With a camera in place, the average expected number of violations per hour is 0.4 . On average approaches without RLR cameras experience 25 times more RLR violations than approaches with cameras.

The RLR program in Council Bluffs, Iowa was instituted in August of 2005. Cameras were placed on seven approaches at five intersections. Only slightly more than one year of crash data was available to evaluate the effectiveness of the Council Bluff program in reducing crashes. 
Crashes per quarter and crash rate were calculated for a before period consisting of 12 quarters and an after period consisting of 4 quarters. A Bayesian statistical analysis will be conducted when 2007 crash data are available, but a more in-depth statistical was not conducted because of the very short after period. Four control intersections were used to reflect crash trends that were independent of the cameras. Changes in crashes from the before to after period were evaluated by comparing change in crashes per quarter and crash rate. Total crashes decreased overall at intersections with camera-enforced approaches by 44\% from before to after cameras were installed. Total crashes also decreased at control intersections overall but only by 11.8 percent. A more dramatic result was found when only RLR-related crashes (non-rear-end) were evaluatedRLR crashes decreased by $90 \%$ after installation of the cameras at intersections. Overall results for the control intersections indicate that no reduction in RLR crashes occurred from the before to after period. Finally, RLR-related rear-end crashes decreased by $40 \%$ at intersections with camera-enforced approaches but increased by $29 \%$ at control intersections. This result was unexpected because rear-end crashes were expected to increase with the use of an RLR camera enforcement system.

The RLR camera system was installed in Davenport at two intersections in August of 2004 and at the remaining three intersections in September and October of 2004. Cameras were present on nine approaches of five intersections. An additional five control locations were selected in Davenport for use in the statistical analysis. One camera-enforced intersection was not used in the final analysis because the camera was moved and replaced, and it was felt that this location was not representative. As a result, four camera-enforced intersections were used in the analysis. Both simple statistics and a Bayesian analysis were used to evaluate Davenport data. Because the cameras were installed in August of 2004, eight quarters of after data were available. Twelve quarters of before data were also used.

Results of the simple statistics and Bayesian analysis are consistent, so only results of the Bayesian analysis are summarized here. The expected average number of crashes per quarter for total crashes decreased by $20 \%$ from the before to after period for intersections with camera enforcement while total crashes increased by almost 7\% for control intersections. The difference in average number of total crashes per quarter for the RLR treatment intersections is statistically significant at the 95\% level of significance. The increase for control intersections is not statistically significant at the 95\% level of significance. The difference in expected number of RLR crashes per quarter is statistically significant at the 95\% level of significance for intersections with camera-enforced approaches. The difference is not statistically significant for control intersections at the $95 \%$ level of significance.

The expected average number of crashes per quarter for RLR-related crashes (non-rear-end) decreased by $40 \%$ after installation of cameras at intersections with camera-enforced approaches. The expected average number of RLR-related crashes (non-rear-end) increased by almost $20 \%$ at control intersections. The expected average number of RLR-related rear end-crashes per quarter changed very little from the before to after period for intersections with camera-enforced approaches. The expected number of rear-end crashes per quarter increased by approximately $33 \%$ for the control intersections. However, the difference in the expected number of RLR rearend crashes was not statistically significant at the $95 \%$ level of significance for either group of intersections. 
This report overviews the RLR programs in Iowa and summarizes results of analyses to evaluate the effectiveness of the cameras. Section 1 provides background on the scope of the RLR problem nationally, discusses factors that have been shown to be related to red light running, provides a background on camera enforcement for red light running and summarizes other research that describes the effectiveness of the RLR cameras. Legal and social concerns that have been raised in areas where RLR programs have been instituted are also discussed. Section 2 summarizes an analysis that quantifies the number and severity of red light running statewide in Iowa. Section 3 describes the RLR program in Clive as well as details the analysis of violations used to evaluate the effectiveness of the Clive program. Violations were evaluated because there was not enough after data to conduct any type of crash analysis. Section 4 overviews the RLR program in Council Bluffs and Section 5 describes the program in Davenport. Section 6 describes the simple and Bayesian statistical methods and summarizes the results of the statistical analyses for Davenport and Council Bluffs. Section 7 provides a summary of the report. 


\subsection{BACKGROUND}

The Federal Highway Administration (FHWA) estimates that red light running causes more than 100,000 crashes and 1,000 fatalities annually and results in an estimated economic loss of over \$14 billion per year in the United States (FHWA, 2007; FHWA, 2006). Retting et al. (1995) indicated that occupant injuries occurred in 45\% of RLR crashes as compared to other urban crashes and account for 16-20\% of total crashes at urban signalized intersections. Red light running can be particularly dangerous since many RLR crashes are right-angle collisions. Bonneson et al. (2004) estimated that red light running costs the state of Texas approximately $\$ 2$ billion each year in societal costs.

Red light running poses a significant safety issue for communities. Communities rarely have the resources to place additional law enforcement in the field to combat the problem and they are increasingly using automated RLR camera-enforcement systems at signalized intersections. As of October 2006, the Insurance Institute of Highway Safety (IIHS) reported that over 170 communities in 22 states and the District of Columbia have implemented RLR programs (IIHS, 2006).

\subsection{Characteristics of Red Light Runners}

Certain driver characteristics have been associated with red light running. Retting et al. (1996) found that drivers under the age of 30 were more likely to run red lights. Porter and Berry (2001) found that drivers aged 18-25 years were more likely to run red lights than other drivers in other age groups, and Kraus and Quiroga (2004) also suggested that younger age groups were more likely to run red lights than other age groups. Retting et al. (1999) also reported that men were more likely to run red lights than women. Retting et al. (1999) found that red light runners were more likely to be driving with a suspended or revoked driver's license and more likely to have prior moving violations than drivers who did not run red lights.

\subsection{Intersection Characteristics and RLR}

Some intersection characteristics can increase prevalence of red light running. Certain designs and configurations can also lead to reduced reaction and stopping times, driver confusion, or limited views of the traffic signals. Many times, a simple engineering analysis of the troubled intersection could have helped the situation before the implementation of an RLR system (AASHTO, 2001).

\subsubsection{Grade}

The grades approaching the intersection can significantly affect the time needed for a vehicle to stop. Grades in excess of 5\% may affect the driver's desire to stop for a red light. A study conducted in 1985 concluded that more drivers will tend to stop at an intersection that is on an uphill grade, but tend to run the red lights on a downhill grade. It was also recommended by this research group that having a longer all-red clearance interval on down grades would 
counterbalance this effect to prevent potential accidents (Chang et al., 1985). In another report, the weight and downhill momentum of a vehicle affects a driver's ability to safely stop at an intersection (ITE, 1994).

\subsubsection{Sight Distance}

Drivers are not able to notice and react to traffic control devices that cannot be seen when approaching an intersection. Obstructions might include overhanging vegetation, billboards, large trucks, commercial signs, low pressure sodium lights, or awkward geometric alignment of the road (ITE, 1994). Line of sight is critical to a driver approaching an intersection.

Obstructions beside the vehicle (e.g., a tree or building) or an obstruction in front of the vehicle (e.g., a large truck or trailer) may reduce reaction time and/or affect driver behavior. The worst case for line of sight obstruction is the intersection located at the base of a hill where the traffic signal is partially or completely hidden from the driver's view until reaching the top (FHWA, 2003).

\subsubsection{Roadside Obstructions}

Roadside obstructions such as parked vehicles, vegetative growth, pedestrians, and billboards may block motorists' view of signs, traffic control devices, or other vehicles (NHTSA, 2005). Intersections with such obstructions should be engineered so roadside parking does not interfere with sign visibility (FHWA, 2003). Traffic control devices and signs should be regularly cleared of vegetation over-growth and/or vandalism (MUTCD, 2001).

\subsubsection{Approach Volumes}

Multiple research studies have indicated that red light running may be influenced by the time or day of the week (Porter and Berry, 1999). During peak hours of the day, traffic volumes and congestion will influence the number of red lights run. Drivers who commute or run errands during these times will experience considerable delays. This is especially true if signals are not properly timed or coordinated, resulting in adverse driver behavior (NHTSA, 2005). On the other hand, many drivers will travel before peak hour congestion when there is little volume on the road. In some cases, traffic signals might be non-traffic actuated signals, making drivers wait for extended periods of time for no vehicles, thus occasionally resulting in red lights being run (FHWA, 2005).

\subsection{Engineering Countermeasures to Reduce Red Light Running}

Although driver behavior is a key element in determining whether someone will run a red light, intersection factors such as an inadequate change signal, sight distance issues, or significant delay may also contribute to red light running; it sometimes can be solved by less expensive countermeasures than automated enforcement (McGee et al., 2003). Bonneson et al. classified engineering countermeasures into three categories based on the method of implementation. "Signal operation" countermeasures include modifications to signal timing, type of signal, cycle length, and change interval. "Motorist information" countermeasures are modifications to 
advanced warning devices, such as signs or flashing lights, to warn drivers of a signalized intersection ahead. "Physical improvements" countermeasures involve sometimes extensive modifications to an intersection to solve dangerous safety concerns or operational problems (Bonneson et al., 2003).

\subsubsection{Signal Operations}

Increased Yellow Interval: Two known studies have evaluated the effectiveness of extending the duration of the yellow interval. Retting and Greene cited numerous sources where extending the yellow time will reduce red light running and right-angle crashes (Retting and Greene, 1997). Another study, performed by Van der Horst and Wilimink, found a relationship between red light running and yellow duration at 11 test intersections. Their conclusions found that yellow intervals of at least 3.5 seconds are associated with minimal RLR cases (Van der Horst and Wilmink, 1996). Bonneson et al. concluded that increasing the yellow time was inversely related to the frequency of red light running and found this decreased red light running 50-70\% (Bonneson et al., 2003). Although this method proved successful, researchers noted that if yellow interval extensions are increased too much, the capacity of the intersection might decrease and delay will increase (McGee et al., 2003). Because delay has been cited as a factor in red light running, the benefits may offset.

Provide Green Extension: Advanced detection devices are used before major intersections with actuated traffic signals to extend the green light duration or change the signal phase by sending an advance signal. Once a vehicle passes the detection device (autoscope or inductive loops), a signal is sent to the traffic signal to extend the green light duration or change the cycle phase. Zegeer and Dean concluded that extending the green light duration would reduce the frequency of red light running by as much as 65\% (Zegeer and Deen,1978; Bonneson et al., 2003). Although many communities have implemented green extension by advance warning devices, it can also increase red light running if drivers realize the extension is in place and intentionally trip the extension.

Coordination: A common practice among cities is to coordinate traffic signals along a corridor to provide less delay, thus resulting in fewer RLR violations. Although this practice improves the flow of traffic along a corridor, Van der Horst and Wilmink concluded that there is a greater chance that a platoon of vehicles formed by signal coordination will run a red light if the platoon arrives close to the end of the green cycle (Van der Horst and Wilmink, 1996; Bonneson et al., 2003). It was also noted that the potential for RLR violations may decrease with traffic signal coordination if cycle lengths were adjusted (Van der Horst and Wilmink, 1996; Bonneson et al., 2003).

Improved Traffic Signal Visibility: One of most common claims for red light running is the complaint that a driver was not able to see the traffic signal or mistook the color of the signal (McGee et al., 2003). Although many times these claims prove false, traffic signals should be visible far enough upstream for a vehicle to safely stop. A FHWA study recommended the following improvements that would help traffic signal visibility to drivers approaching the intersection (McGee et al., 2003): 
Lens Size and Type: Increasing the diameter of the signal head from 8 inches to 12 inches will improve the visibility of the traffic signal. An unpublished research study conducted in WinstonSalem, NC, showed a 47\% decrease in RLR right-angle crashes at intersections with 12-inch lenses using a simple before-and-after study (McGee et al, 2003; Polanis, 2002). The same FHWA report also suggests using LED lights for traffic signal lenses. LED lights last 4-5 years longer and use 90\% less energy that traditional traffic signal lights (McGee et al., 2003). Furthermore, preliminary studies have shown LED lights activate much quicker, giving drivers fractions of a second more to react to the change in color (Marshall, 2006).

Backplates: Backplates are common at most traffic signals and are particularly helpful if a vehicle is traveling east/west to combat possible sun glare. In many communities, it is now standard practice to place backplates on every traffic signal to improve visibility for all directions (McGee et al., 2003). The Manual on Uniform Traffic Control Devices (MUTCD), in section 4D.18, requires the front of the backplate (the view toward oncoming traffic) to be a dull black to minimize light reflection and provide a contrast to the three traffic signal colors (MUTCD, 2001). Polanis investigated the effect backplates had on crash frequency and found they decreased right-angle crashes by 32\% (Polanis, 2002).

In 1998, a research study conducted in British Columbia, Canada, by Miska, de Leur, and Sayed, investigated the effects of installing yellow reflective tape on the edge of the backplates to combat various claims of not being able to visually see the traffic signals at studied intersections. As shown below in Figure 1.1, a 75mm, reflective, 3M tape border was installed on single heads of six traffic signals at six intersections. The cost of installation was minimal at \$35 per signal and around \$420 per intersection. Miska, de Leur, and Sayed concluded that the numbers of claims were reduced up to 60\% (Miska et al., 1998; NCUTCD, 2001).

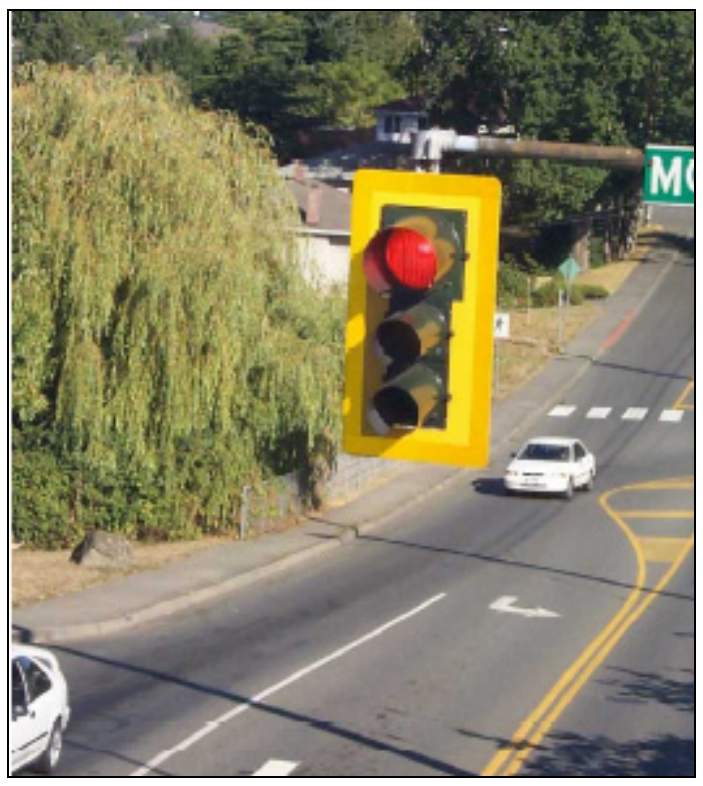

Figure 1.1. Signal with high intensity yellow retroreflective tape on backplate (Miska et al., 1998). 
Placement: Although the MUTCD does not specify or require that the traffic signals be over each lane and attached to a pole, studies in Iowa and Missouri have shown 32\% and 25\% reductions in crashes at intersections with traffic signals attached to mast and poles (McGee et al., 2003). An FHWA report states that traffic signals located above each lane overcome three important obstacles that median or roadside traffic signals have: (1) they generally do not provide good conspicuity, (2) mounting locations may not provide a display with clear meaning and (3) motorists' line-of-sight blockage to the signal head due to other vehicles, particularly trucks, in the traffic stream (McGee et al., 2003). Shown below in Figure 1.2 is a typical highspeed intersection in Colorado where 12-inch diameter traffic signal heads are located over each travel lane. Also note the 8-inch diameter pole-mounted signal head to aid vehicles that cannot see the overhead traffic signals due to blockage from trucks or other large vehicles.

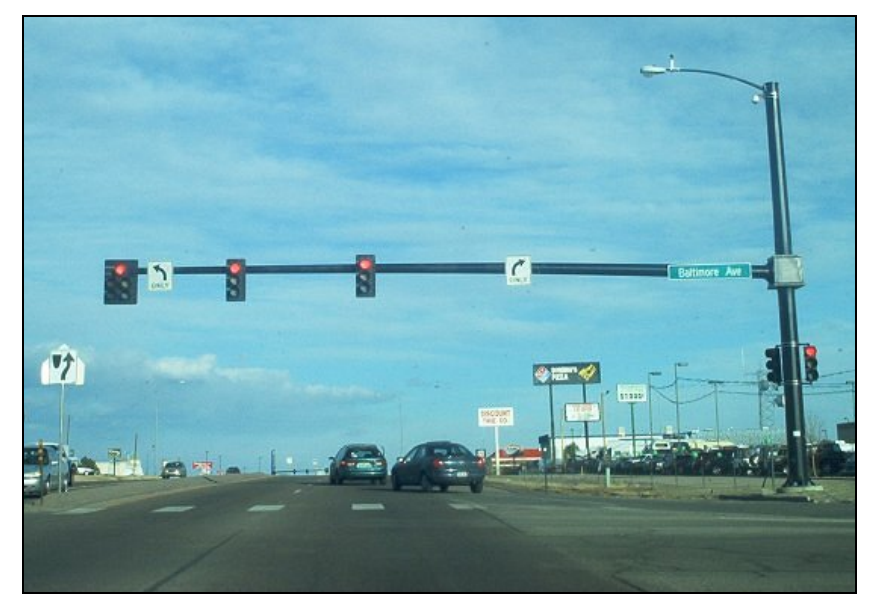

Figure 1.2. CDOT specified high-speed intersection traffic signal (Salek, 2006)

Table 1.1 summarizes the effectiveness of several countermeasures that are used to improve signal visibility at intersections.

Table 1.1. Effectiveness of countermeasures used to improve signal visibility

\begin{tabular}{|c|c|c|c|}
\hline Countermeasure & $\begin{array}{c}\text { Sample Size } \\
\text { (intersections) }\end{array}$ & Effectiveness & Reference \\
\hline $\begin{array}{l}\text { Increase signal lens from } \\
8 \text { to } 12 \text { in. }\end{array}$ & 55 & $\begin{array}{l}\text { 47\% reduction in right-angle } \\
\text { crashes }\end{array}$ & Polaris, 2000 \\
\hline $\begin{array}{l}\text { Add back plates to } \\
\text { signal head }\end{array}$ & 6 & $\begin{array}{l}32 \% \text { reduction in right-angle } \\
\text { crashes }\end{array}$ & Polaris, 2000 \\
\hline $\begin{array}{l}\text { Add supplemental signal } \\
\text { heads }\end{array}$ & 11 & $\begin{array}{l}\text { 47\% reduction in right-angle } \\
\text { crashes }\end{array}$ & Polaris, 2000 \\
\hline $\begin{array}{l}\text { Add second red } \\
\text { indication to each head }\end{array}$ & 9 & $\begin{array}{l}\text { 33\% reduction in right-angle } \\
\text { crashes }\end{array}$ & Polaris, 2000 \\
\hline Add LED signal lenses & 1 & $\begin{array}{l}54 \% \text { reduction in frequency of } \\
\text { red light running }\end{array}$ & $\begin{array}{l}\text { Bonneson, } \\
2002\end{array}$ \\
\hline $\begin{array}{l}\text { Add strobe light to red } \\
\text { indication }\end{array}$ & 6 & $\begin{array}{l}15 \% \text { reduction in right angle } \\
\text { crashes }\end{array}$ & Cottrell, 1995 \\
\hline
\end{tabular}




\subsubsection{Addition of Advance Warning Signs}

One of the most commonly used countermeasures to warn drivers of an approaching intersection is advance warning signage, as shown in Figure 1.4. The sign on the left, a W3-3, is typical in urban areas where advance warning may sometimes be needed in heavy congestion. Furthermore, these signs can be accompanied by flashing warning lights or flags attached to them. In a study conducted by Polanis, it was found that W3-3 warning signs reduced right-angle crashes by $44 \%$ at signalized intersections (Polanis, 2002).

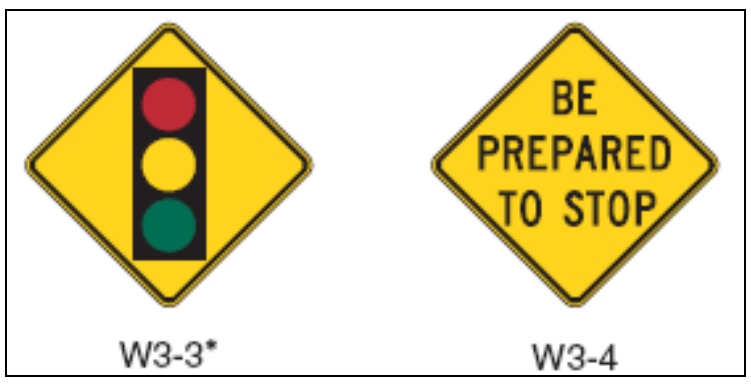

Figure 1.3. Advance intersection warning signs (MUTCD, 2002)

Another type of advance warning device is also shown in Figure 1.4, which is the "Be Prepared to Stop” (W3-4) sign, as specified in the MUTCD. This sign can be used as a stand-alone warning sign for either signalized intersections or conventional four-way stops (MUTCD, 2001). In some cases, flashing lights have been attached to this sign and coordinated with intersections to flash during the green phase of the approach leg. Bonneson et al. state that this sign has been found to particularly reduce RLR-associated crashes up to 67\% (Bonneson et al., 2003).

\subsubsection{Physical Improvements}

Removal of Unneeded Traffic Signals: Removal of traffic signals at low volume intersections can be an effective countermeasure if safety and intersection operation is not degraded. This idea works well at low volume side streets where traffic is directed to main arterial corridors. In a study performed by Retting et al., 199 signals were removed from signalized intersections in Philadelphia, PA, and it was found that crashes were reduced by $24 \%$ (Retting et al., 1998).

Added Capacity with Additional Lanes: Another factor contributing to red light running is the congestion at signalized intersections. Sometimes intersections may not be built to handle peakhour traffic as a result of physical or economic constraints. Many times, drivers have no intentions of running a red light but are forced to do so if they are waiting to make a left turn while in the intersection when the phase change happens. Although many jurisdictions recognize that vehicles in the intersection are not running red lights, drivers of vehicles behind the stop bar may be persuaded to run the red light behind the vehicles that are in the intersection. The first correction that should be considered is adjusting the phasing, which many times can greatly improve traffic congestion (Bonneson et al., 2003). The second, more costly option, is to add additional lanes, whether it is through or turning lanes, or, alternatively, convert the intersection to a roundabout. 
Adjust Curve Geometry: Intersections can be complicated by horizontal or vertical curves, which can lead to a higher frequency of RLR crashes. Vertical curves can affect drivers in both uphill and downhill conditions. This effect may cause the driver to misjudge the stopping distance or prevent the driver from being able to fully see the traffic signals before approaching the intersection (Bonneson et al., 2003). Sharp horizontal curves place high demands on the driver to accurately drive through the curve and negotiate a possible traffic signal at the same time (Bonneson et al., 2003).

\subsection{Use of Automated Enforcement to Reduce Red Light Running}

Automated camera enforcement is also used as an RLR countermeasure. Although automated enforcement has been shown to reduce right-angle crashes by $32-42 \%$, legal battles, public opposition, and upfront costs have prevented many cities from implementing such a system (Retting et al., 1998).

RLR cameras serve three purposes. First, RLR cameras are used to enforce traffic signal compliance. Second, the cameras can reduce the frequency of RLR violations and have proven effective in reducing fatal collisions. Last, RLR cameras generate a revenue for the city that in many cases funds enforcement programs or investing in the community (e.g., parks, recreation, fire department) (Kamyab et al., 2000). The success of these three functions depends on how the camera is set up and the technology that is in place.

A typical red light camera system can cost $\$ 50,000$ or more, depending on the intersection geometry and number of cameras (Kamyab et al., 2000). For many communities, a \$50,000 system might be too expensive for operation and maintenance for the amount of enforcement needed at the intersection. An option to offset the cost of the system is using a portable camera system and a "dummy" flash system. The portable camera system can be moved throughout multiple intersections if the camera is mounted in a vehicle, or can be mounted on existing structures. The dummy flash system is a camera flash that is mounted next to an empty camera box and flashes if there is a red light violator, fooling the driver into thinking he or she was caught by an RLR camera (Kamyab et al., 2000).

RLR cameras are typically located in weatherproof, vandalism-protected metal boxes. Placed close to the intersection on hinged poles, or fixed onto a traffic signal structure, these boxes are mounted 10-15 feet in the air, as shown in Figure 1.5. Other RLR camera systems are integrated into the existing traffic signal hardware, as shown in Figure 1.6. The red light camera system is typically connected to the traffic signal controller and to dedicated inductive loops in the pavement at or before the stop bars or the autoscopes at the intersection. Although many traffic equipment vendors claim one automated enforcement camera system can monitor four lanes of traffic, studies performed in New York City have shown accurate photography can only be accomplished in three travel lanes (Passetti and Hicks, 1997). Typically the RLR camera inductive loop system is separate from signal control inductive loops so that minimal interference will occur. 


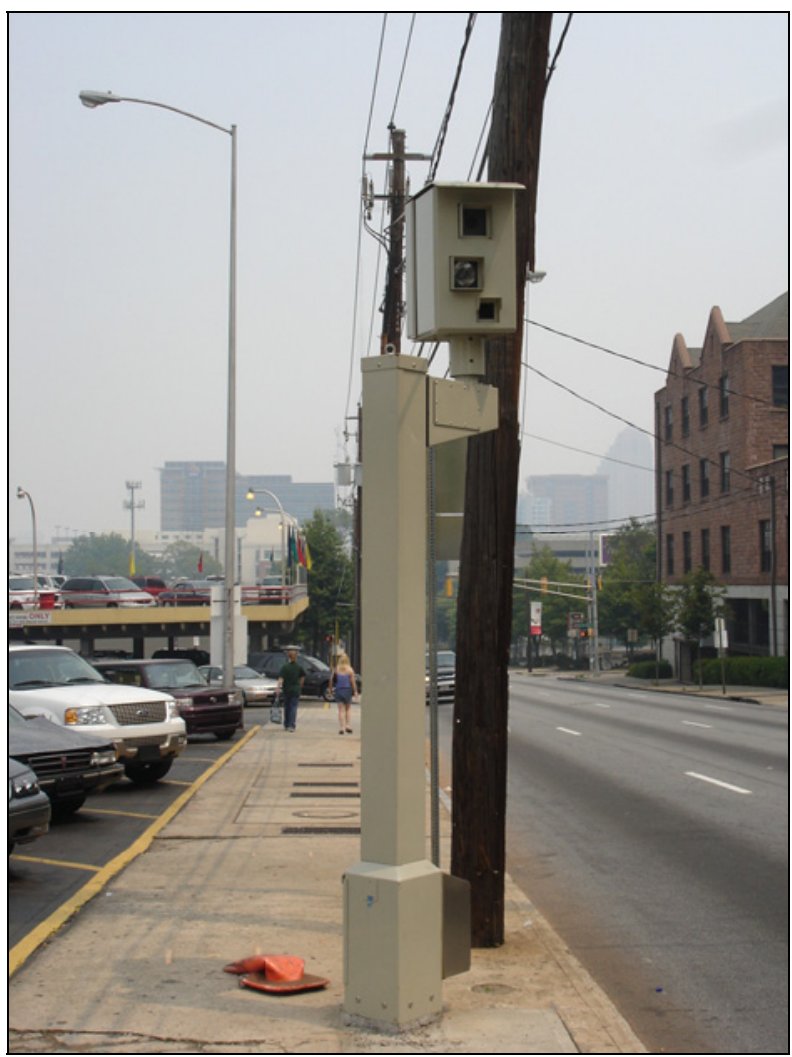

Figure 1.4. Gatso RLR camera system (Atlanta, GA) 


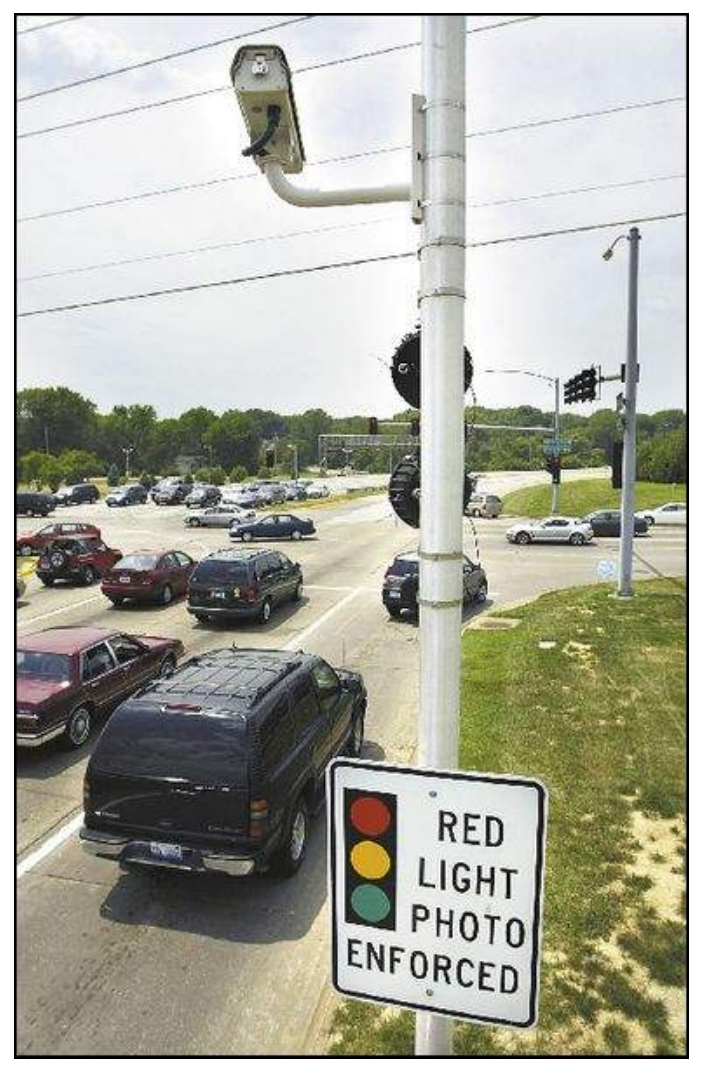

Figure 1.5. Transol RLR camera (Davenport, IA, image source: Quad City Times)

When a traffic signal switches to a red phase, the automated enforcement system is activated, and the camera is ready to take a picture. Vehicles in violation will cross a trigger mechanism, which could include road tubes, inductive loop sensors, piezoelectric strips (pressure sensors), radar, or lasers. A minimum time period and preset speed limit are built into the trigger mechanism, allowing the system to differentiate between vehicles attempting to make a stop, turn, or run through the intersection. This grace period is typically three-tenths of a second, with a typical minimum speed limit of 15-20 mph (Passetti and Hicks, 1997). A second photo of the violating vehicle is taken seconds after the first photo and shows the traffic signal color and offending vehicle in the middle of the intersection. In some cases, a third photograph is taken to capture the offending vehicle's license plate.

Two pictures taken from the Mesa, AZ, red light automated enforcement system are shown in Figures 1.7 and 1.8. The City of Mesa uses advanced digital camera systems, which are estimated to have over a 10 megapixel resolution with zoom capabilities to identify humans in the car and license plate numbers. As shown, the sport utility vehicle (SUV) had clearly passed the stop bar and was proceeding through the crosswalk. The black bar at the top of the photo displayed current information about the picture frame. The date, time, and location are current to the image. The recorded speed is shown at $46 \mathrm{mph}$, and the current signal phase is "R," or red. Red time (RTIME) is shown as 0.2 , or two-tenths of a second, after the traffic signal had turned red. Also shown is the lane number. This number tells which lane the offending vehicle is in. Typically the lanes are counted from the inside out in one direction if more than one camera is present. Last, the frame tells the reader which picture is being shown. For example, frame A 
equals picture 1 and frame B equals picture 2. The second photo shows the SUV clearly inside the intersection. As shown in the photo's black box at the top, much of the information has remained constant except the time and the red time, which is currently at 0.95 seconds. By viewing both images, a police officer can conclude that the SUV entered the intersection illegally 0.2 seconds after the traffic signal had turned red.

Depending on the type of automated enforcement system, photographic evidence of the violating driver will be electronically or physically sent to a photo-processing center where each offending photo is reviewed by a police officer. If the officer concludes that a moving violation has occurred, the owner of the offending vehicle will be issued and mailed a moving citation, municipal citation, or a traffic citation depending on the state legislation.

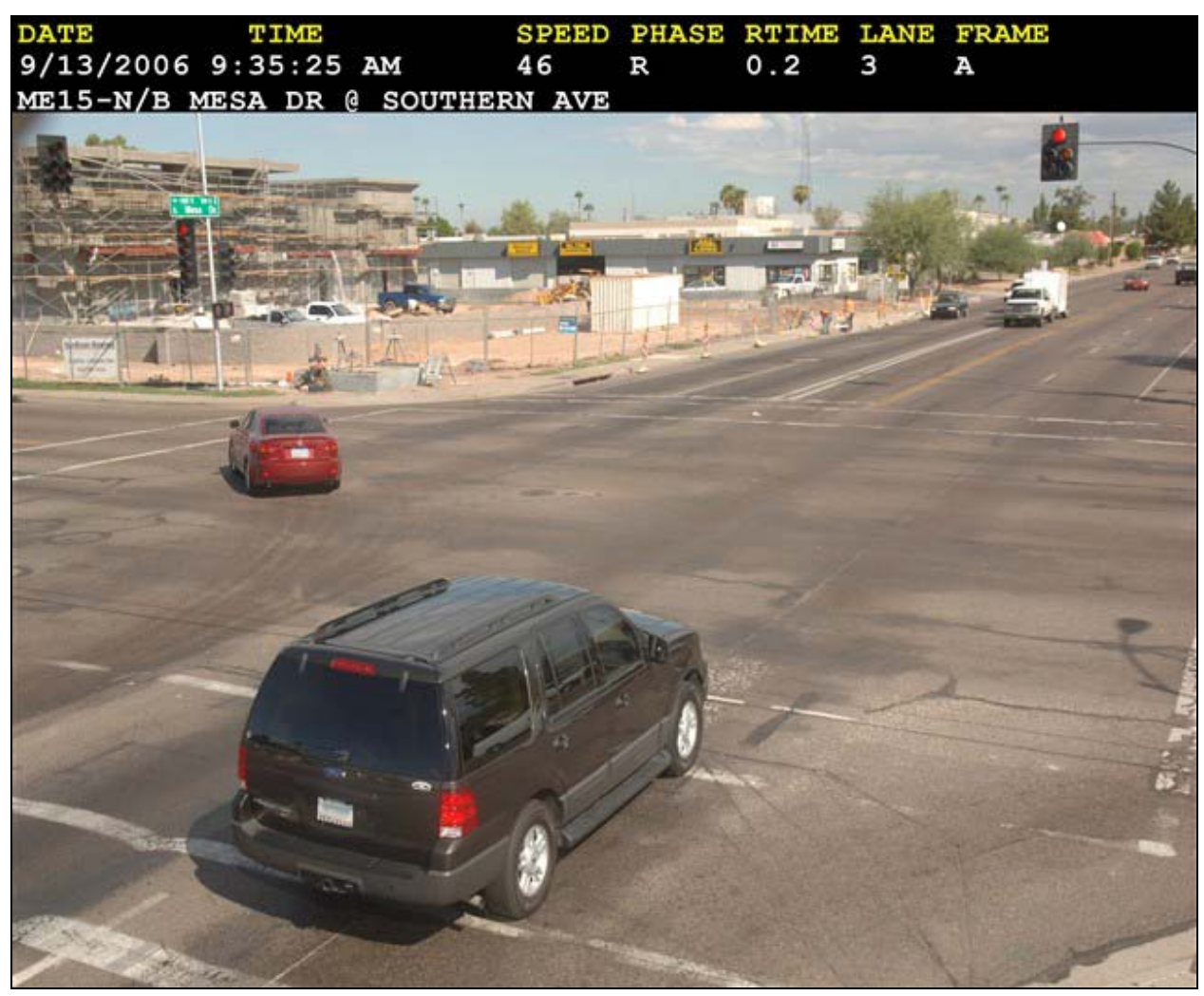

Figure 1.6. First picture taken by an automated RLR enforcement camera (Mesa, AZ) (Image source: City of Mesa Police Department: http://www.cityofmesa.org/police/traffic/redlight_photos.aspx) 


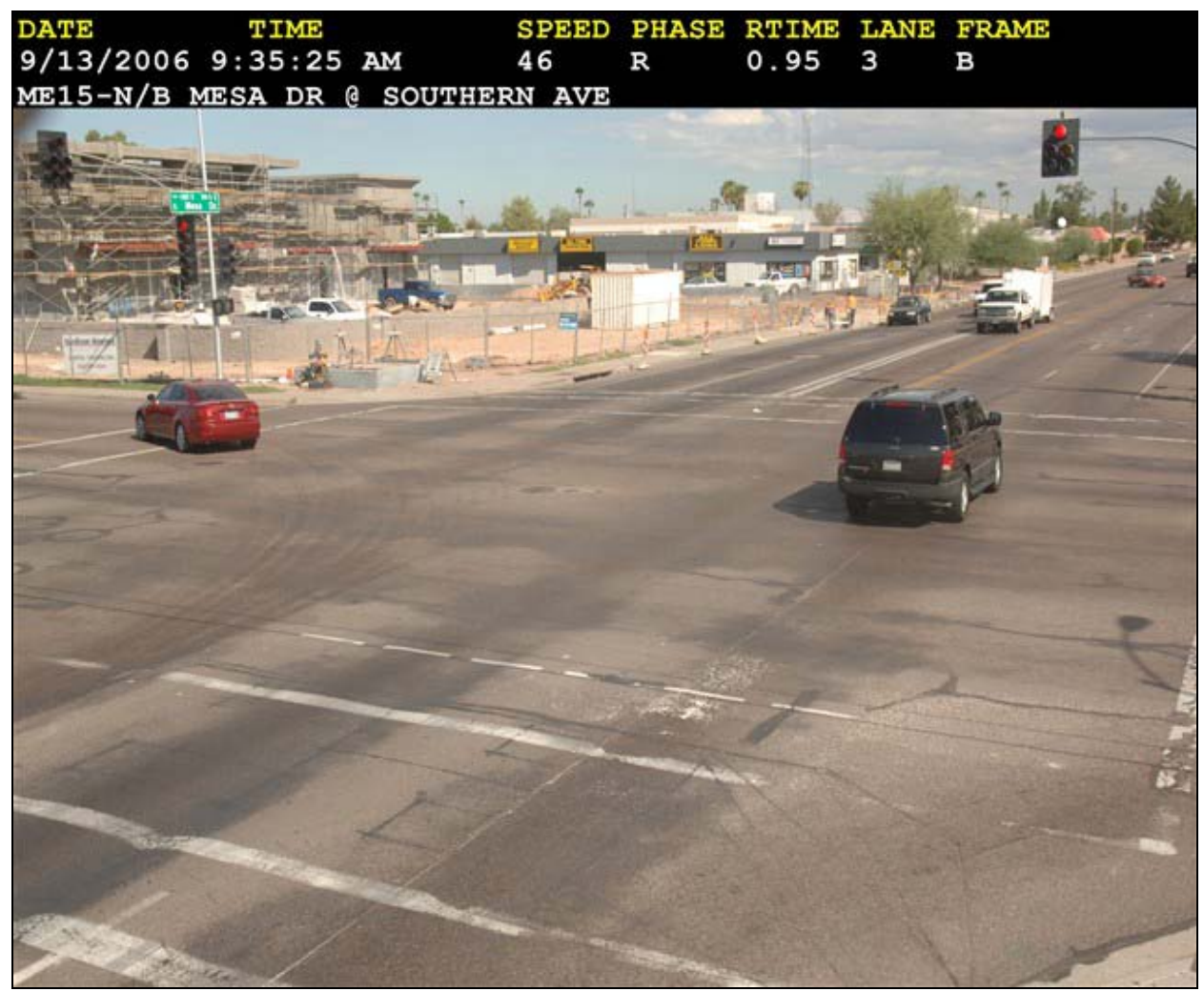

Figure 1.7. Second picture taken by an automated RLR enforcement camera (Mesa, AZ)

(Image source: City of Mesa Police Department:

http://www.cityofmesa.org/police/traffic/redlight_photos.aspx)

\subsection{RLR Programs}

In 1992, in response to the high percentage of intersection crashes, the FHWA began a campaign to increase public awareness about red light running. Six city and county jurisdictions, including Los Angeles County, CA., Polk County, FL., Howard County, FL., Howard County, MD., Charleston, SC., and Washington, D.C., received grants to test and evaluate wet film camera technology to catch RLR violators (Urban Transportation Monitor, 1998).

Since the implementation and study of the six original cities, the FHWA has given out 32 additional grants to numerous cities and counties, and as of 2000 the use of RLR cameras has risen considerably throughout the United States. Today, over 110 cities in 20 states use an RLR system, which includes cameras and/or warning signs (National Campaign to Stop Red Light Running, 2006). Although the technology has greatly improved over the years, it is still a costly and time-consuming project for many cities. Case studies in this section were selected based on the amount of information available and the positive impact the RLR program had on society. 


\subsubsection{New York City, NY}

New York City has one of the largest RLR automated enforcement systems in the United States with over 50 cameras in place. Legislation was just signed to add 50 more, bringing the enforcement up to 100 intersections. Mr. Rudolph E. Popolizio, P.E., chief of the New York City RLR program, has published numerous articles and papers defending the city's view and history of this program, which has proven to be controversial. The New York City Department of Transportation (DOT) started researching RLR technology in 1983 to better understand the technology being used in Europe and Australia (Popolizio, 1995).

Over the last decade, the camera system in New York City has proven successful. During the 2003 fiscal year, the city of New York issued 308,100 red light camera violations (New York City DOT, 2006), while overall violations have decreased 38\% since the program started (McFadden and McGee, 1999).

\subsubsection{San Francisco, CA}

In 1996, the City of San Francisco started an RLR study to see whether a system could combat the ever-increasing number of RLR. violators. Three vendors were invited to participate in the study, although one declined the offer. Electronic Data Systems and U.S. Public Technologies, both currently owned by Lockheed Martin, each set up cameras at two intersections. Each company was paid \$30,000 by the city for the study, and tickets costing \$17.50 were issued for each violation. By March 1997, over 2,500 citations had been issued, and only U.S. Public Technologies was the prime contractor (Urban Transportation Monitor, 1997).

San Francisco started its RLR program after a high profile crash that sparked a media frenzy to have the city take action. In October 1994, a driver ran a red light near the University of San Francisco. Swerving to miss another vehicle, the driver lost control of the automobile and injured 13 students waiting for a bus (Fleck and Smith, 1999).

This incident also prompted the city to start a massive media campaign, which included billboards, TV commercials, radio announcements, and catchy slogans such as "RED Means STOP.” This campaign was generally accepted by the community and local media. This incident also prompted the California State Legislature to amend the California Vehicle Code in 1996 (SB833), which permits the use of “automated enforcement” for RLR violations (California Senate Bill, 1995). With the passing of Senate Bill 833, the California Vehicle Code was amended to make running a red light a moving violation in which a fine and points were assessed to the driver. Another important legislative bill passed in California was Assembly Bill 1191, commonly known as “The Shelly Bill," in 1998. Assembly Bill 1191 passed with overwhelming success, which provided $\$ 80$ out of a $\$ 271$ ticket to cover the cost of existing automated enforcement and provided funding for 25 new RLR camera systems (Passetti and Hicks, 1997).

The 1996 San Francisco RLR campaign was a success. Between 1996 and 1999, the city issued over 10,000 citations that were captured by cameras and recorded an average of 20,000 citations reported by officers in the field (Fleck and Smith, 1999). The most noticeable impacts of the 
RLR campaign was a 42\% decrease in red light runners and a 9\% citywide reduction in collisions and injuries in 1997 (Fleck and Smith, 1999).

\subsubsection{Portland, Oregon}

Portland, OR, started its automated enforcement program in 1995 when the state legislature allowed the cities of Portland and Beaverton to test photo-radar equipment for speeding. After overwhelming success with this pilot program, which lasted until 1997, the photo-radar program was extended indefinitely. Automated RLR enforcement was requested after the city of Portland reported 12,000 collisions per year caused by red light running (Portland Bureau of Traffic Management, 1998). The city of Portland cited that because of the rapidly growing population, city police officials could not enforce all parts of the city with their limited budget. Portland city officials also cited that automated enforcement would be an inexpensive and safe way to enforce problem intersections.

As of 2003, the City of Portland has six operational RLR cameras at five intersections. These intersections were selected due to a high rate of observed red light runners, which ranged from 2.3 to 3.7 violations per hour prior to the installation of the system. During the study period from October 2001 to August 2002, the five intersections reported a 60-87\% decline in violations (Burchfield, 2005).

In 1995, Portland started its public outreach campaign to the community by educating drivers about the photo-radar system, which was the first of the two implemented programs. It was found that the public supported the initiative and a post-survey demonstrated that drivers showed a high awareness of the program (Burchfield, 2005). In 1996, Portland joined the national "Stop! For Red Lights Campaign” and informed the public using such media as television, newsletters, and neighborhood association flyers (Portland Bureau of Traffic Management, 1998). Once the city gained the support of the public, Portland sought legislative approval for the red light camera enforcement, which passed in the 1999 session of Congress. This program has been highly successful, and as of 2006, the city of Portland is looking to expand its RLR and photoradar enforcement program.

\subsection{Metrics to Evaluate the Effectiveness of RLR Cameras}

Reduction in crashes, particularly right-angle crashes, is the most relevant factor in assessing whether RLR cameras are effective because crash reduction is the ultimate goal. However, in some cases, cameras are installed at only a few intersections, resulting in low sample sizes. In addition, before and after crash studies cannot be completed for several years after installation of the treatment in order to have representative samples and avoid regression to the mean. It is still desirable to measure the immediate effectiveness of the enforcement, so other measures have been used as a surrogate safety measure to evaluate effectiveness of RLR cameras. The number of RLR violations, amount of time into the red indicating that vehicles enter an intersection, and number of conflicts have also been used to measure effectiveness. 
Violation studies are a common method to determine the effectiveness of a countermeasure. Violation studies can be performed with a variety of photographic technology (Kamyab et al., 2000). Video is typically taken at intersections of interest with multiple cameras looking at approaching lanes and traffic signals for a certain time duration or at peak hours. Violations can be reduced using either a direct monitoring method or a machine-aided monitoring method. (Tarko and Reddy, 2003). The direct monitoring method is considered the most precise evaluation method available, but can be time-consuming and mistakes can be easily made by the evaluator, depending on his or her judgment of a violation (Tarko and Reddy, 2003). Violation data collected by any of the above methods will result in a total number of RLR violators for a certain movement at an intersection. Frequency of red light running can easily be obtained by adding the total number of violations over the period of time the study took place. The rate of RLR violations can provide a greater insight into the overall problem. In a report by Washburn and Courage, the following equations to find an RLR violation rate were suggested (Washburn and Courage, 2004):

$$
\begin{aligned}
& R L R \text { Rate }(\%)=\frac{N_{R} \times 100}{V} \\
& R L R \text { Rate }(T E V)=\frac{N_{R} \times 1000}{V}
\end{aligned}
$$

where:

RLR Rate (\%) = Average percentage of hourly volume running a red light

RLR Rate $(\mathrm{TEV})=$ Average number of red light runners per thousand entering vehicles $\mathrm{N}_{\mathrm{R}}=$ Average number of red light runners in analysis hour

$\mathrm{V}=$ Peak hour volume

$$
\text { Avg. RLRs per Cycle }=\overline{N_{R}} \div \overline{N_{C}}
$$

where:

$\overline{N_{R}}=$ Average percentage of hourly volume running a red light

$\overline{N_{C}}=$ Average number of cycles in analysis hour

\subsection{RLR Violation Frequency and Crash Relationship}

A study performed by Bonneson et al. developed and tested a regression model to express the relationship between total crashes recorded and red light violation frequency for an approaching leg on an intersection (Bonneson et al., 2003).

$$
C_{3}=m_{y} e^{b_{0}} A D T_{S}^{b_{1}} A D T_{c}^{b_{2}} R L R_{r}^{b_{3}}
$$

where: 
$\mathrm{C}_{3}=$ Three-year count of right-angle and left-turn crashes

$\mathrm{m}_{\mathrm{y}}=$ Number of years associated with the crash data

$\mathrm{ADT}_{\mathrm{s}}=$ Average daily traffic volume on a subject approach

$\mathrm{ADT}_{\mathrm{C}}=$ Average daily traffic volumes on the cross street

$\mathrm{RLR}_{\mathrm{r}}=\mathrm{RLR}$ rate on the subject approach, number of red-light-running events per 1000

vehicles

$b_{i}=$ Regression coefficients (where $i=0,1,2, \ldots$ )

The above model was calibrated and tested using data obtained from 12 Texas intersection approaches. The resulting equation to model this test is shown below.

$$
C_{1}=0.00278 A D T_{C}^{0.614} R L R_{r}^{0.387}
$$

$\mathrm{C}_{1}$ in the above equation is the predicted annual crash frequency rate (crashes per year, rightangle plus left-turn) for a typical intersection approach. The studied intersections approach term (ADT) was not used in the final model calculation because its regression coefficient $\left(\mathrm{b}_{1}\right)$ was close to zero (Bonneson and Zimmerman, 2004). It was also found that the variable $b_{3}$, which is associated with RLR rate, had a large standard deviation in the model. Bonneson et al. concluded "the crash frequency increases with increasing cross-street volume and RLR rate.” This conclusion is illustrated in Figure 1.8; as ADT increases, the crash frequency and RLR rates increase logarithmically.

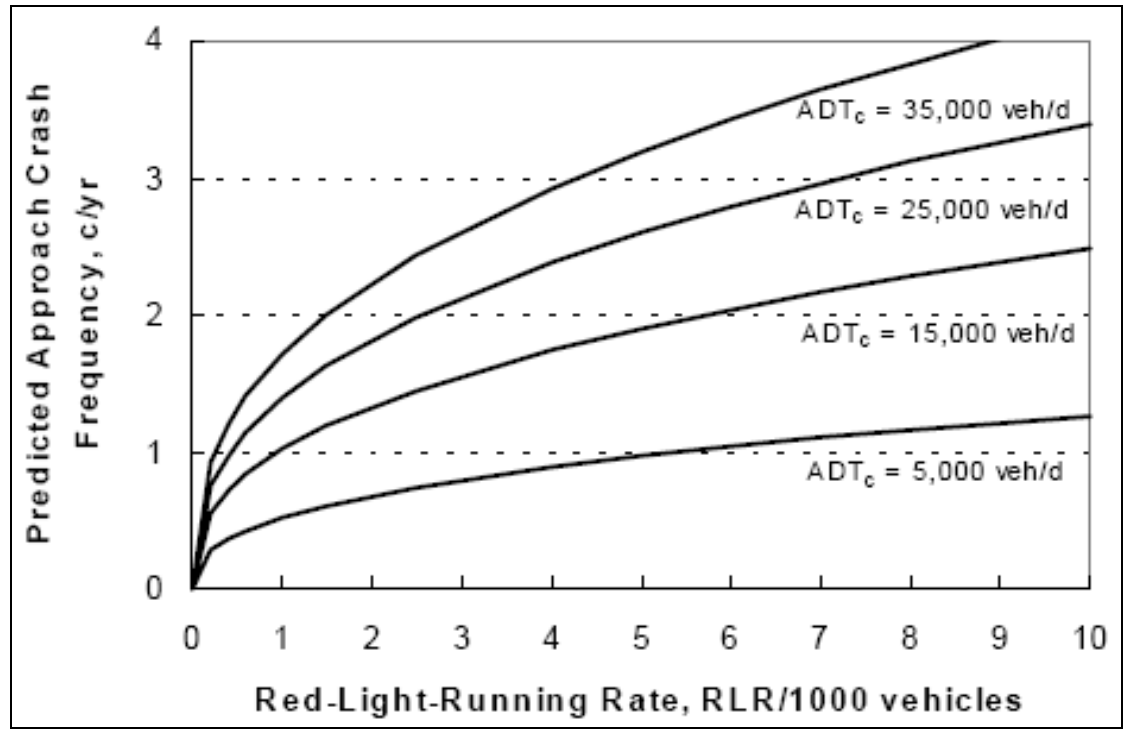

Figure 1.8. Predicted effect of RLR on intersection crash frequency (Bonneson et al., 2003).

\subsection{Effectiveness of Camera Enforcement in Reducing Red Light Running}

One highly regarded RLR study conducted to evaluate the effectiveness of RLR cameras was conducted by Retting and Kyrychenko of the IIHS in 1998 in Oxnard, CA. (Retting and Kyrychenko, 2002). This study evaluated 11 out of the 125 camera-equipped signalized intersections in Oxnard, and three California control cities: Bakersfield, San Bernardino, and 
Santa Barbara. The unique feature of this investigation included the lack of isolation of the 11 intersections located in residential and commercial areas, but also looking at nearby intersections to see if any spillover affects happened. As a control, Retting and Kyrychenko investigated nonsignalized intersections in every town in the study, which included three non-signalized intersections in Oxnard (Retting and Kyrychenko, 2002). Results of the 29-month study for showing changes in total crashes and injury crashes is provided in Table 1.2. As shown, total crashes and injury crashes decreased from the before to after period after RLR cameras were installed.

Table 1.2. Results of Oxnard study

\begin{tabular}{|c|c|c|c|c|c|c|c|}
\hline \multirow[t]{2}{*}{ City } & \multirow{2}{*}{$\begin{array}{l}\text { Intersection } \\
\text { type }\end{array}$} & \multicolumn{3}{|c|}{ Total crashes } & \multicolumn{3}{|c|}{ Injury crashes } \\
\hline & & Before & After & Change & Before & After & Change \\
\hline \multirow{2}{*}{ Bakersfield } & $\begin{array}{l}\text { Non-signalized } \\
\text { control } \\
\text { intersections }\end{array}$ & 760 & 753 & $-0.9 \%$ & 245 & 241 & $-1.6 \%$ \\
\hline & $\begin{array}{l}\text { Signalized } \\
\text { intersection } \\
\text { with cameras }\end{array}$ & 771 & 739 & $-4.2 \%$ & 243 & 233 & $-4.1 \%$ \\
\hline \multirow{2}{*}{$\begin{array}{l}\text { San } \\
\text { Bernadino }\end{array}$} & $\begin{array}{l}\text { Non-signalized } \\
\text { control } \\
\text { intersections }\end{array}$ & 1,220 & 1,283 & $5.2 \%$ & 204 & 225 & $10.3 \%$ \\
\hline & $\begin{array}{l}\text { Signalized } \\
\text { intersection } \\
\text { with cameras }\end{array}$ & 1,324 & 1400 & $5.7 \%$ & 239 & 246 & $2.9 \%$ \\
\hline \multirow{2}{*}{ Oxnard } & $\begin{array}{l}\text { Control non- } \\
\text { signalized } \\
\text { intersections }\end{array}$ & 994 & 1,011 & $1.7 \%$ & 173 & 194 & $12.1 \%$ \\
\hline & $\begin{array}{l}\text { Non-signalized } \\
\text { control } \\
\text { intersections }\end{array}$ & 1,322 & 1,250 & $-5.4 \%$ & 299 & 239 & $-20.1 \%$ \\
\hline
\end{tabular}

After the data were processed, a generalized linear regression model was created to evaluate the crash data, and an analysis of variance was used to test the statistical significance. It was concluded by the researchers that Oxnard's RLR camera system reduced the number of crashes by $7 \%$ with $95 \%$ confidence intervals of 1.3-12.5\% (McGee and Eccles, 2003; Retting and Kyrychenko, 2002).

Another analysis was performed with the data collected in Oxnard, which looked at the two more common types of intersection crashes, including right-angle and rear-end collisions. Right-angle crashes accounted for approximately $36 \%$ of all crashes at signalized intersections, and rear-end collisions accounted for 9\% (Retting and Kyrychenko, 2002). Using a model developed by Retting and Kyrychenko, the percent changes were estimated for intersections with camera enforcement and results were promising. Based on the results of this study, it was concluded by Retting and Kyrychenko that this study "provides evidence that red light cameras in the United 
States can reduce the risk of motor vehicle crashes, in particular injury crashes, at intersections with traffic signals (Retting and Kyrychenko, 2002).”

Results from a two year before and after study (1986-1990) in Sydney, Australia, which evaluated the effectiveness of cameras installed at 16 signalized intersections. The authors of the study found a 50\% reduction in right-angle and left-turn opposed crashes and a $25-60 \%$ reduction in rear-end crashes. Regression to the mean bias may have been present. Additionally, signal timing was adjusted in the middle of the study, which may have influenced results (Hiller et al, 1993). Regression to the mean was a possible problem because the cameras were installed at approaches with very few RLR violations and eight sites had changes performed throughout the study, including left-turn lanes, an S-lane, and additional signal phasing. A log-linear analysis was performed on the change in crashes, but that was all that was mentioned on methodology. Regression to the mean error was mentioned as a possible error because of the sporadic results, which ranged from $+2 \%$ to $-49 \%$, although the author concludes a $50 \%$ average reduction. It was also concluded by the author that there was no presence of halo-effects because control sites did not show a significant reduction in crashes (but these sites were possibly modified during the study).

South et al. (1988) reported results of their evaluation of the effectiveness of RLR crashes at 46 signalized intersections in Melbourne, Australia. They used 50 signalized intersections as control locations. They evaluated right-angle, right-angle turn, right against through, rear-end turn, all crashes, and fatal crashes but found no significant relationship between crash reduction and use of cameras. They did not account for changes in traffic volume. A study in Adelaide, Australia evaluated 13 intersections where cameras were installed and compared them against 14 intersections without cameras. They concluded that the reduction in crashes at the intersections with cameras was not statistically different from the control sites (Mann et al., 1994). Ng et al. (1997) evaluated 42 intersections where RLR cameras were installed as compared to 42 control locations without cameras. They found a $7 \%$ reduction in total crashes and an $8 \%$ reduction in right-angle crashes.

A study in Charlotte, NC, evaluated a reduction in crashes at 17 intersections where RLR cameras were installed. They did not use a control group of intersections. They found that angle crashes for all approaches at the study intersections decreased by $37 \%$ while angle crashes at approaches with cameras decreased by 60 percent. They also found a $4 \%$ increase in rear-end crashes at approaches with cameras (SafeLight, Charlotte). A study in Howard County, MD, evaluated 25 intersections where cameras were installed. No control locations were used for the analysis. A reduction in rear-end crashes of 32\%, a reduction in right-angle crashes of $42 \%$, and a reduction of 22\% for other crashes was reported. A study by Fleck and Smith (1998) used six intersections where cameras were installed and compared the results against city-wide effects. They found that injury collisions caused by red light violations decreased citywide by 9 percent. It is difficult, however, to determine whether RLR cameras at only six intersections or other nonrelated factors resulted in the reduction. Vinzant and Tatro (1999) compared quadrants of Mesa, AZ, where RLR cameras were installed against quadrants with no cameras. Photo-enforced radar had also been installed at some locations. They found a $15.9 \%$ reduction in crashes in the quadrant with both RLR cameras and photo-enforced speed cameras, a 7.5\% reduction in the quadrant with photo-enforced radar, a 9.7\% reduction in the quadrant with only RLR cameras, and a $10.7 \%$ reduction in the quadrant with no treatments. Finally, a study from Glasgow, 
Scotland, compared the effectiveness of cameras at six locations. They found a $62 \%$ reduction in RLR injury crashes (Winn, 1995).

\subsection{Legal and Social Concerns}

The key to a successful automated RLR camera program is the complete understanding of the legal aspects associated with any form of automated enforcement. By understanding what constitutional rights citizens have and what possible arguments can be made in court, any jurisdiction is helped to overcome gray areas when violators contest their violation photos. This section briefly explains some research that was found to understand what laws are out to help automated enforcement.

\subsubsection{Constitutional Privacy Laws}

Many opponents of automated enforcement argue that capturing a vehicle and/or a person with cameras is unconstitutional. The IIHS reports that state courts in California, Colorado, Oregon, and North Carolina, including the United States Ninth Circuit Court of Appeals and Superior Court of the District of Columbia, have rejected constitutional challenges. However, some courts have asked cities to make changes in operational issues to settle disputes (Kendall, 2004).

Passetti notes that although there are no First Amendment cases that define or argue the right to privacy in a vehicle, the Supreme Court has defined privacy for marriage and/or a family. On the other hand, driving is considered a privilege, and not everyone is entitled or guaranteed to drive a vehicle (Passetti and Hicks, 1997). The act of driving is performed on public roads in front of the public eye, thus raising the question whether any constitutional privacy laws protect a driver. Every driver receives a state driver's license by taking a driving exam of some sort. Therefore the driver must abide by certain rules set by the state and federal government, including abiding by traffic signals and regulatory traffic control devices. These driving laws are in place not only to protect the driver, but also to protect the public. In 1986, a court statement from $N Y v$. Class (1986) read, "Automobiles are justifiably the subject of pervasive regulation by the state. Every operator of a motor vehicle must expect that the State, in enforcing its regulations, will intrude to some extent upon that operator's privacy” (Kendall, 2004). The result of this lawsuit included the U.S. Supreme Court determining it was legal for a police officer to search databases for drivers based on the vehicle identification number (VIN) and did not violate the Fourth Amendment regarding search and seizure (Blackburn and Gilbert, 1995).

In a landmark District of Columbia Supreme Court case, the plaintiff's taxi-leasing company, Auto Ward, Inc., and Emelike U. Agomo, filed a class action lawsuit against then-Mayor Anthony A. Williams. Agomo was charged for 11 moving violations, which were captured by automated enforcement systems. Auto Ward, Inc. is a taxi-leasing firm in the District of Columbia, which was served with at least 57 moving violations that totaled $\$ 6,675.00$. This lawsuit assumed the presumption of guilt violates the due process rights of the plaintiffs and an estimated 100,000 registered automobile owners. The main complaint in this lawsuit was a thirdparty company was hired by the District of Columbia to try and identify the owners of each of the automobiles involved in the class action lawsuit. Furthermore, it was argued that this thirdparty company accurately described the movement of the vehicle, and accurately described the 
date, time, and license plate number. However, the plaintiffs believed capturing, identifying, and charging drivers violated the Fifth Amendment regarding trial and punishment and compensation for takings, which the District of Columbia ruled constitutional (DC Watch, 2003). Quoted by the IIHS, the District also noted in a 2003 remark that a judge in the District of Columbia made during Agomo v. Williams (2003):

"[The] fact that there are a high number of persons photographed running the traffic signal or operating at excessive speeds is an example of the magnitude of the problem facing city officials trying to correct a growing situation. Although cameras operated by the Government are a concern regarding privacy issues, those concerns are outweighed by the legitimate concerns of safety on our public streets” (Kendall, 2004).

\subsubsection{Admissibility Issues with Automated Enforcement}

According to a report by Blackburn et al., the general public and most courts will accept photography as evidence under two theories, the first being the picture testimony and the second being the "silent witness theory" (Kendall, 2004). The silent witness theory has become more prevalent in court cases due to an increased use of various photographic and video technologies to monitor or capture evidence. Essentially, the picture speaks for itself. The image, or silent witness, is an automated enforcement photograph of a person, object, or scene that can be used in the court of law without in-court testimony. The second theory of picture testimony includes such items as maps, photographs, or drawings, which can serve as evidence without in-court testimony (McCormick, 1984).

In the case of People v. Pett (1958), the issue of photo-radar automated enforcement was questioned when Louis Pett was charged for driving $41 \mathrm{mph}$ in a 30-mph speed zone in the village of Garden City, NY. Mr. Pett's vehicle was captured with a photo-radar device, which also recorded his license plate. The court found Mr. Pett guilty beyond reasonable doubt, and it was stated by the court, "We have passed the horse and buggy days and are living in a new era. The question is, did the defendant do it and was there sufficient proof offered to find the defendant guilty beyond reasonable doubt?” This case, although early in the era of automated enforcement, questioned the scientific reliability of a photograph of a vehicle (Kendall, 2004).

In 1973, Thomas J. Goger presented a paper that explained three steps for photographic radar to be considered evidence in a court of law. He said a scientific principle must be applied for an instrument to be scientifically reliable (Retting, 2006). It was recommended by Goger that radars used for speed enforcement be properly tested with duel tuning forks (Goger, 1973). To this day, modern radar units used for traffic enforcement are calibrated with tuning forks to 77.6 (5589 $\mathrm{Hz})$ and $33.2(2391 \mathrm{~Hz})$ miles per hour before usage.

Passetti explains that if a jurisdiction decides to use automated RLR enforcement, a calibrated instrument must be used to sequence a series of events. These tasks include taking a photograph or video of the offending vehicle and stamping it with the time and date. Furthermore, if a jurisdiction uses photographic evidence against a driver in a moving violation, a photograph of the driver must be taken as well (Passetti and Hicks, 1997). 


\subsection{MAGNITUDE OF RED LIGHT RUNNING IN IOWA}

The number of RLR-type crashes for the state of Iowa was assessed for 2001-2006. The location for signalized intersections in the state was determined using a database based on the Iowa DOT Geographic Information System GIMS database which is described in Appendix A. The Iowa DOT crash database (version “crashes (2001 2005) Jan 2006” for 2001 to 2005 and "statewide20012006(April2007)" for 2006) was used. Crashes were spatially located, and those crashes within 25 meters of each signalized intersection were extracted for each year. Red light running and RLR-type crashes were then summarized from those signalized intersection crashes.

RLR crashes were defined as crashes where the officer indicated "ran traffic signal” as the major cause. It should be noted that this may not reflect the total number of RLR crashes that occur because officers are not always able to determine, or do not take the time to determine, whether red light running was the case. The total number of RLR crashes for each year from 2001 to 2006, and the number of fatal- and major-injury crashes that were indicated as "ran traffic signal" are shown in Table 2.1. An average of 1,682 RLR crashes occurred per year. This included an average of 51 fatal- and major-injury crashes per year at signalized intersections in Iowa because of red light running.

An average of 8,162 total crashes and 147 fatal- and major-injury crashes occurred at signalized intersections in Iowa every year from 2001 to 2006. The ratio of red light running to total and fatal- and major-injury crashes is shown in Figure 2.1. As shown, RLR crashes accounted for $20.6 \%$ of all signalized intersection crashes, but make up 35\% of the fatal- and major-injury crashes at signalized intersections. As indicated, RLR crashes were disproportionately likely to result in a fatal- or major-injury crash.

Both the number of RLR crashes and total signalized intersection crashes decreased from 2001 to 2006. However, as indicated in Figure 2.1, the ratio of red light running to total crashes has stayed fairly constant, around $21 \%$, over time. The total number of red light running fatal- and major-injury crashes also decreased over time, but the total number of fatal- and major-injury crashes overall decreased as well. As a result, the ratio of red light running fatal- and majorinjury crashes to total fatal- and major-injury crashes at signalized intersections has also remained constant over time at about 35 percent. 
Table 2.1. RLR crashes in Iowa

\begin{tabular}{|c|c|c|c|c|}
\hline Year & Type & $\begin{array}{l}\text { Red light } \\
\text { running } \\
\text { crashes }\end{array}$ & $\begin{array}{c}\text { All signalized } \\
\text { intersection } \\
\text { crashes }\end{array}$ & $\begin{array}{l}\text { Red light running as a } \\
\% \text { of total signalized } \\
\text { intersection crashes }\end{array}$ \\
\hline \multirow[t]{2}{*}{2001} & $\begin{array}{l}\text { Fatal/major } \\
\text { injury }\end{array}$ & 91 & 277 & $33 \%$ \\
\hline & Total & 1881 & 8888 & $21 \%$ \\
\hline \multirow[t]{2}{*}{2002} & $\begin{array}{l}\text { Fatal/major } \\
\text { injury }\end{array}$ & 81 & 219 & $37 \%$ \\
\hline & Total & 1994 & 9188 & $22 \%$ \\
\hline \multirow[t]{2}{*}{2003} & $\begin{array}{l}\text { Fatal/major } \\
\text { injury }\end{array}$ & 73 & 203 & $36 \%$ \\
\hline & Total & 1815 & 8805 & $21 \%$ \\
\hline \multirow[t]{2}{*}{2004} & $\begin{array}{l}\text { Fatal/major } \\
\text { injury }\end{array}$ & 66 & 180 & $37 \%$ \\
\hline & Total & 1809 & 8737 & $21 \%$ \\
\hline \multirow[t]{2}{*}{2005} & $\begin{array}{l}\text { Fatal/major } \\
\text { injury }\end{array}$ & 43 & 145 & $30 \%$ \\
\hline & Total & 1290 & 6449 & $20 \%$ \\
\hline \multirow[t]{2}{*}{2006} & $\begin{array}{l}\text { Fatal/major } \\
\text { injury }\end{array}$ & 45 & 137 & $33 \%$ \\
\hline & Total & 1305 & 6904 & $19 \%$ \\
\hline
\end{tabular}




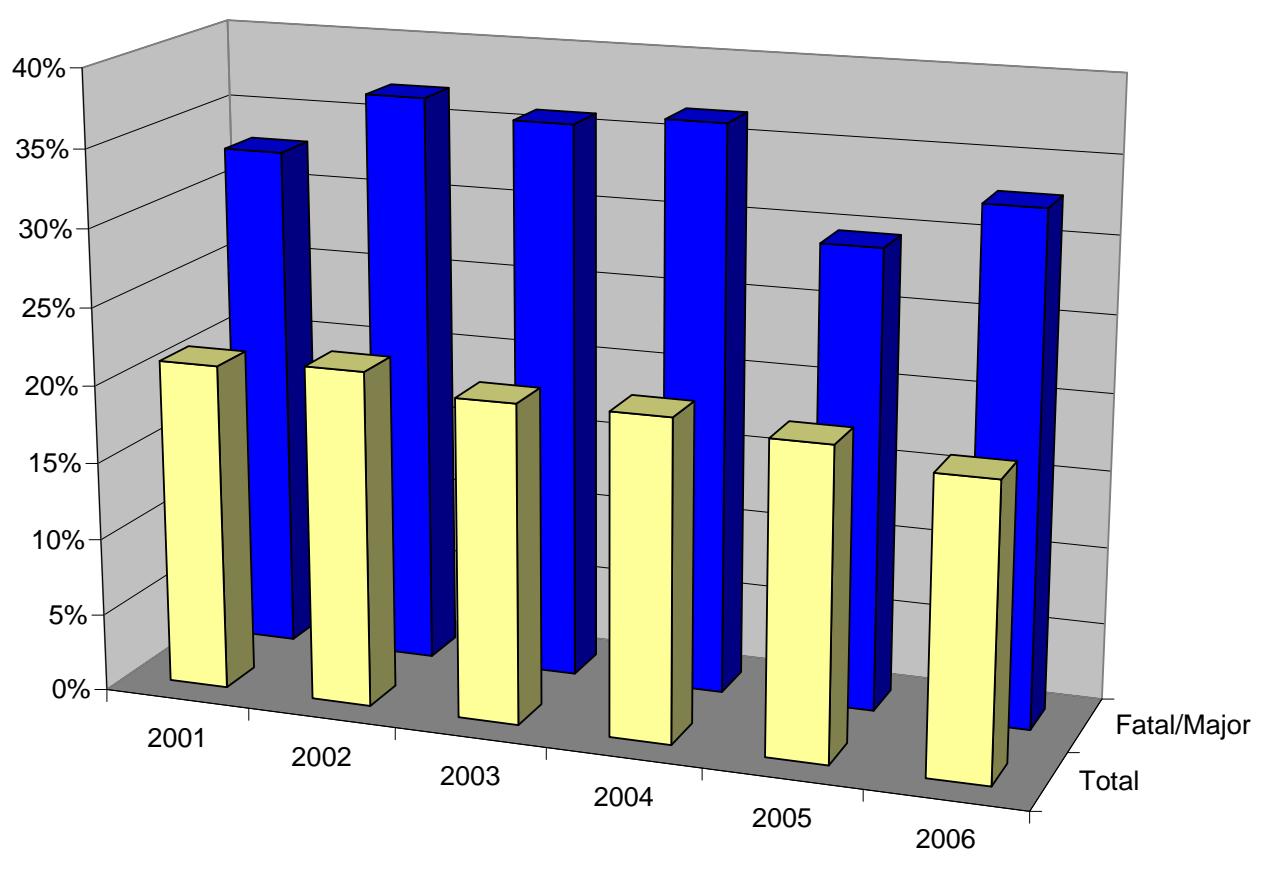

Figure 2.1. RLR crashes as a percentage of all signalized intersection crashes 


\subsection{EFFECTIVENESS OF THE CLIVE RLR CAMERA SYSTEM}

RLR cameras were installed at six approaches at four intersections in Clive, IA, in 2005. The effectiveness of RLR cameras is frequently evaluated in terms of crash reduction. However, before and after crash studies cannot be completed for several years after installation of the treatment in order to have representative samples and avoid regression to the mean. Although crash studies were conducted for Davenport, IA, and Council Bluffs, IA, it was not possible to conduct a crash analysis in Clive because only one year of after crash data were available. Even though sufficient after data were not available, it was still desirable to measure the immediate effectiveness of the enforcement, so reduction in the number of RLR violations was often used as a surrogate safety measure.

\subsection{Background on the Clive RLR Program}

The city of Clive is situated between the cities of Urbandale and West Des Moines. The three major east/west roads of Hickman Road (U.S. 6), University Avenue, and Douglas Avenue divide the three cities with each city owning half of each road's right-of-way. The city has a population of over 14,000 residents (Clive Historical Society, 2006).

On December 18, 2005, the Clive City Council voted unanimously to enter into an exploratory contract with a RLR camera vendor after company representatives contacted city officials who were interested in the safety improvement possibilities that automated enforcement could offer. The initial contract with the vendor included a video study that investigated Clive's high-speed intersections on Hickman Road and University Avenue for potential automated RLR enforcement camera systems. The city council's goal in implementing the cameras was to reduce the number of drivers running red lights and improve safety along Hickman Road and throughout the entire city. They were careful not to give the public the impression that the purposes of the cameras were not to generate a "profit from citizen's misbehavior," as quoted by one city council member during a public meeting. Hickman Road and University Avenue were the two study corridors considered by the RLR camera vendor, Clive City Administration, and the Clive Police Department.

To determine the best locations for the RLR cameras, the vendor videotaped 8- to 12-hour videos at 28 approaches at 11 potential intersections. Although the city of Clive owns only the south lanes of Hickman Road and the north lanes of University Avenue, video was taken at all approaches of the designated intersections. The videos were analyzed by the vendor and a report was submitted to the city council, which included the number of RLR violations at each approach. The report showed six high-violation approach locations along Hickman Road with 611 violations in an 8- to 12-hour video study period. Results of the study are shown in Table 3.1. Based on the study performed, a list of recommended intersections was given to the Clive City Council. Five approaches were initially selected. The city of Clive decided to proceed with the locations recommended, except for the 86th Street and Hickman Road northbound approach because an intersection reconstruction project was scheduled for 2007. In addition to the recommended locations, an RLR camera was installed at the northbound approach of 128th Street and Hickman Road, which was being expanded to a divided four-lane road collector from 
an existing two-lane road because of the increase in residential and commuter through traffic volume. The following approaches were ultimately selected for RLR cameras (approaches are highlighted in Table 3.1):

- 100th Street, northbound approach, at Hickman Road

- Hickman Road, eastbound approach, at 128th Street

- 128th Street, northbound approach, at Hickman Road

- Hickman Road, eastbound approach, at 142nd Street

- Hickman Road, eastbound approach, at 156th Street

- 156th Street, northbound approach at Hickman Road

Table 3.1. Vendor's initial study and the number of violations for each approach

\begin{tabular}{|c|c|c|c|c|c|}
\hline \multirow[b]{2}{*}{ Intersection } & \multirow[b]{2}{*}{ Approach } & \multicolumn{3}{|c|}{ RLR Violation } & \multirow[b]{2}{*}{ Total } \\
\hline & & Left-turn & Through & $\begin{array}{c}\text { Right- } \\
\text { turn }\end{array}$ & \\
\hline \multirow[t]{2}{*}{ Harbach \& 86th } & Northbound & 1 & 3 & 1 & 5 \\
\hline & Southbound & 0 & 2 & 0 & 2 \\
\hline \multirow[t]{4}{*}{ Hickman \& 100th } & Northbound & 2 & 6 & 0 & 8 \\
\hline & Southbound & 3 & 1 & 1 & 5 \\
\hline & Eastbound & 1 & 3 & 0 & 4 \\
\hline & Westbound & 2 & 3 & 1 & 6 \\
\hline \multirow[t]{3}{*}{ Hickman \& 128th } & Northbound & 0 & 3 & 6 & 9 \\
\hline & Eastbound & 0 & 11 & 4 & 15 \\
\hline & Westbound & 1 & 7 & 1 & 9 \\
\hline \multirow[t]{2}{*}{ Hickman \& 142nd } & Eastbound & 0 & 11 & 6 & 17 \\
\hline & Westbound & 0 & 15 & 3 & 18 \\
\hline \multirow[t]{4}{*}{ Hickman \& 156th } & Northbound & 2 & 1 & 5 & 8 \\
\hline & Southbound & 1 & 3 & 1 & 5 \\
\hline & Eastbound & 0 & 6 & 3 & 9 \\
\hline & Westbound & 0 & 0 & 0 & 0 \\
\hline \multirow[t]{2}{*}{ Hickman \& 86th } & Northbound & 5 & 0 & 5 & 10 \\
\hline & Eastbound & 0 & 2 & 0 & 2 \\
\hline Hickman \& I-35/80 & Eastbound & 0 & 5 & 0 & 5 \\
\hline \multirow[t]{4}{*}{ University \& 100th } & Northbound & 1 & 0 & 0 & 1 \\
\hline & Southbound & 0 & 0 & 0 & 0 \\
\hline & Eastbound & 0 & 1 & 4 & 5 \\
\hline & Westbound & 0 & 2 & 0 & 2 \\
\hline \multirow[t]{2}{*}{ University \& 114th } & Eastbound & 0 & 5 & 1 & 6 \\
\hline & Westbound & 0 & 0 & 3 & 0 \\
\hline \multirow[t]{2}{*}{ University \& 86th } & Northbound & 0 & 2 & 0 & 2 \\
\hline & Southbound & 0 & 3 & 0 & 3 \\
\hline \multirow{3}{*}{$\begin{array}{l}\text { University \& I- } \\
35 / 80\end{array}$} & & & & & \\
\hline & Eastbound & 3 & 11 & 1 & 15 \\
\hline & Westbound & 0 & 3 & 2 & 5 \\
\hline
\end{tabular}


For the city of Clive to implement the Hickman Road RLR enforcement program, the city had to amend Chapter 61 of the 2000 Clive Code Ordinances, which specified the use of city traffic control devices. On March 30, 2006, City Ordinance No. 851 was enacted with a four-to-one vote amending Chapter 61.05 of the 2000 Clive Code of Ordinances to include a section that allowed automated RLR enforcement and for the violation to be considered a civil infraction. The city of Clive defines a red light runner in this ordinance as a vehicle that crossed a stop line at the intersection when the traffic signals were showing a red light or arrow. Ordinance 851 also provided a framework for rules, how contracts should be managed with the vendor, and a set fine of $\$ 75$ for issued citations. Clive enacted Ordinance 863 on December 21, 2006 (vote yes was unanimous), which enabled the owner of the vehicle to nominate another driver (Davenport also allows this). The city of Council Bluffs does not have a driver nomination ordinance.

\subsubsection{System Configuration}

The RLR camera systems installed at the Clive intersections faced the rear of vehicles and, as a result, were not able to photograph the driver's face. The camera system connected directly to the roadside traffic control cabinet to synchronize with the signal timing. The camera system housed a vehicle detection system separate than that of the traffic signal detection system. This system included the actual video camera, video detection system, communication system, and two cameras that take still photos. Working similarly to a typical intersection video vehicle detection system, the RLR detection system included calibrating an autoscope camera by capturing a still photo of the enforced intersection with no vehicles. A live, continuous video feed of the intersection was compared to this calibrated image for accuracy and the system might have adjusted or stopped the detection process if there were an obstruction or inclement weather in the live video feed.

Many steps must be completed in a matter of seconds by the automated RLR camera system to photograph a potential red light violation. Using live video detection, four preset points prior to the stop bar were defined by the vehicle detection system as points to collect the vehicle's speed as it approached the intersection. Toward the end of the green phase through the yellow phase, the vehicle detection system monitored vehicles passing the four detection points. Using live video, the camera's computer made a determination of the vehicle's speed based on the time it took for pixels to change in the live video to make a judgment if the violating vehicle is traveling at velocity that would hinder it from stopping before the red phase. There was also a threshold to this process. A $25 \mathrm{mph}$ threshold speed was built into the system where if the vehicle detection system captured a vehicle traveling above $25 \mathrm{mph}$, it would assume the vehicle was traveling too fast to be able to stop before the stop bar. Once the computer determined a vehicle was traveling too fast to be able to stop for the red light, it would activate the video and still-photo camera firing sequence.

Having the still-photo and video camera firing sequence ready, the RLR camera system would receive the same electrical signal that was given out by the Clive intersection traffic controller that turned the traffic signals red. Once the RLR computer received the red call from the traffic signal controller, the camera system would wait for one second before taking the three photos and short video. This amnesty period was built into the camera system to give any benefit of doubt to the driver to stop before the picture was taken, and to let the traffic signal fully 
illuminate. Once the amnesty ran out, three digital photographs were taken and six seconds of buffer video were captured.

Three images were taken of the potential violator: 1) an image that showed the vehicle behind the stop bar with a red traffic indication shown in the background that indicated that the vehicle crossed into the intersection after the red indication was given; 2) a high-resolution image of the license plate; and 3) an image of the vehicle in the intersection (the system used images one and three to determine speed and time elapsed since the vehicle crossed into the intersection). Figure 3.1 showed how these photos were used in a mailed citation from the vendor. The Clive RLR camera system also incorporated a continuous video system. When a potential violation occurred, the cameras fired a sequence of six seconds of live video prior to the violation, which was extracted from the continuous video feed. An additional six-second video clip was extracted from the actual violation. This was performed to give the violator a chance to view the events prior to and during the violation to confirm the signals phase. If a person receiving a ticket wished to dispute the ticket, they were able to go to the Clive Police Department and view the 12 -second video and the three official images. The city indicated that in most cases after people viewed the video it was pretty clear that they ran the red light and they ended up not disputing the ticket.

\subsubsection{Ticket Issuing}

Upon receiving images from the camera, the vendor performed an initial filtering that removed instances of red light running where the images had the following characteristics:

- The vehicle could not be identified due to vehicle obstruction or plate obstruction.

- Police rejections that could include funeral processions, yielding to an emergency vehicle, invalid offenses, or a safe turn on red.

- Registration issues that could include temporary paper license plates, inability of the software to identify the state the license plate was from, out of the country license plates, or the driver information had been obtained from a certain jurisdiction.

The vendor also filters out RLR instances in which the images were not clear or resulted from a system malfunction. The following types of images were filtered:

- camera malfunction that could include digital distortion

- missing images

- blurry image of the license plate

- no flash in one of the three photographs.

The instances of red light running were then sent to the Clive Police Department where an officer reviewed each instance. Police officers reviewed and either accepted or rejected each instance. They may reject instances due to inconclusive images or if, in their judgment, red light running did not occur. Once an officer accepted the instance of red light running, a ticket was issued through the mail. 
The ticket was issued to the person who owned the vehicle. Figure 3.2 shows the notice of violation received by the vehicle owner. The license plate number can easily be read by a computer program or human. Also shown is the signature of the Clive police officer who verified the violation and his or her badge. Shown in Figure 3.3 is the second page of the ticket that described the violator's options upon receiving an RLR citation. Figure 3.3, is the page of the ticket that explained the owner/violator's three options.

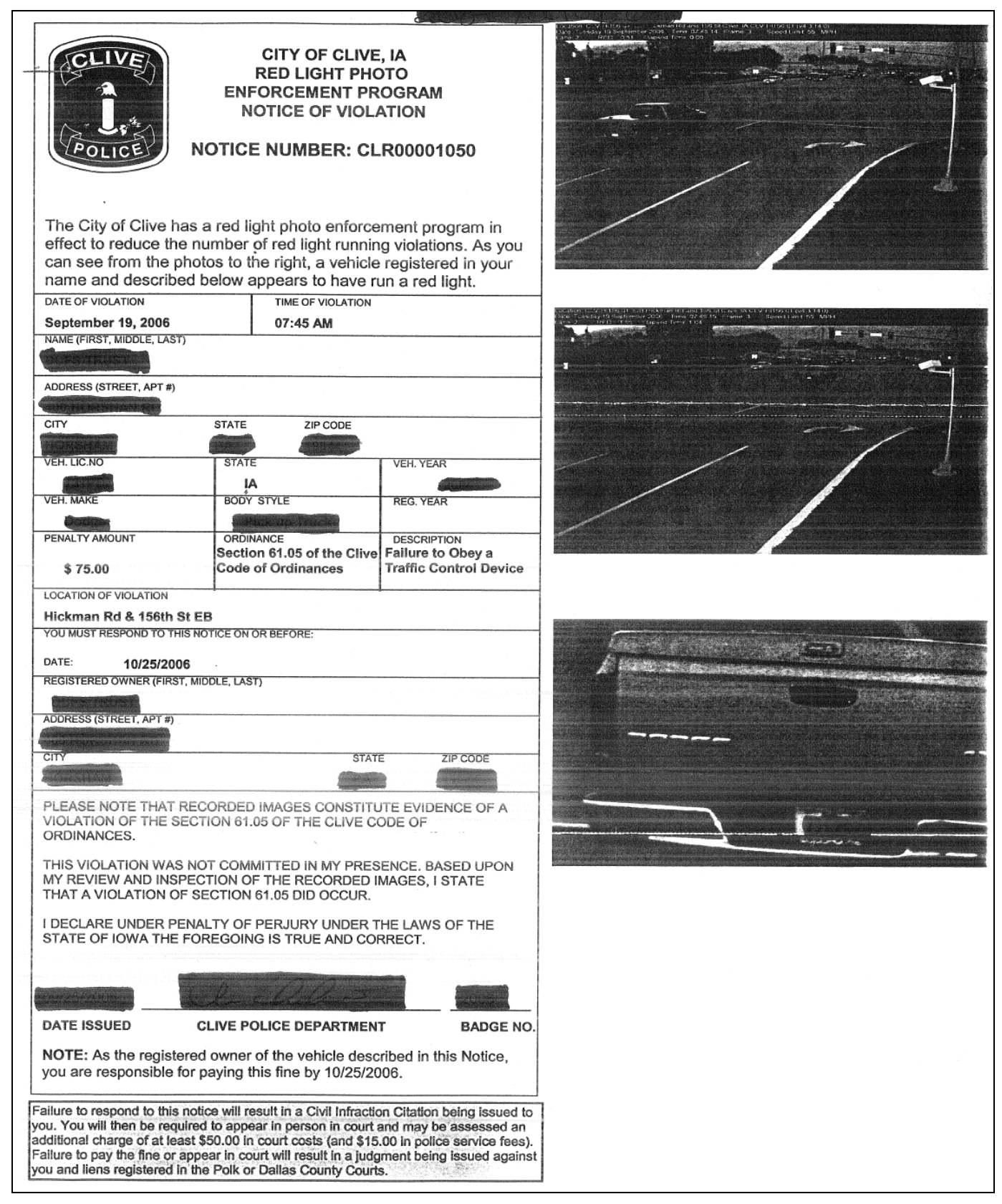

Figure 3.1. Notice of violation page of mailed ticket 


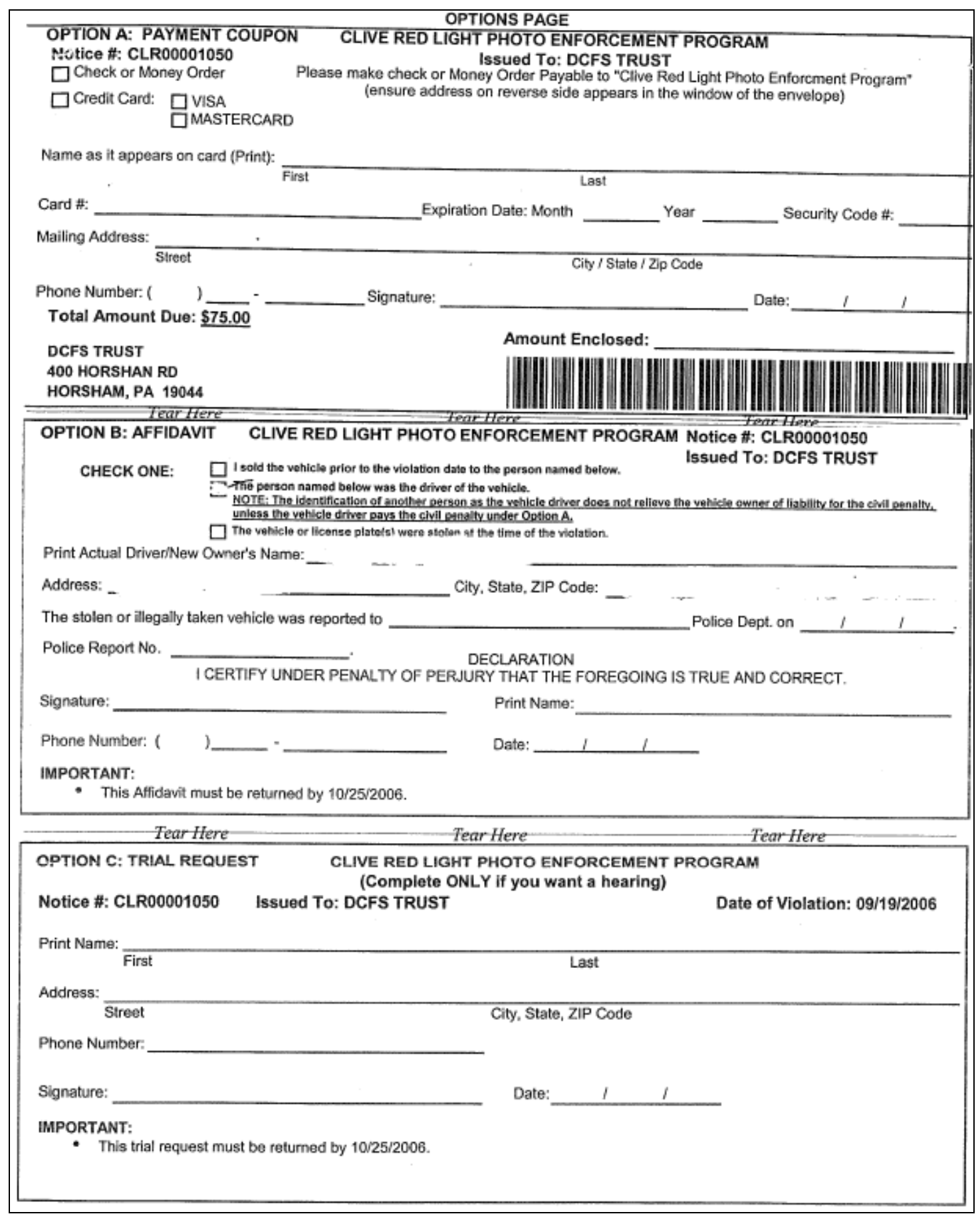

Figure 3.2. Notice of violation for Clive page of mailed ticket 
1. Reason You Received This Notice:

A vehicle registered in your name was photographed running a red light or the registered owner of the vehicle depicted on this Notice has submitted an Affidavit naming you as the driver of the vehicle at the time of the violation. This is a violation of Section 61.05 of the Clive Code of Ordinances.

2. View Violation on the Internet

- The violation has been captured on video and is available to be viewed on the Internet at: www.photonotice,com

(Enter City Code: CLIVE). The video is available online for 60 days from the date of violation.

- If you do not have access to a computer, computers are available at the Public Libraries. Please refer to your phone book for the library most convenient to you.

- Upon request, you may also view the images and video at the Clive Police Department, 8505 Harbach Blvd, Clive, IA 50325. Call 515-278-1312 to schedule an appointment. You will be notified of a date and time to appear.

3. You Must Select One of the Following Options. Complete the coupon on the Options Page for the option you select and return the coupon in the enclosed envelope. Make sure the mailing address on the reverse side of the coupon appears in the window of the enclosed envelope.

the coupon appears in the window of the enclosed envelope. choice but to hold you liable for paying this civil penalty by $10 / 25 / 2006$. No points will be assessed to your driving record and no record of this violation will be sent to your insurance company or the Department of Motor Vehicles.

- Please do not send cash.

- Make Check or Money Order payable to "Clive Red Light Photo Enforcement Program".

- Payments by Personal Check, Money Order or Visa/MasterCard are accepted. Please mail in the enclosed envelope along with the payment coupon found on Option A of page 2 .

- A $\$ 30.00$ administrative fee will be assessed for rejected or declined payments.

B. Affidavit: Identify another Driver, Vehicle Sold or Stolen. Under Section 61.05 of the Clive Code of Ordinances, the owner of the vehicle that ran the red light is liable for the payment of the civil penalty. However, the owner may identify the person who was driving at the time of the violation and request that the driver assume liability for the civil penalty by completing if the Affidavit of Non-Responsibility (Option B of the mail-in coupon on page 2) and returning it within the enclosed envelope by 10/25/2006. You may mail the Affidavit of Non-Responsibility in the enclosed envelope or fax it to the Clive Police Department, 8505 Harbach Blvd, Clive, IA 50325. Fax \# (515) 278-6066.

PLEASE NOTE that the identification of another person as the driver of the vehicle at the time of the violation does NOT relieve the owner of liability for the civil penalty. If the driver does not pay the civil penalty, the vehicle owner is responsible to pay the civil penalty.

- If the vehicie was sold prior to the date of violation, please include a copy of the transfer of sale.

- If the vehicle or license plate was reported stolen at the time of the violation, please include a copy of the police report.

- No record of this violation will be sent to your insurance company or to the Department of Motor Vehicles.

- Please do not nominate another driver if you are paying the fine.

c. Right to a Trial. You have the right to a trial to contest this notice:

To schedule a trial and have the matter reviewed by a Magistrate you MUST do the following:

1. Complete Option C (Request for Trial Coupon on page 2) and mail it to the Clive Police Department, 8505 Harbach Bivd. Clive, IA 50325 or fax it to (515) 278-6066 by 10/25/2006. Please include your phone number. The Polk or Dallas County Court will notify you of a date and time to appear.

2. Trials are held at Polk County Clerk of the Court, River Point Office Center, 500 SW 7th Suite 100, Des Moines, IA 50309 or the Dallas County Court, 801 Court, Adel, IA 50003.

3. If the violation is contested in court, $\$ 50.00$ in filing fees, a $\$ 15.00$ police service fee and any additionai costs wit be assessed if you are found liable. If you fail to appear, you will be responsible for paying the assessment. if you are found not liable, the fees will be waived.

4. Failure to respond to this notice will result in a Civil Infraction Citation being issued to you. An additional $\$ 50.00$ in court costs, a $\$ 15.00$ police service fee and any additional costs will be assessed whether you appear in court on your court date or if you pay the fine before your court date. Failure to pay the fine or appear in court will result in a judgment being issued against you and liens registered in the Polk or Dallas County Courts.

For questions regarding payment, contact Clive Red Light Photo Enforcement Program Customer Service Call Center toll free at 1-877-847-2338 between 9:00am and 4:00pm (MST).

\section{Figure 3.3. Page of mailed ticket with instructions}

The first option was to pay the $\$ 75$ ticket by detaching and returning the top portion. If the owner was not driving the vehicle when the violation happened, he or she could name the individual who was driving the vehicle at the time of the violation so that the violation could be 
assigned to that person. The owner could also state that the vehicle or license plates were stolen prior to the time of the violation and, as a result, was not in possession of them. If the owner named the offending driver, a citation would be mailed to that individual by the vendor. The third option was to ask for a court hearing. With this option, the processed forms were mailed back to the vendor and the company notified the city that the third option was selected by the owner/violator.

The RLR cameras were installed by June 28, 2006, at the intersection approaches selected by the city. During the following month of operation, the city issued 499 warning tickets to violators. After August 1, 2006, ticketing took effect and violators were charged the $\$ 75$ fine. The Clive Police Department estimated that approximately 300 tickets were issued per month. Photography and video evidence of violating drivers were kept for 30 days or until all challenges were completed. The only recorded malfunction of the RLR camera system came during a heavy snowstorm in 2006 when the camera could not determine the speeds of cars due to heavy snowflakes obscuring the vehicle detection system. In 2007, the vendor installed an inductive loop vehicle detection system, separate from the city's loop detection system, to detect vehicle speeds, rather than relying on the speeds computed using the video detection system.

\subsection{Legal Challenges}

In October 2006, Tim Steinmeyer of Urbandale, IA, was photographed by an RLR camera at 100th Street and Hickman Road traveling northbound while making a right turn onto Hickman Road. Steinmeyer thought the arrow was green, but the ticket showed the light above the arrow was red. After reviewing the ticket received from the vendor, Steinmeyer concluded that the photographs were inconclusive. After reviewing the video and noticing the adjacent vehicles ran the red light as well, Steinmeyer decided to contest the violations in front of Polk County Magistrate Jeffery Lipman on January 24, 2007. Steinmeyer cross-examined Sergeant Vernon Lukehart from the city of Clive Police Department and the vendor's training manager. The city of Clive asked the court to consider not only the merits of Steinmeyer's claim, but the also the constitutionality of the city's Chapter 61 ordinances.

On March 26, 2007, in a 26-page disposition, Magistrate Lipman cited that video recording was acceptable evidence in the state of Iowa and cited the Iowa court case Hutchinson v. Am. Family Mut. Ins. Co., 514 N.W.2d 882, 890 (Iowa 1994). This case involved Connie Lee Hutchinson's family, who brought American Family Mutual Insurance Company to the Iowa Supreme Court, appealing their initial district court ruling seeking underinsured motorist benefits. A video tape used in the district court included computer animation that depicted how close-head injury could affect the brain, as suffered by Ms. Hutchinson. The Iowa Supreme Court ruled that the video tape “did not purport to recreate Ms. Hutchinson’s particular accident," but showed an overview of what could happen. It was also ruled that a motion picture [to be] "admissible [it] must be authenticated, although no particular methodology is required." It was also noted that "when the posed photographs go no further in the undisputed testimony, their admission has long been generally approved.” In the case City of Clive v Steinmeyer (2007), Mr. Steinmeyer was found to have run a red light, that the photographs were captured by sensors and did not impact the legitimacy of the evidence, and that the RLR cameras systems and captured images were certified by an internal certificate. 
Although Magistrate Lipman ruled that use of the cameras was admissible, he also cited Iowa Code 364.2(2), which states, "The enumeration of a specific power of a City does not limit or restrict the general grant of home rule power conferred by the constitution of the State of Iowa. A City may exercise its general powers subject only to limitations expressly imposed by a state or city law." Two procedural challenges faced the city of Clive in response to Iowa Code 364.2(2). Citing the court case City of Vinton v. Engledow 258 Iowa 861, 140 N.W.2d (Iowa 1966), [any] "ordinances passed under statute providing that cities and towns shall have to restrain and regulate the riding and driving of horses, livestock, fast or immoderate riding or driving within such limits must comply with requirements of statutes requiring traffic laws to be uniform and requiring ordinances to be consistent with statutes." As specified in the disposition, the city of Clive had violated this statement by establishing a civil fine of $\$ 75$ that differed from a scheduled fine of $\$ 35$. The $\$ 35$ fine was established by the city of Clive if a police officer pulled over an RLR violator, which totaled $\$ 96.20$, including court costs and taxes, and is reported to the Iowa DOT, as specified by Iowa Code 321.491. It states, "Within ten days after the conviction or forfeiture of bail of a person upon a charge of violating any provision of this chapter or other law regulating the operation of vehicles on highways, every magistrate of the court or clerk of the district court of record in which the conviction occurred or bail was forfeited shall prepare and immediately forward to the department an abstract of the record of the case.” Magistrate Lipman noted the same ruling in the district court case City of Davenport v. Monique D. Rhoden (Iowa 2007).

In summary, Magistrate Lipman stated that RLR cameras were sound technology that were admissible in the court of law, and recognized that the city of Clive had the authority to regulate traffic signal offenses. In response to this ruling, the Clive City Council voted unanimously on March 29. 2007, to suspend Ordinances 851, 858, and 863 until the matter could be settled in a district appeals court later in the year. Two main issues were found by Magistrate Lipman. First, the city of Clive violated Chapter 364.2(2) of the Iowa Code (2006) by setting a separate fine scheduled for RLR violations on an existing established scheduled fine of $\$ 35$ for an officer observing a RLR violation. Second, that red light running was considered a criminal traffic violation, as specified in Iowa Code Chapter 321.491, which states that a criminal traffic violation must be reported to the Iowa DOT. Currently, an automated RLR ticket is considered a civil fine that is not reported to the Iowa DOT. 


\subsection{Evaluation of the Effectiveness of the Clive RLR Camera System}

The ideal way to evaluate the effectiveness of RLR cameras is to evaluate the before and after crash reduction rates. However, since the cameras in Clive weren’t installed until June 2006, only one year of after data was available, which is not sufficient to conduct a crash analysis (McGee and Eccles, 2003). As a result, the only way to evaluate the effectiveness of Clive's automated RLR enforcement system was to perform a cross-sectional analysis that compared RLR violations at camera-instrumented intersections to a group of control intersections.

This section discusses a violation study that compared the red light violations at the instrumented intersections against a set of control intersections. Ideally, a violation study would compare the number of violations before and after installation of the RLR cameras. However, the city had not conducted a robust study of violations at the treatment intersections before the RLR cameras were installed, so a before and after study could not be conducted. A cross-sectional analysis was used to compare RLR violations at treatment locations to violations at control locations. RLR data for non-instrumented control intersections were collected by setting up a video camera during peak hours of the day and recording vehicle behavior through the intersection. The number of violations that occurred at instrumented versus non-instrumented intersections is presented.

\subsubsection{Site Selection}

Violation data were collected from the four Clive RLR camera-enforced intersections and seven other non-camera-enforced intersections in the metropolitan Des Moines, IA, area, which were used as control sites. The seven control locations were within the city limits of Clive, Urbandale, West Des Moines, Waukee and Ankeny.

Use of control intersections was important to ensure that reductions in violations were not due to factors other than the RLR enforcement. Retting, Ferguson, and Shalom Hakkart (2003) indicated that spillover effects, regression to the mean, driver behavioral changes, and other factors independent of camera enforcement could influence the number of crashes and violations. As a result, evaluations of the effectiveness of RLR cameras in reducing crashes and violations that do not include control intersections may give misleading results (ITE, 1985).

Control intersections were selected that were similar to the camera-instrumented locations. Several locations in Clive, West Des Moines, and Urbandale were chosen based on the following characteristics:

- Average daily entering vehicle counts

- Geometric characteristics

- Approaching posted speed limits

- Signal timing

- Lane configuration 
Along with these initial criteria, location and approach type were taken into consideration. The intersections selected were within one mile of an intersection on Hickman Road, with camera enforcement, and the approaches studied at these intersections were either: (1) in the city of Clive (one direction: University Ave. and Douglas Ave.); or (2) the approach direction was the same as the camera approach, upstream or downstream; or (3) the field team determined that there was a high number of red light running in a specified approach direction. Permission was granted from the cities of West Des Moines, Clive, Urbandale, Waukee, and Ankeny to park and video tape on city-owned right-of-ways. In addition to the control intersections around the RLR camera locations, two additional intersections were selected outside of Clive, West Des Moines, and Urbandale to ensure that some of the control locations were not influenced by the RLR cameras or corridor. The two intersections were at Oralabor Road and State Street in Ankeny and North Warrior Lane and Hickman Road in Waukee. Both intersections had many of the same characteristics of intersections along Hickman Road, including 45 and 55 mph posted approach speeds and similar traffic movements.

Control intersections were selected based on three main criteria. The first criterion was location. Locations within the corridor where RLR cameras were installed or in the near vicinity of an RLR camera-enforced intersection were not included. The second criterion was that the control intersections had similar approach geometry, traffic signal configuration, signage, daily entering vehicles, and signal timing as the study intersections. This was determined by gathering intersection data from city officials and determining if the control intersections met these criteria. The third criterion was whether the city traffic engineer or police department felt that the location had an RLR problem. Because the study intersections were presumably selected for treatment due to a high number of violations, it was important to ensure that the control locations also were likely to be problem areas for red light running. Whether a location was a problem location was based on a subjective assessment by the city traffic engineer or police department. The following approaches are where the city of Clive installed the RLR camera system and were included in the study:

- North- and eastbound 156th Street \& Hickman Road (Clive,)

- Eastbound 142nd Street \& Hickman Road (Clive)

- $\quad$ North- and eastbound 128th Street \& Hickman Road (Clive)

- Northbound 100th Street \& Hickman Road (Clive)

The following intersections and approaches were selected as control sites. The location of camera-enforced and control sites are illustrated in Figure 3-4.

- North and eastbound 86th Street \& Hickman Road (Clive)

- South- and westbound 86th Street \& Douglas Avenue (Urbandale)

- North-, east-, and westbound 100th Street \& Douglas Avenue (Urbandale)

- Eastbound North Warrior Lane \& Hickman Road (Waukee)

- West- and southbound 35th Street \& University Avenue (West Des Moines)

- North-, west- and eastbound 60th Street \& University Avenue (West Des Moines)

- $\quad$ East-, and northbound Oralabor Road \& State Street (Ankeny) 


\subsubsection{Site Descriptions}

Details about each of the selected intersections and approaches are shown in the following sections. A site visit was made to each treatment and control intersection. Geometry, approach speed limit, and surrounding land use were recorded. It was also noted whether the pedestrian count was high. Peak hour volumes for each movement, signal timing, and type of control were also obtained. The cities of Urbandale, West Des Moines, and Ankeny provided peak hour volumes for the comparison intersections located in their city boundaries. The camera-enforced intersections and the control intersection in Waukee were manually counted on a Tuesday, Wednesday, or Thursday. Signal timing was collected from all of the cities involved in the study.

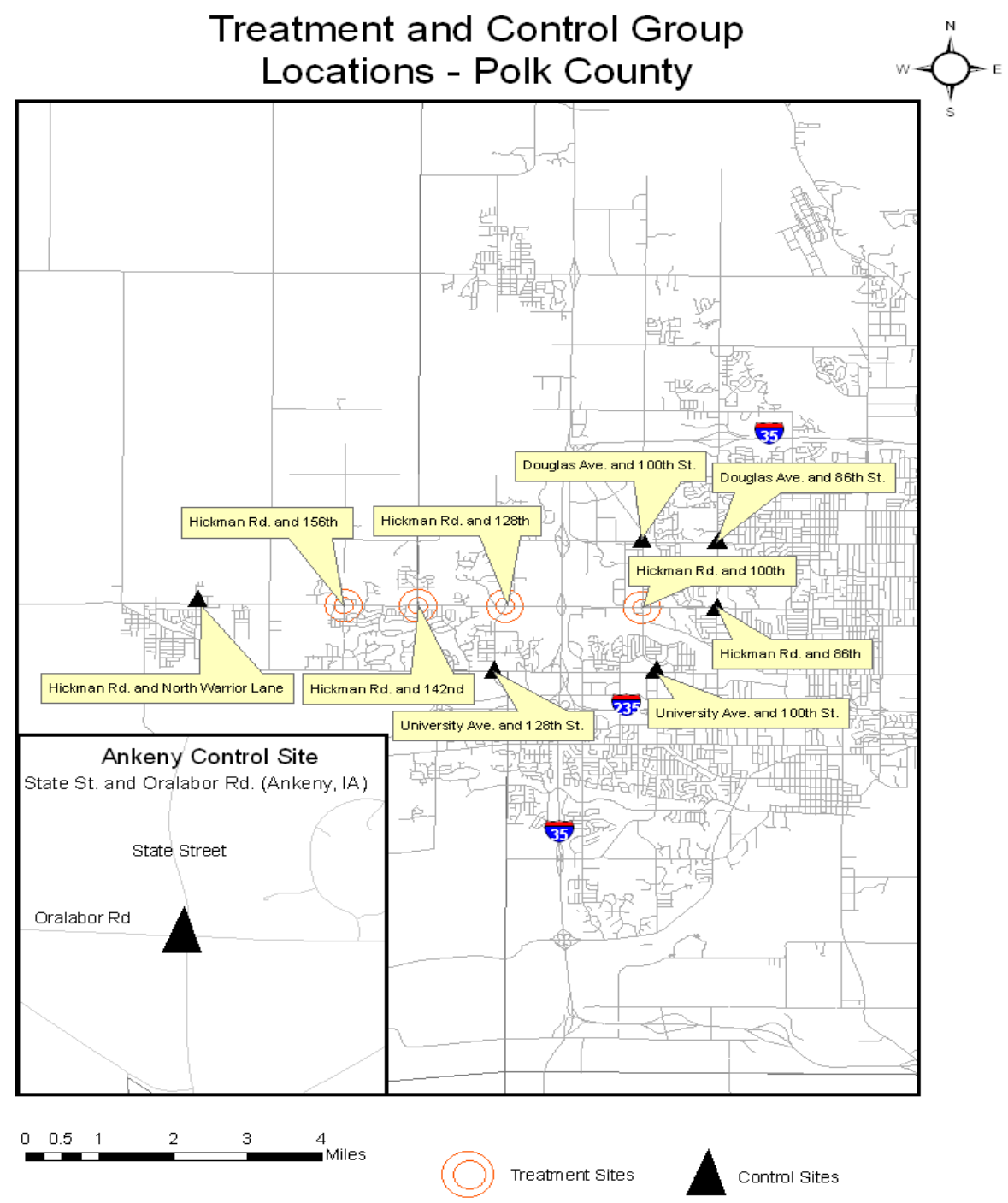

Figure 3.4. Location of study intersections 
156th Street \& Hickman Road [Intersection with Camera(s)]

The intersection at 156th Street and Hickman Road is the farthest west camera-enforced intersection in Clive and is also the last major intersection before the city of Waukee, which is located just west of Clive. On the southeast side of the intersection is a Dahl's grocery store, which is surrounded by residential developments. On the southwest side are a gas station and small commercial businesses. On the northwest side of the intersection is a commercial development and on the northeast side are private residences. This intersection is also has significant pedestrian and bicycle traffic on the north side traveling east and west. One Hundred Fifty-Sixth Street connects to Douglas Avenue to the north and University Avenue to the south. Summary information for 156th Street and Hickman Road are provided in Figures 3.5, 3.6, and 3.7.

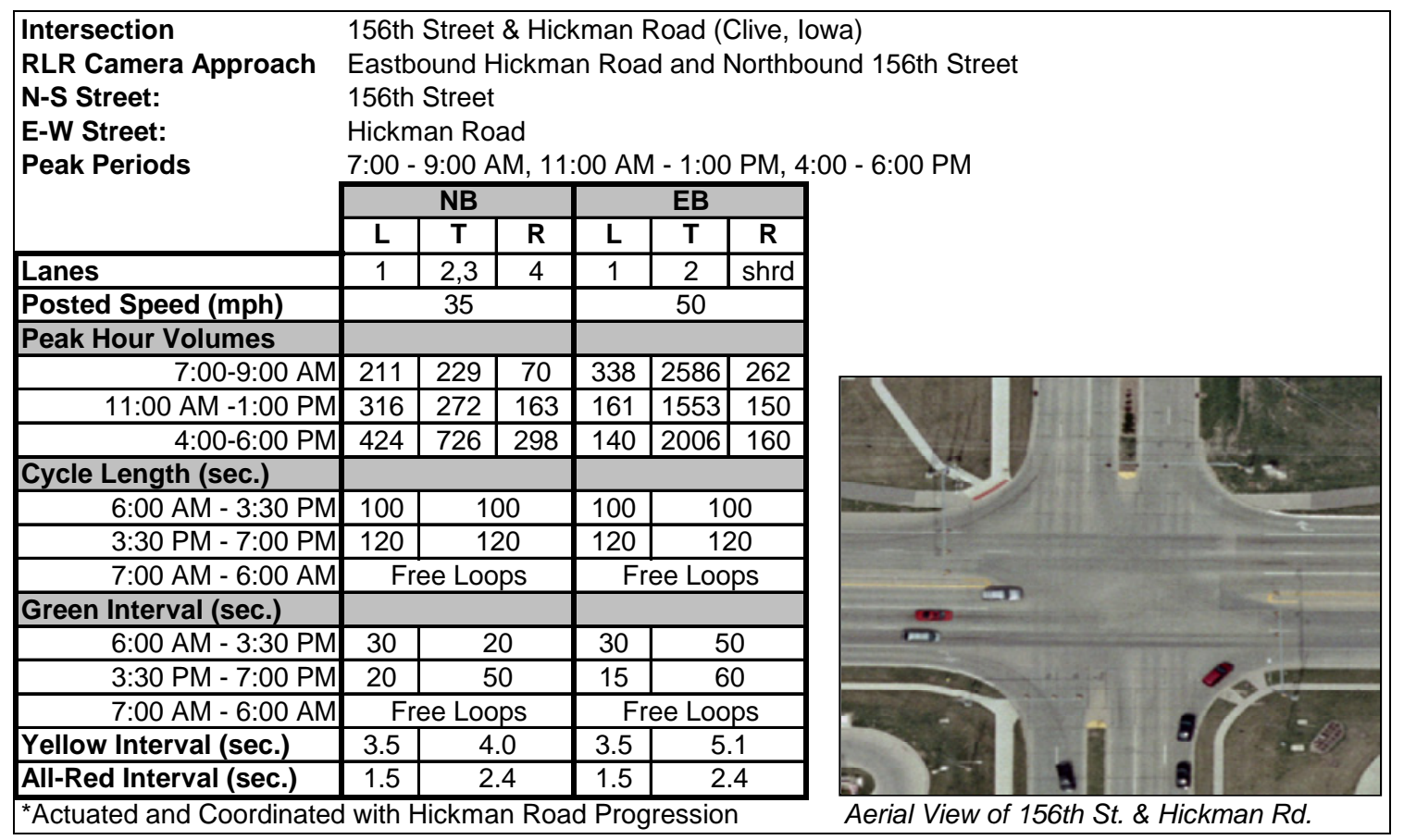

Figure 3.5. Roadway, traffic, and signal timing characteristics for 156th St. \& Hickman Rd. 


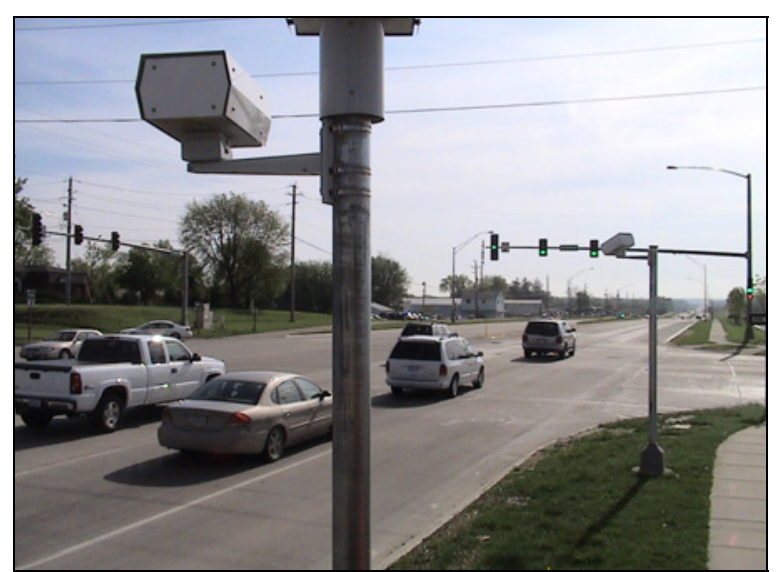

Figure 3.6. RLR camera system monitoring eastbound traffic at 156th St. \& Hickman Rd.

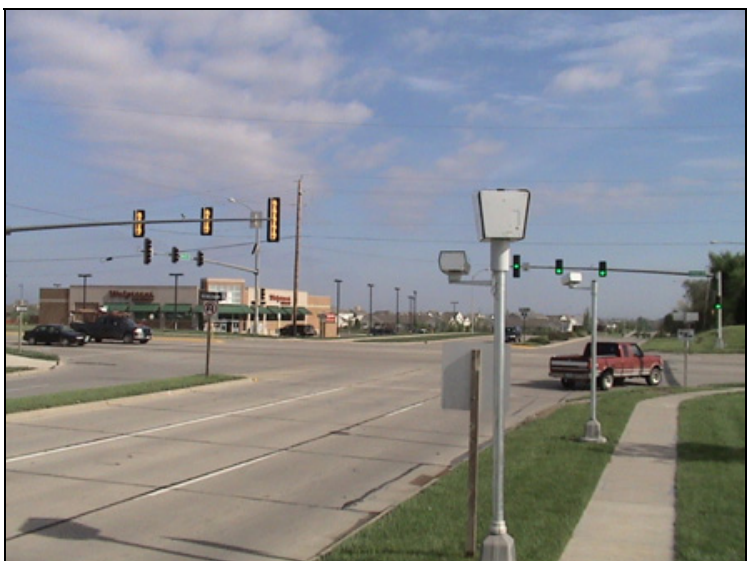

Figure 3.7. RLR camera system monitoring northbound traffic

142nd Street \& Hickman Road [Intersection with Camera(s)]

The intersection of 142nd Street and Hickman Road is located one mile east of 156th Street and Hickman Road and has less commercial development and more private residences south of Hickman Road Significant pedestrian and bicycle traffic cross the north approach because an eight-foot wide paved trail is located to the north of Hickman Road. Summary characteristics are shown in Figures 3.8 and 3.9. 


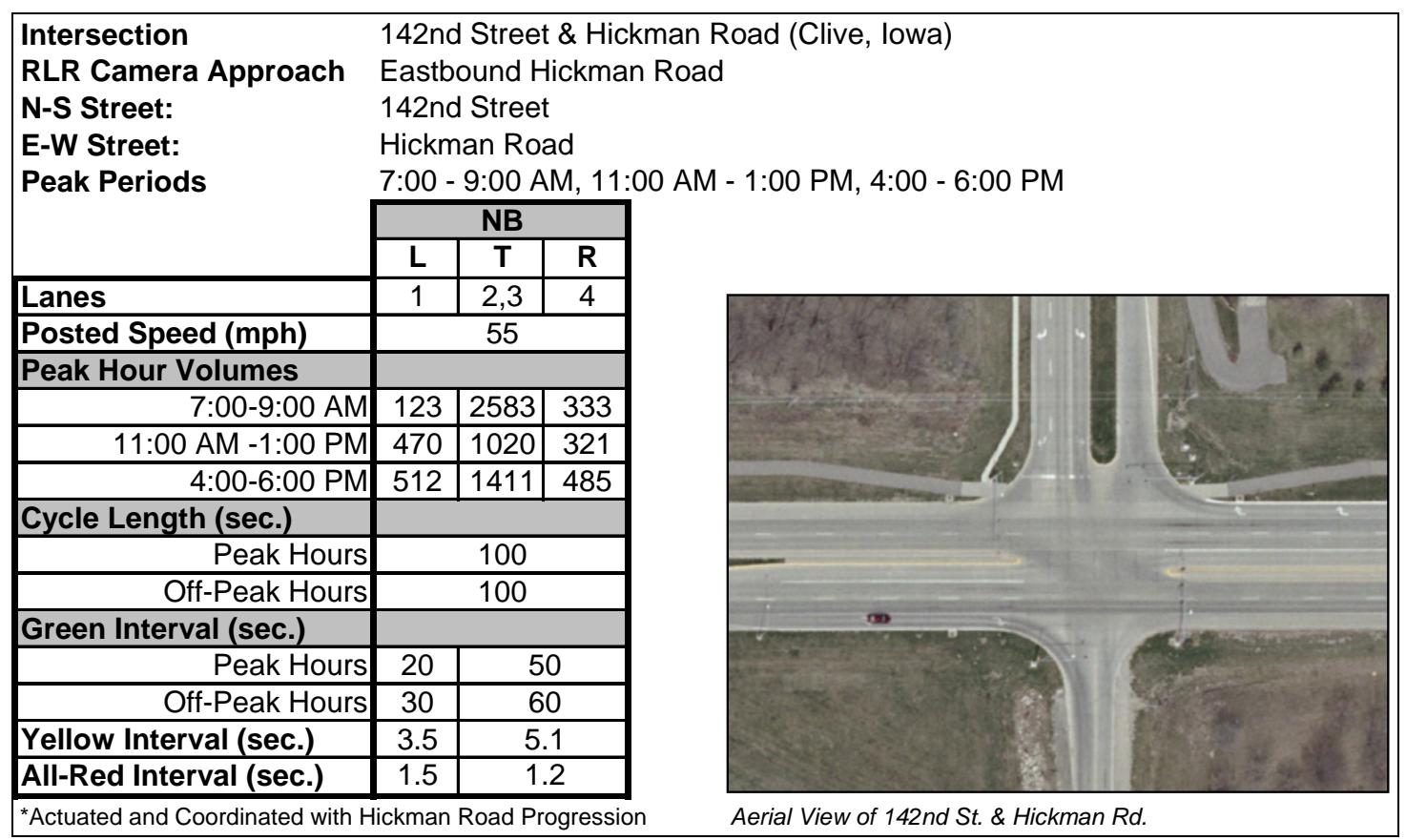

Figure 3.8. Roadway, traffic, and signal timing characteristics for 142nd St. \& Hickman Rd.

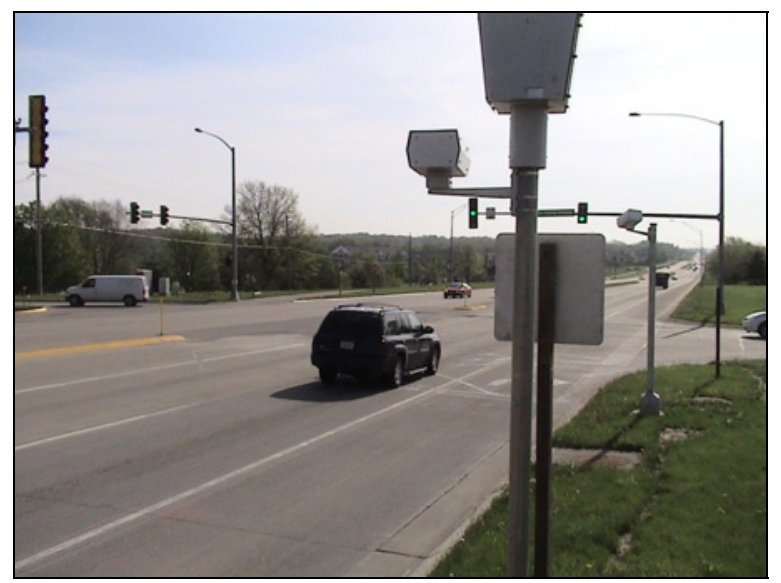

Figure 3.9. RLR camera system monitoring eastbound traffic at 142nd St. \& Hickman Rd.

128th Street \& Hickman Road [Intersection with Camera(s)]

The intersection of 128th Street and Hickman Road is the only camera enforced intersection in Clive that is located on a minor road. Less pedestrian and bicycle traffic occurs here, and truck traffic is present because Interstate $80 / 35$ is only a mile east of this intersection. Two banks are located on the north side of the intersection and a recreation area is located on the southeast side of the intersection. Intersection characteristics are shown in Figures 3.10 and 3.11. 


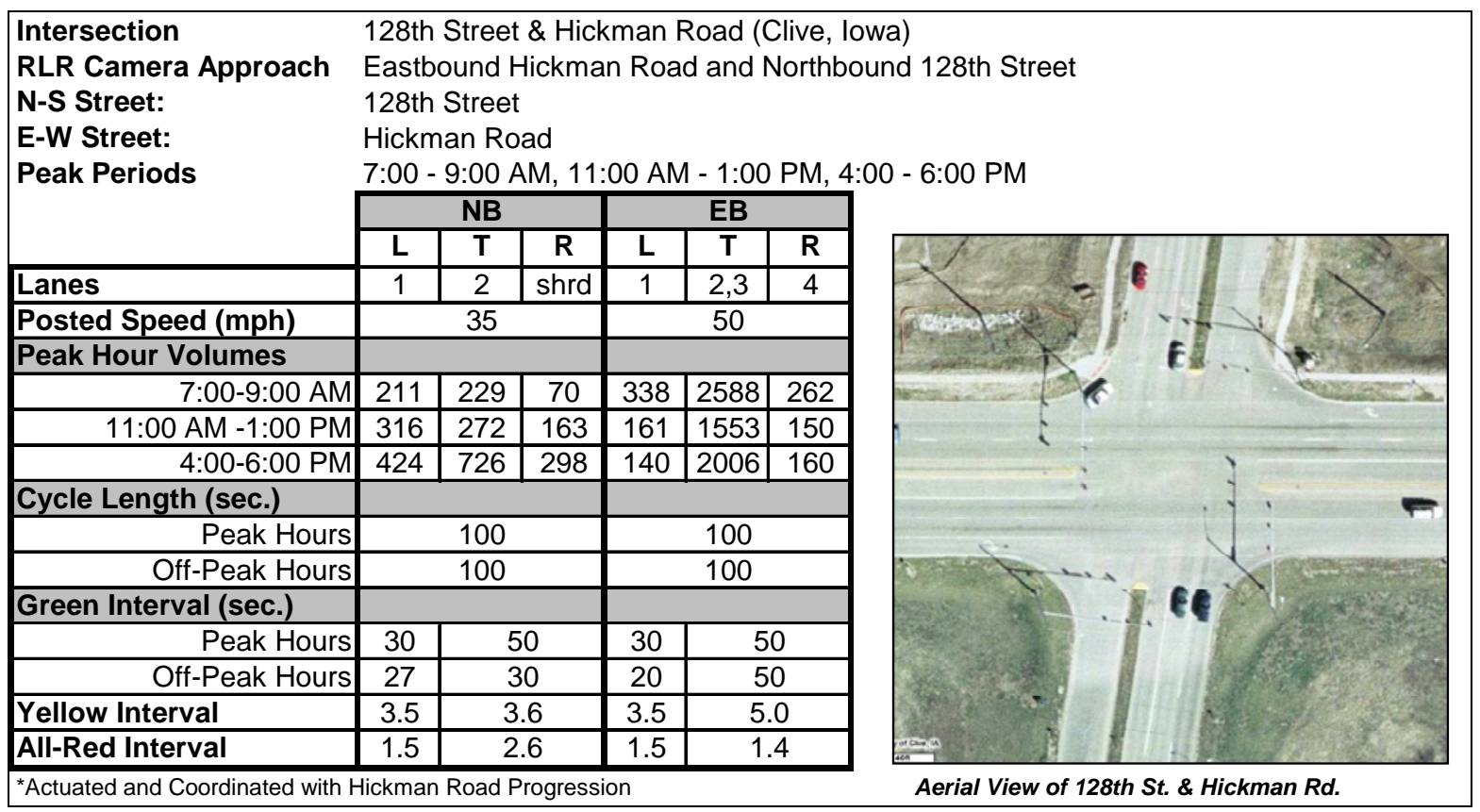

Figure 3.10. Roadway, traffic, and signal timing characteristics for 128th St. \& Hickman Rd.

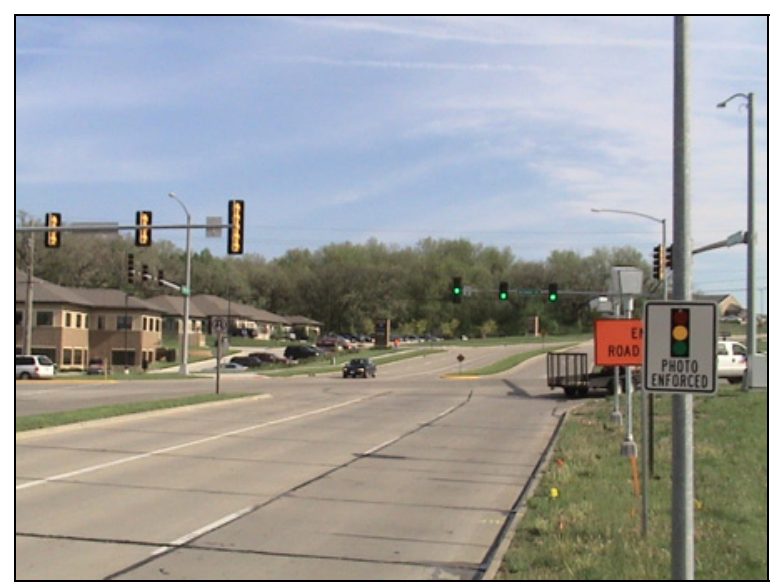

Figure 3.11. Northbound traffic for 128th St. \& Hickman Rd.

100th Street \& Hickman Road [Intersection with Camera(s)]

The intersection of 100th Street and Hickman Road is located in the most eastern location with automated camera enforcement. There is a large commercial area surrounding the intersection, including an auto dealership. One Hundredth Street served as a large collector street for Clive, Urbandale, and West Des Moines. One mile south of this intersection is Valley West Mall, and one mile west is Interstate 80. Less than one mile north of this intersection is an active railroad line connecting to local factories. There is also considerable pedestrian and bicycle traffic north and south which connects to a local trail network. Intersection characteristics are provided in Figures 3.12 and 3.13. 


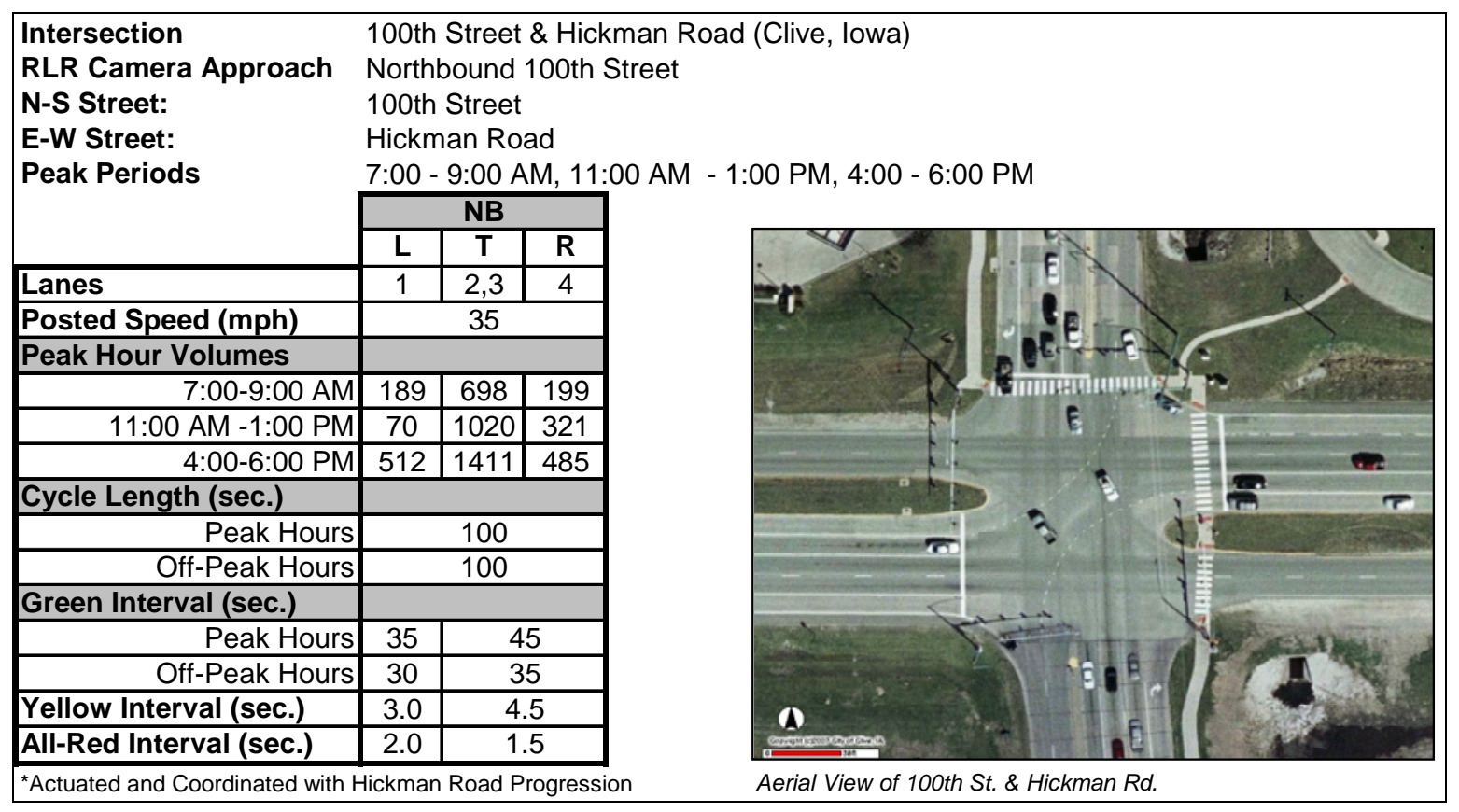

Figure 3.12. Roadway, traffic, and signal timing characteristics for 100th St. \& Hickman Rd.

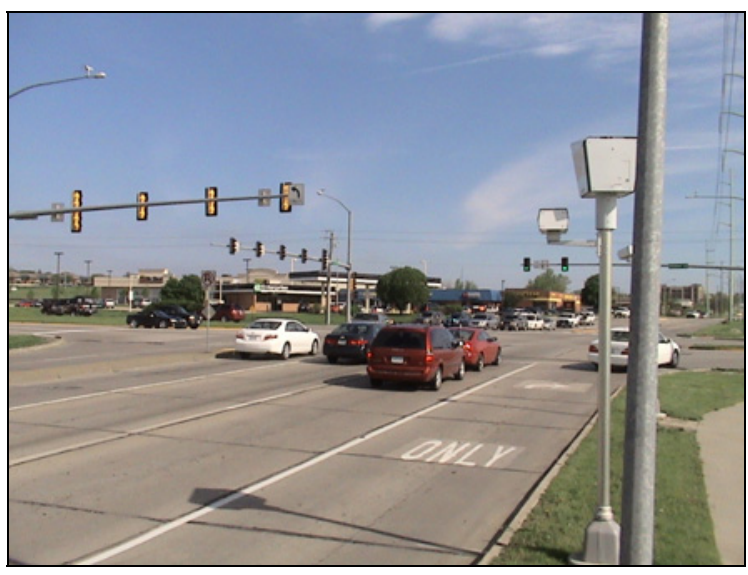

Figure 3.13. Northbound traffic for 100th St. \& Hickman Rd.

\section{6th Street \& Hickman Road [Control Intersection]}

The intersection of 86th Street and Hickman Road is one mile east of 100th Street.

Reconstruction is planned for the near future but did not affect this study. Reconstruction plans include signal coordination, access management along 86th Street, and extension of turning bays. On the southwest side of the intersection is a Dahl's grocery store, and on the southeast side is an auto parts store. On the northeast side of the intersection is a small strip mall, and on the northwest side is a restaurant with a frontage road. The frontage road serves as a shortcut for many commuters when the intersection is at capacity. Intersection characteristics are provided in Figures 3.14 and 3.15. 


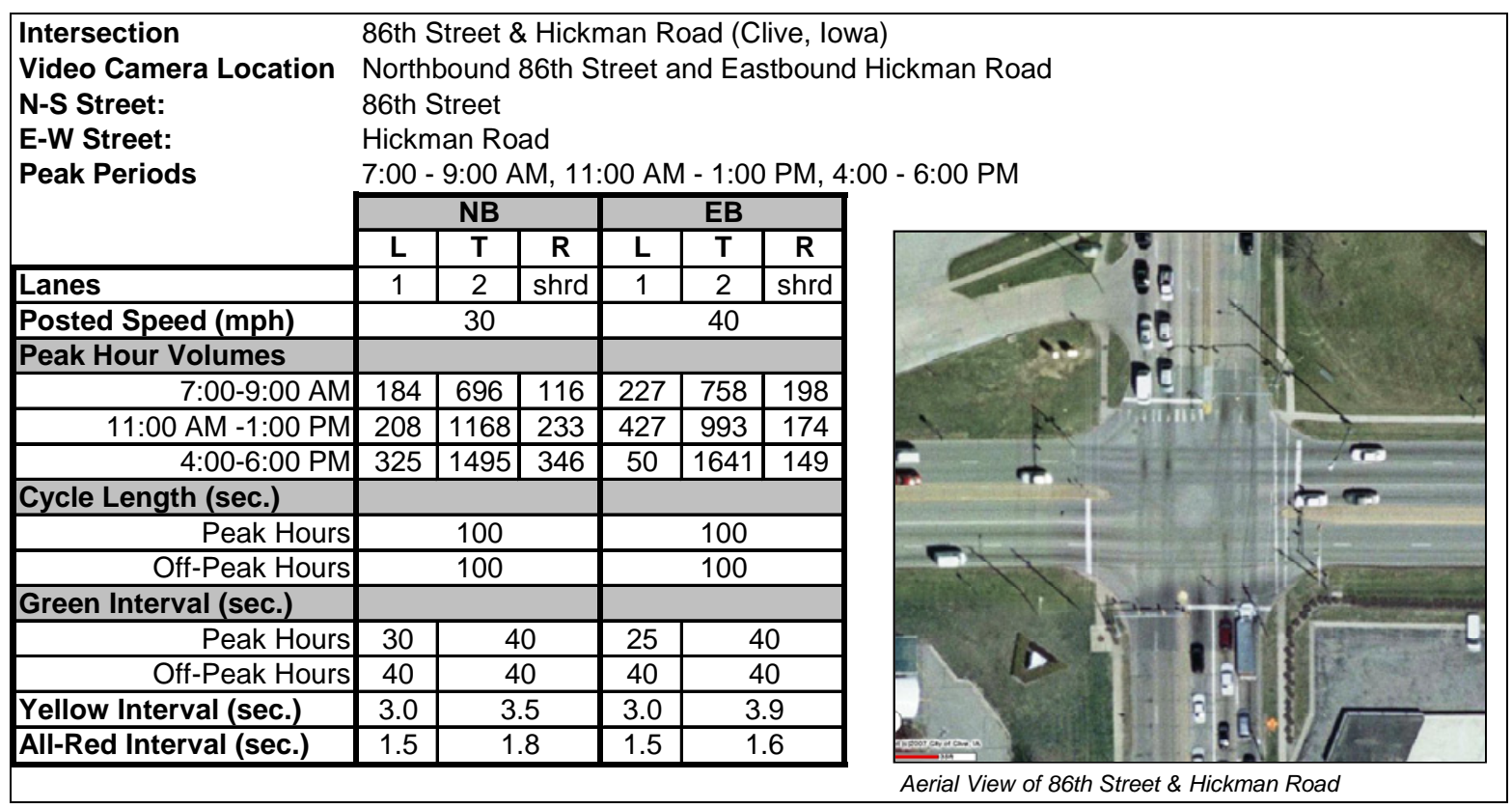

Figure 3.14. Roadway, traffic, and signal timing characteristics for 86th St. \& Hickman Rd.

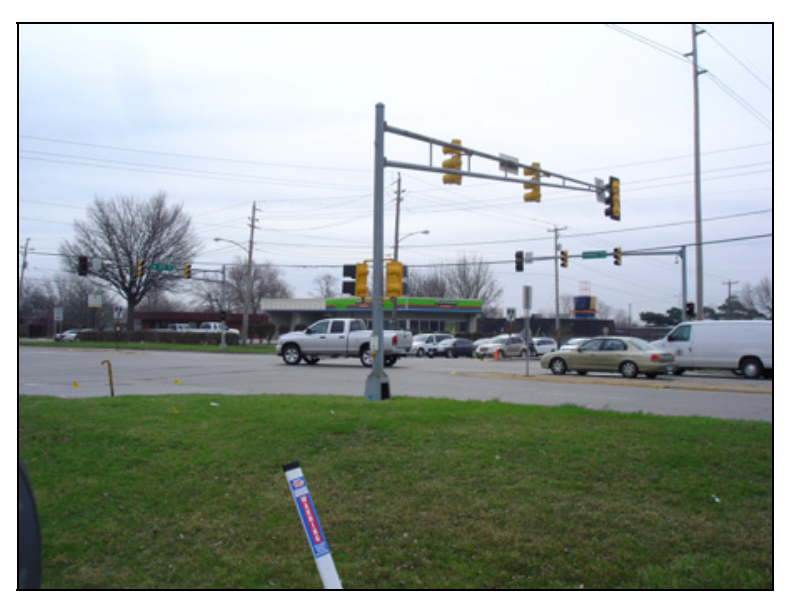

Figure 3.15. Southbound traffic for 86th St. \& Hickman Rd.

86th Street \& Douglas Avenue [Control Intersection]

Located north of the Hickman Road corridor in the city of Urbandale is the intersection of 86th Street and Douglas Avenue. This intersection moves east- and westbound traffic to the north and south with double left turn lanes. On the northwest side of the intersection is a grocery store, and on the northeast side of the intersection are a bank and various commercial businesses. On the southeast side is a commercial development and on the southwest side is the Urbandale Administration Building and Public Library. Intersection characteristics are shown in Figures 3.16 and 3.17. 


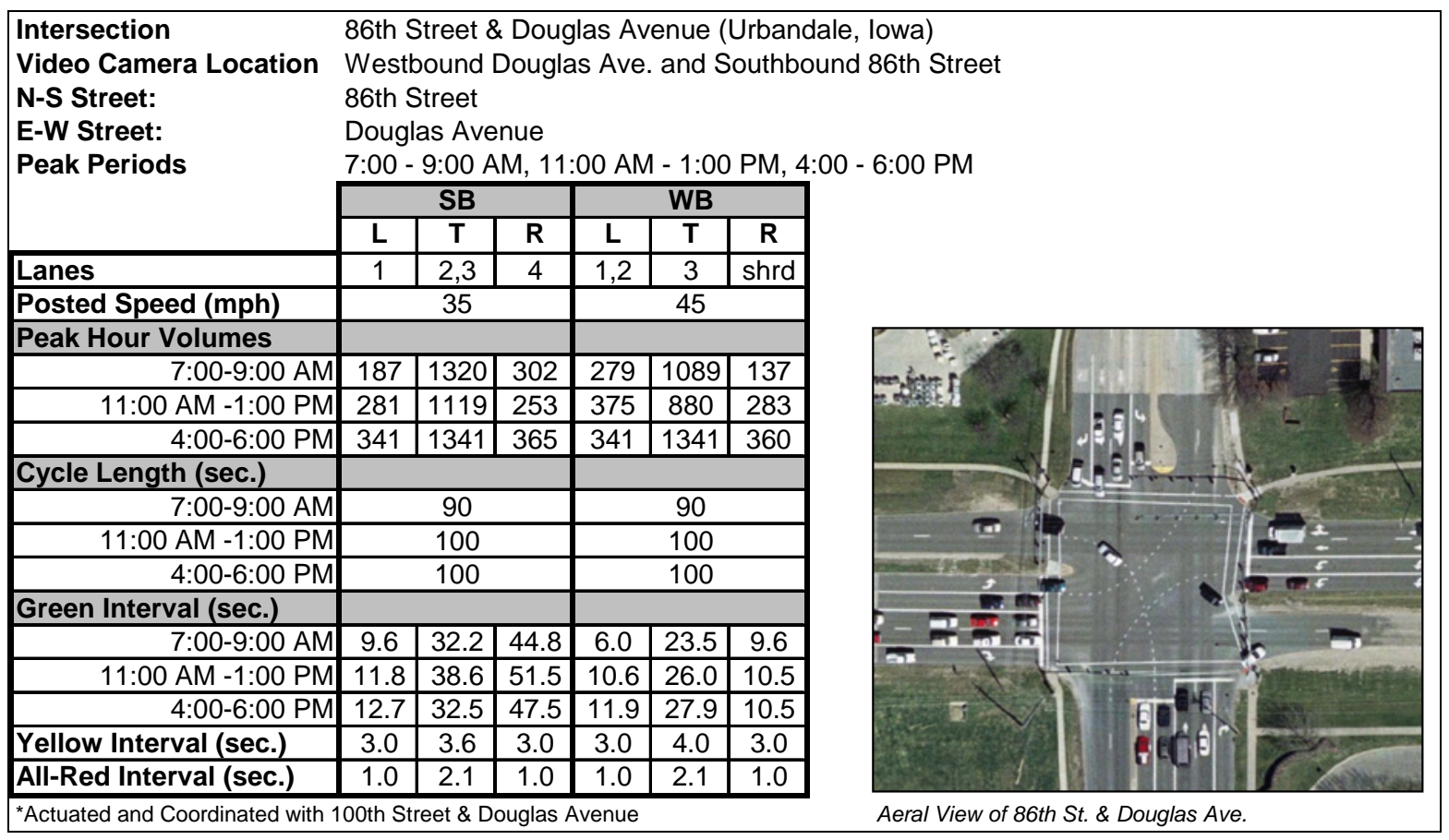

Figure 3.16. Roadway, traffic, and signal timing characteristics for 86th St. \& Douglas Ave.

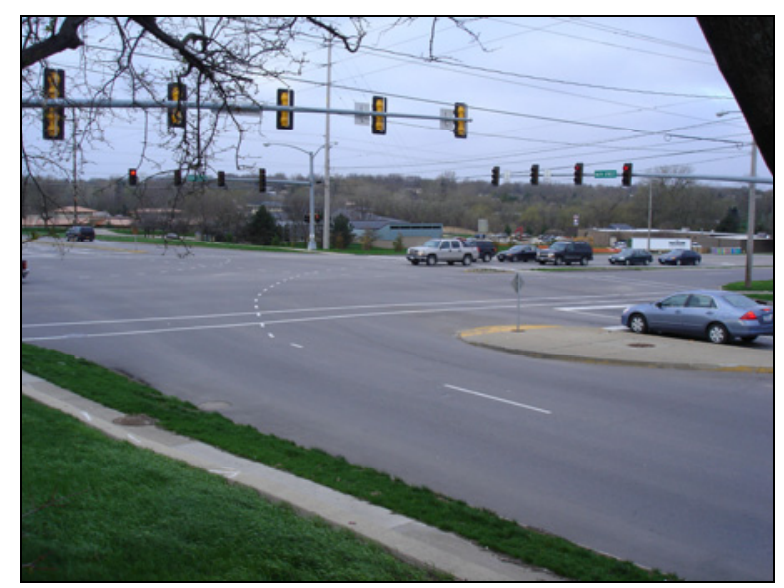

Figure 3.17. Southbound traffic for 86th St. \& Douglas Ave.

100th Street \& Douglas Avenue [Control Intersection]

One mile west of 86th Street, and one mile north of Hickman Road, is the intersection of 100th Street and Douglas Avenue. Located in an industrial area of Urbandale, this intersection moves traffic northbound and southbound from the east. Located on the northeast side of the intersection are large gas station and several fast food establishments. On the northwest side of the intersection are various commercial developments. On the southwest side of the intersection are heavy commercial businesses with a railroad track running diagonal to the west and northbound approaches. On the southeast side of the intersection are residential areas and small 
businesses. This intersection experiences school bus blockage in the morning and afternoon due to the railroad tracks. Intersection characteristics are provided in Figures 3.18, 3.19, and 3.20.

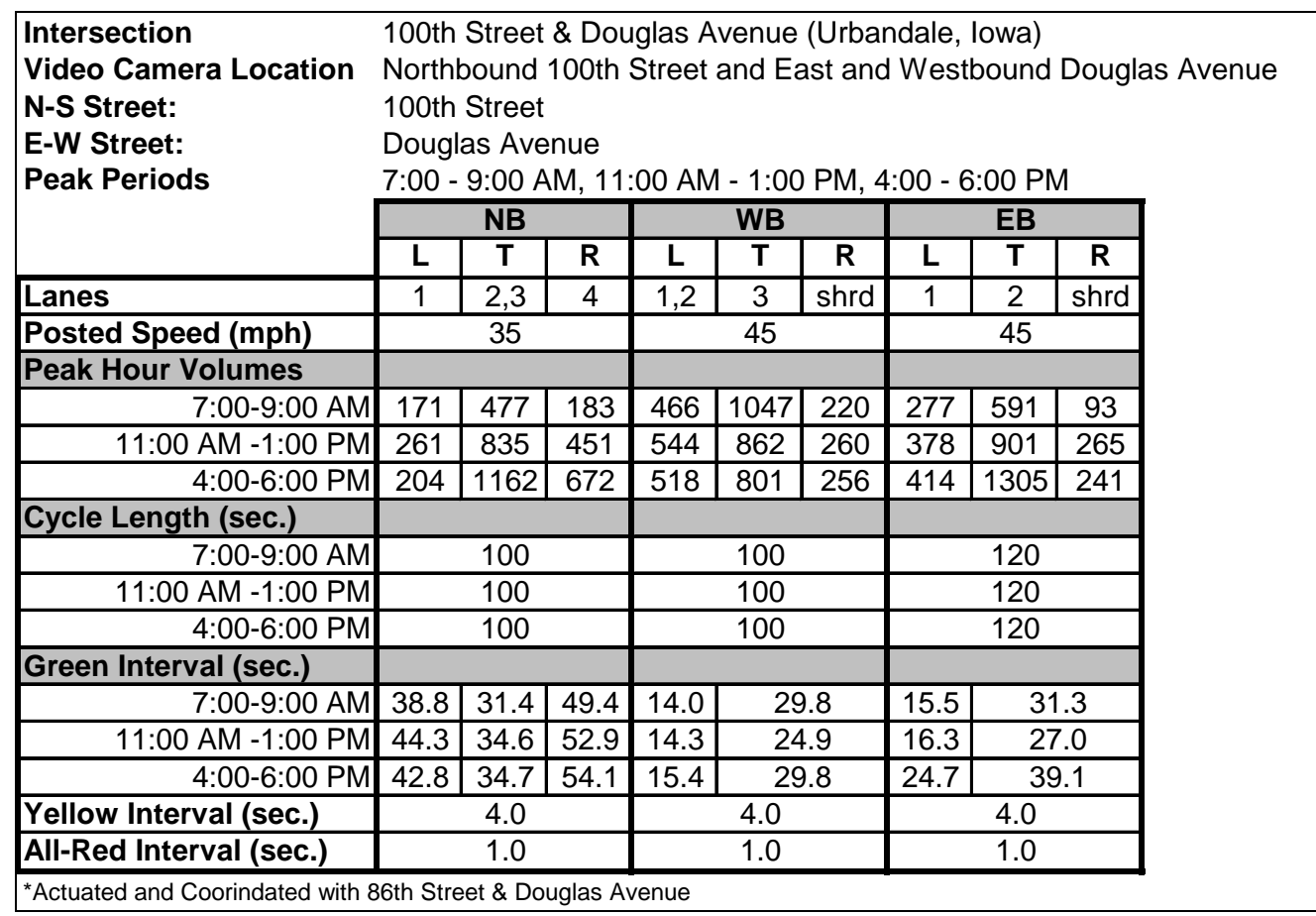

Figure 3.18. Roadway, traffic, and signal timing characteristics for 100th St. \& Douglas Ave.

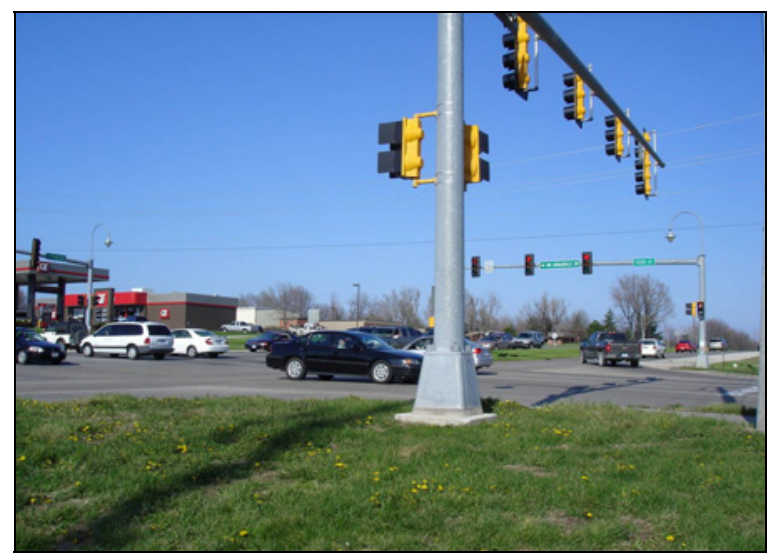

Figure 3.19. Northbound traffic for 100th St. \& Douglas Ave. 


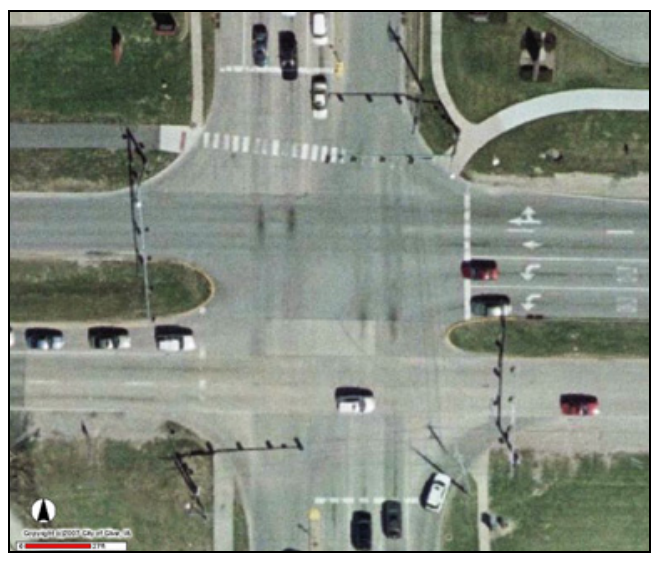

Figure 3.20. Aerial view of traffic for 100th St. \& Douglas Ave.

\section{5th Street \& University Avenue [Control Intersection]}

Located in the north part of the city of West Des Moines, the intersection of 35th Street (Valley West Drive) and University Avenue is located next to Valley West Mall and several large commercial developments including Target, Best Buy, Home Depot, and many others which are located on the south side of the intersection. On the north side of the intersection are small commercial developments surrounded by residential areas. Half of this intersection is located in the City of Clive, but the West Des Moines Traffic Operations Center controls the traffic signals at this intersection. Intersection characteristics are shown in Figures 3.21 and 3.22.

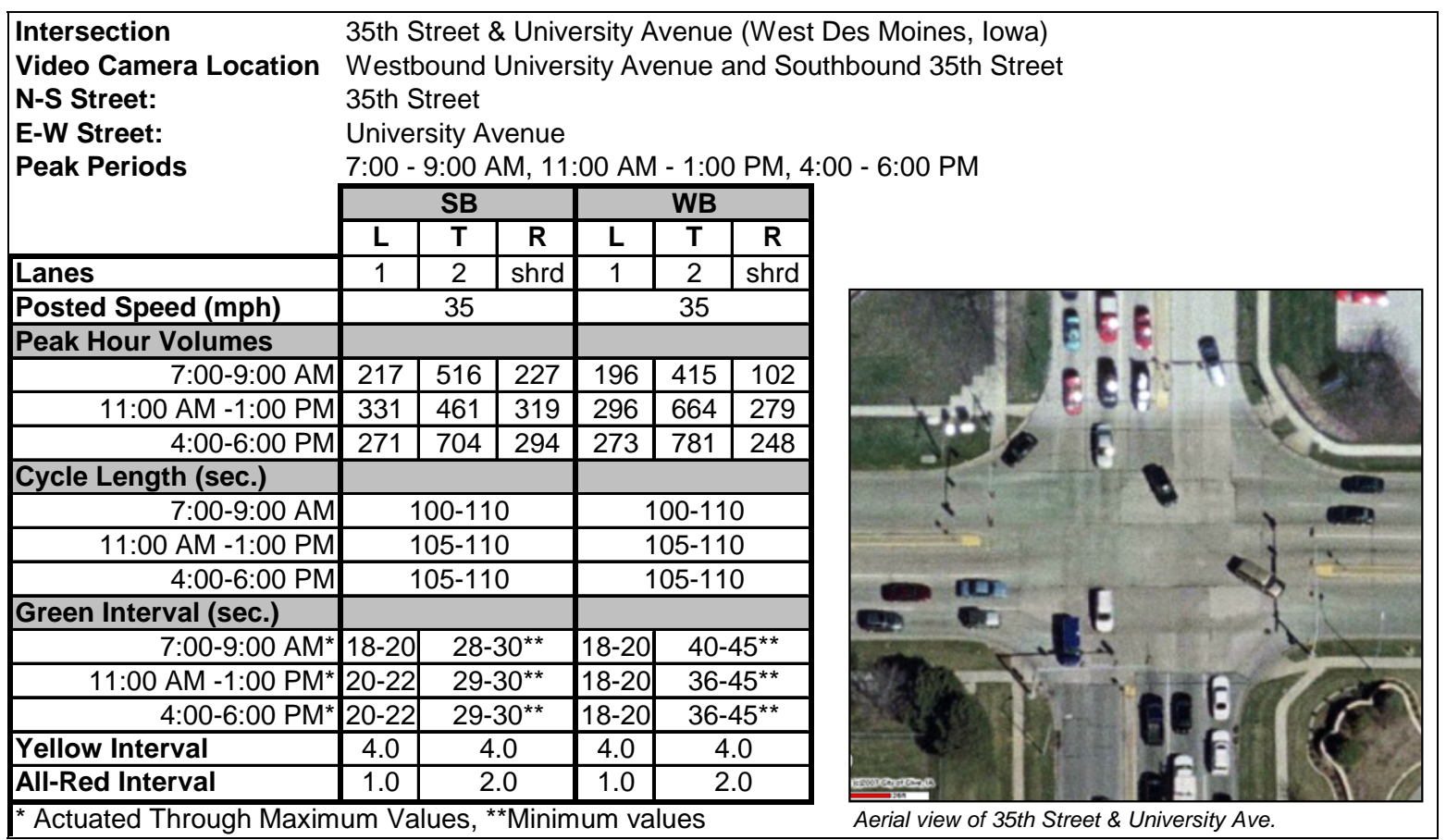

Figure 3.21. Roadway, traffic, and signal timing characteristics for 35th St. \& University Ave. 


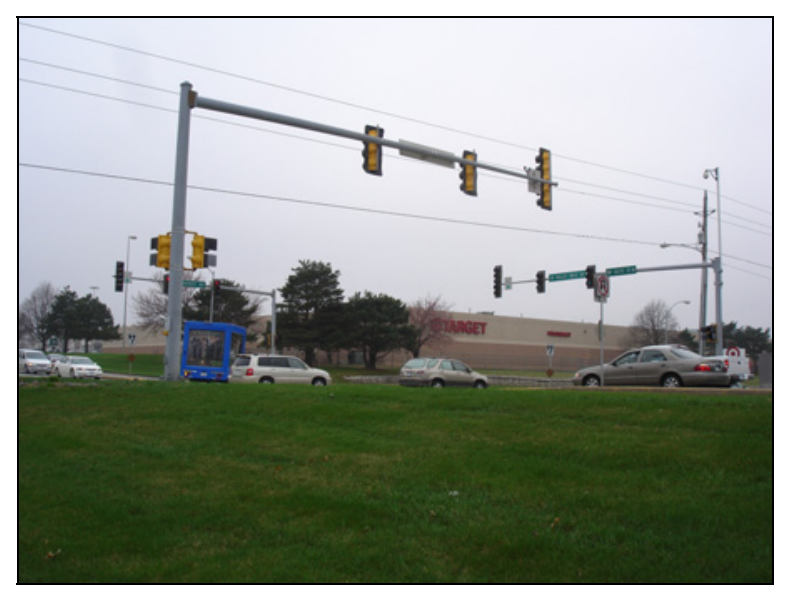

Figure 3.22. Southbound traffic for 35th St. \& University Ave.

\section{8th Street \& University Avenue [Control Intersection]}

Located west of Interstate 80 and one mile south of Hickman Road is the intersection of 128th Street and University Avenue. This intersection is also surrounded by commercial development. On the southwest side of the intersection is the Lakeview Medical Park. A restaurant is located on the southeast side with a Walgreens on the northeast side, and Granite City Brewing Company on the northwest side. This intersection has a number of commuters from Interstate $80 / 35$ in the mornings and evenings. To the north of the intersection, 128th Street is currently a two-lane road passing through residential areas. The city of Clive is in the process of making the road a divided four-lane arterial. However, construction was not going on during this study. Intersection characteristics are shown in Figures 3.23, 3.24, and 3.25.

\begin{tabular}{|c|c|c|c|c|c|c|c|c|c|}
\hline \multirow{3}{*}{$\begin{array}{l}\text { Intersection } \\
\text { Video Camera Location } \\
\text { N-S Street: } \\
\text { E-W Street: } \\
\text { Peak Periods }\end{array}$} & $\begin{array}{l}\text { 60th } \$ \\
\text { Westh } \\
60 \text { th } \$ \\
\text { Unive } \\
7: 00-\end{array}$ & $\begin{array}{l}\text { treet \& } \\
\text { ound L } \\
\text { treet } \\
\text { sity Av } \\
9: 00 \text { A }\end{array}$ & $\begin{array}{l}\text { Unive } \\
\text { Univers } \\
\text { venue } \\
\text { M, 11: }\end{array}$ & $\begin{array}{l}\text { rsity A } \\
\text { ity Av }\end{array}$ & $\begin{array}{l}\text { jenue } \\
\text { nue a }\end{array}$ & $\begin{array}{l}\text { (West } \\
\text { and Sol }\end{array}$ & $\begin{array}{l}\text { Des N } \\
\text { thbou }\end{array}$ & $\begin{array}{l}\text { Moines, } \\
\text { and 60t }\end{array}$ & $\begin{array}{l}\text { lowa) } \\
\text { h Stree }\end{array}$ \\
\hline & \multicolumn{3}{|c|}{ NB } & \multicolumn{3}{|c|}{ SB } & \multicolumn{3}{|c|}{ WB } \\
\hline & $\mathbf{L}$ & $\mathbf{T}$ & $\mathbf{R}$ & $\mathbf{L}$ & $\mathbf{T}$ & $\mathbf{R}$ & $\mathbf{L}$ & $\mathbf{T}$ & $\mathbf{R}$ \\
\hline Lanes & 1 & 2 & shrd & 1 & 2 & shrd & 1 & 2 & shrd \\
\hline Posted Speed (mph) & \multicolumn{3}{|c|}{35} & \multicolumn{3}{|c|}{35} & \multicolumn{3}{|c|}{45} \\
\hline \multicolumn{10}{|l|}{ Peak Hour Volumes } \\
\hline $7: 00-9: 00 \mathrm{AM}$ & 172 & 318 & 205 & 270 & 397 & 352 & 424 & 939 & 108 \\
\hline 11:00 AM -1:00 PM & 219 & 403 & 333 & 201 & 257 & 276 & 419 & 1188 & 245 \\
\hline 4:00-6:00 PM & 373 & 588 & 316 & 202 & 389 & 208 & 363 & 1399 & 444 \\
\hline \multicolumn{10}{|l|}{ Cycle Length (sec.) } \\
\hline Free Loops Actuated & \multicolumn{3}{|c|}{110} & \multicolumn{3}{|c|}{110} & \multicolumn{3}{|c|}{110} \\
\hline 7:15 AM - 10:00 PM & \multicolumn{3}{|c|}{110} & \multicolumn{3}{|c|}{110} & \multicolumn{3}{|c|}{110} \\
\hline \multicolumn{10}{|l|}{ Green Interval (sec.) } \\
\hline Free Loops Actuated & \multicolumn{3}{|c|}{ Actuated } & \multicolumn{3}{|c|}{ Actuated } & \multicolumn{3}{|c|}{ Max Time } \\
\hline 7:15 AM - 10:00 PM & $16^{\star}$ & & $8^{*}$ & $16^{\star}$ & & $6^{*}$ & $24^{*}$ & 48 & ** \\
\hline Yellow Interval (sec.) & 3.6 & 3. & 6 & 3.6 & & 3.6 & 4.4 & 4. & 4 \\
\hline All-Red Interval (sec.) & 2.4 & 2. & .4 & 2.2 & & 2.2 & 1.8 & 1. & 8 \\
\hline
\end{tabular}

Figure 3.23. Roadway, traffic, and signal timing characteristics for 60th St. \& University Ave. 


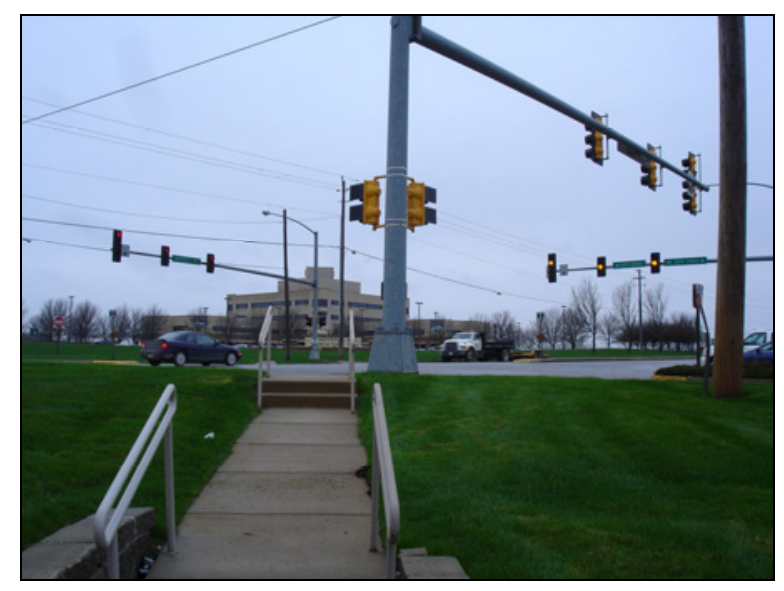

Figure 3.24. Westbound traffic for 60th St. \& University Ave.

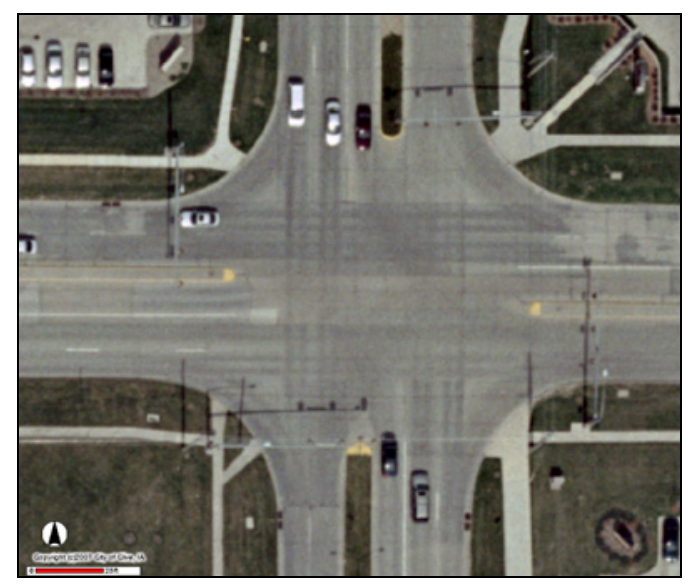

Figure 3.25. Aerial view of traffic for 60th St. \& University Ave.

Oralabor Road \& State Street [Control Intersection]

The intersection of Oralabor Road and State Street was one of two control sites used in the violation study. This high-speed intersection is located in Ankeny approximately 15 miles northeast of the Hickman Road corridor. There are not currently any businesses or residential developments at the corners of the intersection. Many morning and evening commuters travel through this intersection to Interstate 35 which is located a short distance east, or they travel south of State Street to north Des Moines. Intersection characteristics are shown in Figures 3.26 and 3.27. 




Figure 3.26. Roadway, traffic, and signal timing characteristics for Oralabor Rd. \& State St.

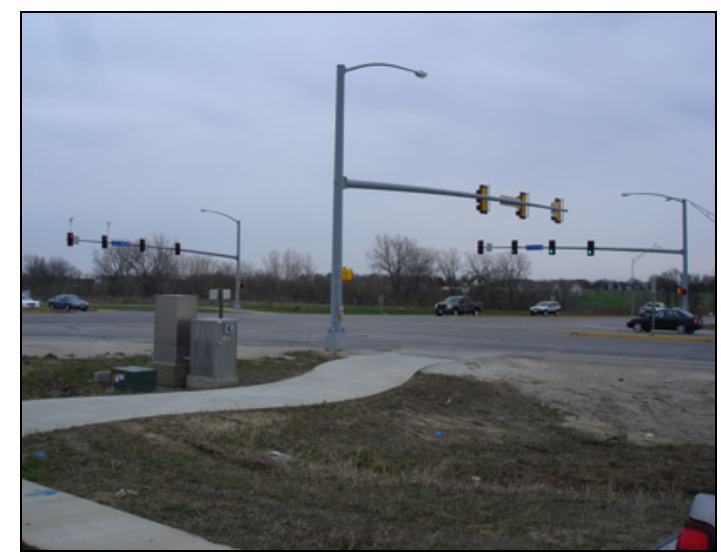

Figure 3.27. Northbound traffic for Oralabor Rd. \& State St.

North Warrior Lane \& Hickman Road [Control Intersection]

The second control site used in the violation study was the intersection of North Warrior Lane and Hickman Road located in Waukee. This intersection is located two miles west of the 156th Street intersection, and the approaching speed limits are $10 \mathrm{mph}$ lower, at $45 \mathrm{mph}$. North Warrior Lane is one of three major roads that lead into the city of Waukee and is surrounded by new 
commercial and light industrial businesses. On the southwest corner of the intersection is a 16pump Casey's General Store which serves as a morning and afternoon staging area for Waukee school buses. Traffic volume is expected to increase over the next 10 years because of expanding development from the Des Moines area. Intersection characteristics are provided in Figures 3.28 and 3.29.

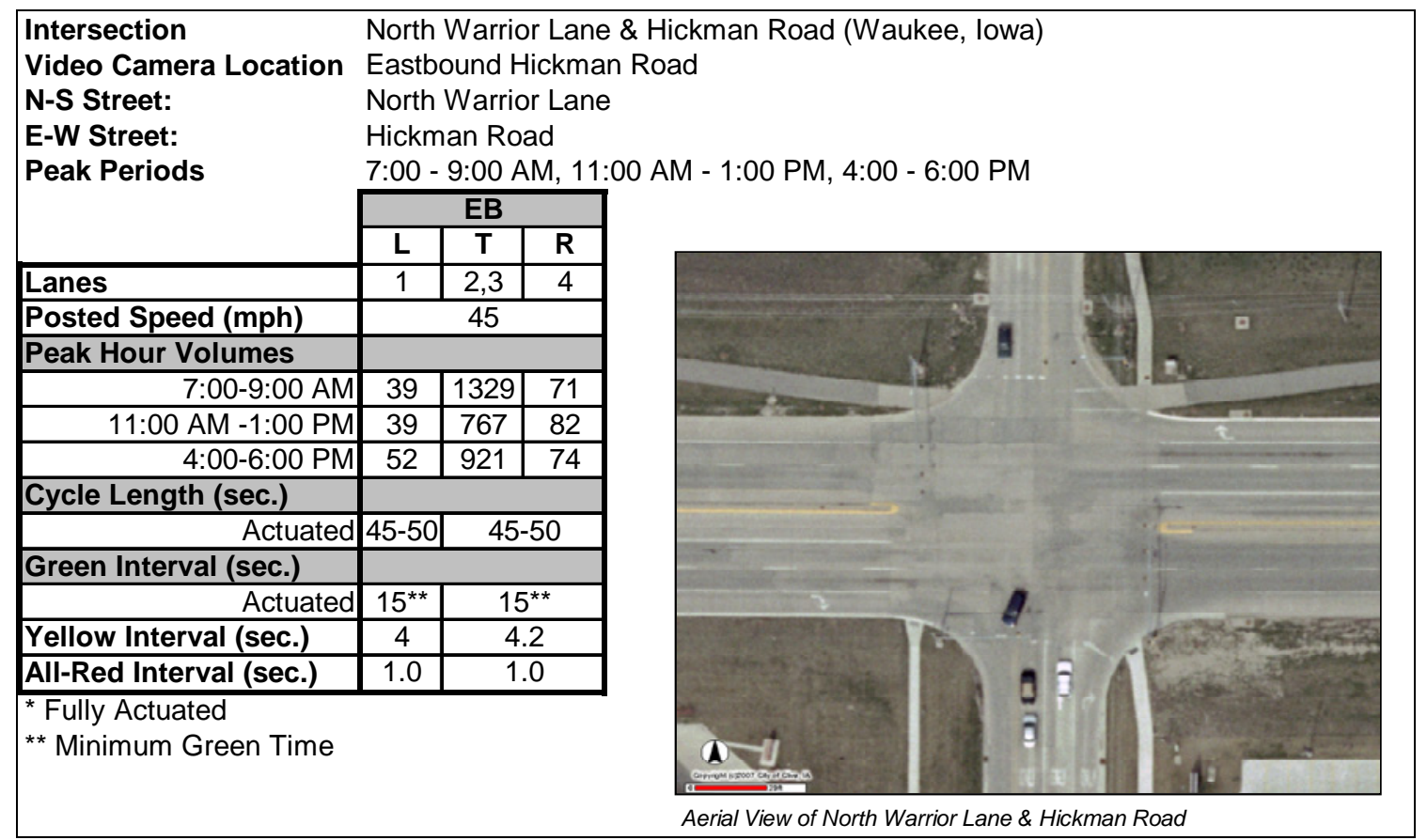

Figure 3.28. Roadway, traffic, and signal timing characteristics for N. Warrior Ln. \& Hickman Rd.

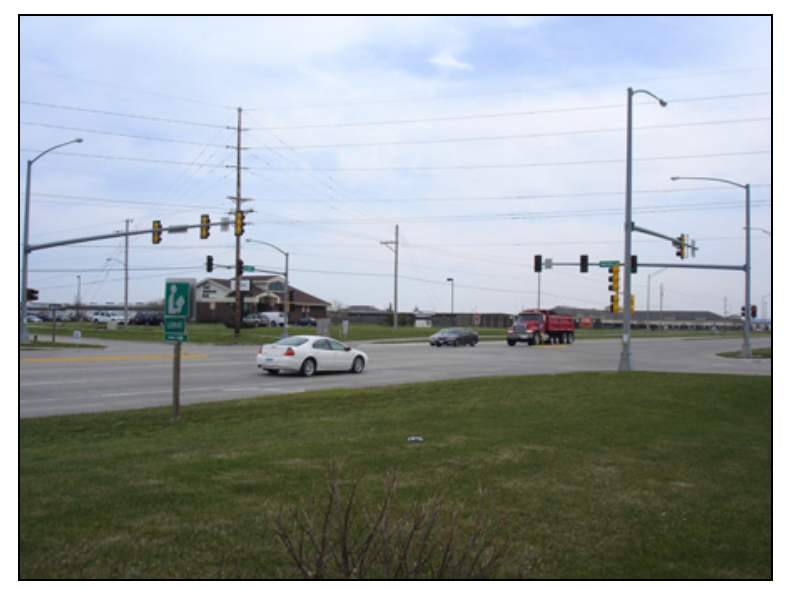

Figure 3.29. Eastbound traffic for N. Warrior Ln. \& Hickman Rd. 


\subsection{Data Collection}

The number of RLR citations issued, and additional collected data, for the instrumented intersections were provided by the city of Clive and are presented in the following sections. Field studies were conducted at the control intersections to collect violation data on a randomly sampled day of the week between Tuesday and Thursday. Because it was difficult to manually monitor an intersection for RLR violations, approaches were videotaped and the number of red light violations was extracted from a review of the captured video.

Violation data for the control intersections were obtained using field data collection. Video of the approach of interest was taken using two DVD-R digital cameras mounted on two tripods in the bed of a pickup truck. A schematic of data collection is shown in Figure 3.30.

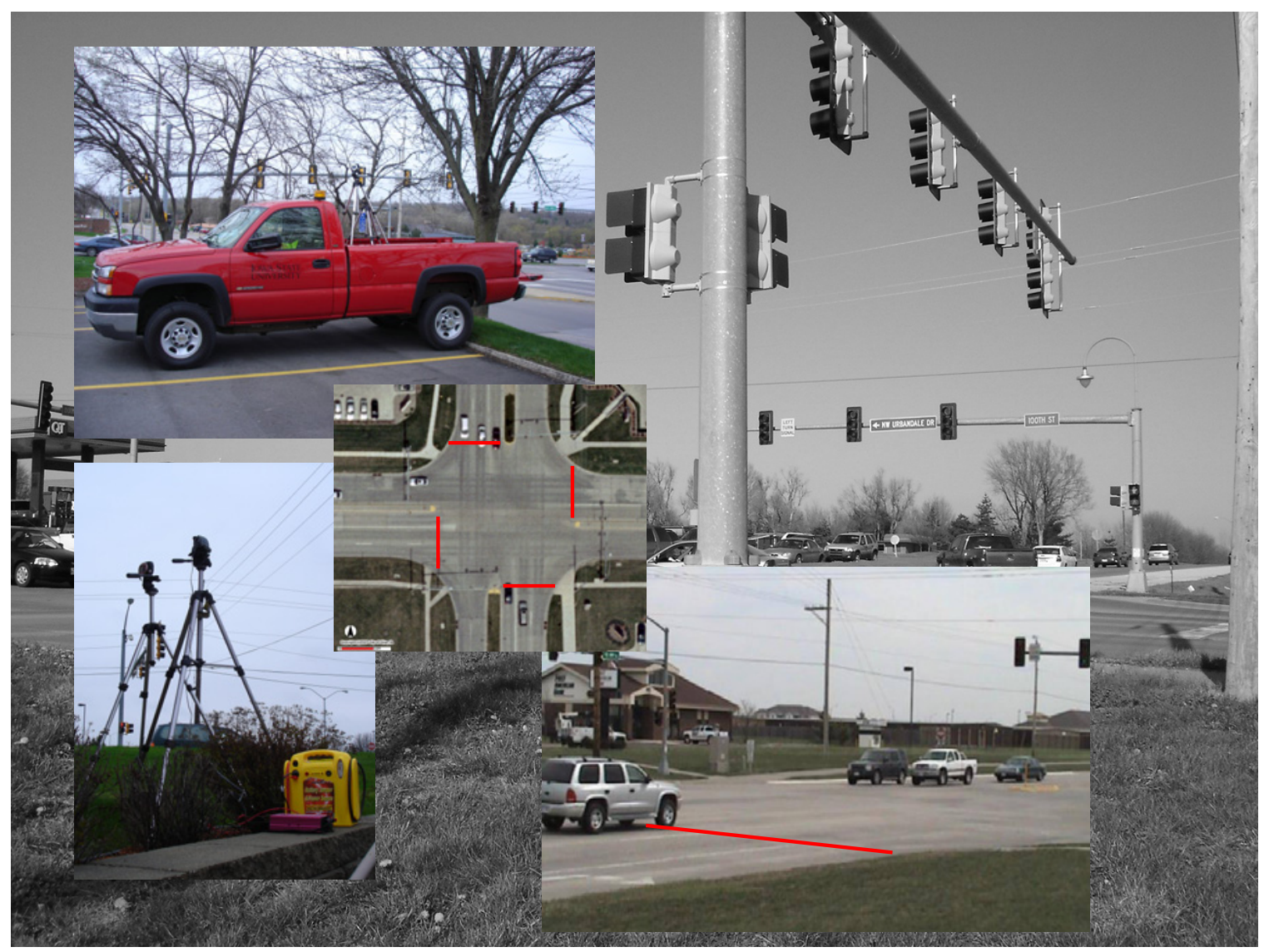

Figure 3.30. Schematic of data collection

Because the self-contained camera battery was limited to 90 minutes, a car battery unit and a $\mathrm{D} / \mathrm{C}$ power converter were used to supply power so that the intersection could be monitored for an entire day. The cameras needed to be near the data collection vehicle for power, so this constrained how far apart the cameras could be placed, thus eliminating ground use or the ability to hide the cameras behind obstructions. The cameras were positioned high on the tripods that could see the stop bar and traffic signal in the same frame. Peak hour videos were taken between the hours of 7:00 a.m. and 9:00 a.m., 11:00 a.m. and 1:00 p.m., and 4:00 p.m. and 6:00 p.m. Each 
DVD-R disk recorded 30 minutes of raw video; thus, the need to change disks resulted in a small amount of lost recording time. Early morning sunlight limited the available viewing angle if video were taken of an eastbound approach. Video recording was halted two times due to heavy rains in March and a late snowstorm in April. Data were recollected in the same week for missing peak hours and every site had three peak hours of data total

Video was manually viewed. When necessary, the video was viewed using zoom and frame-byframe capabilities to determine if an RLR violation occurred. An RLR violation was defined as an instance when the front of a vehicle crossed the stop bar, or end of the center median (if no stop bar were present), after the red indication was given for through and left-turning movements. For vehicles making a right turn on a red, an RLR violation was counted if the vehicle did not come to a complete stop or close to a complete stop before making the right turn as specified by all three cities’ municipal codes.

Video recording took place from March 2007 through April 2007 at the control intersections. Due to the court ruling, the RLR cameras were on hiatus during this study period, so the random day of March 6, 2007, was chosen, and violation data was collected from the city of Clive and compared to the video violation counts. Violations were provided for the entire day. However, only violations for the peak periods were included in the analysis so that the results are consistent because only peak hour data were included for the control intersections. Only peak periods were used because reducing the video manually entailed a significant expenditure of resources.

A day during the field violation study for the control intersections was randomly selected and RLR violations for the camera-enforced intersections were provided by the Clive Police Department. Peak period data were extracted from the day data provided was provided for.

Traffic volume for each intersection was obtained either by the city of West Des Moines or Urbandale depending on who had jurisdiction. When hourly turning movement counts were not available, this data was manually collected during the study interval on a Tuesday, Wednesday, or Thursday. Vehicle counts were recorded on a Jamar Technologies DB-400 Turning Movement Counter, and then later downloaded using the computer program PETRAPro.

\subsection{Analysis of Clive Violation Data}

\subsubsection{RLR Frequency and Rate}

For each intersection, peak hours were defined as Morning Peak (7:00 a.m.-9:00 a.m.), Mid day (11:00 a.m.-1:00 p.m.), and Evening Peak (4:00 p.m -6:00 p.m.). At each designated approach, two hours of video data and traffic volumes were taken during each peak period. Data were collected on Tuesday, Wednesday, or Thursday. The results of the data collection are as follows.

Violation data were used to compare the effectiveness of the Clive RLR camera system. Washburn and Courage (2004) evaluated RLR violations in the Florida area and suggested the use of the following three measures of effectiveness. 
Frequency: The number of RLR violations per peak hour per approach.

RLR Rate: The ratio of RLR violations to total approach volume is expressed as a percent. The two equations were used to find the average percentage of hourly volume running red lights (Equation 3-1), and the average number of red light runners per thousand entering vehicles (Equation 3-2). The two equations are as follows.

$$
\begin{aligned}
& \text { RLR Rate }(\%)=\frac{N_{R} \times 100}{V} \\
& \text { RLR Rate }(T E V)=\frac{N_{R} \times 1,000}{V}
\end{aligned}
$$

Where:

RLR Rate (\%) = Average percentage of hourly volume running a red light RLR Rate $(T E V)=$ Average red light runners per thousand entering vehicles $N_{R}=$ Number of red light runners during each peak hours $\mathrm{V}=$ Average analysis hour volume (as provided by the city of field counts)

Violation metrics for the camera-enforced intersection are shown in Table 3.2. As indicated, only three movements experienced any RLR violations. The rest had no violations during the study period. The left turn movement for the northbound approach for 100th Street and Hickman Road experienced two RLR violations per hour during the morning peak period, six during midday peak period, and three during the evening peak period. The right-turn movement for the northbound approach for 128th Street and Hickman Road had one violation per hour during the morning peak period and two violations per hour during the evening peak period. The right-turn movement for the northbound approach for 100th Street and Hickman Road had three violations per hour during the evening peak period. As shown, all movements and approaches experienced very few RLR violations. 
Table 3.2. RLR violations for camera-enforced intersections-Clive

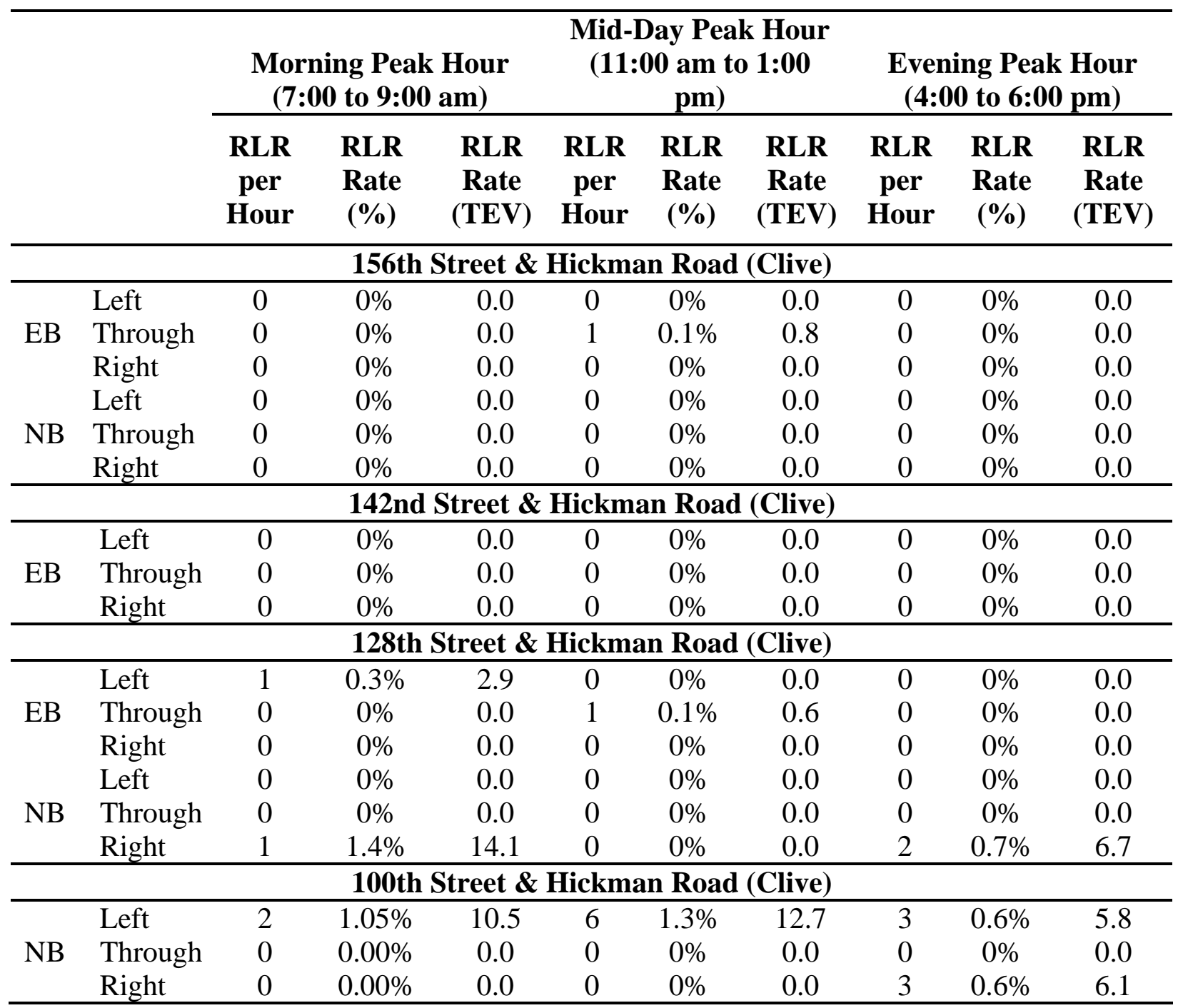

RLR violations for control intersections are shown in Table 3.3. As indicated, red light running was much more prevalent at the control intersections. A wide range of conditions existed. In some cases, only a low number of violations were recorded. In many cases, up to 10 violations per peak hour were recorded and several movements experienced much higher numbers. Overall the number and rates for red light running were significantly lower for camera-enforced approaches than for control approaches. 
Table 3.3. RLR violations for control intersections-Clive

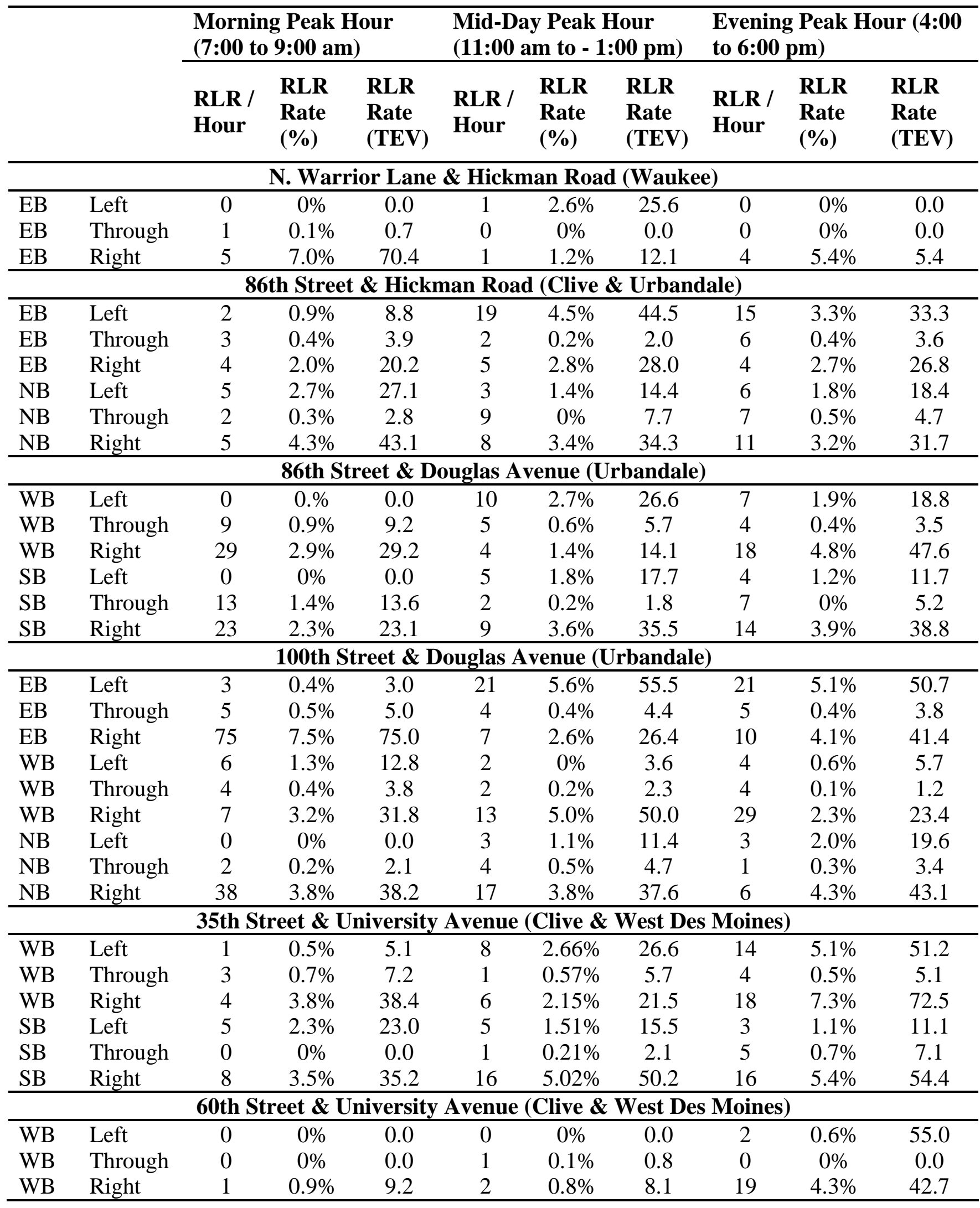


Table 3.3. RLR violations for control intersections-Clive (cont.)

\begin{tabular}{|c|c|c|c|c|c|c|c|c|c|c|}
\hline & & \multicolumn{3}{|c|}{$\begin{array}{l}\text { Morning Peak Hour } \\
\text { (7:00 to 9:00 am) }\end{array}$} & \multicolumn{3}{|c|}{$\begin{array}{l}\text { Mid-Day Peak Hour } \\
\text { (11:00 am to - 1:00 pm) }\end{array}$} & \multicolumn{3}{|c|}{$\begin{array}{l}\text { Evening Peak Hour (4:00 } \\
\text { to 6:00 pm) }\end{array}$} \\
\hline & & $\begin{array}{l}\text { RLR / } \\
\text { Hour }\end{array}$ & $\begin{array}{l}\text { RLR } \\
\text { Rate } \\
(\%)\end{array}$ & $\begin{array}{l}\text { RLR } \\
\text { Rate } \\
\text { (TEV) }\end{array}$ & $\begin{array}{l}\text { RLR / } \\
\text { Hour }\end{array}$ & $\begin{array}{l}\text { RLR } \\
\text { Rate } \\
(\%)\end{array}$ & $\begin{array}{l}\text { RLR } \\
\text { Rate } \\
\text { (TEV) }\end{array}$ & $\begin{array}{l}\text { RLR / } \\
\text { Hour }\end{array}$ & $\begin{array}{l}\text { RLR } \\
\text { Rate } \\
(\%)\end{array}$ & $\begin{array}{l}\text { RLR } \\
\text { Rate } \\
\text { (TEV) }\end{array}$ \\
\hline \multicolumn{11}{|c|}{ 60th Street \& University Avenue (Clive \& West Des Moines) } \\
\hline NB & Left & 3 & $1.7 \%$ & 17.4 & 2 & $0.9 \%$ & 9.1 & 4 & $1.1 \%$ & 10.7 \\
\hline NB & Through & 3 & $0.9 \%$ & 9.4 & 4 & $1.0 \%$ & 9.9 & 12 & $2.0 \%$ & 20.4 \\
\hline NB & Right & 10 & $4.9 \%$ & 48.7 & 13 & $3.9 \%$ & 39.0 & 5 & $1.6 \%$ & 15.8 \\
\hline SB & Left & 3 & $1.1 \%$ & 11.1 & 1 & $0.5 \%$ & 4.9 & 0 & $0 \%$ & 0.0 \\
\hline SB & Through & 3 & $0.8 \%$ & 4.5 & 1 & $0.4 \%$ & 3.8 & 8 & $2.1 \%$ & 20.5 \\
\hline SB & Right & 14 & $4.0 \%$ & 39.7 & 12 & $4.3 \%$ & 43.3 & 7 & $8.2 \%$ & 81.7 \\
\hline \multicolumn{11}{|c|}{ Oralabor Road \& State Street (Ankeny) } \\
\hline EB & Left & 5 & $2.7 \%$ & 26.7 & 2 & $1.9 \%$ & 19.0 & 1 & $0 \%$ & 3.4 \\
\hline EB & Through & 7 & $0.6 \%$ & 6.2 & 2 & $0.3 \%$ & 2.7 & 5 & $0.4 \%$ & 4.1 \\
\hline EB & Right & 30 & $5.5 \%$ & 54.5 & 27 & $14.2 \%$ & 142.1 & 21 & $8.2 \%$ & 82.0 \\
\hline NB & Left & 0 & $0 \%$ & 0.0 & 1 & $0.6 \%$ & 6.4 & 5 & $0.9 \%$ & 8.6 \\
\hline NB & Through & 2 & $0.5 \%$ & 5.0 & 1 & $33.0 \%$ & 3.3 & 6 & $0.5 \%$ & 4.9 \\
\hline NB & Right & 58 & $17.1 \%$ & 171.0 & 33 & $9.1 \%$ & 91.1 & 76 & $10.7 \%$ & 107.0 \\
\hline
\end{tabular}

\subsubsection{Analysis of Violations}

A generalized linear model using a Poisson distribution was used to determine the statistical significance of the differences among violations between the study locations with RLR cameras and the control intersections. The model was fitted using SAS GLIMMIX. The following variables were considered in the model:

- Camera: Presence or absence of camera at each approach (dummy variable, no camera $=0$ and presence of camera $=1$ )

- Approach: East, west, north, or southbound (eastbound =1, westbound = 2, northbound $=3$, southbound $=4$ )

- Posted Speed Limit: 30, 35, 40, 45, 50, or $55 \mathrm{mph}$

- Movement: Right, left, or through movements (left =1, through =2, right =3)

- Time: 7:00-9:00 a.m., 11:00 a.m.-1:00 p.m., and 4:00-6:00 p.m.

- Violations: number of red light violations for each peak hour period

- Volume: Traffic volume by movement for each peak hour period.

In some cases, more than one approach at an intersection was used. To differentiate a given observation made at one specific approach from another coming from a different approach, the variable "site" was created, with a total of 21 sites and 11 intersections. Considered as random effects, the variable "site" accounts for the correlation among observations made at the same site, while "intersection" accounts for the correlation among observations made at the same intersection. 
The specification of the final model is as follows:

$$
\begin{aligned}
& y_{i j} \sim \operatorname{Poisson}\left(\mu_{i j}\right) \\
& \mu_{i j}=\lambda_{i j} * \text { volume } \\
& \log \left(\lambda_{i j}\right)=\beta_{0}+\beta_{1} * \text { Camera }+\beta_{2} * \text { Movement }+\mathrm{b}_{1} * \text { Intersection }+\mathrm{b}_{2} * \text { Site }
\end{aligned}
$$

Where:

$y_{i j}$ is the number of violations at intersection $\mathrm{i}$, approach $\mathrm{j}$

$\mu_{i j}$ is the mean and variance at intersection $\mathrm{i}$, approach $\mathrm{j}$ adjusted by the volume at that specific site.

$\beta_{k}$ represents the fixed effects

$b_{l}$ represents the random effects

and

$$
b_{1} \sim N\left(0, \sigma_{b_{1}}^{2}\right) \text { and } b_{2} \sim N\left(0, \sigma_{b_{2}}^{2}\right)
$$

The final model resulted in two fixed variables: camera presence and movement. Statistical evidence indicates that both variables are significant (p-value<0.001) (Table 3.4).

\section{Table 3.4. F-test for fixed variables}

\begin{tabular}{lcc}
\hline Effect & F value & p-value \\
\hline Camera & 78.4 & $<0.0001$ \\
Movement & 412.35 & $<0.0001$ \\
\hline
\end{tabular}

The final model to estimate the expected mean for a given intersection approach is given by:

$\hat{\mu}_{i j}=\exp \left(\beta_{0}+\beta_{1} *\right.$ Camera $+\beta_{2} *$ Movement $) *$ volume

The parameter estimates are given in Table 3.5.

Table 3.5. Parameter estimates

\begin{tabular}{lccrllll}
\hline Effect & Camera & Movement & Estimate & Standard error & DF & t-value & Pr $>|t|$ \\
Intercept & & & -6.2870 & 0.3360 & 0 & -18.71 & \\
Camera & 0 & & 3.2223 & 0.3639 & 166 & 8.85 & $<.0001$ \\
Camera & 1 & 0 & & & & & \\
Left turn & & 1 & - & 0.0795 & 166 & -13.76 & $<.0001$ \\
& & 2 & -2.4370 & 0.0876 & 166 & -27.81 & $<.0001$ \\
Through & & 3 & 0 & & & & \\
Right turn & & & & & & & \\
\hline
\end{tabular}


The estimation for the intercept is -6.2870 with a standard error of 0.336 . Tables 3.5 and 3.6 show the estimations for the other fixed parameters, so if there is a right turn and a traffic volume of 200, the expected mean can be estimated as follows:

Results are in violations per peak period. The peak period includes two hours of data.

Case 1: Without camera

Violation Mean $=\mathrm{e}^{(-6.287+3.2223+0)} * 200=9.3336$

Case 2: With camera

Violation Mean $=\mathrm{e}^{(-6.287+0+0) * 200=0.3721}$

For a right turn and a peak period traffic volume of 200 vehicles, the expected number of RLR violations was 9.3 violations per peak period with no cameras in place while the expected number of violations per peak period was 0.37 when a RLR camera was in place.

The relationship between the number of violations and independent variables can be compared by dividing the expected number of violations for one set of circumstances by the expected number of violations under a slightly different set of circumstances. The ratio of the expected violations for a right turn with and without RLR cameras is equal to $\mathrm{e}^{(-6.287+3.2223+0)} \div \mathrm{e}^{(-6.287+0+0)}$ $=25.1$. Therefore, the expected number of RLR violations for a right turn movement when a camera is not present is 25 times the expected number of violations when a camera is in place. Similarly for through movements, the ratio of the expected number of violations with and without a RLR camera is

$$
\mathrm{e}^{(-6.287+3.2223-2.437)} \div \mathrm{e}^{(-6.287+0-2.437)}=25.1
$$

and for left turns is

$$
\mathrm{e}^{(-6.287+3.2223-1.094)} \div \mathrm{e}^{(-6.287+0-1.094)}=25.1
$$

Consequently, 25 times more violations are expected for all movements for approaches without RLR cameras as compared to approaches with RLR crashes.

Finally, to determine where differences among movements are significant, a least squares comparison has been provided in Table 3.6. The results suggest that the differences among the different types of movements are significant. However more data is necessary to confirm this finding. 
Table 3.6. Pairwise comparison: movement

\begin{tabular}{lcccc}
\hline \multicolumn{1}{c}{ Comparison } & Estimate & Std. Error & t-value & p-value \\
\hline Left - Through & 1.3429 & 0.1029 & 13.06 & $<0.0001$ \\
Left - Right & -1.094 & 0.07948 & -13.76 & $<0.0001$ \\
\hline
\end{tabular}

\subsection{Characteristics of RLR Violators in Clive}

Characteristics of RLR violations were also evaluated for Clive using data from the cameraenforced intersections. The Clive Police Department provided one day worth of RLR violation data from the camera system.

Violation data were partitioned by different features to illustrate common characteristics of red light running. Violations by day of the week are shown in Table 3.8. As shown, the largest number of violations occurred on Friday, followed by Tuesday.

Table 3.8. Violations by day of week

\begin{tabular}{lcc}
\hline Day & Violations & $\begin{array}{c}\text { Percentage of Total } \\
\text { Violations }\end{array}$ \\
\hline Monday & 1,262 & $14.8 \%$ \\
Tuesday & 1,333 & $15.6 \%$ \\
Wednesday & 1,255 & $14.7 \%$ \\
Thursday & 1,209 & $14.2 \%$ \\
Friday & 1,406 & $16.5 \%$ \\
Saturday & 1,115 & $13.1 \%$ \\
Sunday & 960 & $11.2 \%$ \\
Total & 8,540 & \\
\hline
\end{tabular}

The number of violations by turning movement is shown in Table 3.8. As indicated, the right turning movement had the highest number of violations each day of the week.

Data were also evaluated by time of day. Other studies have shown that RLR violations typically occurred during the morning and afternoon peak hours when drivers tended to run red lights (Porter and Berry, 1999). Violations by hour of the day are shown in Figure 3.31. As shown, the highest number of violations occurred between 4:00 and 5:00 p.m., and the second highest number was between 12:00 and 1:00 p.m. 


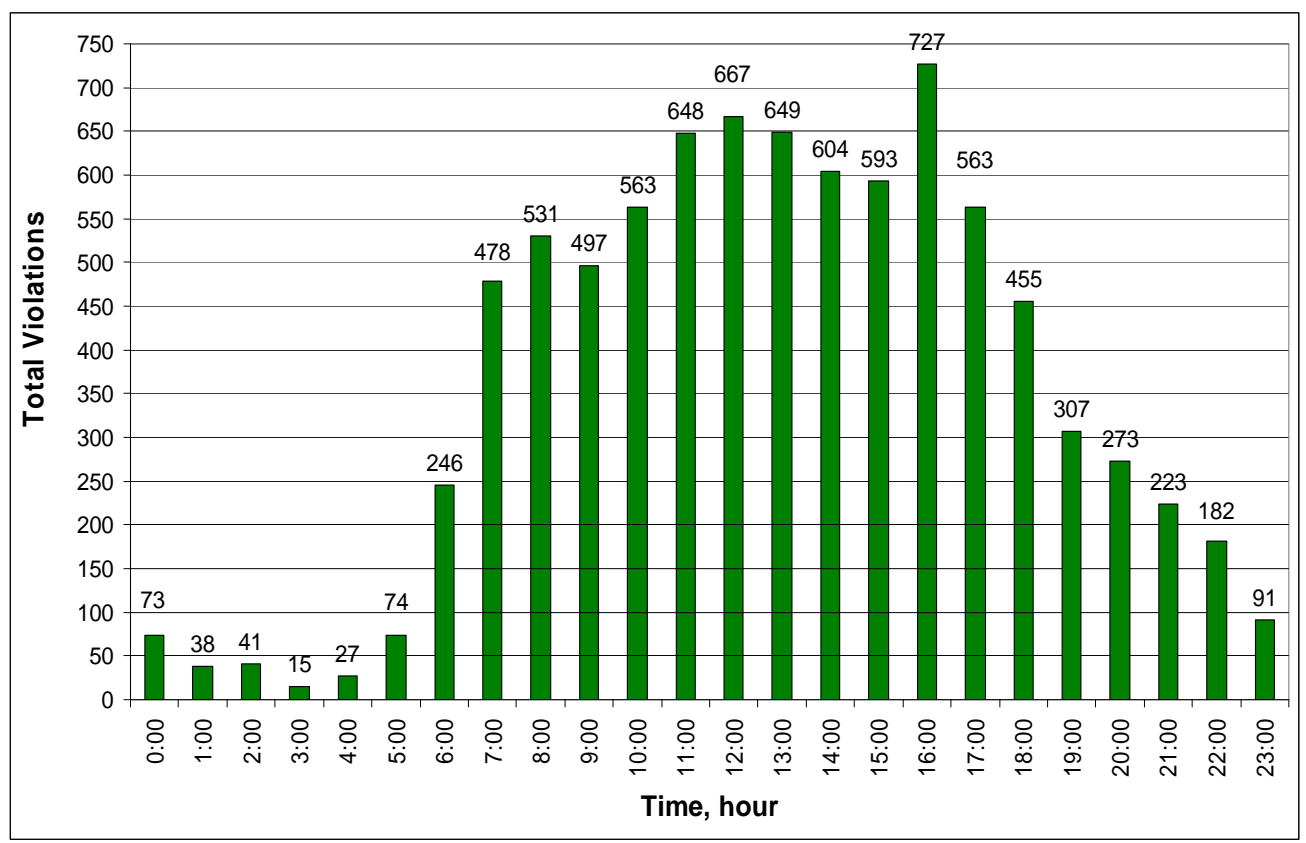

Figure 3.31. RLR violations by hour of the day

A measure to evaluate the potential severity of an RLR crash is by measuring how long after the onset of red a violating vehicle enters the intersection. The longer this time the greater the potential risk and severity (Cunningham and Hummer, 2004). The amount of time into the red interval that violators enter the intersection during red light running was also evaluated. The amount of time violators were entering the intersection after the red interval is shown in Figure 3.32 .

Presented in the following plots are data including the numbers of violations and their associated times into the red phase collected by Clive's automated RLR camera system over the entire enforcement period. Also shown are red lines indicating the city's preset all-red phase (or all-red clearance interval) for left and through/right turning movements. Many jurisdictions will include an optional all-red phase into intersection signal timing. This duration, which is usually around two seconds, is based on intersection geometrics, collision experience, pedestrian activity, approach speeds, local practices, and engineering judgment (Pline, 1999). Vehicles entering the intersection a second or less after the onset of the red phase may pose less of a hazard to serious crashes because of the perception, reaction, and start-up time of possible conflicting vehicles that are currently stopped at the intersection. Although red light running at any time following the onset of the red phase is a concern, a particularly alarming issue found at almost every intersection in Clive was the high number of violators entering the intersection after more than 2.1 seconds into the red phase. Illustrated in Figures 3.32 through 3.34 is the total number of violators for every movement at each intersection. Data were aggregated when greater than or equal to two seconds because this represented the typical all-red interval and this was the only way data were stored in the RLR system.

As noted in Figure 3.32, almost 23\% of left-turning drivers who ran the red light entered the intersection two or more seconds into the red. This percentage did not include vehicles that 
entered the intersection during the green permitted phase and then ended up completing the maneuver after the signal had changed. As shown, in Figure 3.33, over 10\% of through drivers who ran the red light did so two or more seconds into the red. Almost $78 \%$ of right-turning drivers who ran the red did so two or more seconds into the red, as shown in Figure 3.34. Vehicles that slowed significantly or stopped before making a right turn on red were not classified as red light runners.

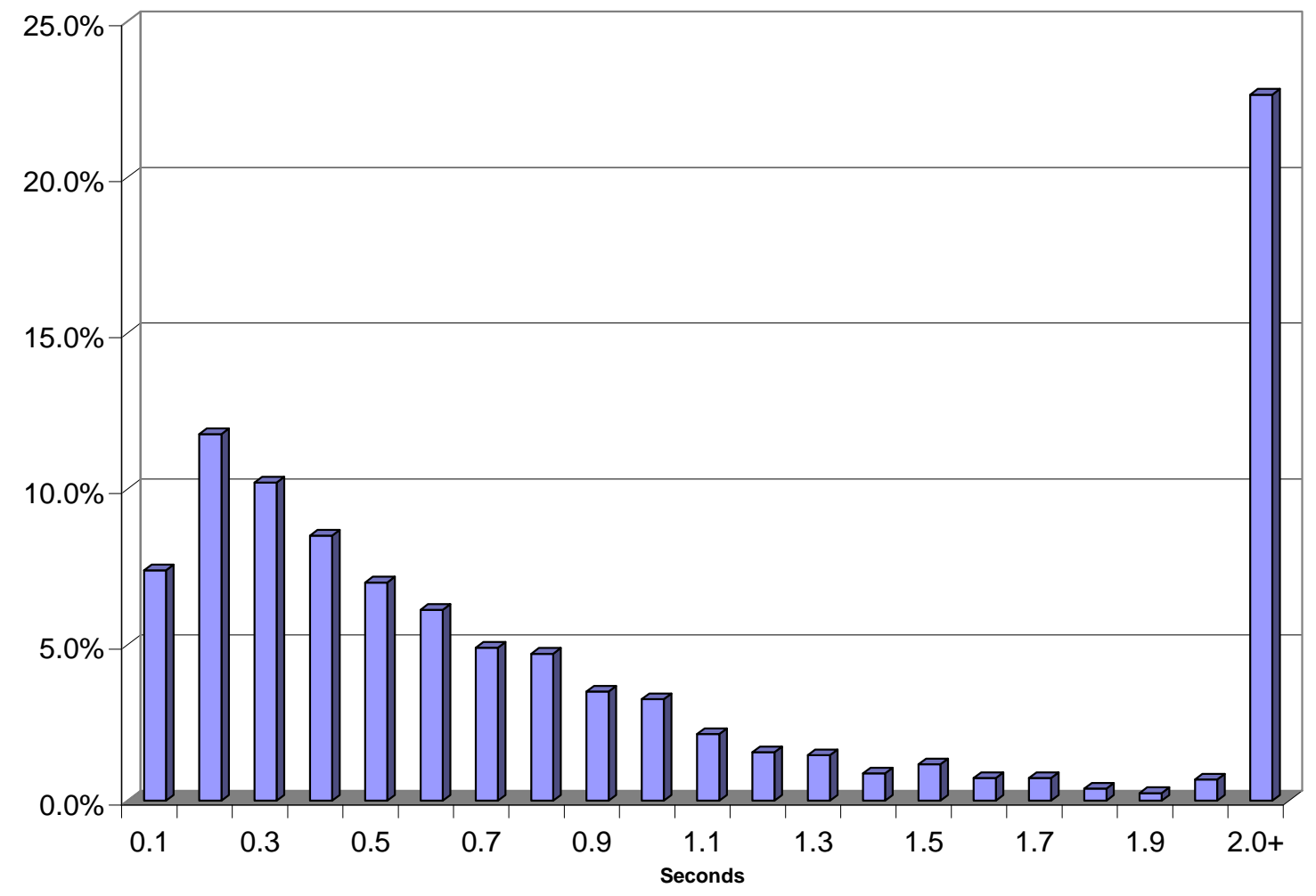

Figure 3.32. Distribution of time into red for left-turning vehicles 


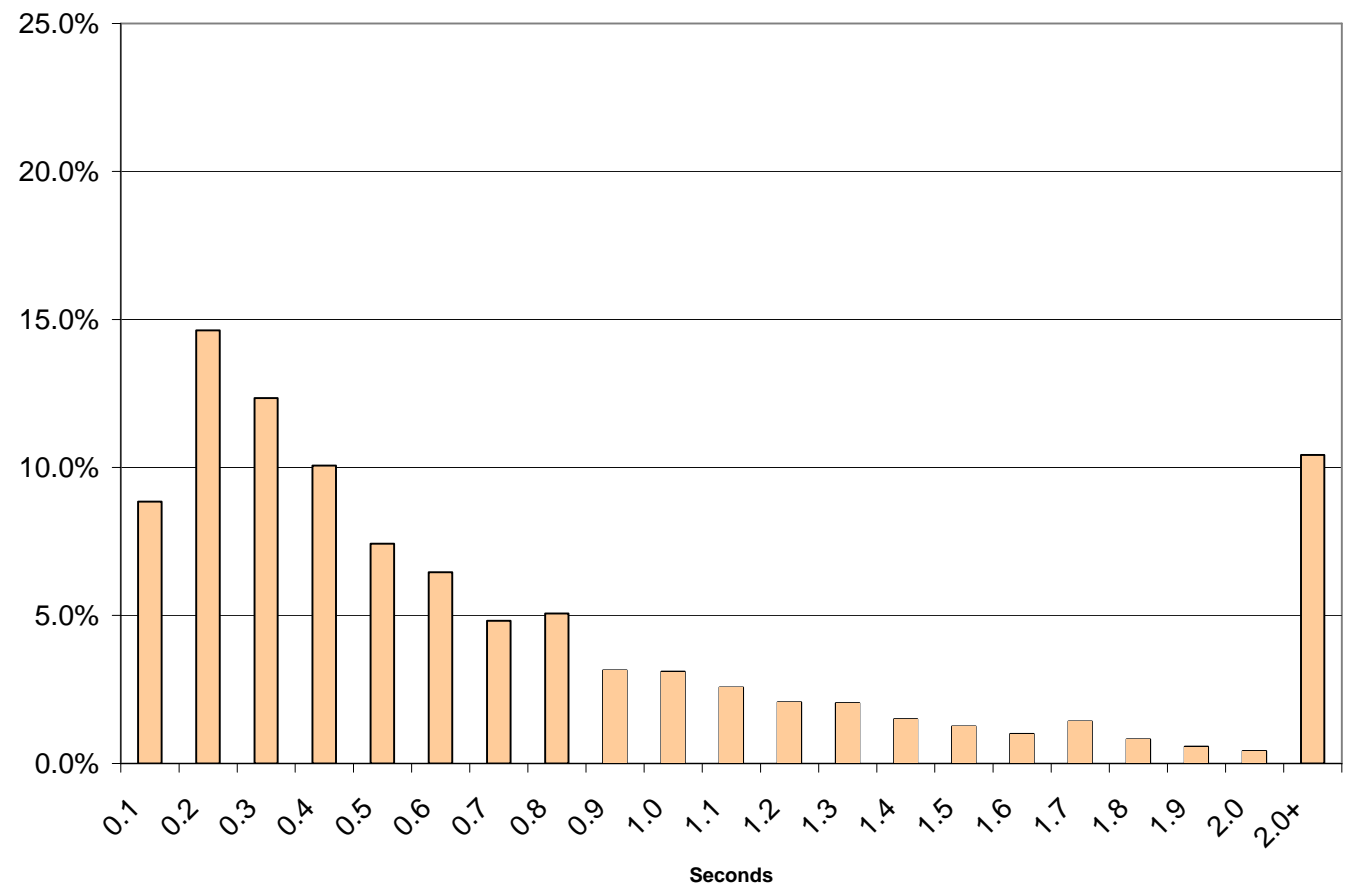

Figure 3.33. Distribution of time into red for through vehicles



Figure 3.34. Distribution of time into red for right-turning vehicles 


\subsection{SUMMARY OF THE RLR CAMERA PROGRAM IN COUNCIL BLUFFS, IA}

The following sections describe the RLR program in Council Bluffs. A crash analysis was conducted that evaluated the reduction in crashes for Council Bluffs and Davenport. A separate chapter describes the crash analysis for both communities.

\subsection{Background}

The city of Council Bluffs has a population of over 58,000 people. The city shares its borders with Omaha, Nebraska. On March 14, 2005, the city of Council Bluffs voted 3-to-1 for the required third time to consider an ordinance to change Chapter 9.16 of the Council Bluffs 2000 Municipal Code to add a section that explained automated enforcement, which includes photographic, video, and electronic cameras. On May 9, 2005, the Council Bluffs City Council authorized the mayor and city clerk to execute an agreement with for an automated RLR system. On October 10, 2005 a second ordinance to amend Chapter 9.16 of the 2000 Council Bluffs Municipal code was passed by a 3-to-1 vote that specified where the civil fines were to be paid. Unlike the cities of Davenport and Clive, Council Bluffs did not have the option for a vehicle's owner to nominate an offending driver if he or she were caught by the system while driving the registered owner's vehicle (i.e., limousine company, fleet vehicle, rental car, etc.).

The vendor initially studied 20 candidate intersections with high traffic volumes for automated enforcement. The city finally decided to install cameras at seven approaches at five intersections, which include the following:

- Willow Way, southbound approach, at 7th Street

- Kanesville Blvd., westbound approach, at 8th Street

- Kanesville Blvd., eastbound approach, at 8th Street

- Broadway, westbound approach, at 16th Street

- Broadway, eastbound approach, at 16th Street

- Broadway, westbound approach, at $21^{\text {st }}$ Street

- Broadway, eastbound approach, at 35th Street

Automated enforcement began on August 4th, 2005, with a 15-day warning period given to violators before regular ticketing began. Written notices were mailed to owners by the vendor and a large public campaign started. In general, the public appeared to support the new enforcement system. City officials also commented that the local media initially tried to highlight public disapproval, but once they realized the level of support the cameras were receiving, the media started to criticize the nearby city of Omaha, NE for not implementing a similar program. Advance "photo enforced" signs (Figure 4.1) were also installed prior to the intersection on each approach in which a camera system was installed. The automated enforcement system went online August 4th, 2005, at five signalized intersections, each with one or two approaches being monitored by cameras.

Control intersections were selected for use in the statistical analysis. Control intersections were selected that had similar traffic volumes and crashes as the camera-enforced intersections. Their 
locations are also illustrated in Figure 4.2. The control intersections selected for this study include the following.

- Broadway and $1^{\text {st }}$ Street

- Broadway and Kanesville Boulevard

- 35th Street and Nebraska Avenue

- 24th Street and 27th Avenue

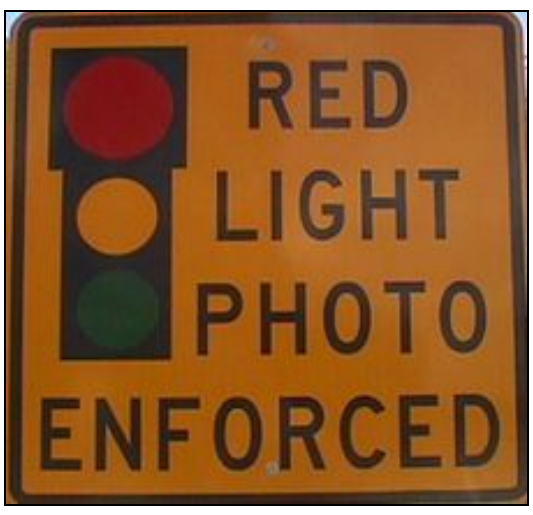

Figure 4.1. Advance warning signs 


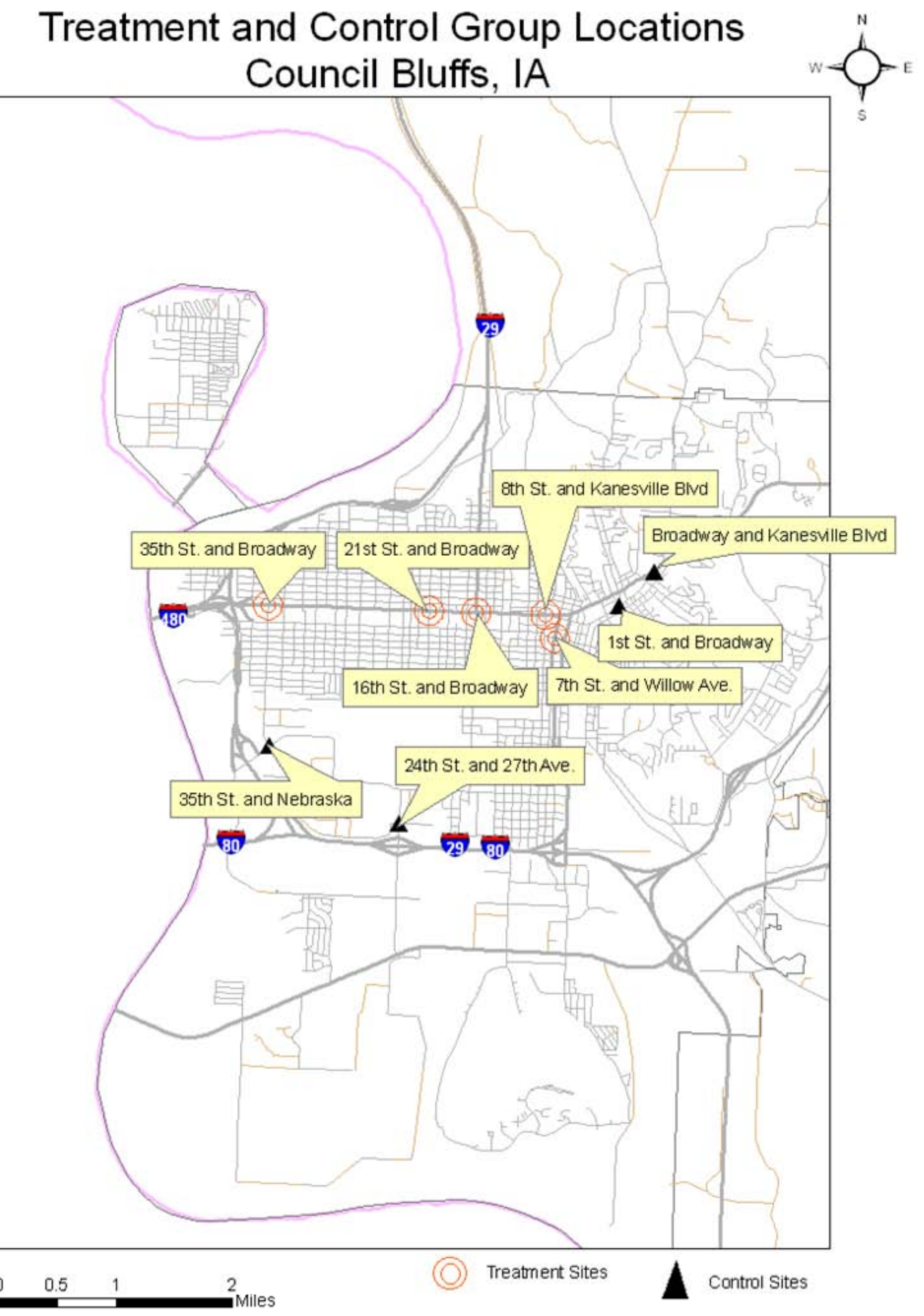

Figure 4.2. Location of camera-enforced and control intersections in Council Bluffs 
The camera system installed in Council Bluffs worked exactly the same as the Clive camera system, described in the previous section. The city considered a violation as a vehicle running a red light when it crossed into the intersection after the light had turned red, upon which three digital images were taken along with a 12-second digital video. Vehicles in the intersection, or waiting for a gap to make a safe turn, were not considered as running a red light. Under the city automated enforcement ordinance, a vehicle's driver who ran a red light, if sufficiently photographed and reviewed, would receive a civil infraction that would not be reported to the Iowa DOT. Similar to Clive, Council Bluffs set the cameras minimum threshold speed to $15 \mathrm{mph}$ with a 0.10 second amnesty period before the triggering sequence. Also, the RLR camera system did not pick up the free right turn on the westbound approach of Kanesville Boulevard and 8th Street. Council Bluffs had reported no vandalism to the camera system, but notes that there were many maintenance problems.

The city of Council Bluffs Police Department had not changed enforcement tactics, but overall had noticed a decrease in accidents citywide and a decrease in red light running at the enforced intersections. The vendor was able to access the Nebraska Department of Motor Vehicles (DMV) records in order to ticket Nebraska drivers, but at the time of this report did not have records from Missouri or South Dakota from which to identify violating vehicles from those states.

\subsection{Description of Sites}

Details about each of the selected intersections and approaches are shown in the following pages. Approach and aerial images were acquired from local GIS departments and field images were taken during data collection. At each intersection, it was noted what businesses were surrounding the area and if the pedestrian count were high. Other important information collected included peak hour volumes for each turning movement, signal timing for left turning and through movements, and whether a lane had a dedicated movement or if it shared a movement (e.g., a through and right turning movement for one lane would be specified as "shrd" in the table). The approach speed limit was also recorded as each approach had a different posted speed limit. The last aspect recorded was whether the intersection was actuated, free loops, pre-timed, or in coordination with nearby intersections.

Broadway (US 6) and 35th Street

The intersection of Broadway and 35th Street is located less than one mile east of Interstate 29 and is the first major intersection east of downtown Omaha, NE. Broadway and 35th Street is located in a heavily commercial area. On the northeast side of the intersection is Automart 150, and on the northwest side is Fleming Motor Company. On the southeast side of the intersection is a Sonic and to the southwest is an empty parcel of land. All four businesses have multiple access points on both 35th Street and Broadway. Characteristics are shown in Figures 4.3 and 4.4. 


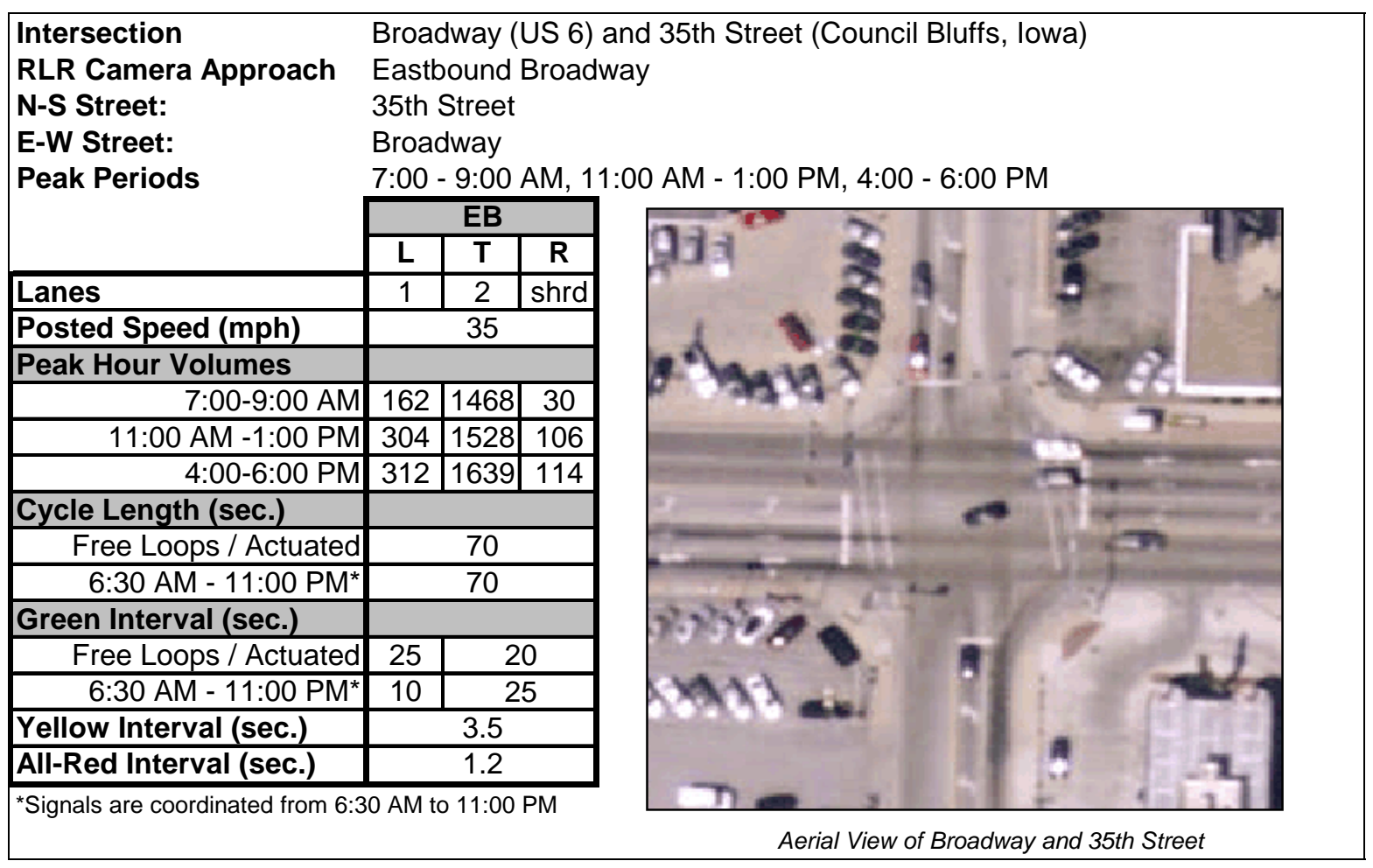

Figure 4.3. Roadway, traffic, and signal timing characteristics for Broadway and 35th St.

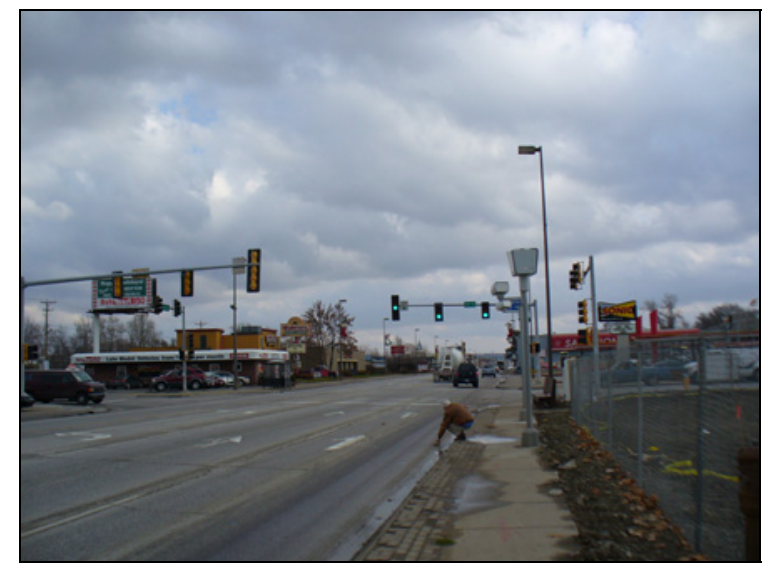

Figure 4.4. Eastbound traffic for Broadway and 35th St.

Broadway (US 6) and $21^{\text {st }}$ Street

Located one half-mile west of Broadway and 16th Street is the intersection of Broadway and 21st Street. This intersection is also surrounded by commercial developments including a building on the northeast side of the street with many small businesses. On the northwest side of the intersection is Glass Doctor. On the southwest side of the intersection is a large Tires Plus building, and finally on the southeast side of the intersection is Auto Connection. These businesses have multiple access points on both 21st Street and Broadway. Intersection characteristics are provided in Figures 4.5 and 4.6. 


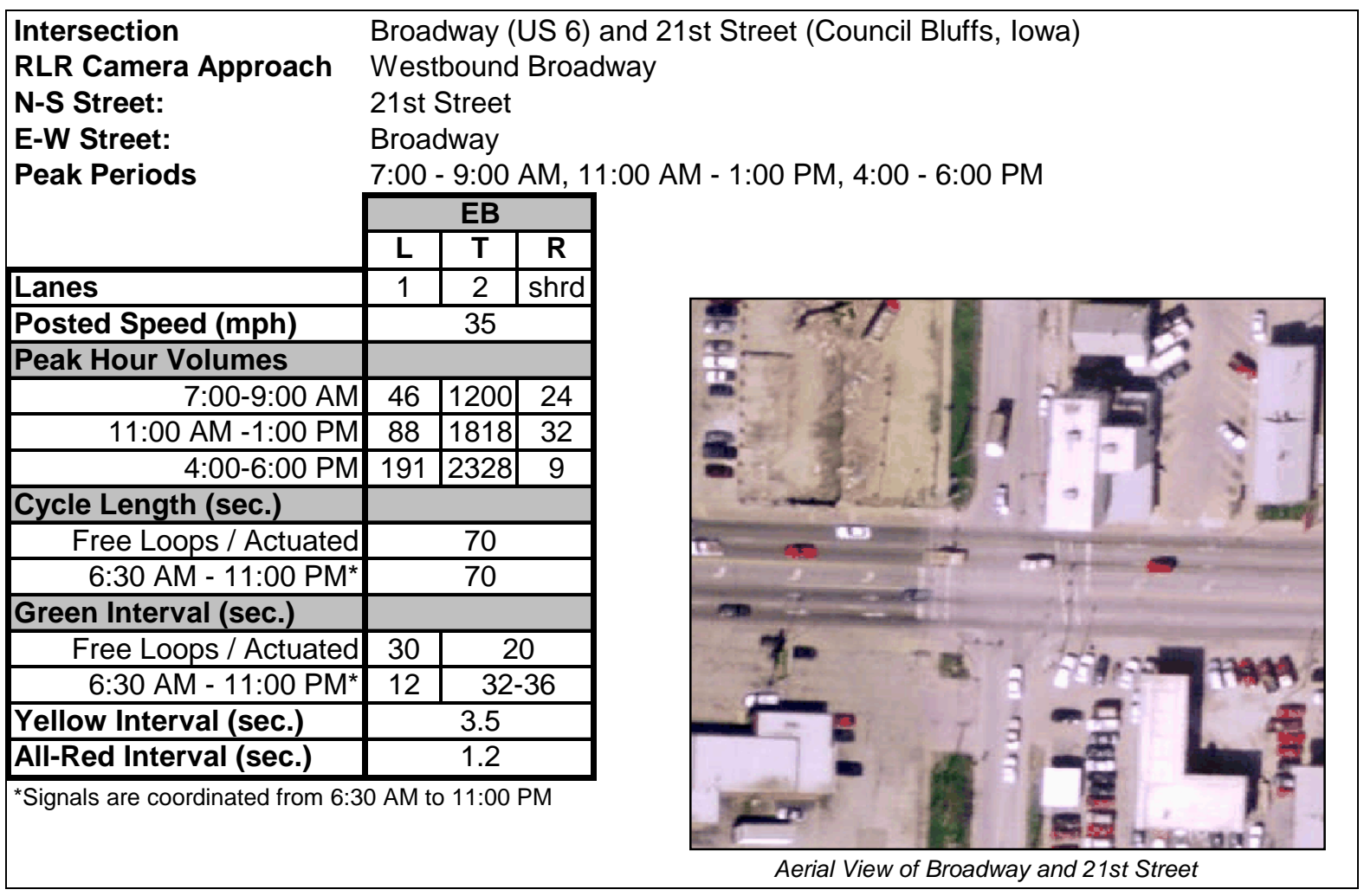

Figure 4.5. Roadway, traffic, and signal timing characteristics for Broadway and 21st St.

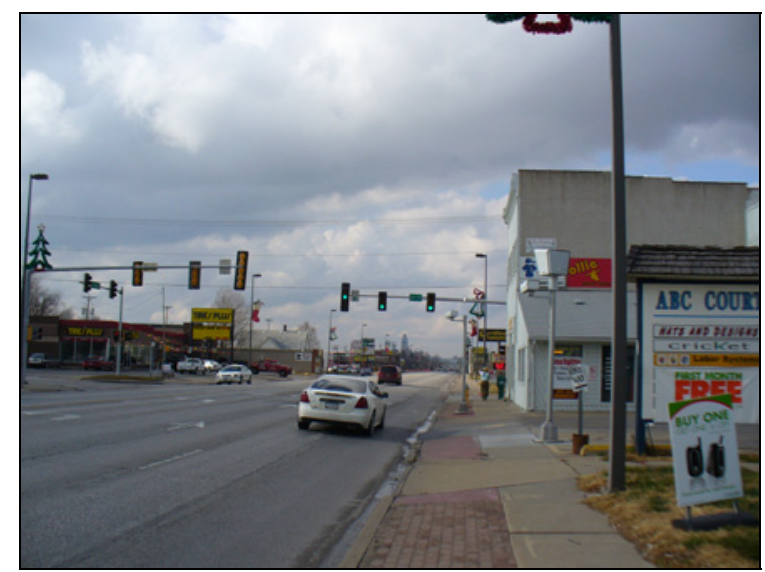

Figure 4.6. Westbound traffic for Broadway and $21^{\text {st }}$ St.

Broadway (US 6) and 16th Street

The intersection of Broadway and 16th Street is centrally located in Council Bluffs' commercial area located one half-mile west of the intersection of Kanesville Boulevard and 8th Street. Many commercial businesses surround this intersection with multiple access points on both roads. The north side of the intersection includes a British Petroleum gas station to the east and a Peoples National Bank to the west. The south side of the road includes two fast food establishments- 
Burger King and McDonalds — that have high turning volumes during the lunch peak hour. Intersection characteristics are shown in Figures 4.7 through 4.9.

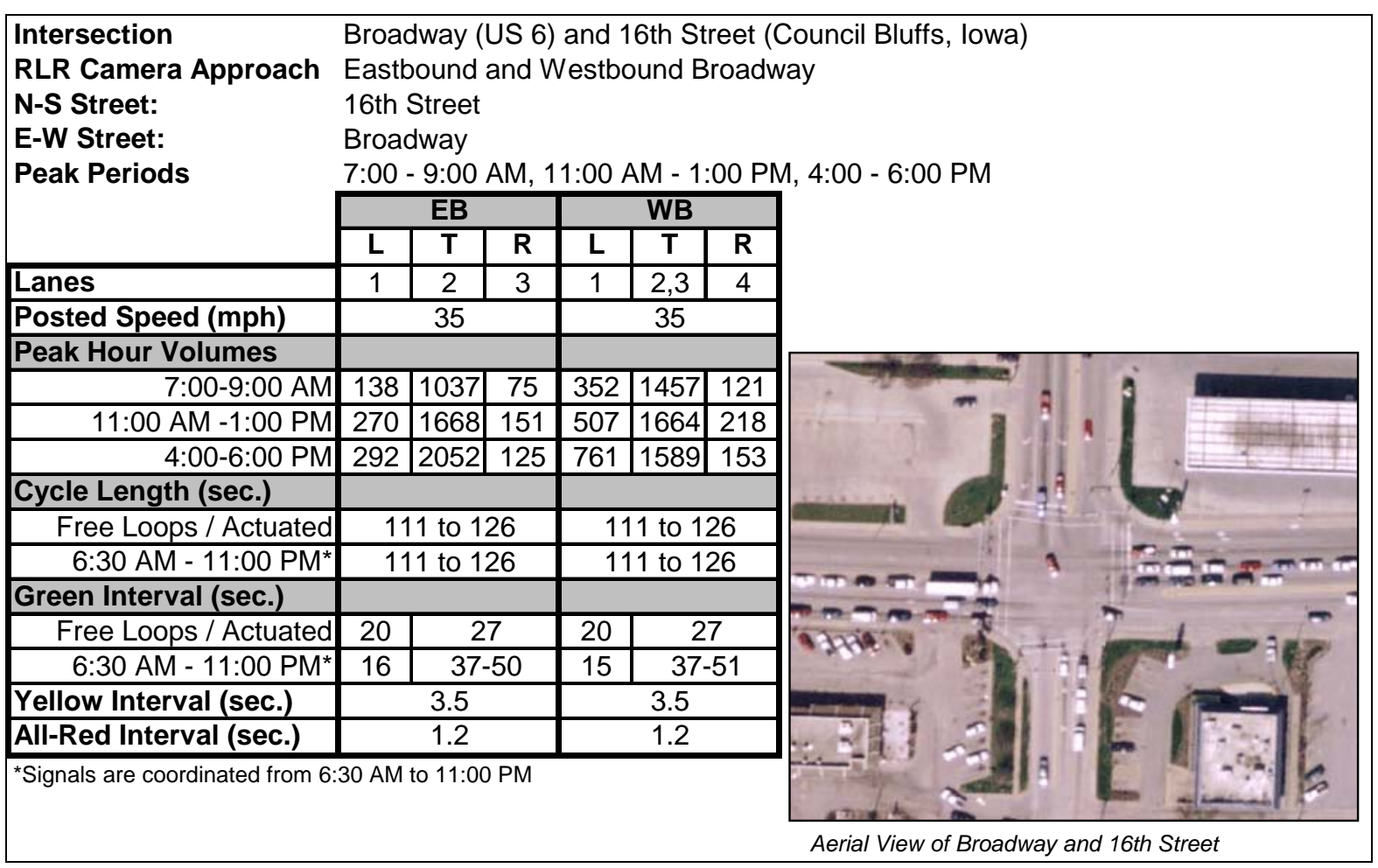

Figure 4.7. Roadway, traffic, and signal timing characteristics for Broadway and 16th St.

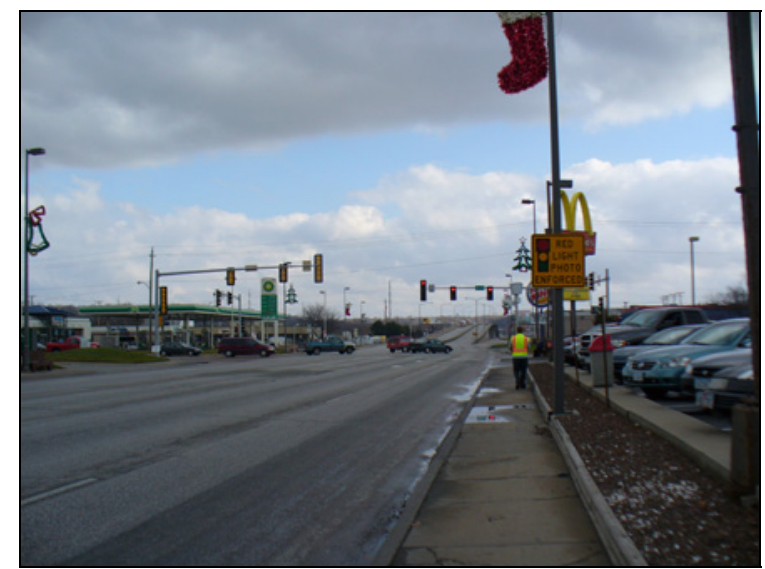

Figure 4.8. Eastbound traffic for Broadway and 16th St. 


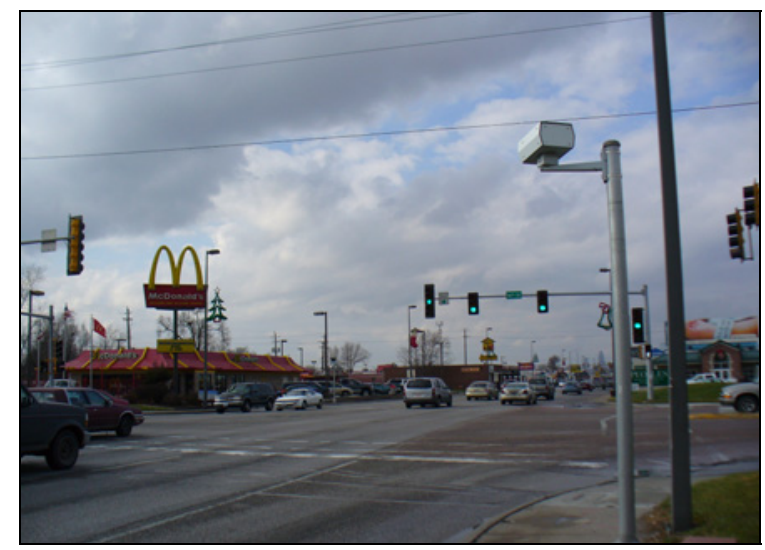

Figure 4.9. Westbound traffic for Broadway and 16th St.

Kanesville Boulevard \& 8th Street

Located on the east side of the Broadway commercial corridor, the intersection of Kanesville Boulevard and 8th Street is situated at the base of a bridge to the west and includes a free eastbound right turn that is not monitored by the camera system. The road divides on the east side of the intersection into Kanesville Boulevard to the north and Broadway continuing to the south. On the north side of the intersection is an open tract and private residences. On the southwest side of the intersection are Kelly's Furniture and Kelly's Carpet, with access points on 8th Street. On the southeast side of the intersection a commercial strip mall which includes Firestone, Ace Hardware, Hy-Vee, and Jensen Auto Care, with access points on both 8th Street and Broadway. Intersection characteristics are provided in Figures 4.10 through 4.12.

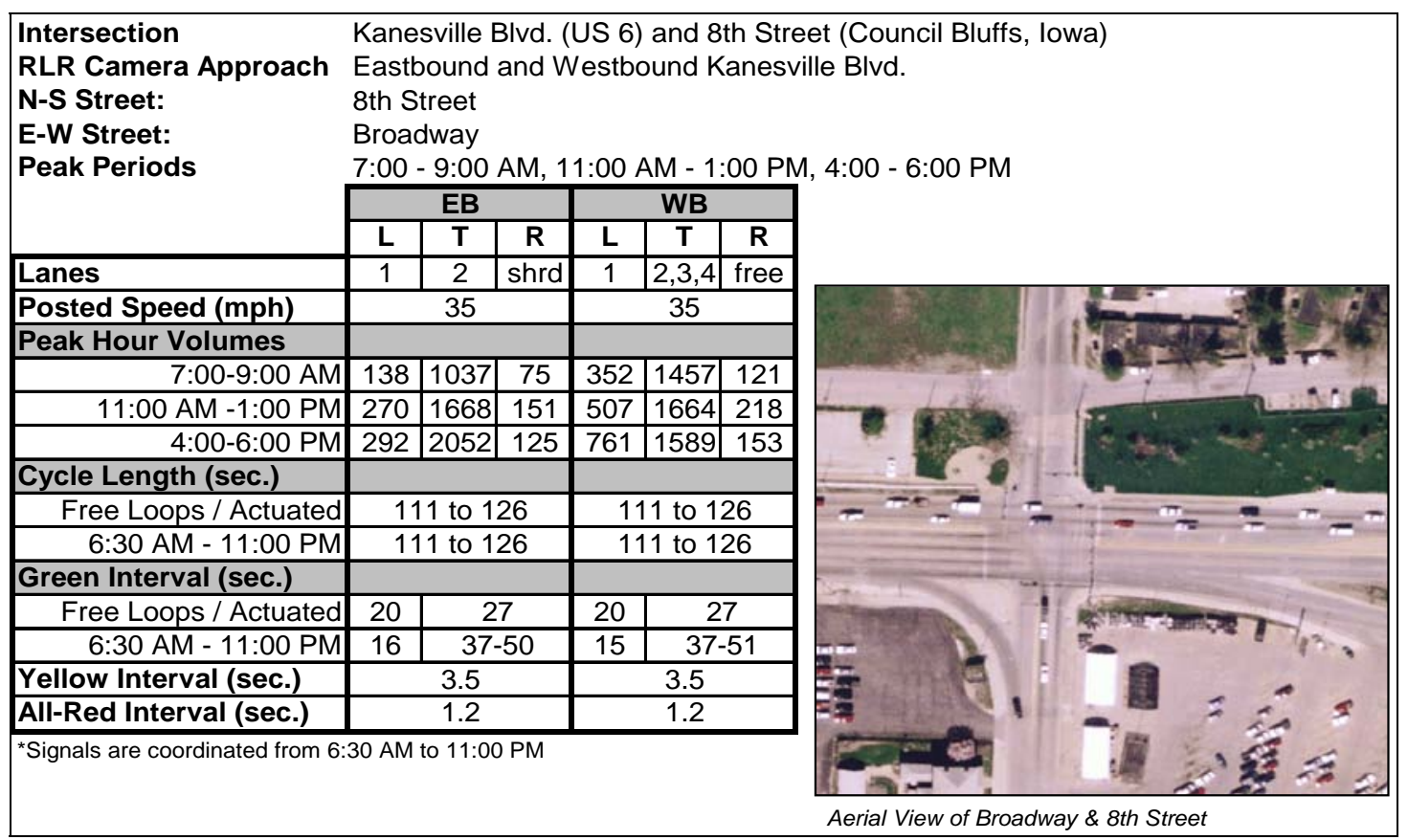

Figure 4.10. Roadway, traffic, and signal timing characteristics for Kanesville Blvd. and 8th St. 


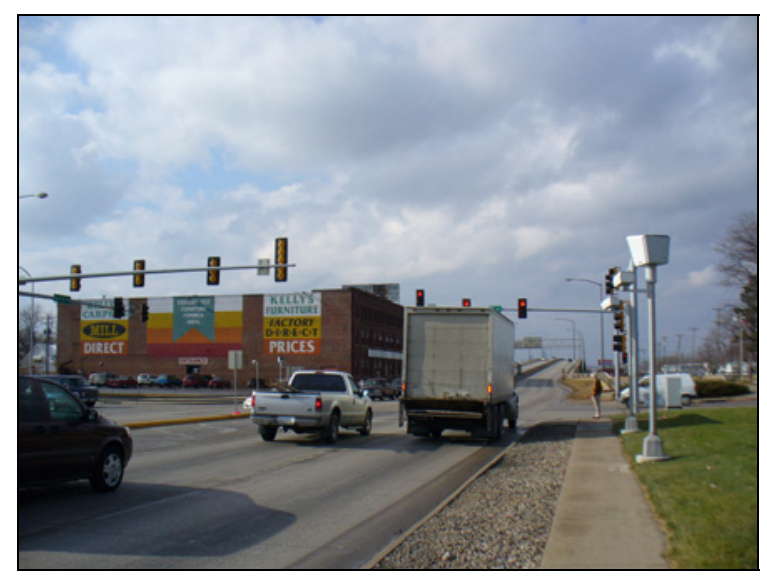

Figure 4.11. Eastbound traffic for Kanesville Blvd. and 8th St.

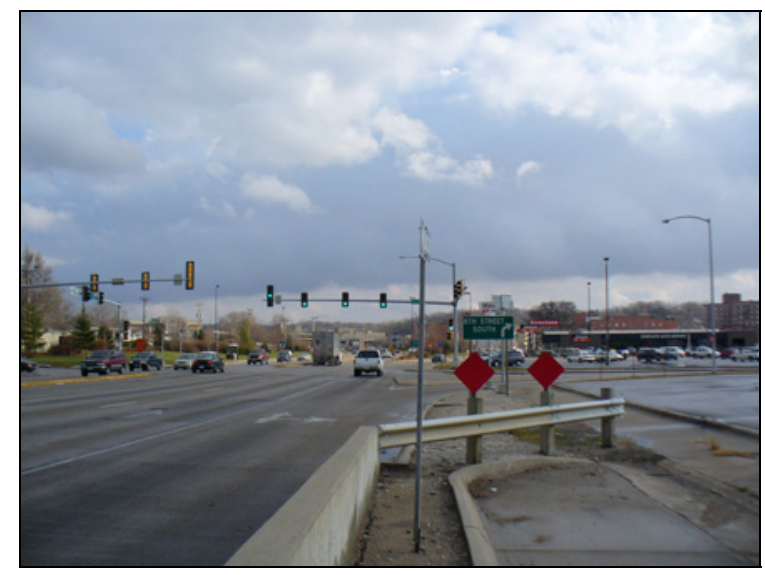

Figure 4.12. Westbound traffic for Kanesville Blvd. and 8th St.

7th Street (IA 192) \& Willow Avenue

Located southwest of Kanesville Boulevard and 8th Street is the residential intersection of 7th Street and Willow Avenue. This intersection, surrounded by many places of worship and educational institutions, is a one-way street intersecting a local arterial. On the southeast side of the intersection is St. John Lutheran Church; on the southwest side is Bloomer Elementary School. On the northwest side of the intersection is St. Francis Academy and on the northeast side is a local funeral home. All of these buildings surrounding the intersection have various access points and street parking on either 7th Street or Willow Avenue. The advance warning signs shown in Figure 4.1 are located at the beginning of the camera-enforced approach block. Intersection characteristics are shown in Figure 4.13-6-15. 


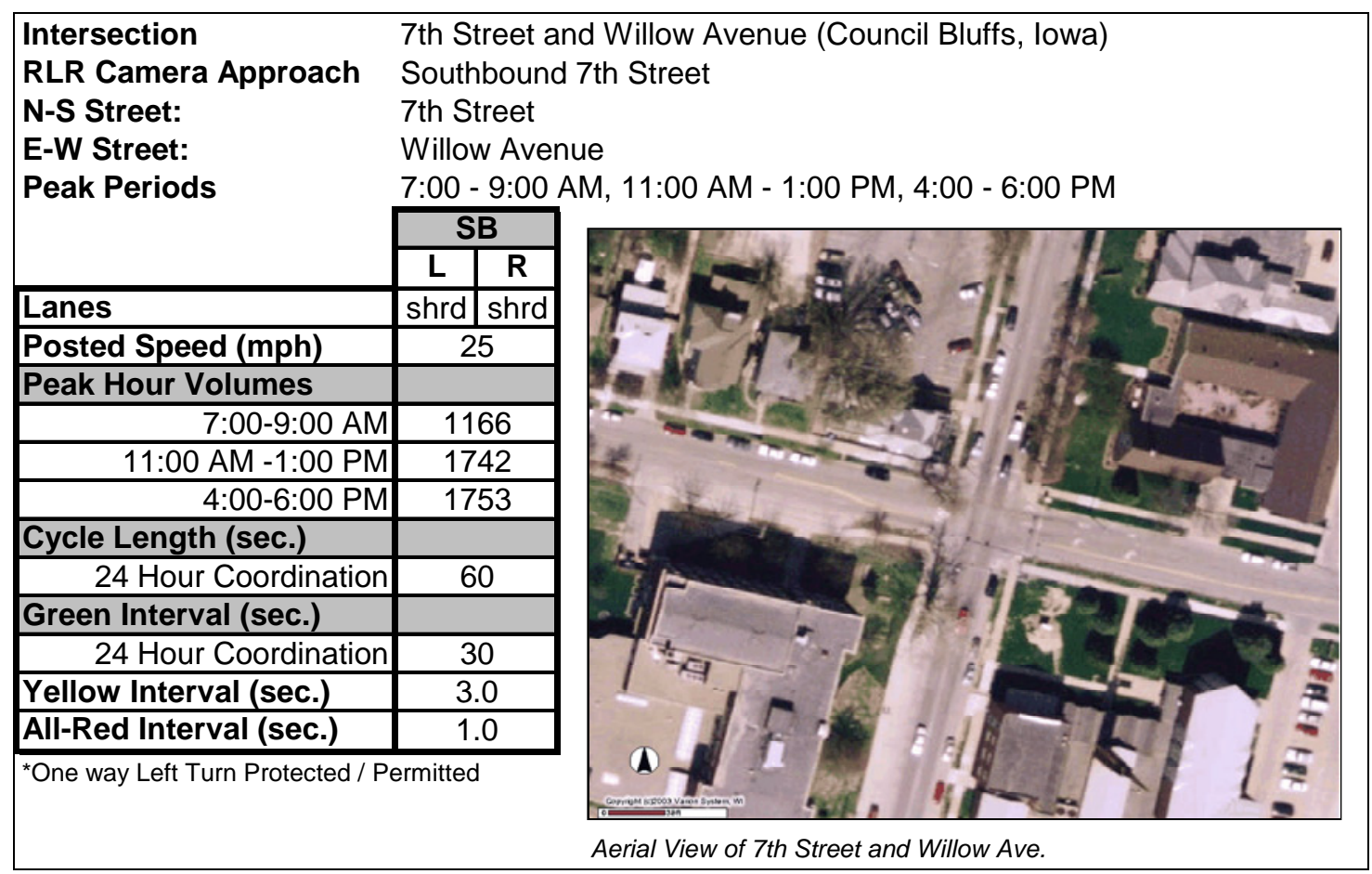

Figure 4.13. Roadway, traffic, and signal timing characteristics for 7th St. and Willow Ave.

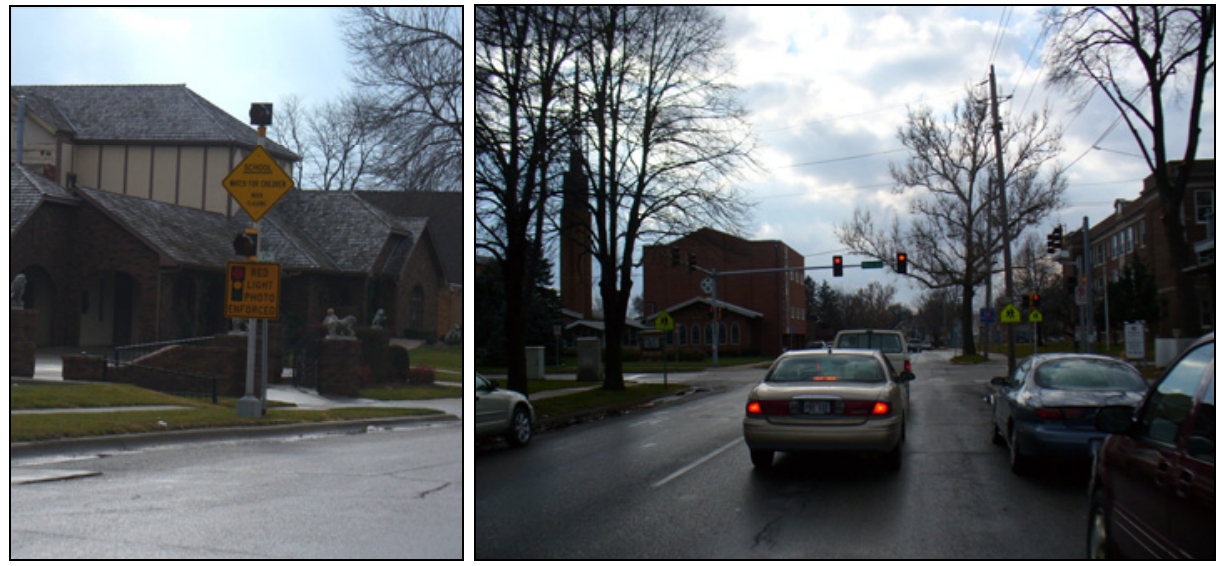

Figure 4.14. Southbound traffic for 7th St. \& Willow Ave. 


\subsection{SUMMARY OF THE RLR PROGRAM IN DAVENPORT, IA}

The following sections describe the RLR program in Davenport. A crash analysis was conducted that evaluated the reduction in crashes for Council Bluffs and Davenport. A separate chapter describes the crash analysis for both communities.

\subsection{Background}

The city of Davenport is part of the Iowa area known as "The Quad Cities," which is made up of Moline, IL, Rock Island, IL, Bettendorf, IA, and Davenport, IA, surrounding the Mississippi River. The population of Davenport is just under 100,000 residents.

On January $21^{\text {st }}$, 2004, the city of Davenport signed a beta test agreement with an automated enforcement company. The agreement was for the vendor to test its latest RLR camera technology in Davenport. Prior to signing the agreement, the Davenport City Engineering Office, along with the Traffic Enforcement Department of the Davenport Police Department, studied intersections for possible automated enforcement based on the total number of crashes. Most of the high-crash intersections were ultimately selected for camera enforcement, although a few were not because of planned construction or other constraints that would not allow an automated enforcement system.

The city of Davenport signed the terms and agreement to start an automated enforcement program after extensive signal progression and engineering countermeasures failed to lower the number of red light runners at high-volume intersections. As stated in the terms of agreement, the city believed an automated enforcement system would benefit the public's health, safety, and welfare, and help reduce potentially dangerous crashes.

In 2004, the Davenport City Code section on traffic control devices was amended to add Section 10.16.070, which specified city ordinances 2004-35 and 2005-361 on automated RLR and speed enforcement. One key element to this section was that the violating driver did not have the opportunity to nominate the driver of the vehicle, and the vehicle's registered owner would receive the $\$ 65$ civil fine.

The city also established an automated speed enforcement program with a different vendor in 2005 to capture drivers exceeding the posted speed limit by $10 \mathrm{mph}$ on major roads throughout the city. Unlike a fixed fine schedule with RLR violations, the civil speeding ticket was based on a tier system ranging from $\$ 5$ to $\$ 120$ based on the number of miles per hour over the speed limit. The city of Davenport also had one mobile speed van that was deployed in strategic places throughout the city where automated enforcement could not be placed. The automated speed enforcement program is not described in this document, however. 
Davenport's terms of agreement were much different than Clive's and Council Bluff's, and included the following stipulations:

- A camera system may be added or subtracted from a location after one year of operation

- The city of Davenport agrees to pay the vendor a fee for installation, operation, and maintenance by one of two payment plans, as specified by the vendor

- The city of Davenport agrees to enter into a five-year contract with the vendor that can be dissolved if automated enforcement is no longer legally enforceable by state law or if legislation or court decisions make it reasonably impossible to operate the system. The entire RLR program will end 30 days after the city notifies the company of the changes in law.

- Every year on the anniversary of the original contract, the city shall review the effectiveness of the RLR system and have the option to terminate the program at the vendor's expense. Furthermore, each year the city may elect to switch payment plans as described later in this section.

- The vendor shall keep the premises around the camera systems clean and free from debris. If necessary, the city may clean the area and may deduct expenses from the monthly fee owed to the vendor.

The RLR camera system began on August 25th, 2004, at the intersections of 4th Street and Division Street and 35th Street and southbound Harrison Street. The second installation occurred during the months of September and October 2004 at the following intersection approaches:

- Brady Street, northbound approach, at Kimberly Road

- Elmore Street, eastbound approach, at Kimberly Road

- Elmore Street, westbound approach, at Kimberly Road

- Welcome Way, southbound approach, at Kimberly Road

Unlike the camera systems in Council Bluffs and Clive, individual lanes were monitored by a single video camera and flash, as shown in Figure 5.1. Advance warning signs with orange flags alerted approaching vehicles of automated enforcement. Video was constantly dumped by the computer system until a violating vehicle's speed was detected by inductive loops (or the video detection system), triggering the video capturing sequence. There was no grace time built into the system and no approaching vehicle threshold speed to give the benefit of doubt to the driver. Short videos that were captured were transmitted to the vendor via a dedicated T1 phone line and were processed and filtered before sending images back to the Davenport Police Department for approval. Once a police officer had reviewed the video and license plate photo, approved violations were sent back to the vendor and mailed to the owner of the vehicle. Unlike Clive, Davenport did not have a driver nomination ordinance to ticket the drivers of the registered vehicle. 


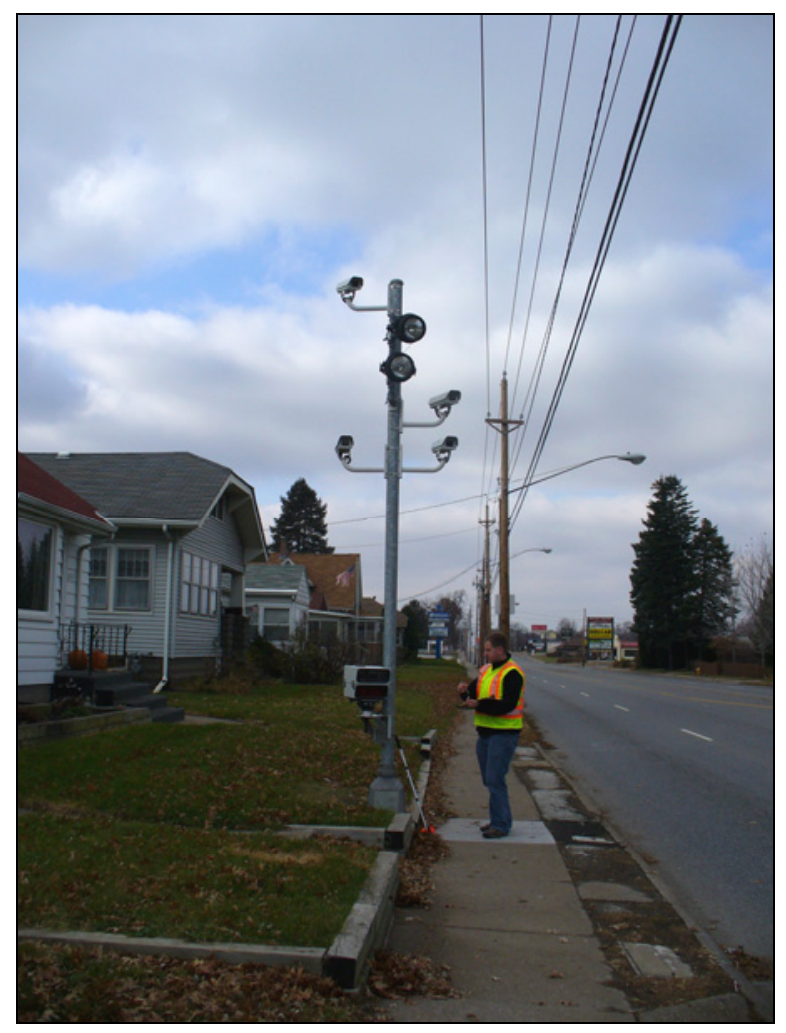

Figure 5.1. Davenport RLR and automated speed camera system.

\subsection{Selection of Sites}

On September 1st, 2005, the city of Davenport signed a memorandum of understanding with a different vendor that took over the existing RLR operations. Prior to this time, the new vendor already had a contract with Davenport to use automated LIDAR technology speed enforcement at the intersections with RLR cameras. The memorandum of understanding signed by city officials with the new vendor included the same terms of agreement made with the original vendor. With a new contract in place, the fee to the new vendor changed from the original \$32 to \$24 per violation, with the city receiving \$41 per violation. Between January and February 2006, the new vendor switched out the old system for the new system, which resulted in significantly fewer violations being recorded during those two months.

In June 2006, one set of cameras was moved from 4th Street and Division Street to Lincoln Avenue and Locust Street because no significant decreases in crashes had occurred. In addition to the equipment move, the city of Davenport requested approval from the Iowa DOT to add east- and westbound enforcement at Kimberly Road and Brady Street, which was approved January 23rd, 2006. RLR cameras were installed at the following locations:

- Brady Street, northbound approach, at Kimberly Road

- Brady Street, eastbound approach, at Kimberly Road

- Brady Street, westbound approach, at Kimberly Road

- Elmore Avenue, eastbound approach, at Kimberly Road 
- Elmore Avenue, westbound approach, at Kimberly Road

- Welcome Way, southbound approach, at Kimberly Road

- North Harrison Street, southbound approach, at West 35th Street

- Locust Street, eastbound approach, at North Lincoln Avenue

- Locust Street, westbound approach, at North Lincoln Avenue

The analysis in crash reduction included:

- Kimberly and Brady (had one approach with a camera since 2004, two approaches added in 2006)

- Kimberly and Welcome Way (no change since 2004)

- 35th and Harrison (no change since 2004)

- Kimberly and Elmore (no change since 2004)

The intersection of Locust Street and Lincoln Avenue was not included because cameras were not installed until 2006. Cameras were removed from 4th Street and Division Street in 2006, so that intersection was not included either because it had a short after analysis.

Control intersections were also selected for use in the statistical analysis. Control intersections were selected because they had similar volumes, similar crash frequencies, and similar roadway locations to RLR camera intersections. The location of both the control and RLR cameras is shown in Figure 5.2. Control intersections included:

- Pine Street and Kimberly Road

- 53rd Street and Elmore Avenue

- Locust Street and Brady Street

- Locust Street and Hickory Grove

- North Division Street and Central Park Avenue 


\section{Treatment and Control Group Locations - Davenport, IA}

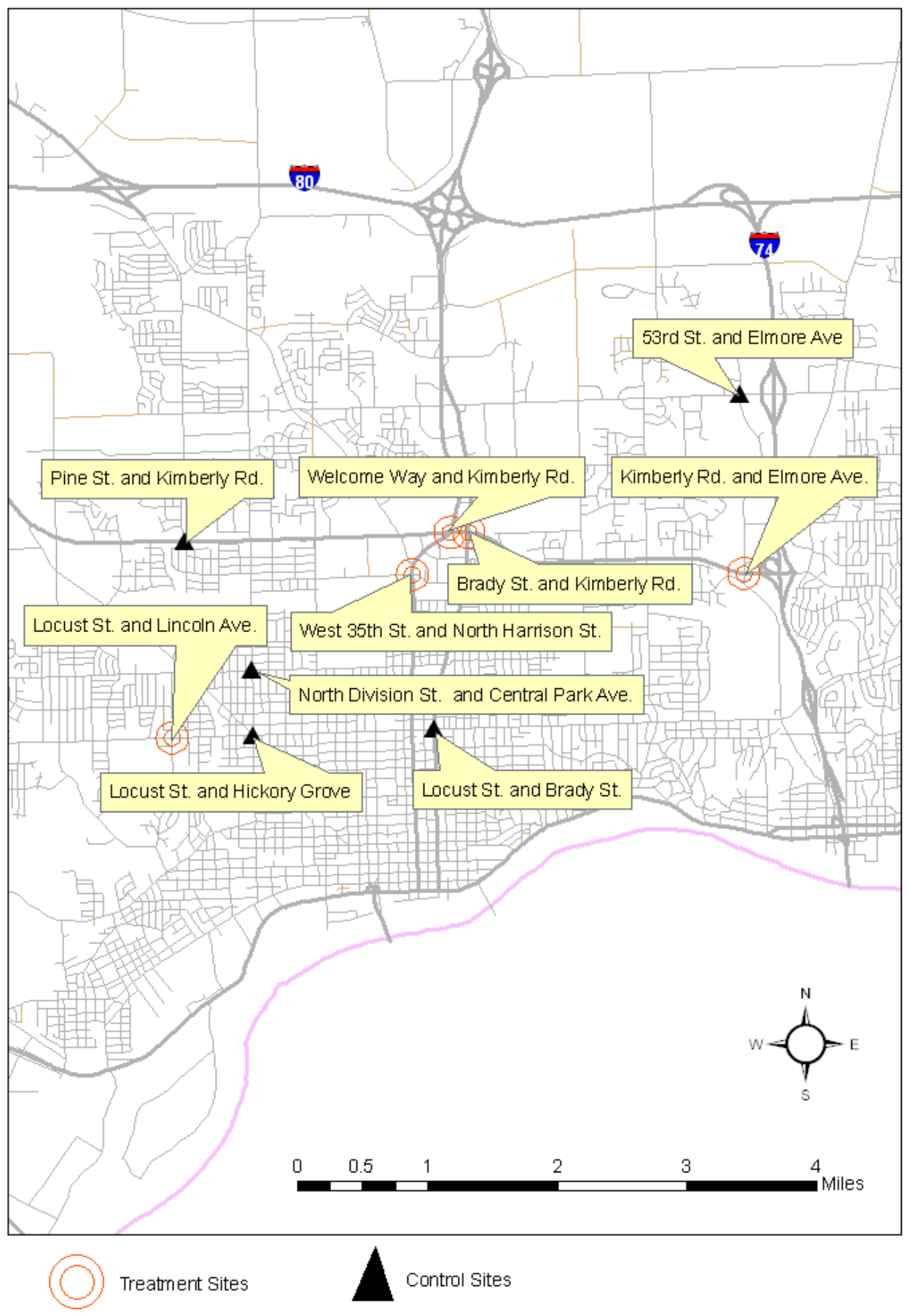

Figure 5.2. Camera-enforced and control intersections in Davenport 


\subsection{Legal Proceedings}

Davenport's automated enforcement systems came under scrutiny twice since enforcement began in 2004. The first lawsuit against the city came when Thomas Seymour disputed the constitutionality behind automated enforcement. The American Civil Liberties Union (ACLU) of Iowa backed Seymour's dispute as a test case that argued the constitutionality of the camera system and how the cameras unfairly put a burden of proof of innocence on those who were captured by the cameras. On July 18th, 2006, Scott County Magistrate Kyle Williamson denied the motion to dismiss the charges against Seymour and ordered him to pay the \$125 ticket he had incurred. Furthermore, Magistrate Williamson cited in his ruling that such automated speed enforcement was not illegal under the Iowa Constitution. The Iowa Supreme Court accepted the appeal by the ACLU on behalf of Seymour, and will hear the case in 2008.

On October 17th, 2006, Monique Rhoden and Curt Canfield challenged the automated enforcement system when Rhoden's 2000 Cadillac was ticketed by the automated speed enforcement camera system as traveling $46 \mathrm{mph}$ in a posted $35 \mathrm{mph}$ zone. District Court Judge Gary McKenrick heard arguments against the system where the plaintiff argued that Section 10.16.070 of the Davenport Municipal Code violated established provisions of Chapter 321 of the Iowa Code (2006). The plaintiff also asserted that the same section of the Davenport Municipal Code was an illegal tax or revenue generator. District Court Judge McKenrick cited that municipal infractions are authorized under Section 364.22(2) of the Iowa Code (2005): an ordinance established by the city may provide that a violation of this ordinance is a municipal infraction and may not exceed \$1,000 as stated by Section 364.22(1) of the Iowa Code (2005). Judge McKenrick found that the city was not illegally collecting fines or taxes because Section 463.22(1) of the Iowa Code (2005) authorized it. Chapter 321 of the Iowa Code explained that disobedience of a traffic control device or speeding was considered a state scheduled violation that was accompanied by a scheduled fine (Sections 805.8(1), 805.8A(5), and 805.8A(8) of the Iowa Code (2005)). Thus, Judge McKenrick stated that Davenport did not follow the Iowa Code by having a separate automated enforcement schedule that differed from state scheduled violation fines.

Davenport Municipal Code Section 10.16.070 stated that citations would not be sent to the Iowa DOT and would not be added to the violator's driving record. McKenrick noted that this violated Section 321.491 of the Iowa Code (2005) that required a person who was charged with a violation to be reported to the DOT within 10 days of conviction.

Responding to the ruling on January 2nd, 2007, the city of Davenport's corporate attorney, Mary Thee, proposed three paths the city could take with the district court ruling. The first path included an appeal to the ruling in front of Scott County District Court or Iowa Supreme Court; the second path involved the city council weakening the ordinance to comply with Chapter 321 of the Iowa Code; and the third path was to heavily lobby state legislators. The appeal process for this ruling is expected to take 12 to 18 months.

Starting in late January 2007, the city alderman decided to take on all three described paths, even with the court ruling setback. The city of Davenport planned to appeal to the Iowa Supreme Court in January 2008 while modifying the ordinance and readjusting its fine structure. The 
recommended proposed fine change would drop an automated RLR enforcement from \$65 to $\$ 35$ and would be reported to the Iowa DOT. Passed with a vote of 7-to-3 on January 24th, 2007, the city ordinance was changed. The cameras continued to capture violators and ticket drivers until March $31^{\text {st }}$, 2007, when both the automated speeding and RLR cameras were put on hiatus by the city until the various lawsuits could be settled.

On April 20th, 2007, Scott County Judge Gary McKenrick ruled the lawsuits to stop Davenport's [speeding and RLR] cameras could become a class action case where refunds would be awarded to drivers caught speeding or running a red light, which could cost the city millions of dollars. Judge McKenrick wrote in his ruling that "[automated enforcement fines were] illegal exaction, unjust enrichment and restitution.” On May 4th, 2007, the city of Davenport hired Attorney Craig Levien of Betty, Neuman, and McMahon of Davenport to appeal the court ruling in front of the Iowa Supreme Court, which agreed to here the case in January 2008. The city of Davenport is heavily lobbying both Iowa House and Senate transportation standing committee to pass automated enforcement legislation to continue RLR and speed camera enforcement.

\subsection{Site Description}

Details about each of the selected intersections and approaches are shown in the following pages. At each intersection, it was noted what businesses were surrounding the area and if pedestrian counts were high. Other important information collected included peak hour volumes for each turning movement, signal timing for left turning and through movements, and if a lane had a dedicated movement or shared a movement (e.g., a through and right turning movement for one lane, which would be specified as "shrd" in the table). The approach speed limit was also recorded as each approach had a different posted speed limit. The last aspect recorded was whether the intersection was actuated, free loops, pre-timed, or in coordination with nearby intersections.

\section{Kimberly Road \& Brady Street}

Considered one of Davenport's busiest downtown intersections, the intersection of Kimberly Road and Brady Street is unique in that Brady Street is a one-way street traveling north that eventually meets Interstate 80 . The intersection is surrounded by many businesses and restaurants including Toys ' $\mathrm{R}$ ' Us on the northwest side, a British Petroleum station on the northeast side, a small commercial development on the southeast side, and the popular restaurant Los Agaves Mexican Grill on the southwest. Although Brady Street has a wide cross section and many access points, coordination between signals located to the north and south are timed quite well, helping control congestion. Kimberly Road is one of many busy east-west corridors in Davenport and carries a heavy volume of traffic in both directions. Intersection characteristics are shown in Figures 5.3 through 5.7. 


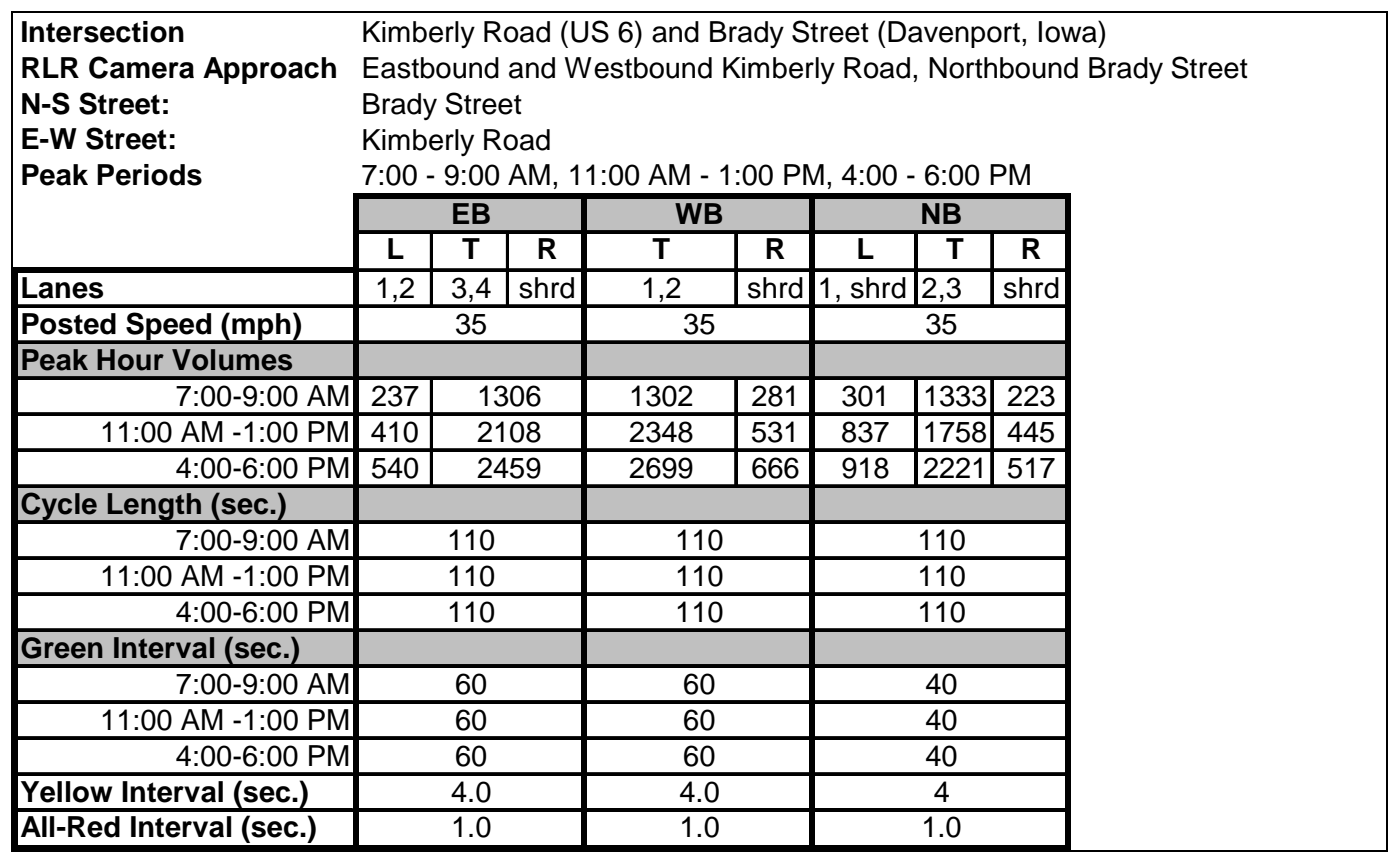

Figure 5.3. Roadway, traffic, and signal timing characteristics for Kimberly Rd. and Brady St.

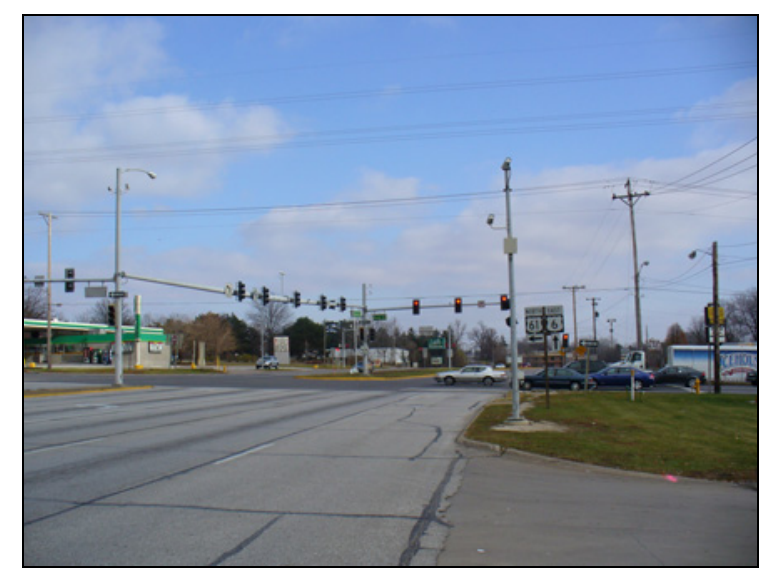

Figure 5.4. Eastbound traffic for Kimberly Rd. and Brady St. 


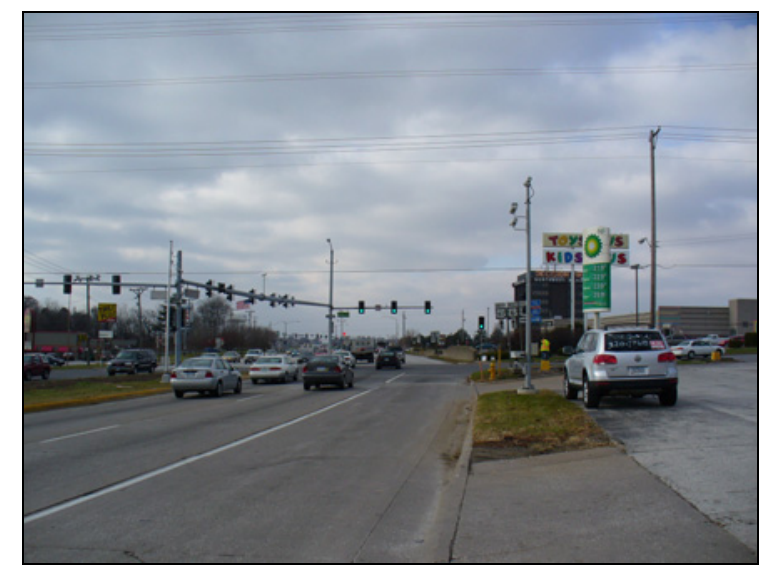

Figure 5.5. Westbound traffic for Kimberly Rd. and Brady St.

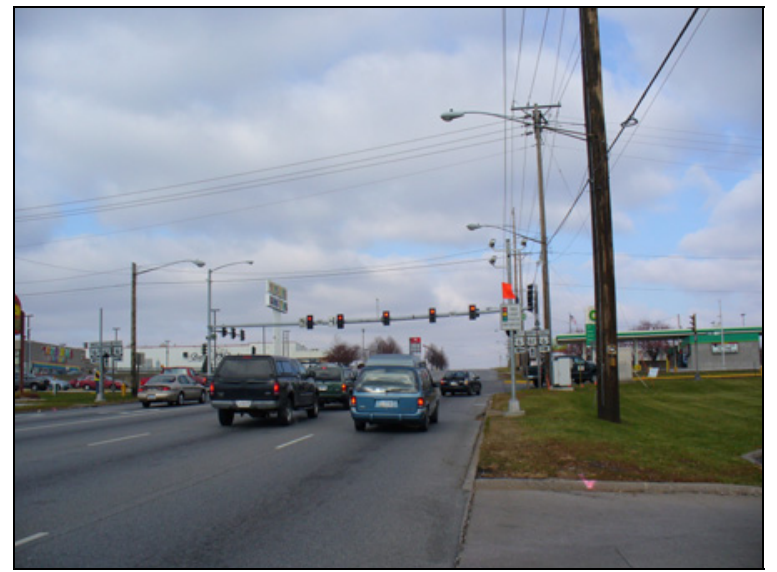

Figure 5.6. Northbound traffic for Kimberly Rd. and Brady St.

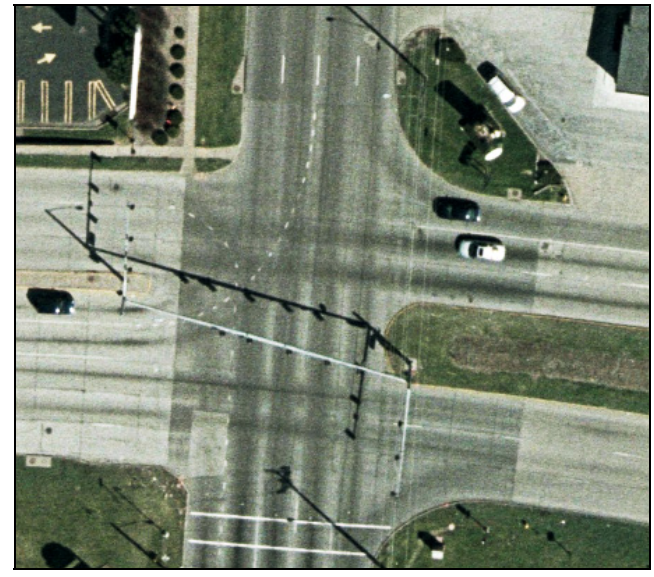

Figure 5.7. An aerial image of traffic for Kimberly Rd. and Brady St. 
Located south of the camera-enforced intersection of Welcome Way and Kimberly Road is the intersection of 35th Street and Harrison Street. Harrison is a one-way southbound street that carries the combined volume of Welcome Way and Harrison Street from where the two roads meet north of this intersection. Located on the both the southeast and southwest of the intersection is a city park. On the northwest side of the intersection is a fire station and on the northeast side is a busy bank that has a driveway less than 30 feet away from the intersection. Thirty-fifth Street is a high-volume arterial that serves many nearby residential areas and terminates at Division Street a couple of miles west of this intersection. Intersection characteristics are shown in Figures 5.8 through 5.10.

\begin{tabular}{|c|c|c|c|}
\hline \multirow{8}{*}{$\begin{array}{l}\text { Intersection } \\
\text { RLR Camera Approach } \\
\text { N-S Street: } \\
\text { E-W Street: } \\
\text { Peak Periods }\end{array}$} & \multirow{2}{*}{\multicolumn{3}{|c|}{ 35th Street and No }} \\
\hline & & & \\
\hline & \multicolumn{3}{|c|}{ Southbound Harrison Street } \\
\hline & \multicolumn{3}{|c|}{ Harrison Street } \\
\hline & \multicolumn{3}{|c|}{ 35th Street } \\
\hline & \multicolumn{3}{|c|}{ 7:00 - 9:00 AM, 11:00 AM - 1:00 PM, 4:00 - 6:00 PM } \\
\hline & \multicolumn{3}{|c|}{ SB } \\
\hline & $\mathbf{L}$ & $\mathbf{T}$ & $\mathbf{R}$ \\
\hline Lanes & shrd & 2,3 & shrd \\
\hline Posted Speed (mph) & \multicolumn{3}{|c|}{35} \\
\hline \multicolumn{4}{|l|}{ Peak Hour Volumes } \\
\hline 7:00-9:00 AM & 99 & 2122 & 201 \\
\hline 11:00 AM -1:00 PM & 155 & 2437 & 239 \\
\hline 4:00-6:00 PM & 238 & 2896 & 352 \\
\hline \multicolumn{4}{|l|}{ Cycle Length (sec.) } \\
\hline 7:00-9:00 AM & \multicolumn{3}{|c|}{110} \\
\hline 11:00 AM - 1:00 PM & \multicolumn{3}{|c|}{110} \\
\hline 4:00-6:00 PM & \multicolumn{3}{|c|}{110} \\
\hline \multicolumn{4}{|l|}{ Green Interval (sec.) } \\
\hline 7:00-9:00 AM & \multicolumn{3}{|c|}{57} \\
\hline 11:00 AM - 1:00 PM & \multicolumn{3}{|c|}{57} \\
\hline 4:00-6:00 PM & \multicolumn{3}{|c|}{57} \\
\hline Yellow Interval (sec.) & \multicolumn{3}{|c|}{4.0} \\
\hline All-Red Interval (sec.) & \multicolumn{3}{|c|}{1.0} \\
\hline
\end{tabular}

Figure 5.8. Roadway, traffic, and signal timing characteristics for 35th St. and N. Harrison St. 


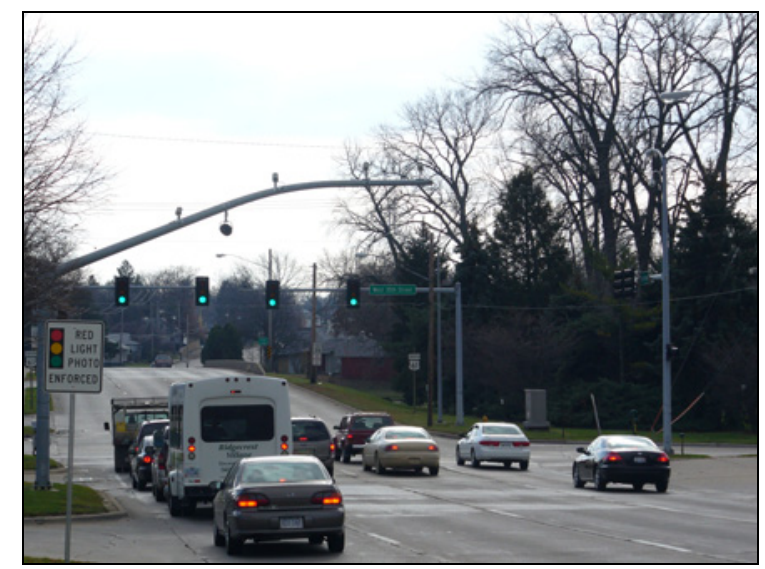

Figure 5.9. Southbound traffic for 35 th St. and N. Harrison St.

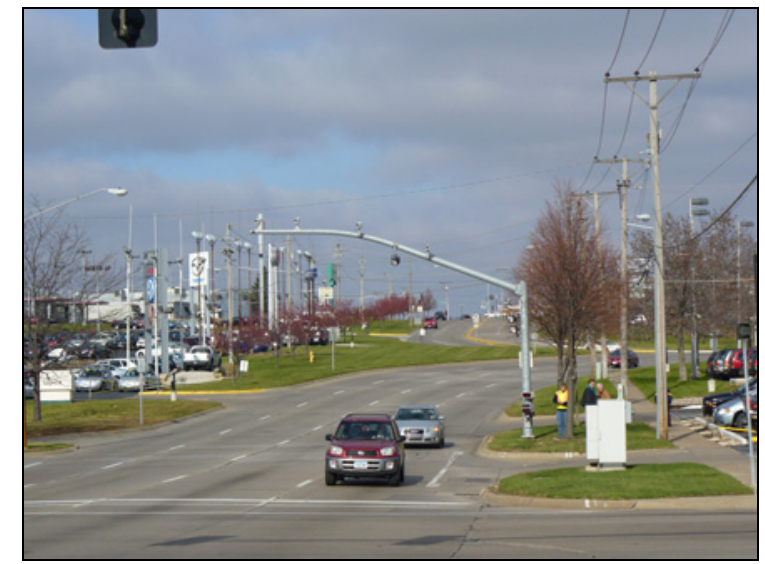

Figure 5.10. Northbound traffic for 35th St. and N. Harrison St.

Welcome Way \& Kimberly Road

Located less than a half-mile west of Brady Street and Kimberly Road, and less than a mile north of 35th Street and Harrison Street, Welcome Way and Kimberly Road is another busy intersection with Welcome Way being a one-way street leading in from Interstate 80. This intersection handles heavy volumes of traffic, particularly turning traffic with dual left and right turning lanes. On the northwest side of the intersection is a multiple-story bank and on the northeast side of the intersection is the back of Toys ' $R$ ' Us. On the southwest side of the intersection is a Lexus car dealership with multiple access points on both Kimberly Road and Welcome Way. Intersection characteristics are provided in Figures 5.11 through 5.13. 


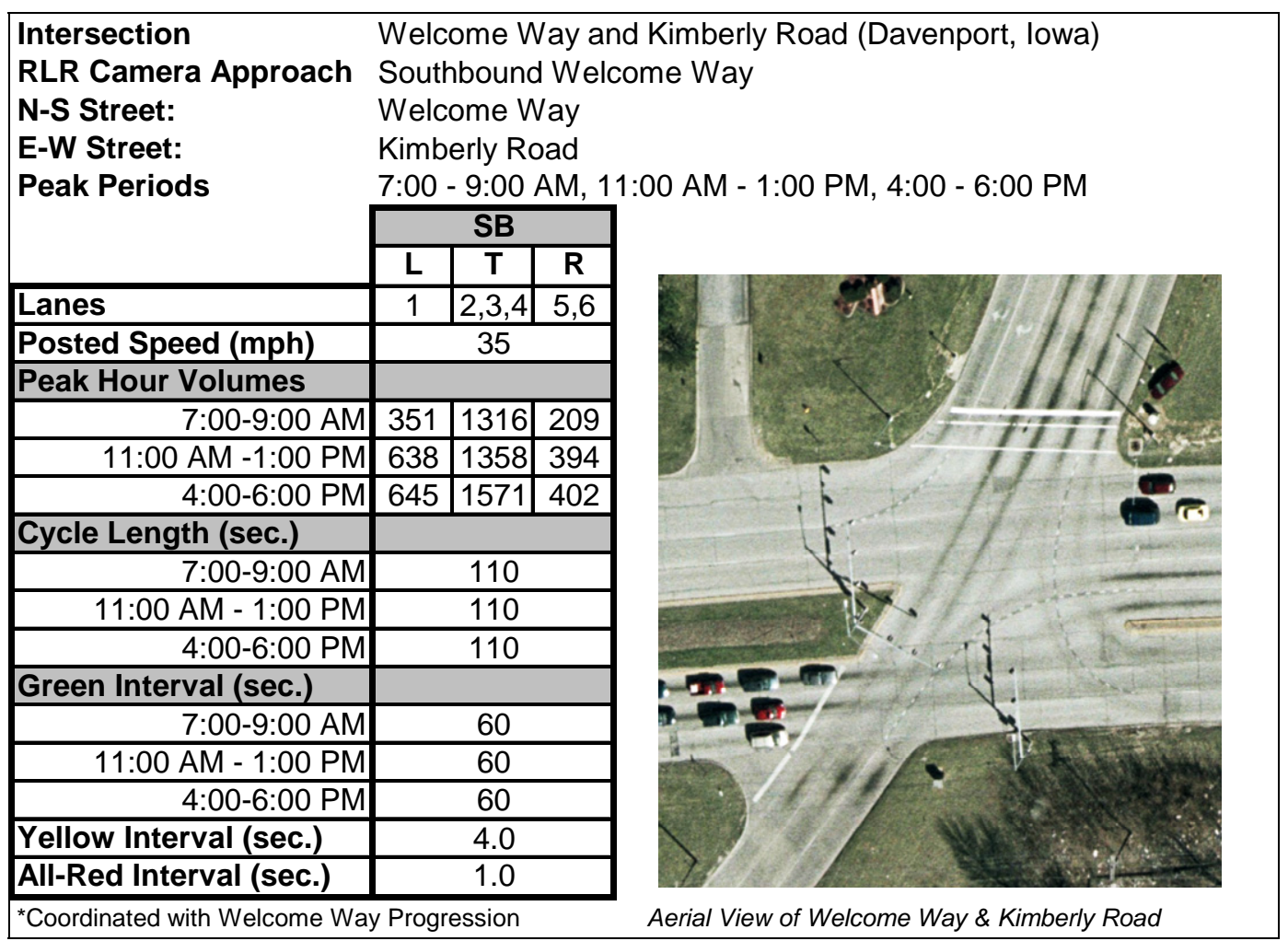

Figure 5.11. Roadway, traffic, and signal timing characteristics for Welcome Way and Kimberly Rd.

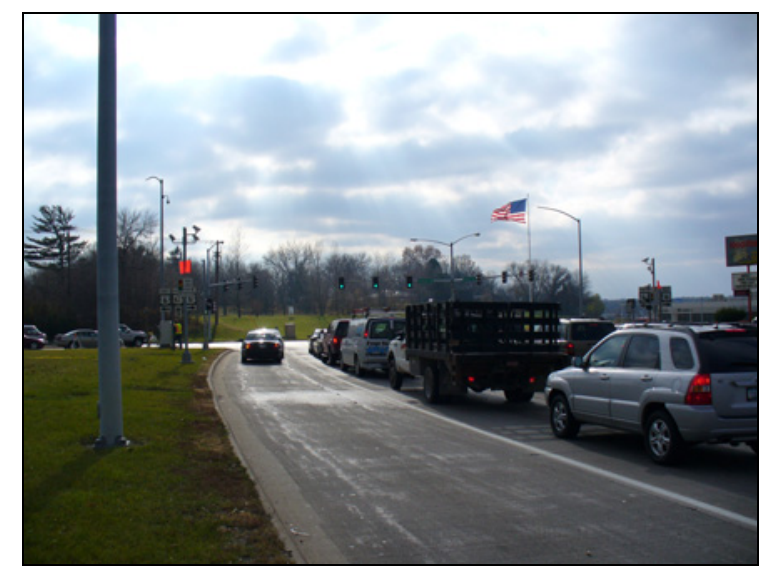

Figure 5.12. Southbound, east lane traffic for Welcome Way and Kimberly Rd. 


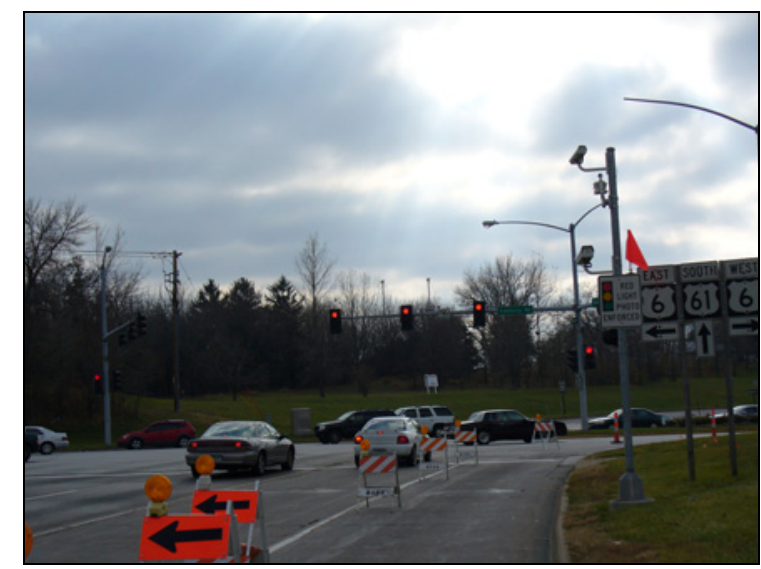

Figure 5.13. Southbound, west lane traffic for Welcome Way and Kimberly Rd.

Lincoln Avenue \& Locust Street

Located west of the other three camera-enforced intersections is the intersection of Lincoln Avenue and Locust Street (Figures 5.14-5.16). This heavy-volume intersection has a Hy-Vee grocery store on its southeast side with multiple access points onto Locust Street. Private residences surround both the north and southwest side of the intersection. The intersection at Lincoln Avenue and Locust Street experiences significant pedestrian traffic in all four directions during peak hours.

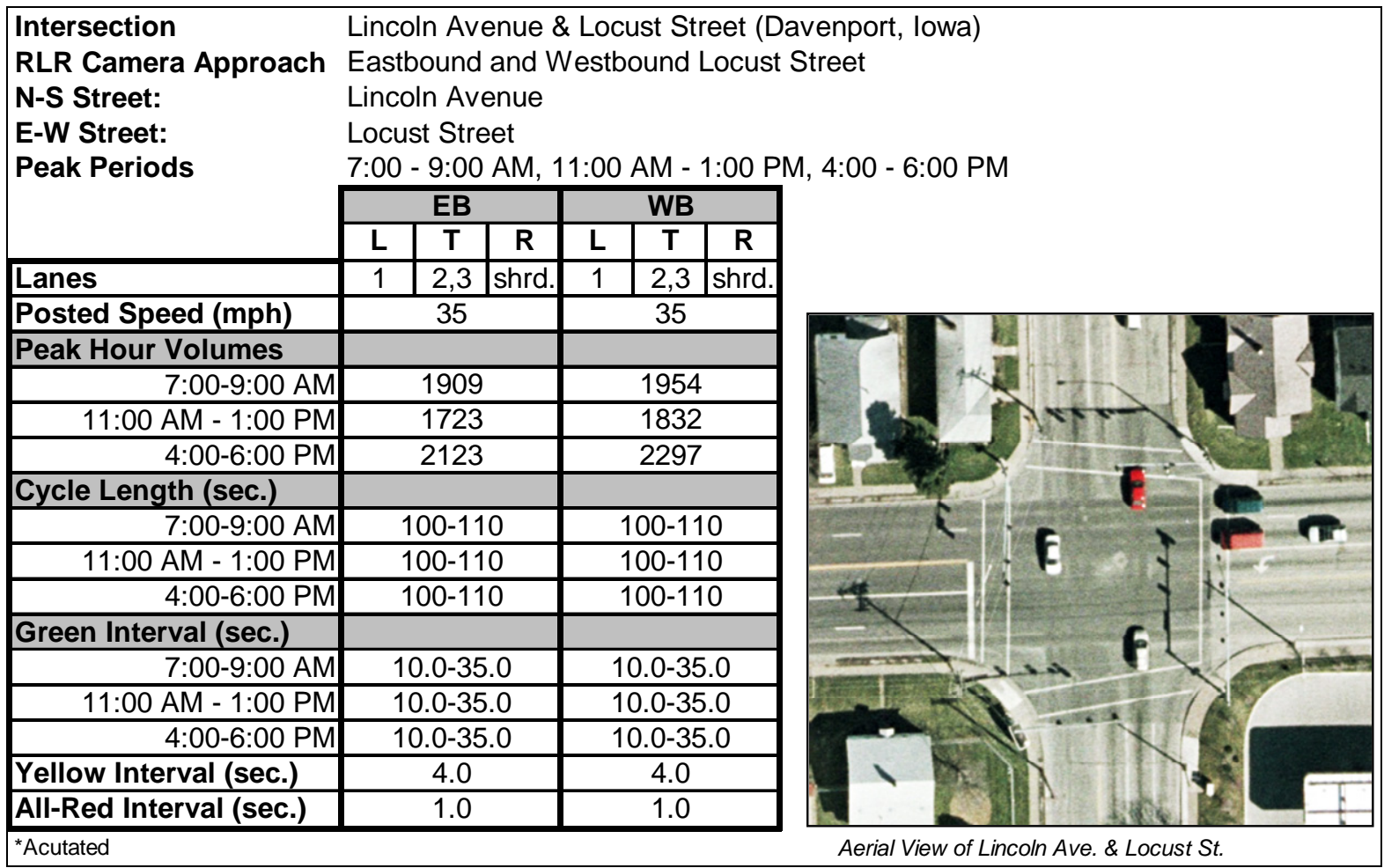

Figure 5.14. Roadway, traffic, and signal characteristics for Lincoln Ave. and Locust St. 


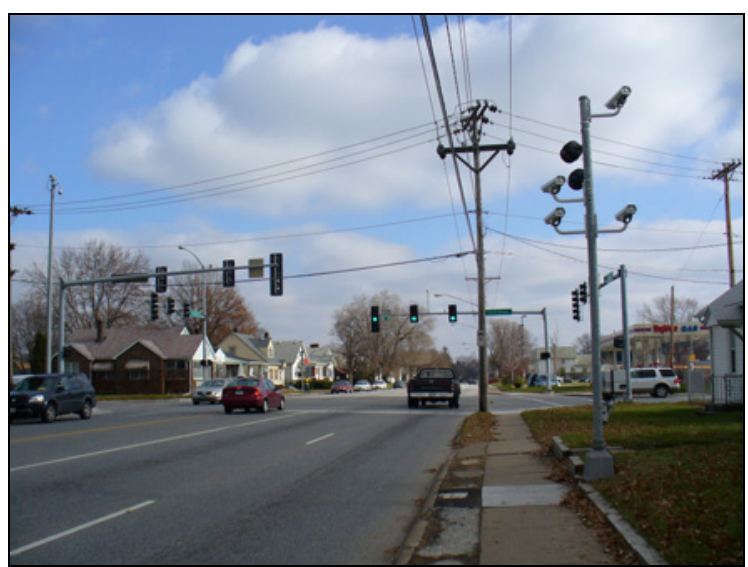

Figure 5.15. Eastbound traffic for Lincoln Ave. and Locust St.

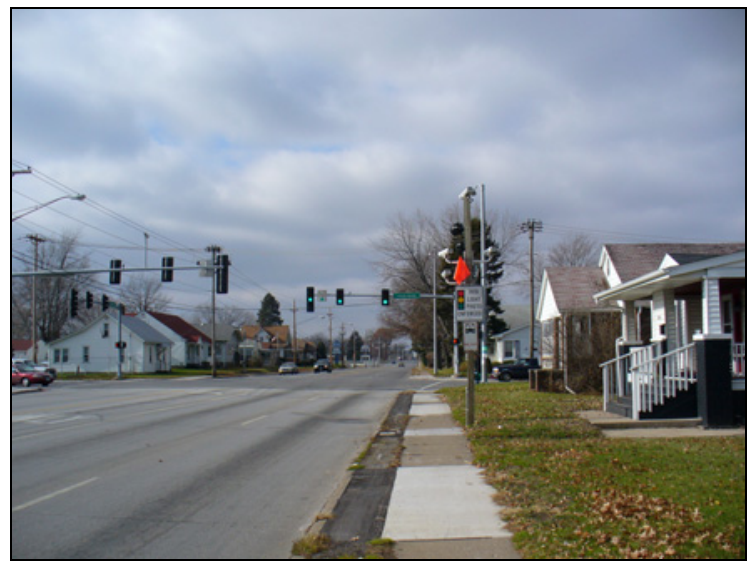

Figure 5.16. Westbound traffic for Lincoln Ave. and Locust St.

Kimberly Road \& Elmore Avenue

Located on the east side of Davenport, the intersection of Kimberly Road and Elmore Avenue is the first intersection west of Interstate 74 and the city of Bettendorf. Private residences can be found on the west side of the intersection. Commercial developments, including banks and shopping centers, can be found on the east side of the intersection. There is pedestrian traffic on the single crosswalk due to complicated signal timing that makes crossing the intersection a challenge. The traffic engineering department has stated that this is a heavy-volume intersection and congestion happens during both the morning and afternoon peak hours. Multiple signal timing updates happened at this intersection in the past two years, helping improve traffic flow. Intersection characteristics are shown in Figures 5.17-5.19. 


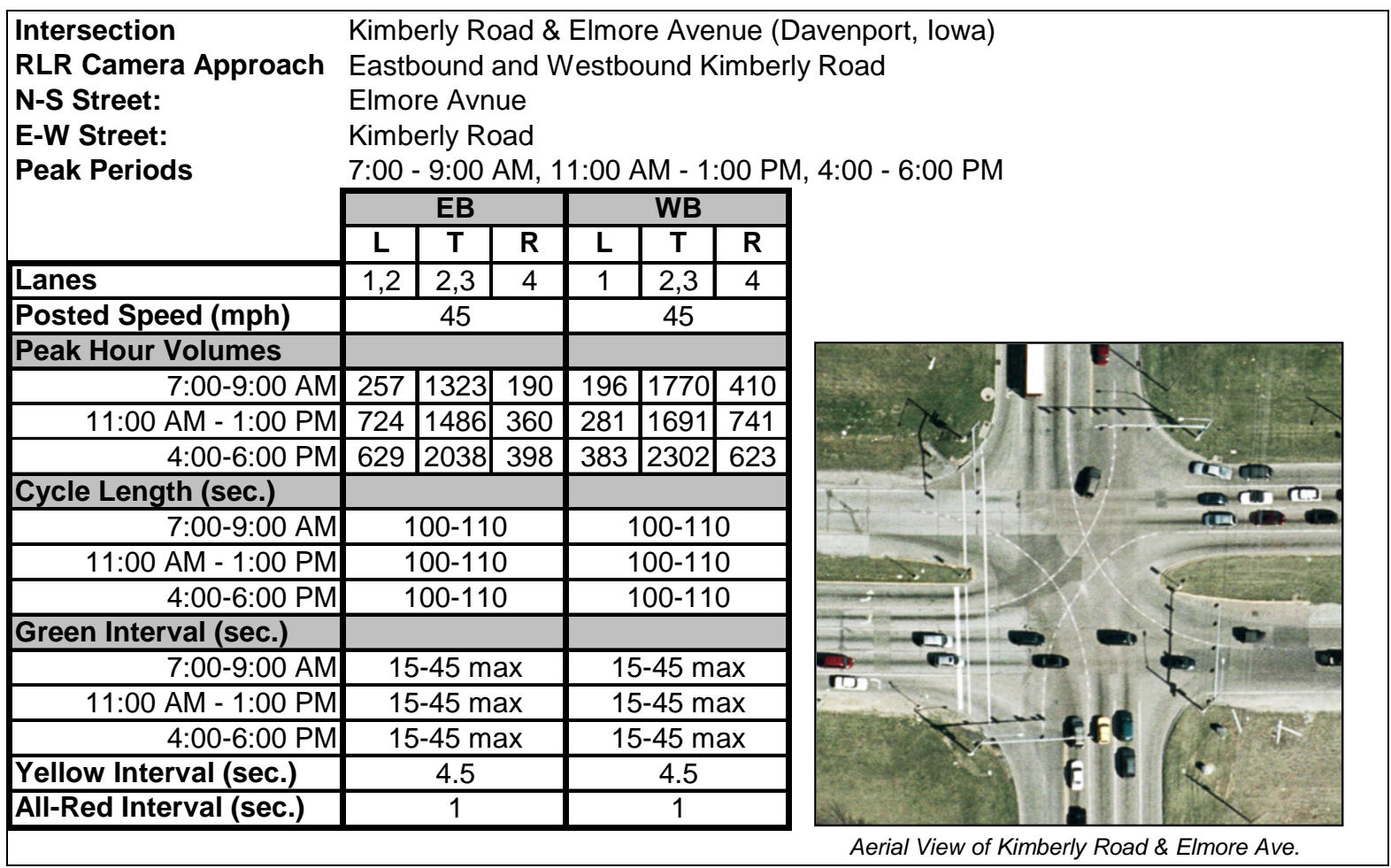

Figure 5.17. Roadway, traffic, and signal timing characteristics for Kimberly Rd. and Elmore Ave.

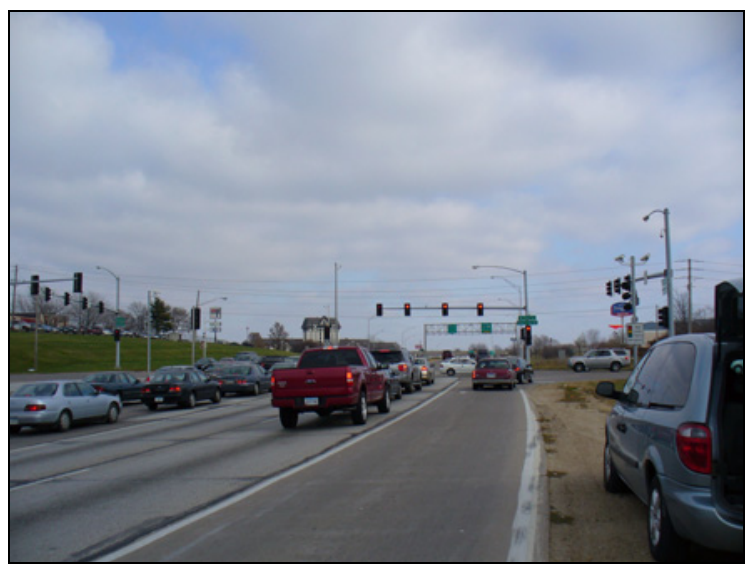

Figure 5.18. Eastbound traffic for Kimberly Rd. and Elmore Ave. 


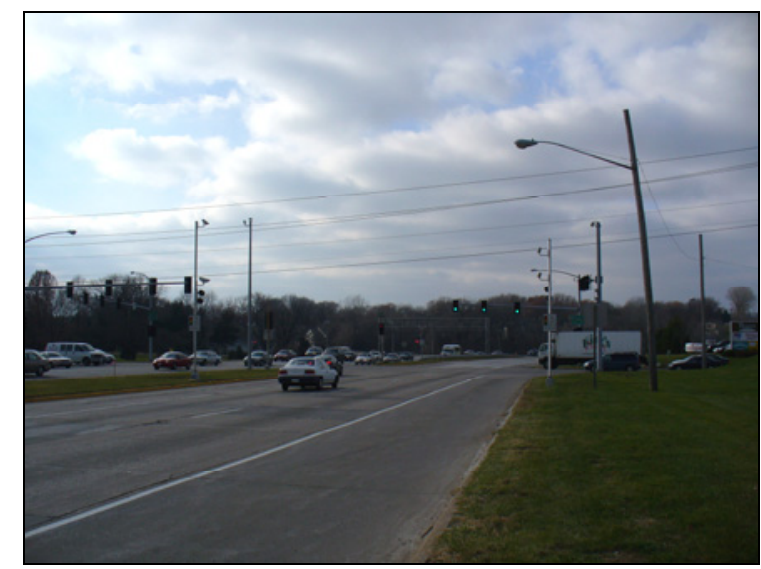

Figure 5.19. Westbound traffic for Kimberly Rd. and Elmore Ave.

\subsection{Summary of Violations}

Data were collected from the Davenport Police Department for the total number of issued citations during the enforcement period, which included both vendors. As shown in Table 5.1, values are lower for 2004 because the first cameras were implemented in August 4th, 2005, and others came online afterwards. The number of total citations issued in Davenport for 2005 and 2006 are also shown. RLR citations made up 15.3\% of total citywide citations in 2005 and $13.6 \%$ in 2006.

The total citywide citations included mobile and fixed speeding citations and RLR-only captured by the camera were separated. Police officers who caught red light runners while on patrol would list the citations in the citywide category.

Table 5.1. RLR citations per year in Davenport

\begin{tabular}{lccc}
\hline Citations & $\mathbf{2 0 0 4}$ & $\mathbf{2 0 0 5}$ & $\mathbf{2 0 0 6}$ \\
\hline Total RLR issued citations & 585 & 3,442 & 6,610 \\
Total citywide citations & NA & 22,508 & 48,734 \\
Percent of total citations & & $15.3 \%$ & $13.6 \%$ \\
\hline
\end{tabular}




\subsection{EVALUATION OF REDUCTION IN CRASHES FOR COUNCIL BLUFFS AND DAVENPORT}

The effectiveness of the RLR camera programs in Council Bluffs and Davenport was evaluated using reduction in crashes before and after installation of the cameras. Each community was evaluated separately. Because crash analyses are observational studies, factors other than the treatment may influence change in crashes from the before to after period. To account for this, a method suggested by Hauer (1997) was used. Hauer suggested comparing crash reduction for the treatment group to crash reduction in a control group, which was not likely to have been affected by the treatment. This control population was used to control for factors outside of the treatment that affect crashes but that cannot be accounted for and may affect study results. Reduction in crashes for intersections where RLR cameras were installed was compared against a set of control intersections for each community. For each community, several intersections with similar crash history and volumes that were not likely to have been influenced by the locations with cameras were selected as control sites. The location of both treatment and control intersections was described in sections 6 and 7.

Only simple statistics were used to evaluate Council Bluffs because the cameras were installed in August 2005 and only slightly more than one year of data was available at the time the study was conducted. One year of after data was not sufficient to conduct a robust statistical analysis. Both descriptive statistics and a Bayesian analysis were used to evaluate the Davenport program. The methodologies and results for both are presented in the following section.

\subsection{Selection of Crash Type}

The effectiveness of RLR programs was usually evaluated by either comparing the reduction in total crashes from the before to after period or by selecting some subset of crashes that appeared to be RLR-related. Use of total crashes was the most easily obtained and easily explained to laypersons. However, some studies have suggested that while RLR cameras reduce broad-angle crashes, rear-end crashes may increase (Council et al., 2005). Consequently, the net result may be little or no change in the total number of crashes. Other studies have attempted to identify RLR crashes. Studies have evaluated right-angle crashes, angle crashes, injury right-angle, rearend crashes, and injury rear-end crashes (Bonneson and Zimmerman, 2006; Council et al., 2005; SafeLight, 2006). However, as indicated by Bonneson and Zimmerman in a study conducted in 2006, it was difficult to identify actual RLR crashes because red light running was not indicated on the crash form of most states. Even when crash form attributes were available that indicated some type of disregard for a traffic signal, officers may not have taken the time to determine whether the crash was RLR-related. For instance, an officer reporting an angle-oncoming left turn crash at a signalized intersection may just assume that the left turning vehicle failed to select an adequate gap, rather than attempting to determine if one of the drivers ran the red light. 
In the same study, Bonneson and Zimmerman listed the following common attributes to identify RLR crashes:

- Intersection relationship: "at" the intersection;

- Crash type: right-angle; and

- First contributing factor: "disregard of stop and go signal"

They evaluated these attributes to identify RLR-related crashes at 70 signalized intersections in three Texas cities for a three-year period. Using these criteria, they found 274 crashes with all three attributes. After reviewing officer reports for 3,338 crashes at those intersections, they found that 232 RLR-related crashes were missed while only four of the 274 were determined to be "not red light running related.” In many cases, "left-turn opposing” crashes resulted from failure to yield right-of-way during a permissive indication and were not typically considered to be RLR-related. However, they found that 75 "left-turn opposing” crashes were in fact RLRrelated. Their conclusions were that RLR crashes were not always coded as right-angle crashes and police officers may have designated disregard of traffic signals in different manners.

Based on the results of other studies, it was decided to evaluate the reduction in total crashes, RLR-related crashes, and RLR rear-end crashes. It was also decided to evaluate individual crash forms to make the determination as to whether a crash was RLR-related.

\subsection{Extraction of Crashes}

Crashes were obtained from the Iowa DOT crash database. Crashes in the Iowa DOT crash database can be spatially located. All crashes within 25 meters of each intersection from 2001 to 2006 were extracted. The Iowa DOT defined an intersection crash as one that occurred within 25 meters of the intersection in urban areas. Next, crashes in which the officer had indicated "Ran Traffic Signal" as the major cause were identified as RLR crashes. Because officers may not always have used the designation "Ran Traffic Signal” to indicate the major cause, or may not have taken the time to determine whether the crash was due to one vehicle running a red light, the crash narrative and report for each crash that was not indicated as having "Ran Traffic Signal” as the major cause was reviewed. A determination was made after reviewing the narrative and report as to whether the crash was likely to have been RLR-related. Two main criteria were used to determine whether this was the case for non-rear end crashes. First, if an officer or witness indicated that at least one vehicle involved in the crash ran the red light, the crash was coded as red light running. Second, crashes where the crash diagram geometry and/or narrative indicated that a collision had occurred between two vehicles that were initially coming from perpendicular approaches were also included as red light running. For instance, a rightangle crash between a vehicle that was going straight westbound and a vehicle going straight southbound would have entailed one of the vehicles running the red light. Exceptions to these two criteria would be an indication by the officer that the signal had failed or if one of the vehicles were an emergency vehicle that had intentionally run the red light. The crash was also not included if a bicycle were the vehicle that ran the red light. This occurred in at least two instances. Because it is not likely that a bicycle would be issued an RLR ticket, it was decided that these types of crashes fell outside the study scope. 
Rear-end crashes were also evaluated to determine whether they were RLR-related. There was some speculation that installation of RLR cameras may actually increase rear-end crashes. In some studies, total rear-end crashes were included in the analyses. However, not all rear-end crashes at intersections are related to a leading vehicle coming to an abrupt stop for a red signal and being rear-ended by a following vehicle. Rear-end crashes, which were coded with a major cause of "Ran Traffic Signal," were included, but none were actually coded as such. The crash record for rear-end crashes was evaluated. It was assumed that a rear-end crash was related to one vehicle stopping for a red or yellow indication and the following vehicle not stopping, unless an officer or witness indicated that the rear-end crash had some other cause. For instance, in a number of cases, it was indicated that the light had just turned green and the following vehicle started up faster than the lead vehicle. In several other cases, a rear-end crash occurred during a lane change that was not related to a red light, and in several others a rear-end crash occurred when vehicles slowed due to downstream congestion or a vehicle was turning into a driveway.

Non-rear-end crashes where either the officer had indicated "ran traffic signal" or the crash had been determined to be RLR-related after a review of the crash narrative and record were defined as "red light running related" crashes. Rear-end crashes where either the officer had indicated "ran traffic signal" or the crash had been determined to be RLR-related after a review of the crash narrative and record were defined as "red light running rear-end crashes.” Remaining crashes were identified as "not red light running.” The category of total crashes included all crashes within 25 meters of the intersection.

Table 6.1 indicates the number of crashes in each category for both Council Bluffs and Davenport. As indicated, none of the RLR rear-end crashes were indicated as "ran traffic signal" by the corresponding police officers. As noted, a large number of other RLR crashes were identified by evaluating the crash narrative as opposed to just using the designation of "ran traffic signal." 
Table 6.1. Origin of RLR crashes for analysis

\begin{tabular}{|c|c|c|c|c|c|}
\hline City & $\begin{array}{l}\text { Intersection } \\
\text { type }\end{array}$ & Crash Type & $\begin{array}{l}\text { Indicated as } \\
\text { "ran traffic } \\
\text { signal" }\end{array}$ & $\begin{array}{l}\text { Extracted from } \\
\text { crash narrative }\end{array}$ & Total \\
\hline \multirow{4}{*}{ Davenport } & Treatment & $\begin{array}{l}\text { Red light running } \\
\text { related other }\end{array}$ & 82 & 36 & 118 \\
\hline & & $\begin{array}{l}\text { Red light running } \\
\text { rear-end }\end{array}$ & 0 & 93 & 93 \\
\hline & Control & $\begin{array}{l}\text { Red light running } \\
\text { related other }\end{array}$ & 59 & 28 & 87 \\
\hline & & $\begin{array}{l}\text { Red light running } \\
\text { rear-end }\end{array}$ & 0 & 122 & 122 \\
\hline \multirow{4}{*}{$\begin{array}{l}\text { Council } \\
\text { Bluffs }\end{array}$} & Treatment & $\begin{array}{l}\text { Red light running } \\
\text { related other }\end{array}$ & 47 & 11 & 58 \\
\hline & & $\begin{array}{l}\text { Red light running } \\
\text { rear end }\end{array}$ & 0 & 79 & 79 \\
\hline & Control & $\begin{array}{l}\text { Red light running } \\
\text { related other }\end{array}$ & 46 & 17 & 63 \\
\hline & & $\begin{array}{l}\text { Red light running } \\
\text { rear end }\end{array}$ & 0 & 23 & 23 \\
\hline
\end{tabular}

Some studies used reduction in broadside (right-angle) accidents as a measure of effectiveness. It was determined from the review of the crash narratives that use of this metric, without making some further determination of red light running, would not have been appropriate. Table 6.2 indicates the number of broadside crashes that were determined to be red light running compared to the number where the crash was not deemed to be a result of red light running. As shown, up to $45 \%$ of the broadside crashes were determined to not be RLR-related. Although not quantified, it was noted that a large number of broadside crashes were actually from vehicles entering or exiting driveways that were located a short distance from the intersection.

It should be noted that it was extremely difficult to determine whether left turn oncoming and right turn on red crashes were a result of red light running if they were not indicated with a major cause of "Ran Red Light." Review of the crash reports indicates that in most cases it did not appear that the officer had attempted to distinguish whether the vehicle involved in a right turn on red accident had slowed or stopped and simply failed to see oncoming traffic, or whether they did not slow and were involved in the crash because they ran the red light. The same applied to left turn oncoming. In most cases the officer indicated that one or more drivers had failed to yield right of way but did not attempt to determine whether the left-turn driver had a permissive signal and simply failed to select an appropriate gap, or whether the driver had a red indication and ran the signal. 
Table 6.2. Broadside crashes by type

\begin{tabular}{lcccc}
\hline City & Intersection type & $\begin{array}{c}\text { RLR-related } \\
\text { broadside }\end{array}$ & $\begin{array}{c}\text { Non-RLR related } \\
\text { broadside }\end{array}$ & Total \\
\hline \multirow{2}{*}{ Davenport } & Treatment & $74(80 \%)$ & $19(20 \%)$ & 93 \\
\multirow{2}{*}{ Council Bluffs } & Control & $50(70 \%)$ & $21(30 \%)$ & 71 \\
& Treatment & $37(55 \%)$ & $30(45 \%)$ & 67 \\
& Control & $41(66 \%)$ & $21(34 \%)$ & 62 \\
\hline
\end{tabular}

\subsection{Data Preparation}

Crash data were extracted for 2001-2006. Normally, full years of crash data were used in a before and after study. The treatment year was often excluded from the analysis. However, because only a very short after period was available, it was decided to analyze data by quarters. Quarters were used rather than years so that the quarter when the camera was installed could be excluded from the analysis, rather than excluding an entire year. The quarter in which the camera was installed was removed for both the study and control intersections. Use of quarters also provided more data points. Quarters consisted of:

- Quarter 1: January, February, March

- Quarter 2: April, May, June

- Quarter 3: July, August, September

- Quarter 4: October, November, December

Data for the "before" period were selected so that the same proportion of each quarter was represented in the before and after period. In both Council Bluffs and Davenport, a total of 12 quarters (three years) of before data were used and eight quarters of data (two years) were available for the after period in Davenport, while four quarters were available in Council Bluffs.

The crash data were sorted into four subgroups as described in the previous section

- Total Crashes: all crashes at the intersection of interest

- RLR Rear-End Crashes: rear-end crashes at the intersection of interest determined to be RLR-related

- RLR Other Crashes: all crashes, except for rear-end crashes, at the intersection of interest determined to be RLR-related

- Not an RLR Crash: crashes at the intersection determined to not be RLR-related. Information for this category is not presented.

Annual average daily traffic (AADT) was extracted from the Iowa DOT GIMS database. Annual Daily Entering Vehicles (DEV) was calculated using equation 6-1:

$$
\mathrm{EV}_{\text {annual_k }}=\frac{\sum \mathrm{AADT}_{\mathrm{i}} \times 365}{2}
$$

Where: 
$\mathrm{EV}_{\text {annual }}=$ annual entering vehicles (veh) for intersection $\mathrm{k}$

$\mathrm{AADT}_{\mathrm{i}}=\mathrm{AADT}$ for approach $\mathrm{i}$

Because no additional data were available, DEV was calculated for each quarter using equation 6-2:

$$
\mathrm{EV}_{\mathrm{qr} \_\mathrm{k}}=\underline{\mathrm{EV}_{\text {annual }}}
$$

Where:

$$
\mathrm{EV}_{\mathrm{qtr}}=\text { quarterly entering vehicles for intersection } \mathrm{k}
$$

Entering vehicles (EV) were calculated for the before and after period for each intersection. Because updated volume data were not available, and no significant changes had occurred from the before to after period, traffic volumes were consistent from the before to after period.

\subsection{Descriptive Statistics Methodology}

The reduction in crashes was compared before and after implementation of the RLR cameras using descriptive statistics. The crash rate was calculated using equation 6-3 (source: ITE, ITE Traffic Engineering Handbook 5th Edition)

Crash Rate per MEV $=(a \times 1,000,000) \div(b \times 365)$

Where:

$$
\begin{aligned}
& \mathrm{a}=\text { number of accidents in one year } \\
& \mathrm{b}=24 \text {-hr total intersection entering volume }
\end{aligned}
$$

Equation 6-4 was adjusted to reflect crashes per quarter because crash data were analyzed by quarter. Equation 6-2 was used to determine the DEV per quarter for both the before and after periods minus the quarter the RLR camera was installed.

$D E V$ per Quarter (before or After $)=\frac{\sum_{+\left[\left(\text {DEV }_{\text {Installation Year }} \times 365 \text { Days }\right) / \# \text { Quarters }_{\text {Before or Affer Quarter of Installation }}\right]}^{\left[\left(\text {Yearly }_{\text {Befre or After installation }} D E V \times 365 \text { Days }\right)\right]}}{\# \text { of Quarters } \text { Before or After Installation }}$

\subsection{Bayesian Methodology}

A Bayesian model was used to evaluate the reduction in crashes from the before to after period after RLR cameras were installed at one or more approaches. Control intersections were also included. Priors were chosen to express uncertainty. They were flat distributions that expressed 
uncertainty in what form the posteriors would take. The following model was defined to make the comparison between the before and after periods:

$$
\begin{aligned}
& y_{i j} \sim \operatorname{Poisson}(\mu) \\
& \mu_{i j}=\lambda_{i j} * \text { aadt } / 1000 \\
& \log \left(\lambda_{i j}\right)=\beta_{1}+\beta_{2} * X_{1 i j}+\beta_{3} * t_{i j}+\beta_{4} *\left(t_{i j}-t_{0 i}\right) * I\left(t_{i j}>t_{0 i}\right)+\beta_{5} * X_{1 i j} * t_{i j}+ \\
& \beta_{6} * X_{1 i j} *\left(t_{i j}-t_{0 i}\right) * I\left(t_{i j}>t_{0 i}\right)+\beta_{7} * X_{2 i j}+\beta_{8} * X_{3 i j}+\beta_{9} * X_{4 i j}+s_{i t e}
\end{aligned}
$$

Where,

$X_{1 i j}= \begin{cases}1 & \text { if there was a camera at the ith site during the quarter } \\ 0 & \text { no camera at the ith sit during the quarter }\end{cases}$

$t_{i j}=$ Quarter for a particular observation at site i quarter $\mathrm{j}$

$t_{0 i}=$ first quarter where camera was used at site $\mathrm{i}$

$I\left(t_{i j}>t_{0 i}\right)=\left\{\begin{array}{cc}1 & \text { if condition is met }\left(t_{i j}>t_{0 i}\right) \\ 0 & 0 . .\end{array}\right.$

$X_{2 i j}, X_{3 i j}, X_{3 i j}$ are functions to express seasonality

$X_{2 i j}=\cos \left(2 * \pi / 4 * s_{i j}\right), \quad \mathrm{s}_{\mathrm{ij}}=1,2,3,4$

$X_{3 i j}=\cos \left(2 * 2 \pi / 4 * s_{i j}\right), \quad \mathrm{s}_{\mathrm{ij}}=1,2,3,4$

$X_{4 i j}=\sin \left(2 * \pi / 4 * \mathrm{~s}_{\mathrm{ij}}\right), \quad \mathrm{s}_{\mathrm{ij}}=1,2,3,4$

The covariate "site" was included and used as a random variable that took into account the correlation that existed among multiple observations made at the same site.

Site was defined as $N\left(0, \sigma_{\text {site }}^{2}\right)$ and

$\sigma_{\text {site }}^{2} \sim$ IGamma $(100,100)$

The second level of the model was specified by giving the distribution of the hyper parameters $\beta_{k}, \mathrm{k}=1, \ldots, 8$.

Thus,
$\beta_{k} \sim N(0,1000)$
$k=1, \ldots, 8$ 
The credible sets for differences among before and after periods were calculated using the following. The variable "seasonal" accounts for the effect of quarters occurring during different times of the year.

$$
\begin{aligned}
& \log \left(\lambda_{i j}\right)=\beta_{1}+\beta_{2} * X_{1 i j}+\beta_{3} * t_{i j}+\beta_{4} *\left(t_{i j}-t_{0 i}\right) * I\left(t_{i j}>t_{0 i}\right)+\beta_{5} * X_{1 i j} * t_{i j}+ \\
& \beta_{6} * X_{1 i j} *\left(t_{i j}-t_{0 i}\right) * I\left(t_{i j}>t_{0 i}\right)+\beta_{7} * X_{2 i j}+\beta_{8} * X_{3 i j}+\beta_{9} * X_{4 i j}+s i t e_{i}
\end{aligned}
$$

The expected value for sites with camera, before the intervention, was

$$
E\left\{\log \left(\lambda_{i j}\right) \mid \text { camera, before }\right\}=\left(\beta_{1}+\beta_{2}\right)+\left(\beta_{3}+\beta_{5}\right) t_{i j}+\text { seasonal }
$$

and, the expected value for sites with camera, after the intervention, was

$$
E\left\{\log \left(\lambda_{i j}\right) \mid \text { camera, after }\right\}=\left(\beta_{1}+\beta_{2}\right)-\left(\beta_{4}+\beta_{6}\right) t_{0}+\left(\beta_{3}+\beta_{4}+\beta_{5}+\beta_{6}\right) t_{i j}+\text { seasonal }
$$

Then, the difference, (eq 6-6) minus (eq 6-7), represented the expected difference of crashes for the sites that had a presence of cameras:

$$
(e q 6-6)-(e q 6-7)=\left(\beta_{4}+\beta_{6}\right) t_{0}-\left(\beta_{4}+\beta_{6}\right) t_{i j}
$$

Similarly, for the control sites, we have:

$$
\begin{aligned}
& E\left\{\log \left(\lambda_{i j}\right) \mid \text { no } \cdot \text { camera, before }\right\}=\beta_{1}+\beta_{3} t_{i j}+\text { seasonal } \\
& E\left\{\log \left(\lambda_{i j}\right) \mid \text { no } \cdot \text { camera, after }\right\}=\beta_{1}+\beta_{3} t_{i j}+\beta_{4}\left(t_{i j}-t_{0}\right)+\text { seasonal } \\
& (\text { eq6 }-8)-(\text { eq6 }-9)=\beta_{4}\left(t_{i j}-t_{0}\right)
\end{aligned}
$$

Using equations 6-8 and 6-11, posterior distributions were generated for the differences. The credible sets can be examined to determine the level of significance of these differences.

\subsection{Results for Council Bluffs}

Results of the descriptive statistical analysis for Council Bluffs are shown in Table 6.3 for total crashes for RLR camera-enforced intersections. Results are provided in Table 6.4 for total crashes for control intersections. The before period represented 12 quarters of data and the after period represented four quarters of data, as described in the methodology section. As shown, the total number of crashes per quarter decreased from the before to after period for the cameraenforced intersections from 11 to 67 percent. This represents an average decrease in total crashes of 44.1 percent. 
Crashes increased from the before to after period at one control intersection by 24 percent. Total crashes decreased by $11.8 \%$ to $40 \%$ at the three other control intersections. Overall total crashes decreased by approximately $12 \%$ in all cases.

Table 6.3. Changes in total crashes for RLR camera-enforced intersections before and after treatment for simple statistics-Council Bluffs

\begin{tabular}{|c|c|c|c|c|c|c|c|}
\hline \multirow[b]{2}{*}{ Intersection } & \multicolumn{3}{|c|}{ Before (represents 12 qtrs) } & \multicolumn{3}{|c|}{ After (represents 4 qtrs) } & \multirow[b]{2}{*}{ Decrease } \\
\hline & Total & $\begin{array}{c}\text { Crashes/ } \\
\text { quarter }\end{array}$ & $\begin{array}{c}\text { Crash } \\
\text { rate } \\
(\mathrm{MEV})\end{array}$ & Total & $\begin{array}{l}\text { Crashes/ } \\
\text { quarter }\end{array}$ & $\begin{array}{c}\text { Crash } \\
\text { rate } \\
(\mathrm{MEV})\end{array}$ & \\
\hline $\begin{array}{l}\text { Broadway and } \\
\text { 16th } \\
\text { Willow and }\end{array}$ & 48 & 4.00 & 1.03 & 8 & 2.00 & 0.52 & $50.0 \%$ \\
\hline $\begin{array}{l}\text { 7th } \\
\text { Broadway and }\end{array}$ & 10 & 0.83 & 0.91 & 2 & 0.50 & 0.55 & $40.0 \%$ \\
\hline $\begin{array}{l}\text { 35th } \\
\text { Broadway and }\end{array}$ & 34 & 2.83 & 0.96 & 10 & 2.50 & 0.84 & $11.8 \%$ \\
\hline $\begin{array}{l}21^{\text {st }} \\
\text { Broadway and }\end{array}$ & 27 & 2.25 & 0.76 & 3 & 0.75 & 0.25 & $66.7 \%$ \\
\hline 8th & 58 & 4.83 & 0.95 & 10 & 2.50 & 0.49 & $48.3 \%$ \\
\hline All & 117 & 14.75 & 0.94 & 33 & 8.25 & 0.52 & $44.1 \%$ \\
\hline
\end{tabular}

Table 6.4. Changes in total crashes for control intersections before and after treatment for simple statistics-Council Bluffs

\begin{tabular}{lccccccc}
\hline & \multicolumn{3}{c}{ Before (represents 12 qtrs) } & After (represents 4 qtrs) & \\
\cline { 2 - 5 } Intersection & Total & $\begin{array}{c}\text { Crashes/ } \\
\text { quarter }\end{array}$ & $\begin{array}{c}\text { Crash } \\
\text { rate } \\
\text { (MEV) }\end{array}$ & Total & $\begin{array}{c}\text { Crashes/ } \\
\text { quarter }\end{array}$ & $\begin{array}{c}\text { Crash } \\
\text { rate } \\
\text { (MEV) }\end{array}$ & Decrease \\
\hline $\begin{array}{l}\text { 24th and } \\
\text { 27th }\end{array}$ & 29 & 2.42 & 1.71 & 12 & 3.00 & 2.12 & $-24.1 \%$ \\
$\begin{array}{l}\text { 35th and } \\
\begin{array}{l}\text { Nebraska } \\
\text { Broadway }\end{array}\end{array}$ & 13 & 1.08 & 0.75 & 4 & 1.00 & 0.69 & $7.7 \%$ \\
$\begin{array}{l}\text { and } \\
\text { Kanesville }\end{array}$ & 15 & 1.25 & 0.44 & 3 & 0.75 & 0.27 & $40.0 \%$ \\
$\begin{array}{l}\text { Broadway } \\
\text { and 1st }\end{array}$ & 28 & 2.33 & 1.19 & 6 & 1.5 & 0.77 & $35.7 \%$ \\
All & 85 & 7.08 & 0.93 & 25 & 6.25 & 0.82 & $11.8 \%$ \\
\hline
\end{tabular}


Results for changes in RLR-related crashes not including rear-end crashes are presented in Tables 6.5 and 6.6. As shown, RLR-related crashes decreased significantly (up to 100\%) at all five of the camera-enforced intersections. Overall, RLR crashes decreased by $90 \%$ at cameraenforced intersections.

Increases in RLR-related crashes occurred at two of the four control intersections, no change was reported at one, and a decrease of 50\% occurred at one intersection. Overall, no change in the number of crashes per quarter or crash rate was observed for RLR crashes at the control intersections.

Table 6.5. Changes in RLR-related (non-rear-end) crashes for RLR camera-enforced intersections before and after treatment for simple statistics-Council Bluffs

\begin{tabular}{llcccccc}
\hline Intersection & \multicolumn{5}{c}{ Before (represents 12 qtrs) } & After (represents 4 qtrs) & \\
\cline { 2 - 6 } & Total & $\begin{array}{c}\text { Crashes/ } \\
\text { quarter }\end{array}$ & $\begin{array}{c}\text { Crash } \\
\text { rate } \\
\text { (MEV) }\end{array}$ & Total & $\begin{array}{c}\text { Crashes/ } \\
\text { quarter }\end{array}$ & $\begin{array}{c}\text { Crash } \\
\text { rate } \\
\text { (MEV) }\end{array}$ & Decrease \\
\hline $\begin{array}{l}\text { Broadway } \\
\text { and 16th }\end{array}$ & 8 & 0.67 & 0.17 & 0 & 0 & 0 & $100.0 \%$ \\
$\begin{array}{l}\text { Willow and } \\
\text { 7th }\end{array}$ & 3 & 0.25 & 0.27 & 0 & 0 & 0 & $100.0 \%$ \\
$\begin{array}{l}\text { Broadway } \\
\text { and 35th }\end{array}$ & 8 & 0.67 & 0.23 & 1 & 0.25 & 0.08 & $62.5 \%$ \\
$\begin{array}{l}\text { Broadway } \\
\text { and 21 }\end{array}$ & 8 & 0.67 & 0.23 & 0 & 0 & 0 & $100.0 \%$ \\
$\begin{array}{l}\text { Broadway } \\
\text { and 8th }\end{array}$ & 4 & 0.33 & 0.07 & 0 & 0 & 0 & $100.0 \%$ \\
\begin{tabular}{l} 
All \\
\hline
\end{tabular} & 31 & 2.58 & 0.16 & 1 & 0.25 & 0.02 & $90.3 \%$ \\
\hline
\end{tabular}

Table 6.6. Changes in RLR-related (non-rear-end) crashes for control intersections before and after treatment for simple statistics-Council Bluffs

\begin{tabular}{|c|c|c|c|c|c|c|c|}
\hline \multirow[t]{2}{*}{ Intersection } & \multicolumn{3}{|c|}{ Before (represents 12 qtrs) } & \multicolumn{3}{|c|}{ After (represents 4 qtrs) } & \multirow[b]{2}{*}{ Decrease } \\
\hline & Total & $\begin{array}{l}\text { Crashes/ } \\
\text { quarter }\end{array}$ & $\begin{array}{c}\text { Crash rate } \\
\text { (MEV) }\end{array}$ & Total & $\begin{array}{c}\text { Crashes/ } \\
\text { quarter }\end{array}$ & $\begin{array}{c}\text { Crash } \\
\text { rate } \\
(\mathrm{MEV})\end{array}$ & \\
\hline $\begin{array}{l}\text { 24th and } \\
\text { 27th } \\
\text { 35th and }\end{array}$ & 3 & 0.25 & 0.18 & 1 & 0.25 & 0.18 & $0 \%$ \\
\hline $\begin{array}{l}\text { Nebraska } \\
\text { Broadway } \\
\text { and }\end{array}$ & 2 & 0.17 & 0.11 & 1 & 0.25 & 0.17 & $-50.0 \%$ \\
\hline $\begin{array}{l}\text { Kanesville } \\
\text { Broadway }\end{array}$ & 4 & 0.33 & 0.12 & 2 & 0.50 & 0.18 & $-50.0 \%$ \\
\hline and 1st & 6 & 0.50 & 0.26 & 1 & 0.25 & 0.13 & $50.0 \%$ \\
\hline All & 15 & 1.25 & 0.16 & 5 & 1.25 & 0.16 & $0.0 \%$ \\
\hline
\end{tabular}


Results for RLR-related rear-end crashes are shown in Table 6.7 for camera-enforced intersections and Table 6.8 for control intersections. As indicated, rear-end crashes decreased by up to $100 \%$ at camera-enforced intersections at four of the camera-enforced intersections. Rearend crashes increased by $31 \%$ for one of the camera-enforced intersections. Overall, rear-end crashes decreased by 40 percent.

Rear-end crashes decreased at one of the four control intersections and remained unchanged at two others. Rear-end crashes increased by 500\% at one control intersection. Overall, rear-end crashes increased at control intersections by almost 30 percent.

Table 6.7. Changes in RLR-related rear-end crashes for RLR camera-enforced intersections before and after treatment for simple statistics-Council Bluffs

\begin{tabular}{|c|c|c|c|c|c|c|c|}
\hline \multirow[b]{2}{*}{ Intersection } & \multicolumn{3}{|c|}{ Before (represents 12 qtrs) } & \multicolumn{3}{|c|}{ After (represents 4 qtrs) } & \multirow[b]{2}{*}{ Decrease } \\
\hline & Total & $\begin{array}{l}\text { Crashes/ } \\
\text { quarter }\end{array}$ & $\begin{array}{c}\text { Crash } \\
\text { rate } \\
(\mathrm{MEV})\end{array}$ & Total & $\begin{array}{l}\text { Crashes/ } \\
\text { quarter }\end{array}$ & $\begin{array}{c}\text { Crash } \\
\text { rate } \\
(\mathrm{MEV})\end{array}$ & \\
\hline \multicolumn{8}{|l|}{ Broadway and } \\
\hline 16th & 8 & 0.67 & 0.17 & 0 & 0.0 & 0 & $100.0 \%$ \\
\hline Willow and 7th & 3 & 0.08 & 0.09 & 0 & 0 & 0 & $100.0 \%$ \\
\hline $\begin{array}{l}\text { Broadway and } \\
\text { 35th }\end{array}$ & 9 & 0.75 & 0.25 & 4 & 1.00 & 0.30 & $-31.3 \%$ \\
\hline Broadway and & & & & & & & \\
\hline $21^{\text {st }}$ & 11 & 0.92 & 0.31 & 1 & 0.25 & 0.08 & $72.7 \%$ \\
\hline Broadway and & & & & & & & \\
\hline 8th & 14 & 1.17 & 0.23 & 4 & 1.0 & 0.20 & $14.3 \%$ \\
\hline All & 45 & 3.75 & 0.24 & 9 & 2.25 & 0.14 & $40.0 \%$ \\
\hline
\end{tabular}

Table 6.8. Changes in RLR-related rear-end crashes for control intersections before and after treatment for simple statistics-Council Bluffs

\begin{tabular}{|c|c|c|c|c|c|c|c|}
\hline \multirow[b]{2}{*}{ Intersection } & \multicolumn{3}{|c|}{ Before (represents 12 qtrs) } & \multicolumn{3}{|c|}{ After (represents 4 qtrs) } & \multirow[b]{2}{*}{ Decrease } \\
\hline & Total & $\begin{array}{l}\text { Crashes/ } \\
\text { quarter }\end{array}$ & $\begin{array}{c}\text { Crash } \\
\text { rate } \\
(\mathrm{MEV})\end{array}$ & Total & $\begin{array}{l}\text { Crashes/ } \\
\text { quarter }\end{array}$ & $\begin{array}{c}\text { Crash } \\
\text { rate } \\
(\mathrm{MEV})\end{array}$ & \\
\hline $\begin{array}{l}\text { 24th and 27th } \\
\text { 35th and }\end{array}$ & 3 & 0.25 & 0.18 & 1 & 0.25 & 0.18 & $0 \%$ \\
\hline $\begin{array}{l}\text { Nebraska } \\
\text { Broadway and }\end{array}$ & 1 & 0.08 & 0.06 & 2 & 0.50 & 0.34 & $-500.0 \%$ \\
\hline $\begin{array}{l}\text { Kanesville } \\
\text { Broadway and }\end{array}$ & 3 & 0.25 & 0.09 & 0 & 0 & 0 & $100.0 \%$ \\
\hline $1 \mathrm{st}$ & 0 & 0 & 0 & 0 & 0 & 0 & $0 \%$ \\
\hline All & 7 & 0.58 & 0.08 & 3 & 0.75 & 0.1 & $-28.6 \%$ \\
\hline
\end{tabular}




\subsection{Results for Davenport}

Results of the simple statistic analysis and Bayesian analysis are presented in the following sections.

\subsubsection{Simple statistics results}

Results for change in all crashes from before to after installation of RLR cameras are shown in Table 6.9. As shown, the crashes per quarter and crash rate increased at the intersection of Kimberly and Elmore but decreases were noted at the other three camera-enforced intersections. Results for all crashes for control intersections are provided in Table 6.28. Crashes per quarter and crash rate increased for all control intersections by up to almost 38 percent. Crashes per quarter and crash rate decreased by $4.5 \%$ at Elmore and 53rd Street. Overall, crashes decreased by almost $13 \%$ after installation of RLR cameras.

Results for control intersections in Davenport are shown in Table 6.10 for all crashes. As indicated, crashes increased at four of the five control intersection by up to 37.5 percent. Crashes decreased at the Elmore and 53rd intersection by 4.5 percent. Overall, total crashes increased at control intersections from the before to after period after installation of RLR cameras by 10 percent.

Table 6.9. Changes in total crashes for RLR camera-enforced intersections before and after treatment for descriptive statistics-Davenport

\begin{tabular}{lccccccc}
\hline & \multicolumn{5}{c}{ Before } & \multicolumn{5}{c}{ After } & \\
\cline { 2 - 5 } Intersection & Total & $\begin{array}{c}\text { Crashes/ } \\
\text { quarter }\end{array}$ & $\begin{array}{c}\text { Crash } \\
\text { rate } \\
\text { (MEV) }\end{array}$ & Total & $\begin{array}{c}\text { Crashes/ } \\
\text { quarter }\end{array}$ & $\begin{array}{c}\text { Crash rate } \\
\text { (MEV) }\end{array}$ & Decrease \\
\hline $\begin{array}{l}\text { Kimberly and } \\
\text { Welcome }\end{array}$ & & & & & & & \\
$\begin{array}{l}\text { Way } \\
\text { Kimberly and }\end{array}$ & 65 & 5.42 & 1.24 & 31 & 3.88 & 0.89 & $28.5 \%$ \\
$\begin{array}{l}\text { Brady } \\
\text { 35th and }\end{array}$ & 55 & 4.58 & 0.93 & 32 & 4.00 & 0.81 & $12.7 \%$ \\
$\begin{array}{l}\text { Harrison } \\
\text { Kimberly and }\end{array}$ & 35 & 2.92 & 1.21 & 14 & 1.75 & 0.72 & $40.0 \%$ \\
$\begin{array}{l}\text { Elmore } \\
\text { All }\end{array}$ & 31 & 2.58 & 0.52 & 31 & 3.88 & 0.78 & $-50.0 \%$ \\
\hline
\end{tabular}


Table 6.10. Changes in total crashes for control intersections before and after treatment for descriptive statistics-Davenport

\begin{tabular}{|c|c|c|c|c|c|c|c|}
\hline \multirow[b]{2}{*}{ Intersection } & \multicolumn{3}{|c|}{ Before } & \multicolumn{3}{|c|}{ After } & \multirow[b]{2}{*}{ Decrease } \\
\hline & Total & $\begin{array}{l}\text { Crashes/ } \\
\text { quarter }\end{array}$ & $\begin{array}{l}\text { Crash } \\
\text { rate } \\
(\mathrm{MEV})\end{array}$ & Total & $\begin{array}{l}\text { Crashes/ } \\
\text { quarter }\end{array}$ & $\begin{array}{c}\text { Crash } \\
\text { rate } \\
(\mathrm{MEV})\end{array}$ & \\
\hline $\begin{array}{l}\text { Elmore and } \\
\text { 53rd } \\
\text { Locust and }\end{array}$ & 66 & 5.50 & 1.81 & 42 & 5.25 & 1.73 & $4.5 \%$ \\
\hline $\begin{array}{l}\text { Brady } \\
\text { Locust and } \\
\text { Hickory }\end{array}$ & 40 & 3.33 & 0.87 & 29 & 3.63 & 0.95 & $-8.8 \%$ \\
\hline $\begin{array}{l}\text { Grove } \\
\text { North }\end{array}$ & 39 & 3.36 & 0.99 & 28 & 3.50 & 1.07 & $-4.1 \%$ \\
\hline $\begin{array}{l}\text { Division and } \\
\text { Central } \\
\text { Pine and }\end{array}$ & 24 & 2.00 & 0.65 & 21 & 2.63 & 0.86 & $-31.3 \%$ \\
\hline Kimberly & 24 & 2.00 & 0.91 & 22 & 2.75 & 1.24 & $-37.5 \%$ \\
\hline All & 193 & 16.08 & 1.05 & 142 & 17.75 & 1.15 & $-10.4 \%$ \\
\hline
\end{tabular}

Changes in the number of RLR-related crashes from the before to after period at cameraenforced intersections is shown in Table 6.11. This included all crashes that were determined to be RLR-related except for rear-end crashes. As shown, crashes per quarter and crash rate decreased from the before to after period by up to $100 \%$ except for the intersection of Kimberly and Brady, where a small increase of 5\% was recorded. Overall, RLR-related crashes decreased by $50 \%$ after RLR cameras were installed.

Results for control intersections are shown in Table 6.12, and, as shown, increases in the number of RLR-related crashes per quarter and crash rate occurred from the before to after period by up to $35 \%$ except for the intersection of Locust and Hickory Grove, which experienced a decrease of 21.4 percent. Overall, RLR crashes increased $20 \%$ from before to after at control intersections. 
Table 6.11. Changes in RLR-related (non-rear-end) crashes for RLR camera-enforced intersections before and after treatment for descriptive statistics-Davenport

\begin{tabular}{|c|c|c|c|c|c|c|c|}
\hline \multirow[b]{2}{*}{ Intersection } & \multicolumn{3}{|c|}{ Before } & \multicolumn{3}{|c|}{ After } & \multirow[b]{2}{*}{ Decrease } \\
\hline & Total & $\begin{array}{l}\text { Crashes/ } \\
\text { quarter }\end{array}$ & $\begin{array}{c}\text { Crash } \\
\text { rate } \\
(\mathrm{MEV})\end{array}$ & Total & $\begin{array}{l}\text { Crashes/ } \\
\text { quarter }\end{array}$ & $\begin{array}{c}\text { Crash } \\
\text { rate } \\
(\mathrm{MEV})\end{array}$ & \\
\hline \multicolumn{8}{|l|}{ Kimberly and } \\
\hline Welcome Way & 28 & 2.33 & 0.53 & 7 & 0.88 & 0.20 & $62.5 \%$ \\
\hline Kimberly and Brady & 10 & 0.83 & 0.17 & 7 & 0.88 & 0.18 & $-5.0 \%$ \\
\hline 35th and Harrison & 10 & 0.83 & 0.34 & 0 & 0 & 0 & $100.0 \%$ \\
\hline Kimberly and & & & & & & & \\
\hline Elmore & 12 & 1.00 & 0.20 & 6 & 0.75 & 0.15 & $25.0 \%$ \\
\hline All & 60 & 5.00 & 0.30 & 20 & 2.5 & 0.15 & $50.0 \%$ \\
\hline
\end{tabular}

Table 6.12. Changes in RLR-related (non-rear-end) crashes for control intersections before and after treatment for descriptive statistics-Davenport

\begin{tabular}{lccccccc}
\hline & \multicolumn{5}{c}{ Before } & \multicolumn{5}{c}{ After } & \\
\cline { 2 - 5 } Intersection & Total & $\begin{array}{c}\text { Crashes/ } \\
\text { quarter }\end{array}$ & $\begin{array}{c}\text { Crash } \\
\text { rate } \\
\text { (MEV) }\end{array}$ & Total & $\begin{array}{c}\text { Crashes/ } \\
\text { quarter }\end{array}$ & $\begin{array}{c}\text { Crash } \\
\text { rate } \\
\text { (MEV) }\end{array}$ & Decrease \\
\hline $\begin{array}{l}\text { Elmore and } \\
\text { 53rd }\end{array}$ & 5 & 0.42 & 0.14 & 4 & 0.50 & 0.16 & $-20.0 \%$ \\
$\begin{array}{l}\text { Locust and } \\
\text { Brady }\end{array}$ & 10 & 0.83 & 0.22 & 8 & 1.00 & 0.26 & $-20.0 \%$ \\
$\begin{array}{l}\text { Locust and } \\
\text { Hickory }\end{array}$ & & & & & & & \\
$\begin{array}{l}\text { Grove } \\
\text { North }\end{array}$ & 7 & 0.64 & 0.18 & 4 & 0.50 & 0.15 & $21.4 \%$ \\
$\begin{array}{l}\text { Division and } \\
\text { Central }\end{array}$ & 8 & 0.67 & 0.22 & 7 & 0.88 & 0.29 & $-31.3 \%$ \\
$\begin{array}{l}\text { Pine and } \\
\text { Kimberly }\end{array}$ & 10 & 0.83 & 0.38 & 9 & 1.13 & 0.51 & $-35.0 \%$ \\
$\begin{array}{l}\text { All } \\
\text { (1) }\end{array}$ & 40 & 3.33 & 0.22 & 32 & 4.00 & 0.26 & $-20.0 \%$ \\
\hline
\end{tabular}

Changes in the RLR-related rear-end crashes from before and after installation of RLR cameras are shown in Table 6.13 for camera-enforced intersections and Table 6.14 for control intersections. As shown, three of the camera-enforced intersections experienced increases in RLR-related rear-end crashes. One camera-enforced intersection showed a decrease. Overall, the number of RLR rear-end crashes increased after the installation of cameras by 34 percent.

All of the control intersections also experienced an increase in RLR-related rear-end crashes by up to 110 percent. Overall, rear-end crashes at control intersections increased by 39 percent. 
Table 6.13. Changes in RLR-related rear-end crashes for RLR camera-enforced intersections before and after treatment for descriptive statistics-Davenport

\begin{tabular}{|c|c|c|c|c|c|c|c|}
\hline \multirow[b]{2}{*}{ Intersection } & \multicolumn{3}{|c|}{ Before } & \multicolumn{3}{|c|}{ After } & \multirow[b]{2}{*}{ Decrease } \\
\hline & Total & $\begin{array}{l}\text { Crashes/ } \\
\text { quarter }\end{array}$ & $\begin{array}{c}\text { Crash } \\
\text { rate } \\
(\mathrm{MEV})\end{array}$ & Total & $\begin{array}{l}\text { Crashes/ } \\
\text { quarter }\end{array}$ & $\begin{array}{c}\text { Crash } \\
\text { rate } \\
\text { (MEV) }\end{array}$ & \\
\hline $\begin{array}{l}\text { Kimberly and } \\
\text { Welcome Way } \\
\text { Kimberly and }\end{array}$ & 13 & 1.08 & 0.25 & 9 & 1.13 & 0.26 & $-3.8 \%$ \\
\hline $\begin{array}{l}\text { Brady } \\
\text { 35th and }\end{array}$ & 14 & 1.17 & 0.24 & 12 & 1.50 & 0.30 & $-28.6 \%$ \\
\hline $\begin{array}{l}\text { Harrison } \\
\text { Kimberly and }\end{array}$ & 4 & 0.33 & 0.14 & 0 & 0 & 0 & $100.0 \%$ \\
\hline Elmore & 7 & 0.58 & 0.12 & 13 & 1.63 & 0.33 & $-178.6 \%$ \\
\hline All & 38 & 3.17 & 0.19 & 34 & 4.25 & 4.25 & $-34.2 \%$ \\
\hline
\end{tabular}

Table 6.14. Changes in RLR-related rear-end crashes for control intersections before and after treatment for descriptive statistics-Davenport

\begin{tabular}{lccccccc}
\hline & \multicolumn{3}{c}{ Before } & \multicolumn{5}{c}{ After } & \\
\cline { 2 - 6 } Intersection & Total & $\begin{array}{c}\text { Crashes/ } \\
\text { quarter }\end{array}$ & $\begin{array}{c}\text { Crash } \\
\text { rate } \\
\text { (MEV) }\end{array}$ & Total & $\begin{array}{c}\text { Crashes/ } \\
\text { quarter }\end{array}$ & $\begin{array}{c}\text { Crash } \\
\text { rate } \\
\text { (MEV) }\end{array}$ & Decrease \\
\hline $\begin{array}{l}\text { Elmore and } \\
\text { 53rd }\end{array}$ & 28 & 2.33 & 0.77 & 20 & 2.50 & 0.82 & $-7.1 \%$ \\
$\begin{array}{l}\text { Locust and } \\
\text { Brady }\end{array}$ & 8 & 0.67 & 0.17 & 10 & 1.25 & 0.33 & $-87.5 \%$ \\
$\begin{array}{l}\text { Locust and } \\
\text { Hickory }\end{array}$ & & & & & & & \\
$\begin{array}{l}\text { Grove } \\
\text { North }\end{array}$ & 9 & 0.82 & 0.23 & 10 & 1.25 & 0.38 & $-52.8 \%$ \\
$\begin{array}{l}\text { Division and } \\
\text { Central }\end{array}$ & 5 & 0.42 & 0.14 & 7 & 0.88 & 0.29 & $-110.0 \%$ \\
$\begin{array}{l}\text { Pine and } \\
\text { Kimberly } \\
\text { All }\end{array}$ & 4 & 0.33 & 0.15 & 3 & 0.38 & 0.17 & $-12.5 \%$ \\
\hline
\end{tabular}

\subsubsection{Bayesian model results}

The Bayesian model was used to develop an expected crash frequency per site during the before and after periods. The intersection of Lincoln and Locust was not included in the analysis because cameras were not installed until 2006 and only two quarters of after data were available. 
Results for Davenport are shown below. Table 6.15 provides results for total crashes at intersections with RLR cameras. Total crashes were reduced by approximately $20 \%$ for intersections with RLR cameras while total crashes increased by almost $7 \%$ at control intersections, as displayed in Table 6.16. Table 6.17 provides the posterior mean and $95 \%$ credible set of the expected crash frequency averaged over controls for the before and after periods.

Table 6.15. Expected crash frequency per site for total crashes for RLR cameraenforced intersections-Davenport

\begin{tabular}{lccccccc}
\hline & \multicolumn{3}{c}{ Before (crashes/qtr) } & \multicolumn{2}{c}{ After (crashes/qtr) } & $\begin{array}{c}\text { Difference } \\
\text { in mean }\end{array}$ \\
\cline { 2 - 7 } Intersection & Mean & $\mathbf{2 . 5 0 \%}$ & $\mathbf{9 7 . 5 0 \%}$ & Mean & $\mathbf{2 . 5 0 \%}$ & $\mathbf{9 7 . 5 0 \%}$ & \\
\hline $\begin{array}{l}\text { Kimberly and } \\
\text { Welcome Way }\end{array}$ & 5.03 & 4.11 & 6.12 & 4.01 & 3.14 & 5.08 & $20.3 \%$ \\
$\begin{array}{l}\text { Kimberly and } \\
\text { Brady }\end{array}$ & 4.67 & 3.72 & 5.67 & 3.72 & 2.87 & 4.62 & $20.3 \%$ \\
$\begin{array}{l}\text { 35th and } \\
\begin{array}{l}\text { Harrison } \\
\text { Kimberly and }\end{array}\end{array}$ & 2.58 & 1.93 & 3.28 & 2.06 & 1.49 & 2.67 & $20.2 \%$ \\
\begin{tabular}{l} 
Elmore \\
\hline
\end{tabular} & 3.56 & 2.78 & 4.38 & 2.84 & 2.12 & 3.69 & $20.2 \%$ \\
\hline
\end{tabular}

Table 6.16. Expected crash frequency per site for total crashes for camera-enforced intersections-Davenport

\begin{tabular}{|c|c|c|c|c|c|c|c|}
\hline \multirow{2}{*}{ Intersection } & \multicolumn{3}{|c|}{ Before } & \multicolumn{3}{|c|}{ After } & \multirow{2}{*}{$\begin{array}{c}\text { Difference } \\
\text { in mean }\end{array}$} \\
\hline & Mean & $2.50 \%$ & $97.50 \%$ & Mean & $2.50 \%$ & $97.50 \%$ & \\
\hline Elmore and 53rd & 4.97 & 3.97 & 6.15 & 5.3 & 4.16 & 6.6 & $-6.6 \%$ \\
\hline $\begin{array}{l}\text { Locust and } \\
\text { Brady } \\
\text { Locust and }\end{array}$ & 3.46 & 2.75 & 4.33 & 3.69 & 2.8 & 4.67 & $-6.6 \%$ \\
\hline $\begin{array}{l}\text { Hickory Grove } \\
\text { North Division }\end{array}$ & 3.3 & 2.59 & 4.11 & 3.52 & 2.67 & 4.43 & $-6.7 \%$ \\
\hline $\begin{array}{l}\text { and Central } \\
\text { Pine and }\end{array}$ & 2.39 & 1.78 & 3.07 & 2.55 & 1.85 & 3.35 & $-6.7 \%$ \\
\hline Kimberly & 2.26 & 1.7 & 2.9 & 2.41 & 1.73 & 3.11 & $-6.6 \%$ \\
\hline
\end{tabular}

Table 6.17. Posterior mean and $95 \%$ credible set of the expected crash frequencyDavenport

\begin{tabular}{rcccccc}
\hline \multirow{2}{*}{ Treatment } & \multicolumn{3}{c}{ Before } & \multicolumn{3}{c}{ After } \\
\cline { 2 - 7 } & Mean & $\mathbf{2 . 5 0 \%}$ & $\mathbf{9 7 . 5 0 \%}$ & Mean & $\mathbf{2 . 5 0 \%}$ & $\mathbf{9 7 . 5 0 \%}$ \\
\hline Camera & 3.96 & 3.42 & 4.48 & 3.16 & 2.59 & 3.78 \\
Control & 3.28 & 2.87 & 3.7 & 3.49 & 2.94 & 4.07 \\
\hline
\end{tabular}


Results for RLR crashes, not including rear-end crashes, are show in Table 6.18 for treatment and Table 6.19 for control intersections. RLR-related crashes were reduced by $40 \%$ at intersections where RLR cameras were installed. RLR-related crashes at control intersections actually increased by almost $20 \%$ from the before to after period. This indicates that the cameras were effective in reducing RLR-related crashes. Table 6.20 provides the posterior mean and 95\% credible set of the expected crash frequency averaged over control intersections for the before and after periods.

Table 6.18. Expected crash frequency per site for RLR-related crashes for cameraenforced intersections-Davenport

\begin{tabular}{lccccccc}
\hline Intersection & Mean & $\begin{array}{c}\text { Before } \\
\mathbf{2 . 5 0 \%}\end{array}$ & $\mathbf{9 7 . 5 0 \%}$ & Mean & $\begin{array}{c}\text { After } \\
\mathbf{2 . 5 0} \%\end{array}$ & $\mathbf{9 7 . 5 0 \%}$ & $\begin{array}{c}\text { Difference } \\
\text { in mean }\end{array}$ \\
\hline $\begin{array}{l}\text { Kimberly and } \\
\text { Welcome Way }\end{array}$ & 1.79 & 1.2 & 2.51 & 1.06 & 0.61 & 1.64 & $40.8 \%$ \\
$\begin{array}{l}\text { Kimberly and } \\
\text { Brady }\end{array}$ & 1.12 & 0.71 & 1.64 & 0.67 & 0.36 & 1.04 & $40.2 \%$ \\
$\begin{array}{l}\text { 35th and } \\
\text { Harrison }\end{array}$ & 0.62 & 0.38 & 0.96 & 0.37 & 0.2 & 0.63 & $40.3 \%$ \\
$\begin{array}{l}\text { Kimberly and } \\
\text { Elmore }\end{array}$ & 1.15 & 0.73 & 1.63 & 0.68 & 0.37 & 1.07 & $40.9 \%$ \\
\hline
\end{tabular}

Table 6.19. Expected crash frequency per site for RLR-related crashes for control intersections-Davenport

\begin{tabular}{lccccccc}
\hline \multirow{2}{*}{ Intersection } & \multicolumn{3}{c}{ Before } & \multicolumn{3}{c}{ After } & $\begin{array}{c}\text { Difference } \\
\text { in mean }\end{array}$ \\
\cline { 2 - 7 } & Mean & $\mathbf{2 . 5 0 \%}$ & $\mathbf{9 7 . 5 0 \%}$ & Mean & $\mathbf{2 . 5 0 \%}$ & $\mathbf{9 7 . 5 0 \%}$ & $-18.9 \%$ \\
\hline $\begin{array}{l}\text { Elmore and 53rd } \\
\begin{array}{l}\text { Locust and } \\
\text { Brady }\end{array}\end{array}$ & 0.53 & 0.29 & 0.81 & 0.63 & 0.34 & 0.97 & $-19.3 \%$ \\
$\begin{array}{l}\text { Locust and } \\
\begin{array}{l}\text { Hickory Grove } \\
\text { North Division }\end{array}\end{array}$ & 0.83 & 0.53 & 1.23 & 0.99 & 0.61 & 1.5 & $-19.7 \%$ \\
$\begin{array}{l}\text { and Central } \\
\begin{array}{l}\text { Pine and } \\
\text { Kimberly }\end{array}\end{array}$ & 0.69 & 0.43 & 1.05 & 0.83 & 0.5 & 1.23 & $-20.3 \%$ \\
\hline
\end{tabular}

Table 6.20. Posterior mean and $95 \%$ credible set of the expected crash frequencyDavenport

\begin{tabular}{rcccccc}
\hline \multirow{2}{*}{ Treatment } & \multicolumn{3}{c}{ Before } & \multicolumn{3}{c}{ After } \\
\cline { 2 - 7 } & Mean & $\mathbf{2 . 5 0 \%}$ & $\mathbf{9 7 . 5 0 \%}$ & Mean & $\mathbf{2 . 5 0 \%}$ & $\mathbf{9 7 . 5 0 \%}$ \\
\hline Camera & 1.17 & 0.91 & 1.47 & 0.7 & 0.44 & 1.01 \\
Control & 0.67 & 0.52 & 0.89 & 0.81 & 0.56 & 1.1 \\
\hline
\end{tabular}




\section{RLR-related Rear-end Crashes}

Results for rear-end crashes that were determined to be related to red light running are shown in Table 6.21 for camera-enforced intersections and Table 6.22 for control intersections for Davenport. As shown, rear-end crashes decreased by 0 to $3 \%$ at camera-enforced intersections. Rear-end crashes actually increased significantly (up to almost 34\%). Table 6.23 provides the posterior mean and $95 \%$ credible set of the expected crash frequency averaged over controls for the before and after periods.

The distribution of the expected mean for the before and after periods is shown in Figures 6.1 through 6.3. As shown are significantly larger differences in the average of expected number of crashes in the before and after periods that occurred at camera-enforced intersections (indicated as cam-before and cam-after) than at control intersections (indicated as no cam-before and no cam-after) for both total and RLR-related crashes. Larger differences in means from the before to after period are noted for control intersections than for camera-enforced intersections.

Table 6.21. Expected crash frequency per site for RLR-related rear-end crashes for camera-enforced intersections-Davenport

\begin{tabular}{lccccccc}
\hline & \multicolumn{3}{c}{ Before } & & & After & \multicolumn{2}{c}{$\begin{array}{c}\text { Difference } \\
\text { in mean }\end{array}$} \\
\cline { 2 - 8 } Intersection & Mean & $\mathbf{2 . 5 0 \%}$ & $\mathbf{9 7 . 5 0 \%}$ & Mean & $\mathbf{2 . 5 0 \%}$ & $\mathbf{9 7 . 5 0 \%}$ & \\
\hline $\begin{array}{l}\text { Kimberly and } \\
\text { Welcome Way }\end{array}$ & 1.07 & 0.66 & 1.59 & 1.04 & 0.6 & 1.58 & $2.8 \%$ \\
$\begin{array}{l}\text { Kimberly and } \\
\text { Brady }\end{array}$ & 1.27 & 0.84 & 1.86 & 1.25 & 0.73 & 1.93 & $1.6 \%$ \\
$\begin{array}{l}\text { 35th and } \\
\begin{array}{l}\text { Harrison } \\
\text { Kimberly and }\end{array}\end{array}$ & 0.3 & 0.13 & 0.55 & 0.3 & 0.12 & 0.58 & $0.0 \%$ \\
Elmore & 1.01 & 0.63 & 1.49 & 0.98 & 0.57 & 1.52 & $3.0 \%$ \\
\hline
\end{tabular}


Table 6.22. Expected crash frequency per site for RLR-Related rear-end crashes for control intersections-Davenport

\begin{tabular}{|c|c|c|c|c|c|c|c|}
\hline \multirow{2}{*}{ Intersection } & \multicolumn{3}{|c|}{ Before } & \multicolumn{3}{|c|}{ After } & \multirow{2}{*}{$\begin{array}{l}\text { Difference } \\
\text { in mean }\end{array}$} \\
\hline & Mean & $2.50 \%$ & $97.50 \%$ & Mean & $2.50 \%$ & $97.50 \%$ & \\
\hline $\begin{array}{l}\text { Elmore and } \\
\text { 53rd } \\
\text { Locust and }\end{array}$ & 2.00 & 1.4 & 2.74 & 2.65 & 1.83 & 3.66 & $-32.5 \%$ \\
\hline $\begin{array}{l}\text { Brady } \\
\text { Locust and }\end{array}$ & 0.82 & 0.5 & 1.22 & 1.1 & 0.64 & 1.66 & $-34.1 \%$ \\
\hline $\begin{array}{l}\text { Hickory Grove } \\
\text { North }\end{array}$ & 0.86 & 0.54 & 1.27 & 1.15 & 0.66 & 1.78 & $-33.7 \%$ \\
\hline $\begin{array}{l}\text { Division and } \\
\text { Central } \\
\text { Pine and }\end{array}$ & 0.59 & 0.31 & 0.93 & 0.78 & 0.41 & 1.28 & $-32.3 \%$ \\
\hline Kimberly & 0.39 & 0.2 & 0.65 & 0.52 & 0.25 & 0.9 & $-33.3 \%$ \\
\hline
\end{tabular}

Table 6.23. Posterior mean and $95 \%$ credible set of the expected crash frequency-Davenport

\begin{tabular}{lcccccc}
\hline \multirow{2}{*}{ Treatment } & \multicolumn{3}{c}{ Before } & \multicolumn{3}{c}{ After } \\
\cline { 2 - 7 } & Mean & $\mathbf{2 . 5 0 \%}$ & $\mathbf{9 7 . 5 0 \%}$ & Mean & $\mathbf{2 . 5 0 \%}$ & $\mathbf{9 7 . 5 0 \%}$ \\
\hline Camera & 0.91 & 0.68 & 1.18 & 0.89 & 0.61 & 1.24 \\
Control & 0.93 & 0.72 & 1.16 & 1.24 & 0.92 & 1.58 \\
\hline
\end{tabular}

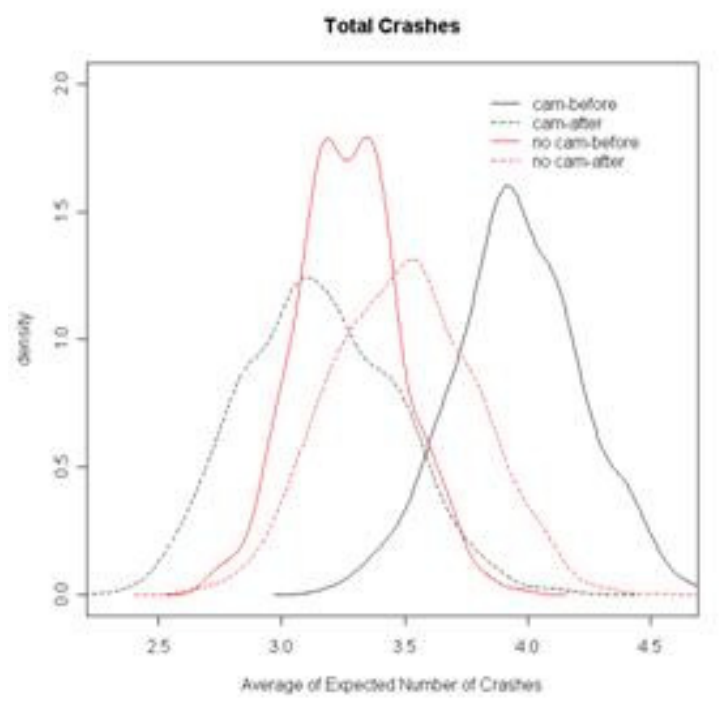

Figure 6.1. Posterior distributions of the average in total crashes over expected crash frequencies for Davenport 




Figure 6.2. Posterior distributions of the average in RLR-related (non-rear-end) crashes over expected crash frequencies for Davenport

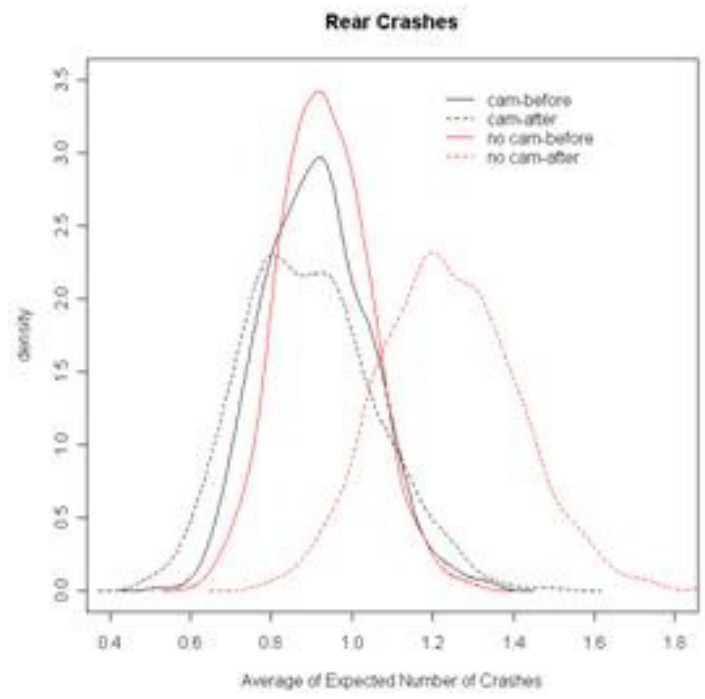

Figure 6.3. Posterior distributions of the average in RLR-related rear-end crashes over expected crash frequencies for Davenport

Results for the credible sets are provided in the following tables. The expected difference in means for crash frequency for total crashes from the before to after period is shown in Table 6.24 for intersections with cameras and in Table 6.25 for control intersections. As shown, the credible set from 2.50 to $97.50 \%$ for the camera-enforced intersections varied from 0.01 to 1.97, while the credible set for the control intersections varied from -0.33 to 0.64 . Because the credible set for the camera-enforced intersections did not include zero, we can interpret this in classical statistics language to mean that there was a 95\% probability that the difference in means was not zero. Similarly, there was less than a 95\% probability that the difference in means for the control 
intersections was not zero. The posterior mean and credible set for the difference in expected means averaged over sites is shown in Table 6.26.

Table 6.24. Expected difference in crash frequency for total crashes for camera-enforced intersections-Davenport

\begin{tabular}{lccc}
\hline \multirow{2}{*}{ Intersection } & \multicolumn{3}{c}{ Difference } \\
\cline { 2 - 4 } & Mean & $\mathbf{2 . 5 0 \%}$ & $\mathbf{9 7 . 5 0 \%}$ \\
\hline Kimberly and Welcome Way & 1.02 & 0.01 & 1.97 \\
Kimberly and Brady & 0.95 & 0.01 & 1.88 \\
35th and Harrison & 0.52 & 0.01 & 1.06 \\
Kimberly and Elmore & 0.72 & 0.01 & 1.41 \\
\hline
\end{tabular}

Table 6.25. Expected difference in crash frequency for total crashes for control intersections-Davenport

\begin{tabular}{lcll}
\hline \multirow{2}{*}{ Intersection } & \multicolumn{3}{c}{ Difference } \\
\cline { 2 - 4 } & Mean & $\mathbf{2 . 5 0 \%}$ & $\mathbf{9 7 . 5 0 \%}$ \\
\hline Elmore and 53rd & -0.33 & -1.37 & 0.64 \\
Locust and Brady & -0.23 & -0.93 & 0.44 \\
Locust and Hickory Grove & -0.22 & -0.9 & 0.44 \\
North Division and Central & -0.16 & -0.67 & 0.3 \\
Pine and Kimberly & -0.15 & -0.62 & 0.3 \\
\hline
\end{tabular}

Table 6.26. Posterior mean and $95 \%$ credible set of the expected difference in crash frequency averaged over sites

\begin{tabular}{lccc}
\hline \multirow{2}{*}{ Treatment } & \multicolumn{3}{c}{ Difference } \\
\cline { 2 - 4 } & Mean & $\mathbf{2 . 5 0 \%}$ & $\mathbf{9 7 . 5 0 \%}$ \\
\hline Camera & 0.8 & 0.01 & 1.55 \\
Control & -0.22 & -0.9 & 0.42 \\
\hline
\end{tabular}

The expected difference in means for crash frequency for RLR-related crashes, not including rear-end crashes from the before to after period, is shown in Table 6.27 for intersections with cameras and in Table 6.28 for control intersections. As shown, the credible set for the distribution of the difference in means for the camera-enforced intersections varied from 0.06 to 1.4, while the credible set for the distribution of the difference in means for the control intersections ranged from -0.56 to 0.17 . Because the credible set for the camera-enforced intersections did not include zero, we can interpret this in classical statistics language to mean that there was a $95 \%$ probability that the difference in means was not zero. Similarly, there was less than a $95 \%$ probability that the difference in means for the control intersections was not 
zero. The posterior mean and credible for the difference in expected means averaged over sites is shown in Table 6.29.

Table 6.27. Expected difference in crash frequency for RLRrelated crashes for camera-enforced intersections-Davenport

\begin{tabular}{lccc}
\hline \multirow{2}{*}{ Intersection } & \multicolumn{3}{c}{ Difference } \\
\cline { 2 - 4 } & Mean & $\mathbf{2 . 5 0 \%}$ & $\mathbf{9 7 . 5 0 \%}$ \\
\hline Kimberly and Welcome Way & 0.73 & 0.17 & 1.4 \\
Kimberly and Brady & 0.46 & 0.10 & 0.84 \\
35th and Harrison & 0.25 & 0.06 & 0.5 \\
Kimberly and Elmore & 0.46 & 0.11 & 0.89 \\
\hline
\end{tabular}

Table 6.28. Expected difference in crash frequency for RLRrelated crashes for control intersections-Davenport

\begin{tabular}{lccc}
\hline \multirow{2}{*}{ Intersection } & \multicolumn{3}{c}{ Difference } \\
\cline { 2 - 4 } & Mean & $\mathbf{2 . 5 0 \%}$ & $\mathbf{9 7 . 5 0 \%}$ \\
\hline Elmore and 53rd & -0.1 & -0.36 & 0.13 \\
Locust and Brady & -0.16 & -0.56 & 0.2 \\
Locust and Hickory Grove & -0.12 & -0.42 & 0.15 \\
North Division and Central & -0.14 & -0.45 & 0.17 \\
Pine and Kimberly & -0.14 & -0.52 & 0.17 \\
\hline
\end{tabular}

Table 6.29. Posterior mean and $95 \%$ credible set of the expected difference in crash frequency averaged over sites-Davenport

\begin{tabular}{lccc}
\hline \multirow{2}{*}{ Treatment } & \multicolumn{3}{c}{ Difference } \\
\cline { 2 - 4 } & Mean & $\mathbf{2 . 5 0 \%}$ & $\mathbf{9 7 . 5 0 \%}$ \\
\hline Camera & 0.48 & 0.11 & 0.85 \\
Control & -0.13 & -0.42 & 0.16 \\
\hline
\end{tabular}

The expected difference in means for crash frequency for RLR rear-end crashes, not including rear-end crashes from the before to after period, is shown in Table 6.30 for intersections with cameras and in Table 6.31 for control intersections. As shown, the credible set for the distribution of the difference in means for the camera-enforced intersections varied from -0.54 to 0.57 while the credible set for the distribution of the difference in means for the control intersections ranged from -1.48 to 0.11 . The posterior mean and credible set for the distribution of differences in expected means averaged over sites is shown in Table 6.32. As shown, the credible set for both the camera-enforced intersections and control intersections includes zero. Interpreting this information using classical statistical language indicates that there was less than a $95 \%$ probability that the difference in means was not zero. 
Table 6.30. Expected difference in crash frequency for RLR rearend crashes for camera-enforced intersections-Davenport

\begin{tabular}{lccc}
\hline \multirow{2}{*}{ Intersection } & \multicolumn{3}{c}{ Difference } \\
\cline { 2 - 4 } & Mean & $\mathbf{2 . 5 0 \%}$ & $\mathbf{9 7 . 5 0 \%}$ \\
\hline Kimberly and Welcome Way & 0.02 & -0.46 & 0.47 \\
Kimberly and Brady & 0.03 & -0.54 & 0.57 \\
35th and Harrison & 0.01 & -0.14 & 0.14 \\
Kimberly and Elmore & 0.02 & -0.42 & 0.44 \\
\hline
\end{tabular}

Table 6.31. Expected difference in crash frequency for RLR rearend for control intersections-Davenport

\begin{tabular}{lccc}
\hline \multirow{2}{*}{ Intersection } & \multicolumn{3}{c}{ Difference } \\
\cline { 2 - 4 } & Mean & $\mathbf{2 . 5 0 \%}$ & $\mathbf{9 7 . 5 0 \%}$ \\
\hline Elmore and 53rd & -0.66 & -1.48 & 0.11 \\
Locust and Brady & -0.27 & -0.64 & 0.04 \\
Locust and Hickory Grove & -0.29 & -0.68 & 0.04 \\
North Division and & & & \\
Central & -0.19 & -0.5 & 0.03 \\
Pine and Kimberly & -0.13 & -0.33 & 0.01 \\
\hline
\end{tabular}

Table 6.32. Posterior mean and $95 \%$ credible set of the expected difference in crash frequency averaged over sites-Davenport

\begin{tabular}{lccc}
\hline \multirow{2}{*}{ Treatment } & \multicolumn{3}{c}{ Difference } \\
\cline { 2 - 4 } & Mean & $\mathbf{2 . 5 0 \%}$ & $\mathbf{9 7 . 5 0 \%}$ \\
\hline Camera & 0.02 & -0.38 & 0.39 \\
Control & -0.31 & -0.67 & 0.05 \\
\hline
\end{tabular}

The distribution of the difference in the average of expected crashes is provided in Figures 6.4 through 6.6. The solid line shows the distribution for difference in expected crashes for intersections with RLR cameras and the dashed line shows the distribution for the control intersections. The difference is the mean of the expected average number of after crashes per site minus the expected average number of before crashes for the site. 


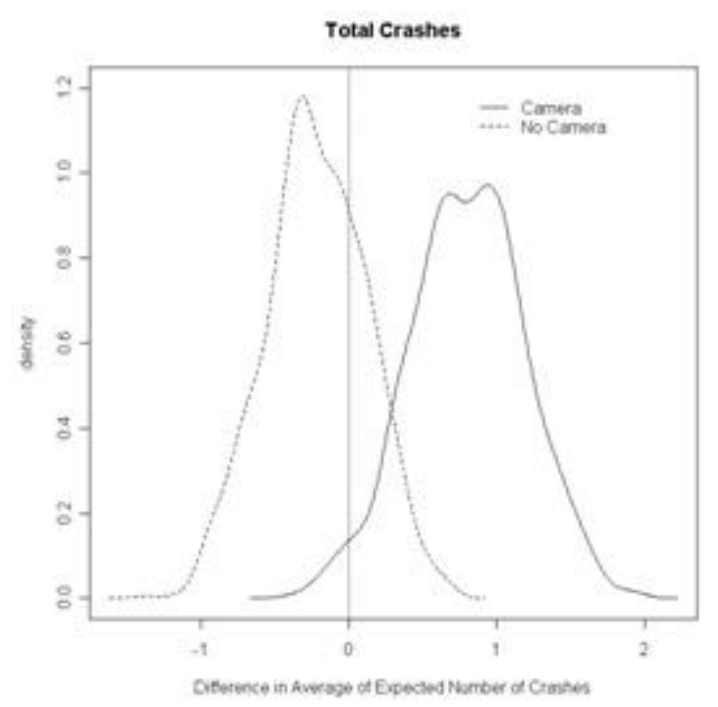

Figure 6.4. Difference in average of expected total crashes (Davenport)

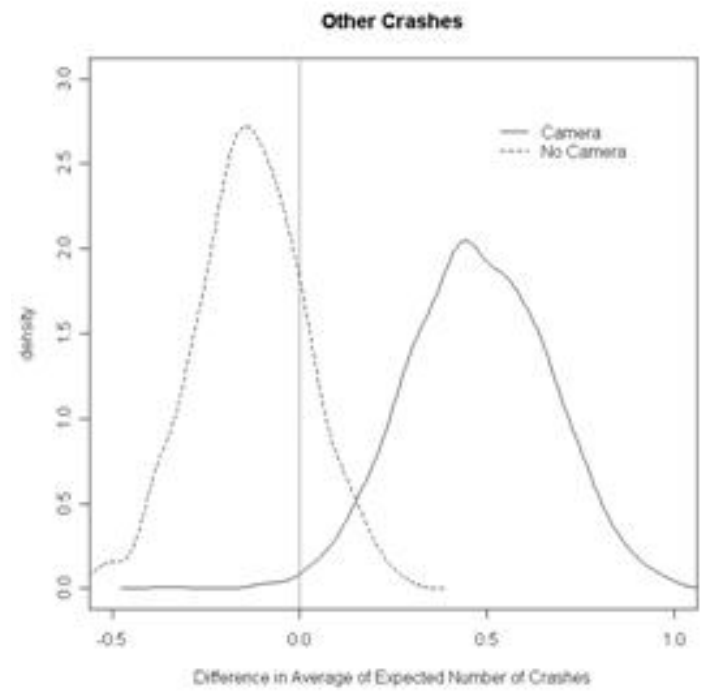

Figure 6.5. Difference in average of expected RLR-related (non-rear-end) crashes (Davenport) 


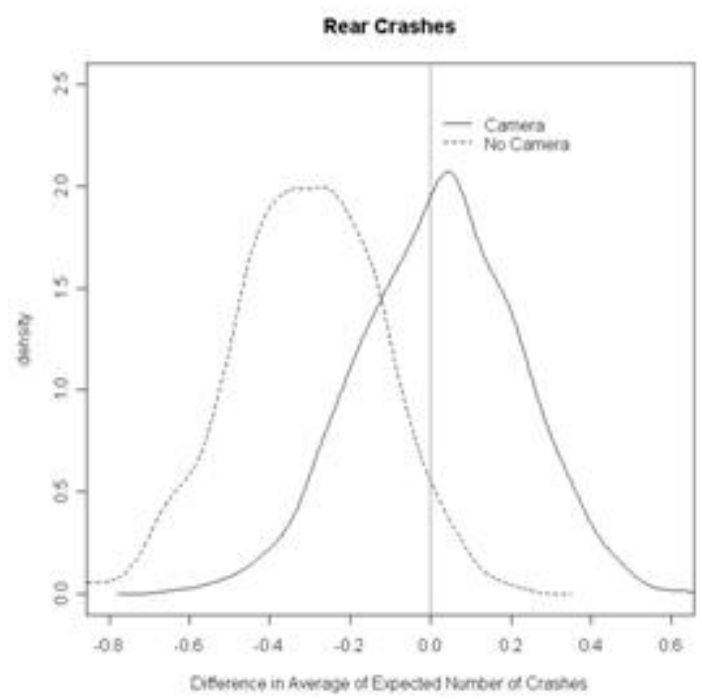

Figure 6.6. Difference in average of expected RLR-related rear-end crashes (Davenport) 


\subsection{SUMMARY}

An analysis of RLR crashes using crash data from 2001 to 2006 indicates that an average of 1,682 RLR crashes occur at signalized intersections in Iowa every year. This accounts for $20.6 \%$ of all crashes and 35\% of fatal- and major-injury crashes at signalized intersections. RLR crashes tend to be broadside and other types of more severe crash types, which may explain the disproportionate percentage of fatal- and major-injury crashes.

As communities across the United States attempt to address red light running, a number of communities have implemented RLR camera enforcement programs. Iowa currently has three communities that have started using camera enforcement since 2004. These communities include Davenport, Council Bluffs, and Clive. All of the RLR programs implemented city ordinances to treat the red light running as Iowa does not currently, as of October 2007, have a state statute that addresses the legality of red light running or speed cameras.

The objective of this research project was to evaluate the effectiveness of RLR cameras in Iowa. Cameras were installed on five approaches at three intersections in Clive in June 2006. The ideal way to evaluate the effectiveness of RLR cameras was to evaluate the reduction in crashes from before cameras were installed to after. However, because the cameras in Clive weren't installed until the end of 2006, less than one year of after data was available, which was not sufficient to conduct a crash analysis. As a result, the only way to evaluate the effectiveness of Clive's automated RLR enforcement system was to perform a cross-sectional analysis that compared RLR violations at camera instrumented intersections to a group of control intersections. Approaches at seven control intersections were chosen that had similar characteristics to the camera-enforced approaches. RLR violations were collected by movement at the control intersection approaches for one day. Violation data for the RLR camera-enforced approaches were also collected from the city. A generalized linear model was used to determine statistical significance of the differences between violations between the study locations with RLR cameras and the control intersection. The model indicated that approaches with cameras had a significant and statistically significant lower number of RLR violations than the approaches at control intersections. The reduction depends on volume and movement. To illustrate, the average expected number of violations for a right-turn movement with a volume of 200 vehicles per hour without a camera was 9.3 violations per peak period. With a camera in place, the average expected number of violations per hour was 0.4 violations. On average, approaches without RLR cameras experienced 25 times more RLR violations than approaches with cameras.

The RLR program in Council Bluffs was instituted in August of 2005. Cameras were placed on seven approaches at five intersections. Only slightly more than one year of crash data was available to evaluate the effectiveness of the Council Bluff program in reducing crashes. The crashes per quarter and crash rate were calculated for a before period consisting of 12 quarters and an after period consisting of four quarters. A Bayesian statistical analysis will be conducted when 2007 crash data are available, but a more in-depth statistical was not conducted because of the very short after period. Four control intersections were used to reflect crash trends that were independent of the cameras. Changes in crashes from the before to after period were evaluated by comparing change in crashes per quarter and crash rate. Total crashes decreased overall at intersections with camera-enforced approaches by $44 \%$ from before to after cameras were 
installed. Total crashes also decreased at control intersections overall but only by 11.8 percent. A more dramatic result was found when only RLR-related crashes (non-rear-end) were evaluated. RLR crashes decreased by $90 \%$ after installation of the cameras at intersections. Overall, results for the control intersections indicated that no reduction in RLR crashes occurred from the before to after period. Finally, RLR-related rear-end crashes decreased by $40 \%$ at intersections with camera-enforced approaches but increased by $29 \%$ at control intersections. This result was unexpected because rear-end crashes were expected to increase with the use of a RLR cameraenforcement system.

The RLR camera system was installed in Davenport at two intersections in August of 2004 and at the remaining three intersections in September and October of 2004. Cameras were present on nine approaches of five intersections. An additional five control locations were selected in Davenport for use in the statistical analysis. One camera-enforced intersection was not used in the final analysis because the camera was moved and replaced, and it was felt that this location was not representative. As a result, four camera-enforced intersections were used in the analysis. Both simple statistics and a Bayesian analysis were used to evaluate Davenport data. Because the cameras were installed in August of 2004, eight quarters of after data were available. Twelve quarters of before data were also used.

Results of the simple statistics and Bayesian analysis were consistent, so only results of the Bayesian analysis are summarized here. The expected average number of crashes per quarter for total crashes decreased by $20 \%$ from the before to after period for intersections with camera enforcement while total crashes increased by almost 7\% for control intersections. The difference in the average number of total crashes per quarter for the RLR treatment intersections was statistically significant at the 95\% level of significance. The increase for control intersections was not statistically significant at the $95 \%$ level of significance. The difference in expected number of RLR crashes per quarter was statistically significant at the 95\% level of significance for intersections with camera-enforced approaches. The difference was not statistically significant for control intersections at the $95 \%$ level of significance.

The expected average number of crashes per quarter for RLR-related crashes (non-rear-end) decreased by $40 \%$ after installation of cameras at intersections with camera-enforced approaches. The expected average number of RLR-related crashes (non-rear-end) increased by almost 20\% at control intersections. The average expected number of RLR-related rear-end crashes per quarter changed very little from the before to after period for intersections with camera-enforced approaches. The expected number of rear-end crashes per quarter increased by around 33\% for the control intersections. However, the difference in the expected number of RLR rear-end crashes was not statistically significant at the 95\% level of significance for either group of intersections. 


\subsection{REFERENCES}

1. Federal Highway Administration. Stop Red Light Running Facts and Statistics, U.S. Department of Transportation. FHWA Safety. August 3, 2006.

http://safety.fhwa.dot.gov/intersections/redl_facts.htm. Accessed Oct. 2, 2006.

2. Bonneson, J., and K. Zimmerman. Red-Light-Running Handbook: An Engineer's Guide to Reducing Red-Light-Related Crashes. Texas Transportation Institute, Texas A\&M University, College Station, 2004.

3. Federal Highway Administration Technical Advisory T7570.2.2. Motor Vehicle Accident Cost. Washington D.C., 1989, pp.21-27.

4. Institute of Highway Safety, Highway Loss Data Institute, Communities with Red Light Cameras. Nov. 2006. http://www.iihs.org/research/topics/rlc_cities.html. Accessed October 10, 2006.

5. The Michie Company. Uniform Vehicle Code and Model Traffic Ordinances. National Committee on Uniform Traffic Laws and Ordinances. Charlottesville, Virginia, 1968.

6. Institute of Transportation Engineers. Determining Vehicle Signal Change and Clearance Intervals. ITE Technical Council Task Force 4TF-1. Washington, D.C., 1985.

7. Yang, C.Y., and W. Najm. Analysis of Red Light Violation Data Collected from Intersections Equipped with Red Light Photo Enforcement Cameras. Report DOT HS 810 580. FHWA, U.S. Department of Transportation Research and Innovative Technology Administration, 2006.

8. Kraus, E. and C. Quiroga. Red Light Running Trends in Texas. In Preprint CD-ROM of the 83rd Annual Meeting of the Transportation Research Board (CD-ROM), TRB, National Research Council, Washington, D.C., 2004.

9. Porter, B.E., and T.D. Berry. A Nationwide Survey of Self-Reported Red Light Running: Measuring Prevalence, Predictors, and Perceived Consequences. Accident Analysis and Prevention, Vol. 33, 2001, pp. 735-741.

10. Retting, R.A., R.G Ulmer, and A.F. Williams. Prevalence and Characteristics of Red Light Running Crashes in the United States. Accident Analysis and Prevention, Vol. 31, 1999, pp. 687-694.

11. Retting, R.A., and A.F. Williams. Characteristics of Red Light Violators: Results of Field Investigation. Journal of Safety Research, Vol. 27, No. 1, 1996, pp. 9-15.

12. Bonneson J., K. Zimmerman, and M.A. Brewer. Engineering Countermeasures to Red-LightRunning. In Proceedings of the ITE 2002 Spring Conference and Exhibit (CD-ROM). Institute of Transportation Engineers, Washington D.C., 2002. 
13. Eccles, P.L., and H.W. McGee. A History of the Yellow and All-Red Intervals for Traffic Signals. Washington D.C: Institute of Transportation Engineers, 2001.

14. Chang, M.S., C.J. Messer, and A.J. Santiago. Timing Traffic Signal Change Intervals Based on Driver Behavior. In Transportation Research Record 1027, TRB, National Research Council, Washington, D.C., 1985, pp. 20-30.

15. Porter B.E., and K.J. England. Predicting Red-Light Running Behavior: A Traffic Safety Study in Three Urban Settings. Journal of Safety Research, Vol. 31, No. 1, pp. 1-8.

16. Kamyab, A., T. McDonald, and J.J. Stribiak. The Scope and Impact of Red Light Running in Iowa. In Preprint CD-ROM of the $81^{\text {st }}$ Annual Meeting of the Transportation Research Board (CD-ROM), TRB, National Research Council, Washington, D.C., 2002.

17. Kamyab, A., T. McDonald, and J.J. Stribiak. Red Light Running in Iowa: The Scope, Impact, and Possible Implications. Center for Transportation Research and Education, Iowa State University, Ames, 2000.

18. Retting, R.A., A.F Williams, and M.A. Greene. Red-Light Running and Sensible Countermeasures: Summary of Research Findings. In Transportation Research Record 1640, TRB, National Research Council, Washington, D.C., 1998, pp. 23-26.

19. American Association of State Highway and Transportation Officials. A policy on Geometric Design of Highways and Streets. AASHTO, Washington D.C., 2001.

20. Institute of Transportation Engineers. Determining Vehicle Signal Change and Clearance Intervals. ITE Technical Council Task Force 4TF-1. Washington, D.C., 1994.

21. Federal Highway Administration. Red Light Camera Systems Operational Guidelines. National Highway Traffic Safety Administration, U.S. Department of Transportation, Washington D.C., 2005.

22. Federal Highway Administration. Guidance for Using Red Light Cameras. National Highway Traffic Safety Administration, U.S. Department of Transportation, Washington D.C., 2003.

23. Federal Highway Administration. Manual on Uniform Traffic Control Devices (MUTCD) 2003. U.S. Department of Transportation, Washington D.C., 2002.

24. Porter, B.E., and T.D. Berry. A Nationwide Survey of Red Light Running: Measuring Driver Behaviors for the "Stop Red Light Running Program. Behavioral Community Psychology for the DaimlerChrysler Corporation, The American Trauma Society, and Federal Highway Administration, Old Dominion University, Norfolk, 1999.

25. Evans, L., and R.W. Rothery. Influence of Vehicle Size and Performance on Intersection Saturation Flow. Proceedings of the Eighth International Symposium on Transportation and Traffic Theory. University of Toronto Press, Toronto, 1983. 
26. Results of unpublished research conducted by BMI for the Federal Highway Administration as quoted by Making Intersections Safer: a Toolbox of Engineering Countermeasures to Reduce Red Light Running. Institute of Transportation Engineers, 2003.

27. McGee, H.W. et al. Making Intersections Safer: A Toolbox of Engineering Countermeasures to Reduce Red Light Running, An Informational Report. Report IR-115. Institute of Transportation Engineers, Federal Highway Administration, U.S. Department of Transportation, 2003.

28. Bonneson, J., K. Zimmerman, and M.A. Brewer. Engineering Countermeasures to Reduce Red-Light Running. Federal Highway Administration Report FHWA/TX-03/4027-2, College Station, Texas, 2003.

29. Retting, R.A., and M.A. Greene. Influence of Traffic Signal Timing on Red Light Running and Potential Vehicle Conflicts at Urban Intersections. Transportation Research Record 1595, TRB, National Research Council, Washington D.C., 1997, pp. 1-7.

30. Van der Horst, R., and A. Wilmink. Driver's Decision-Making at Signalized Intersections: An Optimization of Yellow Timing. Traffic Engineering \& Control. Crowthorne, England, 1996, pp. 615-622.

31. Zegeer, C.V., and R.C. Deen. Green-Extension Systems at High-Speed Intersections. ITE Journal, 1978, pp. 19-24.

32. Polanis, S. Improving Safety Through Design and Operations. Compendium of Papers for the ITE Springs Conference. Institute of Transportation Engineers, Washington D.C., 2002.

33. Marshall, B. How Stuff Works-Question 1789. May, 2002. http://www.howstuffworks.com. Accessed October 18, 2006.

34. Miska, E., P. de Leur, and T. Sayed. Road Safety Performance Associated with Improved Traffic Signal Design and Increased Signal Conspicuity. Institute of Transportation Engineers, 1998.

35. "Visibility of Traffic Signal Displays for Aging and Color Deficient Drivers-Final Report." Final report: National Committee on Uniform Control, September 2001.

36. Salek, M.E. Colorado Highway Photo Gallery: Signals From Around the State. July 9, 2006. http://www.mesalek.com/colo/picts/pgsignal.html. Accessed November 1, 2006.

37. Bonneson, J., C. Quiroga, E. Kraud, and I.V. Schalkwyk. Red Light Running - A Policy Review. Texas Transportation Institute, Texas A\&M University, College Station, 2003.

38. Federal Highway Administration. Red Light Camera Systems Operational Guidelines. Report FHWA-SA-05-002. FHWA, U.S. Department of Transportation, 2005.

39. Capka, J.R. 2005 National Roadway Safety Awards. Roadway Safety Foundation, Federal 
Highway Administration, U.S. Department of Transportation.

http://safety.fhwa.dot.gov/awards.pdf Accessed March 2, 2007.

40. Lynn, C., and W. Ferguson. Automated Speed Enforcement Pilot Project for the Capital Beltway: Feasibility of Photo Radar. Virginia Transportation Research Council, November 1992.

41. Obituary: Maurice Gatsonides. The London Independent, Dec. 22, 2001.

42. Gatso meter BV, Company overview and History. http://www.gatsometer.com. Accessed September 29, 2006.

43. St. Vincent College, Speed. http://www.stivincent.ac.uk/Resources/Physics/Speed/speedcam2.html. Accessed September 29, 2006.

44. Erikson, G. Digital Traffic Cameras for Violators Enforcement. Traffic Technology International. Annual 1996, pp. 332-336.

45. Passetti, K.A., and T.H. Hicks. Use of Automated Enforcement for Red Light Violations. Department of Civil Engineering, Texas A\&M University, College Station, 1997.

46. Retting, R.A. Automated Enforcement of Traffic Laws. TR News, Vol. 29, No. 201, 1999, PP. 15-18.

47. MacCubbin, R.P., Staples B.L., and A.E. Salwin. Automated Enforcement of Traffic Signals: A Literature Review. Federal Highway Administration, U.S. Department of Transportation. http://www.itsdocs.fhwa.dot.gov/jpodocs/repts_te//13603.html. Accessed Nov. 1, 2006.

48. Automated Photo Speed and Red Light Photo Enforcement Systems. Traffipax vendor information, Columbia, Maryland, 2006.

49. Battle Lines Drawn in California Legislature over Red Light Running Cameras. Urban Transportation Monitor, 1998, pp. 3-4.

50. Red Light Camera Enforcement, National Campaign to Stop Red Light Running, Communities with Red Light Camera Programs. http://www.stopredlightrunning.com/html/rlc_cities.htm. Accessed October 17, 2006.

51. Popolizio, R.E. New York City’s Red Light Camera Demonstration Program. Institute of Transportation Engineers Compendium of Technical Papers, 1995.

52. McFadden, J., and H.W. McGee. Synthesis and Evaluation of Red Light Running Automated Enforcement Programs in the United States. Report FHWA-IF-00-004. FHWA, U.S. Department of Transportation, 1999.

53. New York City Government, New York City Department of Transportation, DOT to Add 
Red Light Camera Warning Signs. Oct. 2, 2003.

http://www.nyc.gov/html/dot/html/about/pr2003/pr03_109.html. Accessed October 3, 2006.

54. Cameras Reduced Red Light Running by 20-30\%. Urban Transportation Monitor, Vol. 11, No.2, 1997, pp. 1-3.

55. Fleck, J.L., and B. Smith. Can We Make Red Light Runners Stop? San Francisco Department of Parking and Traffic, 1999.

56. California Senate Bill 833. Approved October 14, 1995.

57. San Francisco Government, Department of Parking and Traffic, Red Light Photo Enforcement Program. http://www.sfgov.org/site/livablestreets_index.asp?id=14440. Accessed October 15, 2006.

58. Automated Enforcement for Red Light Running: Issues, Models, and Implementation. Portland Bureau of Traffic Management, 1998.

59. Burchfield, R.M. Red Light Running Camera Program Biennial Report. City of Portland, 2005.

60. McGee, H.W., and K.A. Eccles. NCHRP Synthesis of Highway Practice 310: Impact of Red Light Camera Enforcement on Crash Experience. TRB, National Research Council, Washington D.C., 2003.

61. Retting, R.A. Establishing a Uniform Definition of Red-Light Running Crashes. ITE Journal, Vol. 76, No. 3, 2006, pp. 20-22.

62. Council, F.M., B. Persaud, K. Eccles, C. Lyon, and M.S. Griffith. Safety Evaluation of RedLight Cameras. Report FHWA-HRT-05-048. FHWA, U.S. Department of Transportation, 2005.

63. Hiller, W., J. Ronczka, and F. Schnerring. An Evaluation of Red Light Cameras in Sydney. Report Number 1/93. Road Traffic Authority NSW: Road Safety Bureau. Rosebery, Australia, 1993.

64. South D., W. Harrison, I. Portans, and M. King. Evaluation of Red Light Camera Programs and Owner Onus Legislation. Victoria Transport: Road Traffic Authority. Hawthorn, Victoria, 1988.

65. Andersen, D. A Long Term Study of Red Light Cameras and Accidents. Research Report \#261. Australian Road Research Board, Victoria, Australia, 1995.

66. Kent, S., B. Corben, B. Fildes, and D. Dyte. Red Light Running Behavior at Red Light Camera and Control Intersections. Report \#73. Monash University: Accident Research Centre. Clayton, Australia, 1995. 
67. Mann, T., S. Brown, and C. Coxon. Evaluation of the Effectiveness of Installing Red Light Running Cameras at Selected Adelide Intersections. Report 7/94. South Australian Department of Transport, Office of Road Safety, Walkerville, Australia 1994.

68. London Accident Analysis Unit. West London Speed Camera Demonstration Project: An Analysis of Accidents and Casualty Data 36 Months “After” Implementation and Comparison with the 36 Months “Before” Data. London Research Centre: Environmental and Transport Studies. London, England, 1997.

69. Hooke, A., J. Knox, and D. Portas. Cost Benefit Analysis of Traffic and Speed Cameras. Police Research Series Paper 20. Police Research Group, Home Office. London, England, 1996.

70. Ng, C.H., Y.D. Wong, and K.M. Lum. The Impact of Red Light Surveillance Cameras on Road Safety in Singapore. In Transportation Research Record Vol 6, No. 2, TRB National Research Council, Washington D.C., 1997, pp. 72-80.

71. Retting, R.A., and S. Kyrychenko. Crash Reductions Associated with Red Light Enforcement in Oxnard, California. Insurance Institute for Highway Safety, 2001.

72. SafeLight. The Charlotte Department of Transportation.

73. http://www.ci.charlotte.nc.us/citransportation/programs/safelight.htm. Accessed October 4, 2006.

74. Maryland House of Delegates Commerce and Government Matter Committee. Automated Enforcement Review - Red-Light Running Detection Camera Systems. Howard County Maryland, 2001.

75. Fleck, J.L., and B.B. Smith. Can we Make Red Light Runners Stop? Red Light Photo Enforcement in San Francisco, California. In Transportation Research Record 1693, TRB, National Research Council, Washington, D.C., 2001.

76. Vinzant, J.C., and B.J. Tatro. Evaluation of Effects of Photo Radar Speed and Red Light Camera Technology on Motor Vehicle Crash Rates. City of Mesa Police Department, 1999. http://www.ci.meswa.az.us/police/traffic/march_1999_report.htm. Accessed October, 24, 2006.

77. Fox, H. Accidents at Signal Controlled Junctions in Glasgow. Research Findings No. 23. The Scottish Office: Central Research Unit, Development Department Research Programme, 1996. http://www.scotland.gov.uk/cru/resfind/drf23-00.htm. Accessed October, 24, 2006.

78. Winn, R. Running the Red and Evaluations of Strathclyde Police's Red Light Camera Initiative. The Scottish Central Research Unit: Glasgow, Scotland, 1995. http://www.scotland.gov.uk/cru/resfinds/drf7-00.htm. Accessed October, 24, 2006.

79. Retting, R.A., and S.Y. Kyrychenko. Reductions in Red Light Camera Enforcement in Oxnard, California. American Journal of Public Health, Vol. 92, No.11, 2002, pp.18221825. 
80. Cunningham, C.M., and J.S. Hummer. Evaluating the Use of Red Light Running Photographic Enforcement Using Collisions and Red Light Running Violation. Institute for Transportation Research and Education, North Carolina State University, Raleigh, 2004.

81. Burkey, M.L., and K. Obeng. A Detailed Investigation of Crash Risk Reduction Resulting From Red Light Cameras in Small Urban Areas. Urban Transit Institute, North Carolina Agricultural \& Technical State University, Greensboro, 2004.

82. Michalopoulos, P.G. Machine Vision: The Way Ahead, The Emerging Technology for Advance Traffic Surveillance Management and Control. ITS International, 1996.

83. Retting, R.A., S.A. Ferguson, and C.M. Farmer. Reducing Red Light Running Through Longer Yellow Signal Timing and Red Light Camera Enforcement: Results of a Field Investigation. Insurance Institute for Highway Safety, 2007.

84. Tarko, A.P., and N. Lakshmi Kanth Reddy. Evaluation of Safety Enforcement on Changing Driver Behavior - Runs on Red. School of Civil Engineering, Purdue University, West Lafayette, 2003.

85. Washburn, S.S., and K.G. Courage. Investigation of Red Light Running Factors - Final Report. Department of Civil and Coastal Engineering, University of Florida, Gainesville, 2004.

86. Maisey, G.E. The Effect of a Mechanical Surveillance Device on Urban Signalized Intersection Accidents. Research and Statistics Report No. 17, Road Traffic Authority, Perth, Western Australia, 1981.

87. Gains, A, M. Nordstrom, B. Heydecker, and J. Shrewsbury. The National Safety Camera Programme, Four-year Evaluation Report. PA Consulting Group and UCL, 2005.

88. Kendall, S. Is Automated Enforcement Constitutional? Insurance Institute for Highway Safety, 2004.

89. Blackburn, R.R., and D.T. Gilbert. NCHRP Synthesis of Highway Practice 219: Photographic Enforcement of Traffic Laws. TRB, National Research Council, Washington D.C., May 1995.

90. DC Watch, Privacy vs. Security Issues, Automated Traffic Enforcement System (ATES). April, 2003. http://www.dcwatch.com/issues/privacy15.htm. Accessed October 22, 2006.

91. McCormick, C. McCormick on Evidence, 3rd Ed., Sec. 214, at 671, 1984.

92. Goger, T.J. Proof, by Radar or Other Mechanical or Electronic Devices, or Violation of Speed Regulations. 47 American Law Reports. Ed 822, 1973. 
93. Photo Blocker, http://www.photoblocker.com. Accessed November 2, 2006.

94. Clive Historical Society. Clive History. http://www.clivehistoricalsociety.com/clive_history.htm. Accessed April 20, 2006.

95. Council Bluffs Historic Preservation Alliance. Ann 1887 Introduction about Council Bluffs. http://www.cbhpa.com/1887CBwriteup.htm. Accessed April 21, 2007.

96. Quad-Cities Convention \& Visitors Bureau. Quad City History. http://www.visitquadcities.com/for_the_media/nr_history.html. Accessed April 22, 2007.

97. John Deere. Company Information. http://www.deere.com/en_US/compinfo/histoyr/index.html. Accessed April 22, 2007.

98. Pline, J.L., Traffic engineering handbook. [Washington, D.C.]: Institute of Transportation Engineers, 1999.

99. Bonneson, J.A., and K. Zimmerman. Identifying Intersections with Potential for Red LightRelated Safety Improvements. In Transportation Research Record 1953, TRB, National Research Council, Washington D.C., 2006, pp. 128-136.

100. Federal Highway Administration. Stop Red Light Running Facts and Statistics, U.S. Department of Transportation. FHWA Safety. August 3, 2006. http://safety.fhwa.dot.gov/intersections/redl_facts.htm. Accessed July 25, 2006.

101. ITE Traffic Engineering Handbook 5th Edition. 


\section{APPENDIX A: METHODOLOGY TO IDENTIFY SIGNALIZED INTERSECTIONS}

The location of signalized intersections in the state was determined using a database based on the Iowa DOT GIMS database. A statewide intersection database was developed for Iowa based on the 1999 GIMS snapshot linework from the Iowa DOT (see report on SICL for description of how the intersection database was created). This database represents the intersection of any location where three or more approaches join. No statewide inventory of signalized intersections exists. To determine where signalized intersections were located, a database created by Dr. Michael Pawlovich was used. Crashes from 2001 to 2005 that were within 25 meters of an intersection node in the statewide intersection database were extracted. The total number of crashes was summed for each location. The number of crash cases that had some indication that a traffic signal was present from the Traffic Controls crash option was recorded in one field. The total number of crash cases where a traffic signal was indicated in either the Traffic Controls crash option or Contributing Circumstances, Driver crash option were summarized. This suggested that the reporting officer had indicated a presence of a traffic signal. Officers may not have always filled in either option when reporting a crash. The point ID was related to the point ID from the statewide intersection database. An intersection was determined to be signalized if the following conditions were met:

- 2 to 4 crashes had occurred and a signal was indicated for at least 2 crashes

- 6 or 7 crashes had occurred and a signal was indicated for at least 3 crashes

- 8 or more crashes had occurred and a signal was indicated for at least 4 crashes 